\title{
Obesity treatment and weight maintenance
}

Citation for published version (APA):

Pasman, W. J. (1998). Obesity treatment and weight maintenance. [Doctoral Thesis, Maastricht University]. Universiteit Maastricht. https://doi.org/10.26481/dis.19980206wp

Document status and date:

Published: 01/01/1998

DOI:

10.26481/dis.19980206wp

Document Version:

Publisher's PDF, also known as Version of record

\section{Please check the document version of this publication:}

- A submitted manuscript is the version of the article upon submission and before peer-review. There can be important differences between the submitted version and the official published version of record.

People interested in the research are advised to contact the author for the final version of the publication, or visit the DOI to the publisher's website.

- The final author version and the galley proof are versions of the publication after peer review.

- The final published version features the final layout of the paper including the volume, issue and page numbers.

Link to publication

\footnotetext{
General rights rights.

- You may freely distribute the URL identifying the publication in the public portal. please follow below link for the End User Agreement:

www.umlib.nl/taverne-license

Take down policy

If you believe that this document breaches copyright please contact us at:

repository@maastrichtuniversity.nl

providing details and we will investigate your claim.
}

Copyright and moral rights for the publications made accessible in the public portal are retained by the authors and/or other copyright owners and it is a condition of accessing publications that users recognise and abide by the legal requirements associated with these

- Users may download and print one copy of any publication from the public portal for the purpose of private study or research.

- You may not further distribute the material or use it for any profit-making activity or commercial gain

If the publication is distributed under the terms of Article $25 \mathrm{fa}$ of the Dutch Copyright Act, indicated by the "Taverne" license above, 


\title{
OBESITY TREATMENT AND WEIGHT MAINTENANCE
}

\author{
PROEFSCHRIFT
}

ter verkrijging van de graad van doctor aan de Universiteit Maastricht, op gezag van de Rector Magnificus,

Prof. dr. A.C. Nieuwenhuijzen Kruseman, volgens het besluit van het College van Decanen, in het openbaar te verdedigen op vrijdag 6 februari 1998 om 16.00 uur

door

Wilrike Jeannette Pasman

geboren te Zutphen 
Promotor:

Co-promotor:

Beoordelingscommissie:" $\quad$ Prof.dr. H. Kuipers (voorzitter)

dr. M.A. van Baak

Prof.dr. T.W.A. de Bruin

Prof.dr. S. Rössner (Karolinska Institute, Zweden)

dr. J.C. Seidell (RIVM, Bilthoven) 


\section{Contents}

$\begin{array}{lll}\text { Chapter } 1 \text { Introduction } & 7\end{array}$

$\begin{array}{lll}\text { Chapter } 2 \text { Dietary fiber and body weight control: a review. } & 19\end{array}$

Chapter 3 The effect of one week of fibre supplementation on hunger and satiety or energy intake.

Chapter 4 The effectiveness of long-term fiber supplementation on Weight maintenance in weight-reduced women.

Chapter 5 The effectiveness of Jong-term supplementation of carbohydrate, chromium, fiber and caffeine on weight maintenance. 67

Chapter 6 The effect of exercise training on long-term weight maintenance in weight-reduced men.

Chapter $7 \quad$ The effect of exercise training on leptin levels in obese males. $\quad 93$

Chapter 8 The effect of exercise training on 24 h substrate utilization. 107

Chapter 9 Predictors of weight maintenance.

Chapter 10 General Discussion

Summary

Samenvatting

Abbreviations

Dankwoord

Curriculum vitae

Publications 


\section{Chapter 1}

\section{Introduction}

\section{Prevalence of obesity}

The prevalence of obesity, defined as a body mass index (BMI $=$ body weight.height ${ }^{-2}$ ) $>30$ kg. $\mathrm{m}^{-2}$, has increased in affluent countries as is clearly shown in fig.1.1 (Ashwell, 1994; Seidell, 1995; Seidell and Flegal, 1997). In the United States (Kuczmarski et al., 1994), and in the United Kingdom (Prentice and Jebb, 1995) the prevalence has almost doubled in the last twenty years. In contrast, in the Netherlands the prevalence of obesity has been found to be relatively stable in comparison to other countries (fig.1.1) (Blokstra and Kromhout, 1991; Seidell, 1995). The variation in prevalence of obesity between the countries might be explained by demographic factors (age, gender, ethnicity), socio-cultural differences (education level and income) and behavioural factors (dietary intake, smoking , alcohol consumption and physical activity) (Seidell and Flegal, 1997). The decreased physical activity has probably caused the increase in obesity in most countries (Seidell and Flegal, 1997). The stable obesity prevalence in the Netherlands indicates that energy consumption and physical activity are balanced.

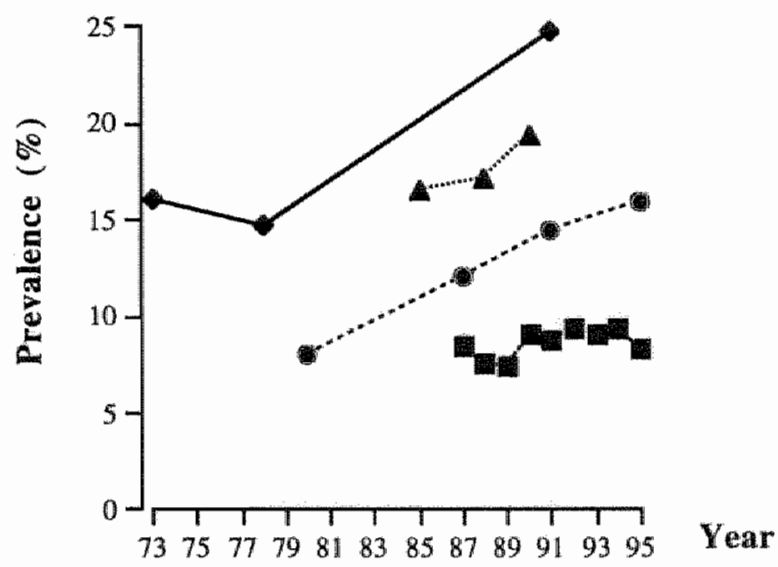

Fig. 1. I Time trends in obesity (women). Prevalence of obese women with a BMI $>30 \mathrm{~kg} \cdot \mathrm{m}^{-2}$ in the United States of America (diamonds), in Getmany (triangles), in the United Kingdom (circles) and in the Netherlands (squares) (figure adapted from Seidell and Flegal "1997).

Besides differences in BMI among countries, it is known that with age, BMI increases in men and women (fig.1.2) (Seidell, 1995). Because of the known relation of obesity with cardiovascular diseases (CVD) (Noppa, 1980; Hubert et al., 1983), prevention of obesity and overweight are of clinical importance, especially in young adults and children.

Not only CVD, also other disorders like increased blood pressure, cholesterol, diabetes mellitus, hyperlipidaemia, gallbladder disorders, certain types of cancer, breathlessness, tiredness, low back pain, arthritis of hips and knees, menstruall disturbances and 


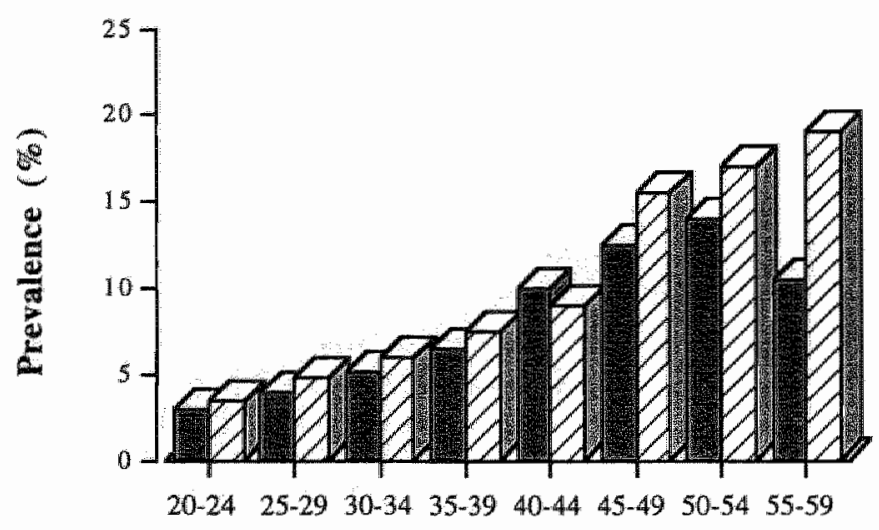

Age (yrs)

Fig. 1.2 Prevalence of obesity (BMI $>30 \mathrm{~kg} \cdot \mathrm{m}^{-2}$ ) according to age in about 36.000 men (filled bars) and women (hatched bars) participating in the Monitoring Project on Cardiovascular Disease Risk Factors in the Netherlandsi 1987-1991 (adapted from Seidell, 1995).

incontinence in women and consequent depression have all been found to be related to an increased body weight (Kannel et al., 1967; Stamler et al., 1978; Noppa, 1980; Kromhout, 1983; Anderson and Kannel, 1992; Ravussin and Swinburn, 1992; Lean, 1997). The J- or U.shaped curve of BMI and mortality risk further showed that extreme leanness and obesity are related to increased risk of mortality (Waaler, 1984; Manson et al., 1995). Overweight women showed a two to three times higher risk compared to the normal weight reference group (Manson et al., 1995).

\section{Etiology of obesity}

Important factors suggested to be related with the development and increasing prevalence of obesity, are decreased physical activity, high-fat diets and unadjusted energy intake compared with the lowered energy expenditure (Ravussin and Swinburn, 1992; Ravussin et al, 1993; Barnard and Wen, 1994; Lissner et al., 1997; Seidell and Flegal, 1997). A history of obesity in the family indicates the genetic component of obesity (Stunkard et al., 1986; Bouchard, 1996). Shared genes, diet, cultural background and a certain lifestyle make separation of the genetic and environmental components difficult (Ravussin et al., 1993). Although a clear genetic component of obesity is found, low-fat diets and increased physical activity can still prevent weight gain in predisposed subjects (Astrup and Raben, 1992; Flatt, 1995). In industrialized countries the need for physical activity during labour and transport is decreased with automation and number of cars. Also leisure time activities are dominated by television viewing and other inactive pastimes (Prentice and Jebb, 1995). Therefore, it is clear that daily energy expenditure decreases and affects energy balance when energy intake remains the same. The relative high-fat diets consumed nowadays has further been suggested to be an important factor for the etiology of obesity. The increased fat consumption coincided with a decrease in carbohydrate ( $\mathrm{CHO}$ ) as is seen in all affluent countries over the past 50 years (Prentice and Jebb, 1995). Highly palatable fat-rich foods are available abundantly in

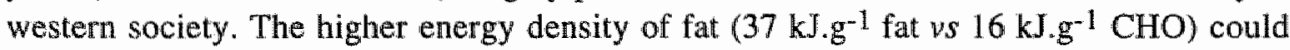
easily result in increased energy consumption, as was found in studies with varying levels of fat (Prentice and Jebb, 1995; Lissner et al., 1987). Low-fat diets and fat substitutes are 
therefore suggested diet interventions for prevention of obesity and weight gain (Astrup et al., 1997), although there is still debate whether low-fat, high-carbohydrate diets can be advised to everyone (Connor et al., 1997).

Other suggested causes for obesity are a low resting metabolic rate (RMR) (Shah and Jeffery, 1991) and a failure to promote fat oxidation after fat intake, indicated by an increased respiratory quotient (RQ) (Schutz et al., 1989). A reduced fat oxidation and a normal fat intake will already result in a positive energy and fat balance, causing obesity (Ravussin and Swinburn, 1992; Ravussin et al., 1993). Several drugs can lead to an increase in body weight, for example glucocorticoids and tricyclic antidepressants (Bray, 1992). Increase of body weight has also been reported with certain endocrine diseases, after surgery, after pregnancy and cessation of smoking (Bray, 1992; Seidell and Flegal, 1997). Finally, obesity is found to be more prevalent in the lower socio-economic classes. An increase in prevalence of obesity was found in those with relatively low education levels and low income (Ravussin and Swinburn, 1992; Seidell, 1995; Seidell and Flegal, 1997).

\section{Beneficial effects of weight loss}

The increased risk for mortality and morbidity in obese subjects is lowered when weight loss had taken place (Goldstein, 1992). Substantial weight loss as was seen in the Swedish Obese Subjects-project after gastric restrictive surgery, improved risk factors for cardiovascular diseases, but also the health-related quality of life (Karlsson et al., 1997). However, weight loss of more than $30 \mathrm{~kg}$ is for most subjects not a realistic goal (Fairburn and Cooper, 1996). Modest weight loss, 5-10\% of the initial body weight, could be achieved by more subjects (Goldstein, 1992; Fairburn and Cooper, 1996; van Gaal et al., 1997). Also for a weight loss of 5-10\% beneficial health effects have been found in most obese patients with medical complications of obesity. Improvement of insulin sensitivity, hypertension and HDL-cholesterol, which have been reported after weight loss (Goldstein, 1992; van Gaal et al., 1997), contribute to the decrease of the mortality and morbidity risk. In 1992 Wing and coworkers reported that loss of body weight was correlated with a reduced waist and hip circumference, and decreases in waist-hip ratio (WHR) in men and women (Wing et al., 1992a). Cardiovascular risk factors, (like hypercholesterolemia, hypertension, diabetes mellitus, smoking, physical inactivity, obesity (especially abdominal obesity) and stress), improved significantly with weight loss (Wing et al, 1992a). A reduction in blood pressure, glucose levels, body weight, fat mass and stress, and an increase in physical activity are beneficial for a proper heart function. Long-term effects of moderate weight loss at cardiovascular risk factors were also studied by the group of Wing. It was found that men and women both benefit at 18 months following weight loss, with similar changes in cardiovascular risk factors (Wing et al., 1995a). A reduction of $10 \%$ of the initial body weight was found to result in a decreased risk for CVD. This modest weight loss seems a realistic goal for obesity treatment. However, only $30 \%$ of the experimental group achieved and maintained a weight loss of this magnitude. Despite the limited success of long-term weight reduction programs, even a small amount of weight loss should be recommended, because of its beneficial health effects (Goldstein, 1992; van Gaal et al., 1997). Therefore normalization of body weight is not necessarily the ultimate goal of a weight reduction strategy (Rössner, 1997). Health benefits are the main factors of interest. 
Adverse effects of dieting are the development of eating disorders. Binge eating disorders, Anorexia Nervosa and Bulimia Nervosa have been found to be iniliated by dieting (Wardle, 1996).

\section{Physiological and psychological consequences of weight cycling}

The regain found after a weight-loss period in which the weight lost is gained again is together with the weight loss itself called a weight cycle'. Although mostly beneficial effects were found of weight loss in obese subjects, weight cycling seems to be less beneficial. Equivocal results have been found in weight cyclers with respect to efficiency of food storage, risk of CVD, etc. (Saris, 1989; Lissner et al., 1991; Wing, 1992a; Wing; 1992b; National Task Force, 1994). Data of the Framingham Heart Study showed that fluctuations of body weight were related to increased mortality and CVD (Lissner et al., 1991). The National Task Foree (1994) concluded that long-term health effects of weight cycling are lacking, and advice non-obese subjects to attempt to maintain a stable body weight. Only obese subjects with a BMI > 30 seem to benefit from weight loss (National Task Force, 1994). They should however reallize that they have to be ready to commit lifelong changes in their behawioural pattern, diet and physical activity (National Task Force, 1994; Wing, 1995b). In a two year study in which subjects were subject to two weight cycles, Kempen found that the B-adrenergic thermogenesis was blunted in weight cyclers (Kempen, 1996). Thus some adverse effects of weight cycling have been reported. Further long-term studies are necessary to elucidate the problem of weight-cycling in humans.

The poor weight maintenance results (Wadden et al., 1988; Kramer et al., 1989) indicate that subjects are not able to change behaviour adequately (Westerterp-Plantenga et al., 1998), resulting in increased psychological stress and discomfort (Wadden et al., 1988; Garner and Wooley, 1991). Weight fluctuation is found to be strongly associated with negative psychological attributes in both normal weight and obese individuals (Foreyt et al., 1995). The subjects of Wadden reported that the failure to maintain the lowered body weight had a negative effect on many aspects of their lives. Self-esteem, satisfaction with appearance, physical health, job performance, and sex life had been negatively affected by regain of body weight (Wadden et al., 1988; Garner and Wooley, 1991). These factors may interact with weight fluctuation (Foreyt et al., 1995).

\section{Long*term weight control}

Prevention of obesity and prevention of regain after a weight-loss intervention might require partly the same strategies. A stable body weight will be maintained when energy intake (EI) and energy expenditure (EE) are balanced. However, physiological mechanisms related to maintenance of a certain decreased body weight indicate that treatment of obesity is not so simple. Genetics, body weight set-point and fat cell size and number, and eating behaviour attitudes present in obese subjects, will after a weight-loss intervention act in fayour of weight regain, to achieve the initial body weight (Sjoström, 1974; Keesey and Corbett, 1984; Bouchard, 1992). Pre- and post-obese subjects will therefore need different strategies to achieve weight maintenance.

Besides energy balance, the theory of Flatt states that macronutrients must be in balance too (Fiatt, 1987; Flatt, 1993). Nutrient balance is mainly examined by comparison of the amount of oxygen necessary for substrate oxidation and the amount of carbondioxide produced in the body $v s$ the amount of oxygen necessary for oxidation of a representative sample of the 


\section{Introduction}

food consumed and the amount of carbondioxide produced. The ratio of carbondioxide production and oxygen consumption is called the respiratory quotent (RQ). The same ratio for the representative food sample measured in the lab, is called a food quotient (FQ). When the same amount of $\mathrm{CHO}$, fat and protein are consumed as oxidized, the $\mathrm{RQ}$ will be similar to the FQ. Whenever the $\mathrm{RQ}$ is not equal to the $\mathrm{FQ}$, some changes in the CHO storage (glycogen) and/or fat stores in the body, are necessary (Flatt, 1993). When high-fat foods are consumed (low FQ), an increase in fat oxidation must take place to achieve fat balance. A lowering of the glycogen stores will occur when a high-fat diet is consumed and result in an increased use of fat as a fuel. Because of the increased fat oxidation, the RQ will decrease, resulting in an adaptation of $\mathrm{RQ}$ to $\mathrm{FQ}$. Another adaptation for fat balance at a high-fat diet is the expansion of adipose tissue mass, increasing the contribution of fat to the fuel mix metabolized (Astrup et al., 1994). The increased fat mass results in higher circulating FFA levels, inducing insulin resistance (Flatt, 1993). Insulin resistance will ultimately limit further fat accumulation and has been stated to be an adaptation to weight maintenance at a higher level of body weight (Eckel, 1992; Flatt, 1993; Ravussin et al., 1993).

Weight maintenance can thus be achieved by manipulating EI, or the macromutrients, and / or EE. Different long-term studies restricting EI or EE have been performed for weight maintenance. Low-fat diets (high-CHO diets) have been studied in different trials (Raben et al., 1995; Siggaard et al., 1996; Westerterp et al., 1996; van het Hof et al., 1997; Toubro et al., 1997). Replacement of macronutrients, for example carbohydrates by sweeteners has been found to be beneficial for weight maintenance (Blackburn et al., 1997). Replacement of fat by fat replacers such as Olestra (a sucrose polyester) (Rolls et al., 1992; WesterterpPlantenga et al., 1997) has been reported to be effective especially in short term studies. Lowering energy density of the food consumed and increasing the volume was the hypothesis behind studies in which dietary fiber was supplied in addition to normal food (Tuomilehto et al., 1980; Uusitupa et al., 1989; Ryttig et al., 1989). Promising effects with respect to weight control have been found in short-term fiber supplementation studies (Evans and Miller, 1975; Porikos et al., 1986; Burley et al., 1987). Dietary fiber has been suggested to be beneficial for weight maintenance in the long-term (Hamilton and Anderson, 1992; Rössner, 1992a).

Manipulation of EE is possible via stimulating agents like caffeine, ephedrine, and pharmacological drugs, but the best effector is physical activity (Dulloo et al., 1989; Saris, 1991; Guy-Grand, 1997). The acute effect of exercise and the enhanced post-exercise oxygen consumption (EPOC) result in a clear disturbance of the energy balance, and can have beneficial effects for weight loss and weight maintenance (Bielinski et al., 1985; Bouchard et al., 1993; Tremblay and Buemann, 1995). An exercise intervention has frequently been used after an energy restricted diet period, to prevent weight gain and achieve weight maintenance ( Pavlou et al., 1989; van Dale, 1990; Hartman et al., 1993; Katzel et al., 1995). At this time consensus about the weight controlling aspect of exercise is achieved (Stefanick, 1993; Bouchard et al., 1993; Buemann and Tremblay, 1995; Saris, 1996). However, as for changes in energy intake and eating behaviour, implementing exercise in daily life is not an easy task. Drop-outs, bad compliance and even discontinuation of the intervention makes examination of the effect of the intervention at weight maintenance difficult (Martin et al., 1984; Kruse et al., 1990; Westerterp et al., 1992). However, true weight maintainers indicate that exercise is a prerequisite for their weight maintenamce (van 
Dale et al., 1990; Haus et al., 1994; Harris et al., 1994; DePue et al., 1995; St. Jeor et al., 1995).

Besides dietary treatment of obesity and increase of physical activity as a method for weight maintenance, phamacological approaches have been studied. Acceptance of anti-obesity drugs for clinical use can take place when various criteria are met. The drug must decrease body weight and improve weight dependent diseases. Side-effects of the drugs must be tolerable and/or transient. The drug needs to be safe and effective when used long-term, and have no addictive properties. It is furthermore required that the mechanism of action of the drug is known (Guy-Grand, 1997).

Multidisciplinary interventions, containing more complete approaches with diet and exercise advice, besides behavioural therapy, seem beneficial for an effective weight maintenance program (Saris, 1982; Rössner, 1992b; Ravussin et al., 1993; Wing, 1995b).

Effective interventions for treatment of obesity have to be performed for more than a year, to prove effectiveness of the intervention in the long-term (Jéquier, 1987). Long-term intervention studies examining weight maintenance after a weight loss intervention should preferably be performed in free living subjects, because beneficial effects in laboratory situations are not informative for normal life conditions.

In conclusion: in terms of health, treatment of obesity is beneficial, however the results so far showed that long-term maintenance of a lowered body weight can be described as unsuccessful. Interventions improving long-term weight maintenance are needed for effective treatment of obesity.

\section{Outline of the thesis}

Examination of weight gain and weight maintenance in a normal population would require a life-long observation. However, by selecting subjects who are at risk to increase body weight, it is possible to study weight maintenance interventions in shorter periods of time. Interventions for weight maintenance were therefore studied in obese subjects after a weightloss period. In the present thesis maintenance of body weight has been investigated with three different interventions in the weight maintenance phase. The studies influenced energy balance by manipulation of energy intake or energy expenditure. Only one factor was changed in the intervention, to make a clear comparison possible with the control group that did not receive an intervention.

The study design of the three studies was similar. After a very low energy diet (VLED) of 2 months, subjects participated in a weight maintenance program of 14 months under free living conditions. The general design of the studies is presented in fig. 1.3. The type of intervention varied among the studies.

In the first study obese women consumed a fiber supplement in the weight maintenance phase. The rationale of supplementation of dietary fiber in relation to weight maintenance was reviewed (chapter 2). The short-term effects of the fiber supplement were examined in two pillot studies, in which energy intake and hunger and satiety feelings were investigated (chapter 3). The promising results of the fiber supplement with respect to weight control led to the long-term fiber supplementation trial (chapter 4). Weight maintenance was the major point of interest in the study. 

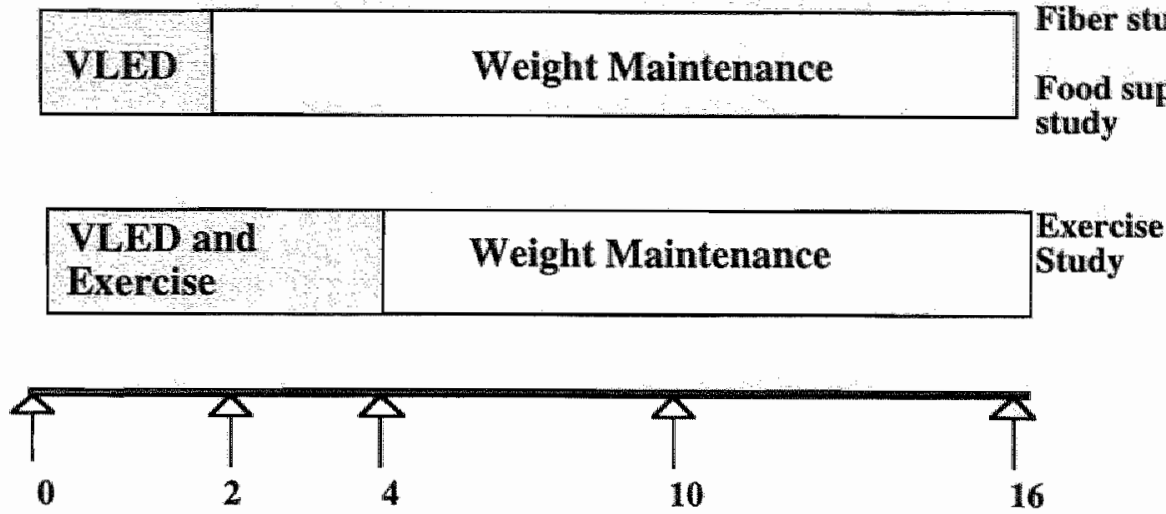

Time (months)

Fig. 1.3 Study design of the three intervention studies. The exercise study has a weight maintenance phase of $\mathbb{1 1} 2$ months, in contrast to the fiber and food supplement study which have a weight maintenance phase of 1.4 months. Measurements were performed at $0,2,4,10$ and 16 months of the study.

In the study reported in chapter 5 the effectiveness of another food supplement was tested in obese women. The supplement contained a mixture of promising functional ingredients. Carbohydrates, chromium-picolinate, caffeine and dietary fiber were supplied in a sachet, that together with $250 \mathrm{ml}$ of water, resulted in a tasteful lemonade. A supplement containing only carbohydrates was studied as a separate group. Body weight, but also macronutrient intake and body composition were examined for the food supplemented groups $v s$ the nonsupplemented group. The same study design as in the fiber study was used (fig.1.3). In both the fiber and food supplement study the control group did not receive a placebo supplement. In the fiber study this was done because no real placebo of a fiber supplement is possible (Rössner, 1993). In the food supplement study the conditions for the control group were kept the same as for the fiber study, to make comparisons between the studies possible. In a long-term intervention study with obese men, energy expenditure was affected (chapter 6) in contrast to the other two studies in which energy intake was manipulated. A small difference in study design was present. The 15 male subjects all participated in a VLED of two months and an exercise program of four months, to prevent a fast regain of body weight in the first two months after VLED. After the four month treatment two groups appeared. One group continued the exercise training and one group stopped exercising (fig. 1.3). The effect of exercise was studied in relation to body weight, body composition and physical fitness (chapter 6). The recently discovered hormone leptin (Zhang et al., 1994), known to be secreted from the adipose tissue, was studied in detail in relation to exercise. No information is available about the effect of exercise at leptin and the relation with insulin, so specific analysis to unravel the interaction of both hormones with exercise was carried out in chapter 7 . The effect of exercise on substrate oxidation is well-known during exercise in mostly lean subjects (Turcotte et al., 1992; Brooks and Mercier, 1994; Calles-Escadón, 1996). However, well-controlled $24 \mathrm{~h}$ substrate utilization data in obese subjects is lacking. Therefore, substrate oxidation data measured in respiration chambers are shown in chapter 8 . In order to get some insight into the factors that contribute to weight maintenance, the results of the long-term intervention studies were used for a meta-analysis of predictors of weight 
maintenance. The avalability of predictors of maintenance is of importance for support to subjects who are at risk for weight regain (chapter 9). Adequate and especially simple predictors would be of benefit for estimating and improving the long-term results in weight maintenance studies.

Finally, the regain found in the different studies is summarized and discussed in the general discussion (chapter 10).

\section{References}

Anderson KM, Kannel WB. Obesity and disease. In: Obesity. Ed. Björntorp P, Brodoff BN. Lippincott company, Philadelphia, pg: 465-473, 1992

Astwell M. Obesity in mem and women. Int.J.Obes.18(suppl.1): S1-S7, 1994

Astrup $A_{\text {. }}$ Raben $A$. Obesity: an inherited metabolic deficiency in the control of macronutrient balance? Eur.J.Clin.Nutr.46: $611-620,1992$

Astrup A, Busemann B. Western P, Toubro S, Raben A, Christensen NJ. Obesity as an adaptation to a highfat diet: evidence from a cross-sectional study. Am.J.Clin.Nutr.59: 350-355, 1994

Astrup $A$, Toubro $S_{\|}$Raben $A$, Skov A. The role of low-fat diets and fat substitutes in body wejght management: what have we learned from clinical studies? J.Am.Diet.Assoc.97(suppl.): S82-S87, 1997

Barnard RJ, Wen SJ. Exercise and diet in the prevention and control of the metabolic syndrome. Sports Med.18: 218-228, 1994

Bielinski $\mathbb{R}_{\text {. Schutz }} \mathrm{Y}$, Jequier E. Energy metabolism during the postexercise recovery in man. Am.J.Clin.Nutr. 42: 69-82, 1985

Blackbun GL, Kanders BS, Lavin PT, Keller SD, Whatley J. The effect of aspartame as part of a multidisciplinary weight-control program on short-and long-term control of body weight. AmJ.Clin. Nutr.65: 409-41.8, 1997

Blokstra A, Kromhout D. Trends in obesity in young adults in The Netherlands from 1974 to 1986. Int.J.Obes. 15: 513-521, 1991

Bouchard C. Genetic aspects of human obesity. In: Björntorp, P. and Brodoff, B.N., ed.." Obesity, J.B. Lippincott Company, Philadelphia, pg: 343-351, 1992

Bouchard C, Deprés J-P, Tremblay A. Exercise and abesity. Obes Res.1: 133-147, 1993

Biouchard $C$. The causes of obesity: advances in molecular biology but stagnation on the genetic front. Diabetologia 39: 1532-1533, 1996

Bray GA. An approach to the classification and evaluation of obesity. In: Björntorp, P. and Brodoff, B.N., ed.": Obesity, J.B. Lippincott Company, Philadelphia, pg: 294-308, 1992

Brooks GA, Mercier J. Balance of carbohydrate and lipid utilization during exercise: the "crossover" concept. J.Appl.Physiol. 76: 2253-2261, 1994

Buemann B, Tremblay A. Effects of exercise training on abdominal obesity and related metabolic complications. Sports Med. 21: 191-212, 1996

Burley VJ, Leeds AR, Blundell JE. The effect of high and low-fibre breakfasts on hunger, satiety and food intake in a subsequent meal. Int.J.Obes.11 (Suppl.1), 87-93, 1987

Calles-Escandión I, Goran MI, O'Connell Mo Sreekumaran Nair K, Danforth E. Exercise increases fat oxidation at rest unrelated to changes in energy balance or lipolysis. Am.J.Physiol.270(Endocrin. Metab. 33): $\mathbb{E} 1009-\mathbb{E} 1014,1996$

Connor WE, Connor SL, Katan MB, Grundy SM, Willett WC. Should a low-fat, high-carbohydrate diet be recommended for everyone? N.Eng.J.Med.337: 562-567, 1997

Dalle D van, Saris WHM, Hoor F ten. Weight maintenance and resting metabolic rate 18-40 months after a diet/exercise treatment. Int J.Obes. 14: 347-359, 1990

DePue $J D$, Clark MM, Ruggiero $L$, Medeiros ML, Pera V. Maintenance of weight loss: a needs assessment. Obes.Res. 3: 241-248, 1995

Dulloo AG, Geisster CA, Horton 'T, Collins A, Miller DS. Normal caffeine consumption: influence on thermogenesis and daily energy expenditure in lean and post-obese human volunteers. Am. J. Clin. Nutr. 49: 44-50, 1989

Eckel RH. Insulin resistance: an adaptation for weight maintenance. Lancet 340:1452-1453, 1992

Evans $E_{2}$ Miller DS. Bulking agents in the treatment of obesity. Nutr.Metab. 18:199 - 203, 1975

Fairburn $\mathrm{CG}$, Cooper Z. New perspectives on dietary and behavioural treatments for obesity. Int J.Obes. 20 (suppl.1): S9-S13, 1996 


\section{Introduction}

Flatt JP. Dietary fat, carbohydrate balance, and weight maintenance: effects of exercise. Am J.Chn. Nutr.4s: $296-306,1987$

Filatt IP. Dietary lat, carbohydrate balance, and weight maintenance. Ann.N.Y.Acad Sci.683: 122-140,1993

FFlatt JP. MoCollum Award Lecture, 1995: Diet, lifestyle, and weight maintenance. Am J.Clin. Nutr.62* 820. 836,1995

Foreyt JP, Brunner RL, Goodrick GK, Cutter $G$, Brownell KD, St. Jeor ST. Psychological cortelates of wellght fluctiation. Int.J.Eat.Dis 17:263-275, 1995

Gaal LF van, Wauters MA, Leeuw IH de. The beneficial effects of modest weight loss on cardiovascular risk factors. Int.J.Obes.21 (suppl.1): $\$ 5$-S9, 1997

Garner DM, Wooley SC. Confronting the failure of behavioral and dietary treatments for obesity. Clin.Psychol.Rev.11: 729-780, 1991

Goldstein DJ. Beneficial effects of modest weight loss. Int.J,Obes. 16: 397-415, 1992

Guy-Grand B. Pharmacologicall approaches to intervention. Int.J.Obes.21 (suppl.1): \$22-S24, 1997

Hamilton CC, Anderson JW. Fiber and weight maintenance. J.Florida M.A.79:379-381, 1992

Hantis JK, French SA, Jeffery RW, McGowern PG, Wing RR. Dietary and physical activity correlates of long-term weight loss. Obes.Res.2: 307-313, 1994

Hartman WM, Stroud M, Sweet DM, Saxton J. Long-term maintenance of weight loss following supplemented fasting. Int. J.Eat.Dis. 14: 87-93, 1993

Haws $\mathrm{G}$, Hoer SL, Mavis B, Robinson J. Key modifiable factors in weight maintenance: fat intake, exercise, and weight cycling. J.Am.Diet.Assoc.94: 409-413, 1994

Hof $\mathrm{KH}$ wan het, Westrate JA, Berg $H$ van den, Velthuis-te Wierilk $\mathbb{E} J M$, de Graaf C, Zimmermans NJH, Westerterp KR, Westerterp-Plantenga $\mathrm{MS}_{\text {" }}$ Verboeket-van de Venne WPHG. A long-term study on the effect of the spontameous consumption of reduced fat products as part of a normal diet on indications of health. Intu.Food Sc.Nutr.48: 19-29, 1997

Hubert HB, Feinleib M, McNamara PM, Castelli WP. Obesity as an independent risk factor for cardiovascular disease: a 26-year follow-up of participants in the Framinghan Heart Study. Circulation 67: $968-977,1983$

Jécquier E. Energy, obesity, and body weight standards. Panel summary statements Am.J.Clin.Nutr.45: 10351036,1987

Kannel WB, Brand N, Skinner JJ, Dawber TR McNamamara PM. The relation of adiposity to blood pressure and development of hypertension. Ann. Int.Med.67: 48-59, 1967

Karlsson J, Sullivan M, Sjöström L. Swedish obese subjects (SOS) - an intervention study of obesity. Fouryear follow-up of weight-loss and quality of life. Int.J.Obes.21 (suppl.2): S122, 1997

Katzel LI, Bleecker ER, Colman EG, Rogus EM, Sorkin JD, Goldberg AP. Effects of weight loss vs aerobic exercise training on risk factors for coronary disease in healthy, obese, middle-aged and older men. JAMA 274: 1915-1921, 1995

Keesey RE, Corbett SW. Metabolic defence of the body weight set-point. In: Eating and its disorders. Ed: Stunkard AJ, Stellar, E. Raven Press, New York, 1984, pg:87-96

Kempen KPG. Metabolic effects of weight cycling in obesity. Thesis at the Manstrich Universily, 1996

Kramer FM, Jeffery RW, Forster JL, Snell MK. Long-term follow up of behavioral trentment for obestly patterns of weight regain among men and women. Int.J.Obes.13:123-136, 1989

Kromhout D. Body weight, diet, and serum cholesterol in 871 middle-aged men during 10 years of follow-up (the Zutphen Study). Am.J.Clin.Nutr.38:591-598, 1983

Kruse W, Schlierf G. Weber E. Monitoring compliance in clinical trials. Lancet 335: 803-804, 1990

Kuczmarski RJ, Flegal KM, Campbell SM, Johnson CL. lncreasing prevalence of overweight among US adults. The national health and nutrition examination surveys, 1960 to 1991. JAMA 272: 205-211, 1994

Lean MEJ. Sibutramine - a review of clinical efficacy. Int.J.Obes, 21 (suppl.1): \$30-\$36, 1997

Lissner L, Levitsky DA, Strupp BJ, Kalkwarf HJ, Ro DA. Dietary fot and the regulation of energy intake in human subjects. Am.J.Clin.Nutr, 46:886-892, 1987

Lissner L. Odelli PM, D'Agostino RB, Sitokes J, Kreger BE, Belanger AJ, Brownell KD. Variability of borly weight and health outcomes in the Framingham population. N.Fng. IMed.324: 1839-44, 1991

Lissner $L$, Heitmann BL, Bengtsson C. Low-fat diets may prevent weight gain in sedentary women: prospective abservations from the population stidy of women in Gothenburg, Sweden. Obes. Res. 5: 4348,1997

Manson JE, Willet WC, Stampfer MJ, Golditz GA, Hunter DI, Hankinson SE, Hennekens CH, Speizer FE. Body weight and mortality among women. N.Eng.J. Med. 333: 677-685, 1995 


\section{Chapter 1}

Martin IE, Dubben PM, Katell AD, Thompson JK, Raczynski JR, Lake M, Smith PO, Webster IS, Sikora $T$, Cohen RE. Behavioral control of exercise in sedentary adults: studies 1 through 6 . J.Consulli.Clin.Psych. 52: 795-811, 1984

National Task Force on the Prevention and Treatment of Obesity. Weight cycling. JAMA 272: 1196-1202, 1994

Noppa H. Body weight change in relation to incidence of ischemic heart disease and change in risk factors for ischemic heart disease. Am. J.Epidemiol 111: $693-704,1980$

Pavlou KN, Whatley IE, Jannace PW, DiBartolomeo JI, Burrows BA, Duthie EAM, Lerman RH. Physical activity as a supplement to a weight-1oss dietary regimen. Am.J.Clin.Nutr.49: $1110-1114,1989$

Porikos K, Hagamen $\mathbf{S}$. Is fiber satiating? Effects of a high fiber prelload on subsequent food intake of normal-weight and obese young men. Appetite 7: 153-162, 1986

Prentice AM, Jebb SA. Obesity in Britain: gluttony or sloth? B.M.J. 311: 437.439, 1995

Raben A, Due Jensen N, Marckmann $P_{s}$ Sandström B, Astrup A. Spontaneous weight loss during 11 weeks' ad Mbitum intake of a low fat/high fiber diet in young, normal weight subjects. Int.J.Obes. 19: 916-923, 1995

Ravussin $\mathbb{E}, 3$ winburn BA. Pathophysiology of obesity. Lancet 340: 404-408, 1992

Ravussin E, Fontvieille AM, swinburn BA, Bogardus C. Risk factors for the development of obesitty. Ann.N.Y.Acad.Sc.683: 14.1-150, 1993

Rolls BJ, Pirraglia PA, Jones MB, Peters JC. Effects of olestra, a noncaloric fat substitute, on daily energy and fat intake in lean men. Am.J,Clin.Nutr.56: 84-92, 1992

Rössner S. Dietary fiber in the prevention and treatment of obesity. In: Dietary fiber - A component of food. Chapter 15 (pg. 265-277). Ed. Schweizer TF, Edwards CA. London: Springer-Verlag, 1992a

Rössner S: Factors determiming the long-term outcome of obesity treatment. In: Björntorp, P, and Brodoff, B.N, ed: Obesity. Lippincott Company, Philadelphia, pg:712-719, 1992b

Rössner S. Dietary fíber - no panacea. Editorial. J.Int.Med.233: 433-434, 1993

Rössner S. Defining success in obesity management. Int.J.Obes.21 (suppl.1): S2-S4, 1997

Ryttig KR, Tellnes G, Hagh L, Bøe E, Fagerthun H. A dietary fibre supplement and weight maintenance after weight reduction: a randomized, double-blind, placebo-controlled long-term trial. Int.J.Obes.13: 165171,1989

Saris WHM, Binkhorst RA, Cramwinckel AB, Hegger WG, König KG. The development of a health education program for school children. T.Soc.Geneesk.60: 680-684, 1982

Saris WHM. Physiological aspects of exercise in weight cycling. Am.J.Clin.Nutr.49: 1099-1104, 1989

Saris WHM. Exercise, nutrition and weight control. In: Advances in nutrition and top sport. F.Brouns (ed.) Med.Sport Sci. Basel, Karger, pg:200-215, 1991

Saris WHM. Physical acti wity and body weight regulation. In: Bouchard, C. and Bray, G.A., ed.: Regulation of body weight: Biological and biohavioral mechanisms. John Wiley \& Sons Ltd., pg. 135-148, 1996

Schutz $Y$, Flatt JP, Jéquier $E$. Failure of dietary fat intake to promote fat oxidation: a factor favoring the development of obesity. Am.J.Clin. Nutr.50:307-314, 1989

Seidell JC: Obesity in Europe. Obes. Res.3(suppl.2): 89S-935, 1995

Seidell JC, Flegal KM. Assessing obesity: classification and epidemiology. Brit.Med.Bull. 53: 238-252, 1997

Shat $M$, Jeffery $R$ W. Is obesity due to overeating and inactivity or to a defective metabolic rate? A review. Ann.Behav.Med.13: 73-81, 1991

Siggaard R, Raben A. Astrup A. Weight loss during 12 weeks' ad libilum carbohydrate-rich diet in overweight and normall-weight subjects at a Danisly work site. Obes.Res. 4: 347 356, 1996

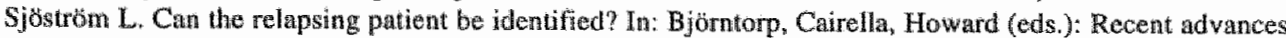
in obesity research: III. Proceedings of the third International Congress on Obesity. Libbey: London,pp 85 $-93,1974$

St. Jeor ST, Brunner RL. Harrington ME, Scott BJ, Cutter GR, Brownell KD, Dyer AR, Foreyt JP. Who are the weight maintainers? Obes.Res.3 (suppl.2): 2495-259s, 1995

Stamler $\mathbb{R}$, Stamler J, Riedlinger WF, Algera $\mathbf{G}$, Roberts RH. Weight and blood pressure. Findings in hypertension screening of 1 million Americans. JAMA 240: 1607-1610, 1978

Stefanick ML. Exercise and weight control. Excrc.Sport Sci.Rev.21: 363-396, 1993

Stunkard AJ, Sørensen TIA, Hanis $C_{n}$ Teasdale TW, Chakraborty R, Schuill WI, Schulsinger F. An adoption study of human obesity. N.Engl.J.Med. 314; 193-198, 1986

Toubro S, Astrup A. Randomised comparison of diets for maintaining obese subjects" weight after major weight loss: ad lit, low fat, high carbohydrate diet $v$ fixed energy intake. B.M.J. 314: 29-34, 1997 
Tremblay A, Buemann B. Exercise-raining, macrontrient balance and body weight control. Tht. 1. Obes 19 : $79-86,1995$

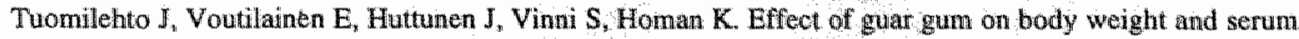
hids in hypercholesterolemic females. Acta Med.Scand.208; 5 -48,1980

Turcotte LP, Richter EA, Kiens B. Increased plasma FFA wptake and ox dation during prolonged exercise in trained vs. untrained humans. Am. Physilol 262 (Endocrinol. Metab. 25): E791-B979, 1992

Uusitupa M, Sitonen O, Savolainen $\mathrm{K}$, Silvasti M, Pentila I., Parviaunen M. Metabolic and trutritional effects of long-tem use of guar gum in the treatment of non-insulin dependent diabetes of poor metabolic controll. J.Clin.Nutr. 49: 345-351, 1989

Waaler HT. Height, weight and mortality: the Norwegian experience. Acta Med.Scand.679 (5nppl): 1-56, 1984

Wadden TA, Stunkard AJ, Liebschutz J. Three-year follow-up of the treatment of obesity by wery llow calorie diet, behavior therapy, and their combination. J.Consult.Clin. Psycol.56: 925-928, 1988

Wardle J. Obesity and behaviour chage: matching probletins to practice. Int J "Obes.20 (suppl. 1): S1-S8, 1996

Westerterp KR, Meijer GAL, Janssen EME, Saris. WHM, ten Hoor F. Long-term effect of physical activity on energy ballance and body composition. Bi. J.Nutr.68: 21-30, 1992

Westerterp KR, Verboeket-wan de Venne WPHG, Westerterp-Plantenga MS, Velthuis-to Wierik EM, de Graaf $\mathrm{C}$, Westrate $\mathrm{JA}$. Dietary fat and body fat: an intervention study. Int J.Obes.20: 1022-1026, 1996

Westerterp-Plantenga MS, Wijckmans-Duijsens NEG, ten Hoor F. Westrate IA. Eftects of replacement of fat by nonabsorbable fat (Sucrose Polyester) in meals or snacks a function of dietary restraint. Physiol. Behav. 61: 939-947, 1997

Westerterp-Planteng a MS Kempen KPG, Saris WHM. Determinants of weight maintenance in women after diet-induced weight reduction. Int.J.Obes. 1998 (in press)

Wing RR, Jeffery RW, Burton LR, Thorson C, Kuller LH, Folsom AR. Change in waist thip ratio with weight loss and its association with change in cardiovascular risk factors. Am.J.Clin.Nutr.55: 1086-1092, $1992 \mathrm{a}$

Wing RR. Weight cycling in humans: a review of the literature. Ann.Behaw.Med. 14: 113i-119, 1992b

Wing RR, Jeffery RW. Effect of modest weight loss on changes in cardiovascular risk factors: atre there differences between men and women or between welght loss and maintenance? Int J.Obes.19: 67.73, $1995 \mathrm{a}$

Wing RR. Changing diet and exercise behaviors in indiviuals at risk for weight gain. Obes. Res. 3. (suppl.2)* 277S-282S, $1995 b$

Zhang Y, Proenca R, Maffei M, Barone M, Leopold L, Friedinan JM. Positional cloning of the mouse obese gene and its human homologue. Nature $372: 425-432,1994$ 



\title{
Chapter 2
}

\section{Dietary fiber and body weight control.}

\author{
A review.
}

\author{
W.J. Pasman* ${ }^{*}$ M.S. Westerterp-Plantenga* , and W.H.M. Saris* \\ * Maastricht University, Maastricht, \#pen University, Heerlen, The Netherlands
}

Br.J.Nutr.(submitted)

\begin{abstract}
Dietary fiber is a general term referring to non-digestable cell wall components of plant foods, that cannot be digested by human alimentary enzymes. The fiber action in relation to body weight control is mainly based upon 3 aspects: (1) fiber displaces available nutrients; (2) fiber demands chewing; (3) fiber reduces the absorptive efficiency of the intestines (Heaton, 1973).

Water soluble and water insoluble fibers have different physical functions. The water soluble type of fiber has the capacity to absorb elements, and is mainly effective to lower cholesterol, blood pressure and the glucose-insulin response. The insoluble fibers increase fecal bulk and decrease the intestinal transit time.

Although experimental studies with fiber on food intake and weight control are difficult to compare, in short-term studies most results are in favour of fiber supplementation. Fiber was found to reduce energy intake, lower hunger scores and increase satiety scores. However, in long-term studies conflicting results were found of fiber at weight control.. Convincing evidence is presented that fiber supplementation besides an energy restricted diet improves compliance. Epidemiologic data supporting the positive results of fiber supplementation at weight control are rare. It was found that a high fiber intake was coincided with a low body weight. Supplementation of fiber is an easy way to increase habitual fiber intake in comparison to changes in diet consumption.

It is concluded that supplementation of fiber is mainly effective in short-term studies and the applicability for long-term weight control is still under debate.
\end{abstract}

\section{Introduction}

The increasing prevalence of obesity in industrialized countries deserves our attention and care (Kuczmarski, 1994; Seidell, 1995). Obesity defined as a body mass index (BMI) $>30$ $\mathrm{kg} \cdot \mathrm{m}^{-2}$, is known to be correlated with increased risks of coronary heart diseases, hypertension and diabetes mellitus (Stamler et al., 1978; Hubert et al., 1983; Kromhout, 1983). Modest weight loss has been shown to result in improved blood pressure, blood lipids, and gucose and insulin levels (Goldstein et al.,1992; Wing et al., 1995). However, it is common knowledge nowadays that weight loss is hardly maintained in most subjects (Björvell and Rössner, 1986; Garner and Wooley, 1991; Wadden et al., 1994). Since it is known that long-term weight maintenance is a major problem in the treatment of obesity, in 
contrast to weight loss, a diversity of interventions to achieve weight maintenance has been suggested.

Because weight maintenance is achieved when energy intake and energy expenditure are balanced, manipulation of the type and quantity of food consumed seems to be the easiest way of changing energy balance. Studies with bulking agents like fibers were carried out to investigate whether supplementation of fiber resulted in decreased food intake. Fibers were found to be effectively increasing feelings of fullness (Evans and Miller, 1975; Leeds, 1987; Raben et al., 1994; van de Ven et al., 1994) and had a satiating effect (Ryttig et al.,1989; Spiller, 1993). This could result in a decreased energy-intake. The lowered energy intake would then result in weight maintenance (Evans and Miller, 1975; Krotkiewski, 1984; Rigaud et al, 1990; Hamilton and Anderson, 1992).

In this paper the metabolic and physiologic properties of dietary fiber in relation to weight maintenance will be reviewed.

\section{The defintion of dietary fiber}

\section{Dietary niber}

The definition of dietary fiber has been under debate for many decades (Anderson, 1985; Anderson, 1986a; Roberfroid, 1993). In 1976 Trowell and colleagues defined fiber as "plant polysaccharides and lignin resistant to digestion by the smail intestinal enzymes of man" (Trowell et al., 1976). This definition is now equivalent for Non Starch Polysaccharides (NSP). Dietary fiber however includes besides NSP, also other non-digestable cell wall material of plants. Dietary fiber is nowadays a general term referring to non-digestible cell wall components of plant foods (Hamilton and Anderson, 1992). Dietary fiber components consist mainly of polysaccharides, complex polymers of sugar units. The problem of digestion of dietary fiber in contrast to the family of carbohydrates it belongs to, is the linkage of the saccharides in B-1,4 bonds (cellulose) instead of alfa 1,4 bonds (like starch) (Gurr and Asp, 1994). All types of dietary fiber have in common that they cannot be digested by the human alimentary enzymes, because we do not have enzymes that can cleave B-1,4 bonds. The dietary fubers can be hydrolyzed and fermented by gastrointestinal microflora (Roberfroid, 1993).

\section{Classification of dietary fiber}

Dietary fibers can be classified according to their solubility in water.

Water soluble fibers (like gums, pectin and mucilages) are polysaccharides characterized by their solubility in hot water and their ability to form gels (Bennett and Cerda, 1996). In the food industry the thickening agent pectin is used to stabilize food products (for example jelly). Pectin is mostly found in fruit and berries. Also gums are used as thickening agents. Mucilages (like the Ispagula) have high water binding capacities and are therefore used as laxatives (Gurr and Asp, 1994).

Water insoluble fibers (like cellulose and hemicellulose) have a stable structure, forming strong fibers; a structure that is very insoluble and undergoes minimal change in the digestive tract (Gurr and Asp, 1994; Bennett and Cerda, 1996). The linear molecules of cellulose pack together closely in long fibres stabilized by chemical attraction between the chains (Gurr and Asp, 1994). Insoluble fibers are mainly found in fruits, wegetables and cereals.

The solubility of some components depends upon the method of analysis used. Two types of methods to analyze dietary fiber have evolved, neither which can be regarded as ideal. The 


\section{Dietary fiber and body weight control}

analytical method used is depended upon the purpose required (Spiller, 1993; Gurr and Asp, 1994). The Englyst method and the method accepted by the Association of Official Analytical Chemists $(A O A C)$ have been suggested to be complementary with respect to fiber analysis. Using the Englyst method, based upon principles laid down by Southgate (1985), fractions of dietary fiber like total dietary fiber, soluble and insoluble fibers, cellulose and resistant starch can be determined. The AOAC method is a gravimetric method, meaning that the extraction method is based upon weighing of the separate fractions restricted of the dietary fiber. With this method non-starch polysaccharides (NSP), resistant starch and lignin are measured (Spiller, 1993).

\section{Properties of dietary fiber}

The physical properties of dietary fiber polysaccharides depends upon: the content of sugar units with ionic charges, the size of the sugar chains, the proportion of straight to branched chains and the linkage between the sugar units (Gurr and Asp, 1994). Important physicochemical properties with respect to food structure and physiological function are; the ionic charge, degree of water-holding capacity, adsorption capacity and viscosity (Gurr and Asp, 1994).

Processing of food products affect the content of dietary fiber. Furthermore the action of the fiber will be influenced too when it is processed, for example heating, cooking, drying or purification. Supplemental fiber is usually a purified fiber that has properties of either soluble or insoluble fiber (Bennett and Cerda, 1996). The effect of fiber isolates or tablets is expected to be different when administered with or without food (Spiller, 1991). Furthermore the effect of the fiber in fiber-rich food products might differ too in comparison with fiber isolates (Blundell and Burley, 1987).

\section{Physiological implication of soluble and insoluble dietary fibers}

The classification of dietary fiber in water soluble and insoluble has physiological implications. Depending upon the solubility the fiber is better able to hold water, affect satiety, adsorb agents in the colon, etc. (Anderson, 1985, 1986a; Blundell and Burley, 1987).

\section{Soluble dietary fiber}

The soluble fiber has the capacity to adsorb elements, for example resulting in lowering of cholesterol and hypertension. Also absorption of glucose is delayed with soluble fibers. The viscosity property of soluble fibers delays gastric emptying and slows food transit time (Hamilton and Anderson, 1992; Roberfroid, 1993). Water soluble viscous fibers are thought to lower the digestion rate in the intestines, because viscous fibers might reduce the diffusion in the bulk phase and increase the thickness of the unstirred water layer. In this way nutrient absorption is thought to be reduced. Furthermore, food items containing fiber, may reduce the rate of penetration by digestive enzymes and so reduce the rate of supply of substrates for adsorption (Jenkins et al.,1986). The gel forming properties of the water soluble fibers improve the glycemic control of diabetic patients by slowing adsorption of glucose from the small intestine into the blood stream. The cholesterol lowering effect of fiber is also found with water soluble fibers (like guar gum and pectin), probably by uptake of bile acids, which are excreted with the fecal bulk. Lowered bile acids concentrations and the formation of Short Chain Fatty Acids (SCFA) in the colon, result in reduced synthesis of cholesterol in the liver (Anderson, 1985). 


\section{Chapter 2}

\section{Insoluble dietary fiber}

of the insoluble fiber ("roughage") it is known that they increase fecal bulk and decrease intestinal transit time. The gastric emptying rate is higher with insoluble fiber. Supplementation of insoluble fiber intake will result in correction of defecation to normal; constipation will be cured by softening of the feces (based upon the laxative effect of the insoluble fibers, resulting in less water resorption of the feces because transit time is reduced) and diarheia will be cured by water uptake of the fibers and increased fecal bulk, resulting in more solid stools (Jenkins et al., 1986; Roberfroid, 1993). The reduction in transit time (decreased transport time from mouth to anus) is called "intestinal hurry". The decrease in contact time in the intestines will result in a lowered uptake of nutrients (Jenkins et al., 1986). The glucose absorption is delayed from the small intestine with insoluble fiber (Albrink, 1978; Anderson et al., 1986b).

Based upon their physicochemical and their physiological properties, dietary fibers can be subclassified as soluble-viscous-fermentable $v s$ insoluble-nonviscous-unfermentable, or mixed fibers (Roberfroid, 1993). The first subclass mainly affects gastric emptying, slows down or reduces glucose absorption, and is thought to be hypocholesterolemic. The insoluble subclass mainly affects fecal bulk and decreases transit time (Jenkins et al., 1986). Because of the diverse effects of the soluble and insoluble fibers, intake of different fibers has been suggested to be beneficial for treatment or prevention of a whole range of diseases. A combination of soluble and insoluble fiber will result in beneficial effects at health and weight control. The effect of fiber at energy intake and hunger and satiety does not seem to be affected by the type of fiber. In obesity research both types of fiber, water soluble and insoluble, have been used, both seeming equally effective (Rössner, 1992; Hamilton and Anderson, 1992" Bennett and Cerda, 1996). Combinations of insoluble and soluble fiber may therefore offer the most beneficial health related effects (Anderson et al., 1986b; Spiller, 1993).

\section{The dietary fiber hypothesis}

The fiber pioneers Burkitt and Trowell formulated the "dietary fiber hypothesis" in 1975. They hypothesized that a low fiber intake was related to the high incidence of colon cancer, coronary heart disease, obesity, diabetes, hypertension and certain other diseases in modern industrialized societies (Trowell, 1973; Burkitt and Trowell, 1975; Anderson, 1986a; Jenkins et al. 1986). Related to the dietary fiber hypothesis and some of the diseases mentioned, is the glycenic index (GI). This aspect of dietary fiber is important in relation to weight control and diabetes. The postprandial insulin and glucose response of food products vested companed with a standard test meal ( 50 grams of white bread or 50 grams of glucose) has been termed the glycemic index of that food product. Food items containing especially simple carbohydrates have a high Gl. Products with complex carbohydrates or containing dietary fibers, or no carbohydrate at all, have a low GI, indicating that a flattened insulin and glucose response were found postprandially (Wolever, 1990). Studies of Jenkins and Wolever already in the 70 s showed that high-fiber diets result in reduced glucose and insulin responses post-prandially (Jenkins et al., 1977; Jenkins et al., 1978). Although much debate about the importance of the GI has taken place (Jenkins et al., 1988), the clinical relevance of the GI is now accepted (Wolever et al., 1991; Jenkins et al., 1994). Despite the variation found in GI of test meals within subjects, between subjects, between test centers, and lack of 
differences in a complete meal (Jenkins et al., 1988), the application of GI in patients revealed that consumption of low Gr-food items resulted in lower insulin levels, better control of blood glucose, reduction of insulin secretion and lower blood lipid concentrations in patients with hypertriglyceridemia (Wolever et al, 1991). Recently, Jenkins again stressed the importance of consumption of low GI food, because of the prolongation of absorption time of nutrients. The effect of low GI food could be mimicked by small portions of feeding consumed in an increased frequency (=nibbling), improving glycemic control (Jenkins et al., 1994). Other actions of dietary fiber related to energy intake are the reported flattening of insulin and glucose levels found after fiber consumption, resulting in a decreased appetite (Albrink, 1978; Rössner, 1992; Hamilton and Anderson, 1992) and less food intake.

Albrink concluded further that a high-carbohydrate fiber-rich diet (high in simple sugars) by repeatedly stimulating an excessive insulin response may lead to insulin resistance and obesity (1978), although it was recently reviewed that this is still under debate (Blaak and Saris, 1995). The presence of dietary fiber in a meal resulting in the flattening response of glucose and insulin levels may have an insulin sparing effect (Albrink, 1978; Hamilton and Anderson, 1992; Holt and Miller, 1995). A high fiber intake has been found to be significantly correlated with an increased insulin serisitivity (Lovejoy and DiGirilamo, 1992). This indicates that fiber consumption might be effective to prevent insulin resistance, a disorder associated with a number of abnormalities (Barnard and Wen, 1994).

\section{The fiber action in relation to weight control - energy intake}

According to Heaton (1973) dietary fiber is an obstacle to energy intake, resulting in less energy intake. Dietary fiber would slow down energy intake in the following ways; (1) it displaces available nutrients; (2) it demands chewing, therefore slows down the intake and induces satiety; and (3) it reduces the absorptive efficiency of the intestine (Heaton, 1973). The more extensive lists of dietary fiber action published (van Itallie, 1978; Anderson, 1986a; Rössner, 1992; Leeds, 1992; Hamilton and Anderson, 1992) are all based upon the obstacles discussed by Heaton (1973). The different aspects of dietary fiber in relation to energy intake will be discussed in detail.

ad. 1 Displacement of available nutrients.

The space occupied by unavailable carbohydrates, as dietary fiber is, cannot be occupted by available nutrients (Heaton, 1973). This aspect of dietary fiber is related to the lowered energy density, less energy per 100 grams of food, especially in the intestines. However, the displacement theory can also be formulated for food intake itself. An indirect effect of food rich in fibers is that they displace foods from the diet that contain saturated fat and cholesterol (Spiller, 1993; Hamilton and Anderson, 1992). The choice for fiber-rich food products therefore affects nutrient uptake twice; directly (in the intestines) and indirectly (macronutrient composition of food). Food products rich in fiber, contain mostly carbohydrates, therefore a change to a fiber-rich diet is mostly a change to a low-fat diet (Raben et al., 1995). The lowered energy density results in reduced energy intake when a constant volume of food is eaten (Duncan et al.,1983; Hamilton and Anderson, 1992; Poppitt, 1995). According to Poppitt the low energy dense diets rather than the low-fat/high$\mathrm{CHO}$ diets generate a greater satiety signal, at least in the range that they reported. Studies of Stubbs showed that a constant energy density for diets varying in energy percentage fat, resulted in a similar energy intake, indicating that in a limited range energy density instead of 


\section{Chapter 2}

fat percentage affects food intake. Satiety may therefore be controlled by the weight or bulk of the food that is eaten (Stubbs et al., 1995; Westerterp-Plantenga et al., 1998), and changes in energy density may result in an inadequate compensation of energy (Poppitt, 1995; Westerterp-Plantenga et al., 1996). Therefore the current healthy-eating advice which emphasizes the need to increase consumption of complex carbohydrates remains an effective way to decrease the energy density of diets, and thus aid in the regulation of energy balance (Prentice and Poppitt, 1996; Westerterp-Plantenga et al., 1996).

At the time of formulation of the dietary fiber hypothesis, obesity was rare in developing countries where a high proportion of energy intake was abtained from starchy carbohydrate products mostly rich in fiber (Heaton, 1973; Trowell, 1973; Hamilton and Anderson, 1992; Spiller, 1993). The association between the decreased carbohydrate and fiber intake and the increased prevalence of obesity today has been suggested by others too (v. Itallie, 1978; Hamilton and Anderson, 1992; Prentice and Jebb, 1995). Prentice and Jebb suggested that the increase un fat intake, and thus the decrease in carbohydrate intake, together with the diminished physical activity were the major causes for the increase in prevalence of obesity in Britain (1995). High-fat diets are also high energy dense diets. Addition of dietary fiber lowers the energy density of a diet. When a constant amount of food is consumed, a low energy dense diet would result in reduced energy intake (Poppitt, 1995; WesterterpPlantenga et al., 1996).

ad. 2 Chewing of fiber-rich food.

The increased chewing that fiber-rich food products require, results in increased saliva production (Rössner, 1992). Chewing increases the effort to eat and retards the rate of food ingestion (v. Itallie, 1978). The limitation of food intake is a direct result of the distension of the stomach inducing satiety (Heaton, 1973; Anderson et al., 1986b; Leeds, 1987; Rössner, 1992). The delay in gastric emptying by soluble fibers like guar gum and pectin has also been suggested to enhance satiety (Anderson, 1986a; Anderson, 1986b). However, whether this delay at gastric emptying is of physiological importance is not clear (Blackburn et al., 1984). Studies in experimental animals with sham feeding, transplantation of organs or obstruction or disruption of organ signals, has suggested that a hormonal mechanism may be involved in triggering satiety from the stomach (Read et al., 1994). Cholecystokinin (CCK) is a peptide that is stored in the endothelium of the duodenum and is released when lipids and peptides are present in the lumen. However, as found by Holt and coworkers (1992), CCK also reacts at carbohydrate containing food products, although the hormonal signal is less intense (Holt et al., 1992). Food items with a low glycemic index (GI) (mostly fiber-rich containing food products or containing no carbohydrate at all) were found to be related with a higher satiety value. The relation of CCK release with gastric distension and action as a satiety hormone is under debate (Read et al., 1994). In a study of Holt et al.(1992) and Meier et al.(1993) clear relations of satiety and CCK were found, and between transit time and $\mathrm{CCK}$, resp. A change in gastrointestinal motility by $\mathrm{CCK}$, for example inhibiting gastric emptying and prolongation of transit time could be related to the enhanced satiety feelings. CCK thus reduces meal size, but also meal interval, resulting in increased meal frequency (Riedy et al., 1995). Other hormones like bombesin, gastric inhibitory peptide (GIP), glycogen-like insulinotropic peptide, and pancreatic glucagon, may also influence satiety, but so far there are no convincing data to implicate these in humans (Read et al., 1994).

ad. 3 Decreased absorptive efficiency 
The more fiber is added to the diet, the less dietary energy is absorbed (Heaton, 1973; v.Itallie, 1978; Leeds, 1987; Miles, 1992). Dietary fiber has been suggested to hinder intestinal absorption, simply by acting as a mechanical barrier preventing contact between the digested nutrient and the intestinal membrane. Not only the dietary fiber itself, also the increased bulk volume in the intestines with undigested material and water, might impair absorption (Heaton, 1973). The reduced digestability has also been suggested to be a consequence of the increased transit time (Heaton, 1973; Rössner, 1992). More energy (from gross energy; GE) is excreted via the feces when fiber-rich food products were consumed (Heaton, 1973; Rigaud et al., 1987; Rössner, 1992; Miles, 1992). Recently Baer and coworkers (1997) once again tried to find out how dietary fiber affected the metabolizable content and nutrient digestibility. Diets varying in fat content (3 levels; 47-33$16 \mathrm{En} \%$ of fat) and amount of fiber (3 levels; $39.5-29.6-19.4 \mathrm{~g}$ ) were supplied to 15 (male and female) subjects. Subjects were fed three diets ( 2 weeks for each diets) containing different levels of fiber and one level of fat. On average the metabolizable energy (ME) of the high-fiber diet was $88.1 \%$; of the medium-fiber diet $90.1 \%$ and of the low-fiber diet $91.2 \%$ (the difference in gross energy and $\mathrm{ME}$ was: $1.4 \mathrm{MJ} ; 1.2 \mathrm{MJ}$; and $1.0 \mathrm{MJ}$, resp.). This difference in energy content of the diet has important consequences for weight control. An increase in fiber content of the diet from $\pm 20 \mathrm{~g}$ to $\pm 40 \mathrm{~g}$ results in a lower energy availability, resulting in a lowered energy uptake $(\Delta 400 \mathrm{~kJ})$. This $4-5 \%$ reduction in energy uptake (when consuming a diet of 8-10 MJ) would be beneficial for weight maintenance. The reduction in $\mathrm{ME}$ by increasing fiber content of the diet has been found before (Rigaud et al., 1987; Miles, 1992). In normal weight subjects an increase in fecal energy excretion was found when $7.3 \mathrm{~g}$ of fiber was supplied per day: $723 \mathrm{~kJ} /$ day $(173 \mathrm{kcal} / \mathrm{d}) \mathrm{vs} 640 \mathrm{~kJ} / \mathrm{day}(153$ $\mathrm{kcal} / \mathrm{d}$ ) (Rigaud et al., 1987). This difference of $83 \mathrm{~kJ}$ per day ( $\pm 1 \%$ of a daily energy intake of 8-10 MJ) could attribute to weight control. An increased fecal energy loss of $83 \mathrm{~kJ}$ daily represents $1 \mathrm{~kg}$ fat loss after 446 days. The fecal energy loss through dietary fiber is therefore a serious tool for body weight control.

The different results found are probably related to the variation in amount of fiber supplied, resulting in differences in GE and $\mathrm{ME}$.

\section{The fiber action in relation to weight control - energy expenditure}

\section{Diet induced thermogenesis}

The effect of dietary fiber at thermogenesis, diet induced thermogenesis (DIT) and $24 \mathrm{~h}$ energy expenditure, showed conflicting results with important consequences for weight control. A reduction in diet induced thermogenesis (DTT) (as a percentage of metabolizable energy) was found with consumption of a high-fiber diet (7.7\%) compared to an 190energetic low-fiber diet (8.7\%) (Rössner, 1992; Raben et al., 1994). This difference in thermogenesis and oxidation was recently explained by a time-shift in oxidation by a high fiber intake (Sparti et al, 1997). A high-fiber diet resulted in significantly higher carbohydrate oxidation during the night and significantly lower fat oxidation. During daytime the differences could probably result in a lowered carbohydrate oxidation (although not significant) after a high-fiber intake, as found by Raben and coworkers (1994). The 1\% difference in DIT would, if it is just a reduction and not part of the blunted DIT, on a $24 \mathrm{~h}$ basis account for $132-198 \mathrm{~kJ}, 1-2 \%$ of the total energy intake and affect energy balance. However, as stated by Raben and colleagues (1994), the reduced DIT has to be considered together with the fact that subjects felt more full and would probably under normal 
coudtows cat less after a fber-rich meat, than the fixed amoun in their study. It is furhermore possible that the dfference in DT is not foud at a $24 \mathrm{~h}$ basis, because fermentation of dietary fiber in the large intestine (taking place at 6-10 after a meal) may increase the shot-chan faty achds production and contribute energy. This implicates that there may be dfferences in thermogenesis between carbohydrates (simple and complex), however there is no convincing evidence that smple and complex carbohydrates act differenty on energy and substrate balance (Blaak and Saris, 1995). The increased thermogenesis after carbohydrate ingestion is suggested not to be dependent upon the insulin concentration, but on the augmented cellular metabolism, indicating that different types of carbohydrates can have a similar increased themogenests (Blaak and Saris, 1995).

The effect of macromutrient composition of the diet on thermogenesis is also studied. An increased themogenesis was found after consumption of a high carbohydrate diet ws a high fat diet $(5.8 \mathrm{w}: 3.5 \%$ of energy expendivure) (Lean and James, 1988). The tiber content of the two diets was not presented. Also Westerterp and colleagues reported a higher DT after a reduced-fat wnch ws a fwl-fat wnch $(6.7 \%$ v $5.2 \%$, resp. p<0.05) (Westerterp-Plantenga et a1. 1997\%. The difference in themogenic effects as indicated above illustrate the importance of a clear description of the diet prescribed. Furthermore it is clear hat more information about the effect of macromutrient and fiber at themogenesis is needed, to find a proper diet with respect to themogenesis and weight control.

2. Short chain fatty acids

With respect to energy contribution the production of short-chain fatty acid (SCFA) or volatife fatty acids with fermentation of dietary fiber needs to be discussed. Not only dietary fiber also carbohydrates and carbohydrate derivates are fermented in the large intestine, together accounting to 6-9\% of the daily energy needs. In the colon microbial fermentation of dietary fiber to SCFA, results mostly in production of acetate, proprionate and butyrate (together $90 \%$ of the SCFA formed), of which acetate is the most prevalent one (60\%) (Roberfroid, 1993). The proportion of the major SCFA varies with diet and other conditions. Depending upon the time of fiber consumption (habituation) and the type of fiber consumed (Jenkins et al., 1986; Eastwood and Morris, 1992; Woods and Gorbach, 1993; Fleming, 1993) more or less SCFA are produced. A period of ingestion of fiber is required before SCFA are found with fermentation, so production varies after chronic fiber consumption with acute findings (Eastwood and Morris, 1992). It is further known that consumption of solvble-fermentable fiber results in more SCFA production than insolubleunfermentable fibers (Roberfroid, 1993). The SCFA may be absorbed, the energy liberated by colonic fermentation contributing to bacterial cell growth (Jenkins et al., 1986; Eastwood and Morris, 1992; Fleming, 1993). In the colon the remaining fiber, the bacteria, and associated salts and water pass out to form the fecal mass (Eastwood and Morris, 1992). With respect to energy output the following is of importance. Eastwood and Morris clearly outline that of a control diet $\pm 20 \%$ of the overall ingested fiber is recovered in the stools. Each day approximately $20 \mathrm{~g}$ of cell-wall polysaccharides and other carbohydrates are fermented in the human colon. Although $\pm 200 \mathrm{mmol}$ of SCFA are produced, only 7-20 mmol are excreted in stools each day. The substantial absorption of SCFA in the colon and subsequent metabolism suggest that fermentable fibers have the potential to provide $\pm 4.2-$ $8.4 \mathrm{~kJ}(1-2 \mathrm{kcal}) / \mathrm{g}$ fermentable fiber to the system. However, the estimation of energy provided is complicated because of an associated increase in fecal fat with fermentable fibers. A high dose of fermentable fibers resulting in increased SCFA absorption and fecal loss of 
fatty acids, makes it difficult to calculate the overall colonic balance (Eastwood and Morris, 1992). Consumption of 10-15 $\mathrm{g}$ of soluble fiber daily (on average $50 \%$ soluble and $50 \%$ insoluble) will therefore contribute $40-120 \mathrm{~kJ}$ to the energy balance, in favour of a positive energy balance and weight gain. This result would suggest that consumption of insolubie fibers are preferential with respect to energy balance.

Taken together, a number of positive effects of fiber intake in relation to energy intake and energy expenditure have been discussed. In theory, based upon the actions mentioned, fiber supplementation or consumption of a fiber-rich diet seems a realistic and potential method for weight control (Anderson et al., 1986b; Krotkiewski and Smith, 1985). Not only different kinds of actions exist of dietary fiber, the action is also dependent upon the type of fiber consumed.

\section{Experimental studies}

Numerous studies investigating the effect of fiber at body weight, hunger and satiety, and energy-intake have been carried out. Differing in duration of supplementation to investigate acute, short-term effects in comparison to chronic, long-term supplementation studies. Although performed in vivo in human volunteers, comparison of the studies is difficult because they vary in the type of fiber used, the dosage and frequency consumed during the day, duration of supplementation, way of administration, etc. (Blundell and Burley, 1987). Already a number of reports have listed outcomes of fiber intervention studies (Blundell and Burley, 1987; Stevens, 1988; Leeds, 1992; Rössner, 1992; Pasman et al., 1997a).

In this section the effectiveness of dietary fiber with respect to weight control will be examined with the results of short-term (table 2.1) and long-term intervention studies (table 2.2 and table 2.3 ).

\section{Short-term fiber studies}

In general a decreased energy intake has been observed when subjects were supplemented with dietary fiber (Rössner, 1992). Short-term intervention studies (see table 2.1) supplementing 20 grams of methylcellulose or guar gum a day, for one week was found to decrease energy intake already two decades ago (Evans and Miller, 1975). Recently these findings have been confirmed with supplementation of 20 grams of guar gum isolate to lean and obese subjects, resulting in a decrease in energy intake of $6.7 \pm 0.4 \mathrm{MJ}$ to $5.4 \pm 0.2 \mathrm{MJ}$ a day (Pasman et al., 1997b). Porikos (1986) found a reduction of energy intake (EI) when crude fiber was added in bread and given as a pre-load to obese subjects. In normal weight subjects no decrease in energy intake was found (Porikos et al, 1986). Supplementation of cereals during breakfast effectively reduced EI during lunch (Levine et al., 1989). Delargy et al. also tested the effect of $20 \mathrm{~g}$ (mostly insoluble) fiber in bieakfast at EI during lunch-time. Although the amount of EI consumed at Junch was less with a high-fiber breakfast in contrast to a low-iber breakfast, the total El of the day was similar (Delargy et al., 1995). Also a psyllium pre-load resulted in a lowered El of the meal (Cybulski et al., 1991). As found by Delargy, Cybulski found a similar total Ex; pre-load and meal resulted in a similar EL. No difference in EI was found when $20 \mathrm{~g}$ of Plantago ovata seed was used in the pre-load at test meal (Tumbull et al., 1995). However, the increased fullness and lowering of the energy percentage of fat intake, seem to indicate that this supplement might be useful for control of food consumption. Also short-term studies of one week of supplementation showed reduced hunger feelings in the fiber supplemented condition (Hylander and Rössner, 
Chapter 2

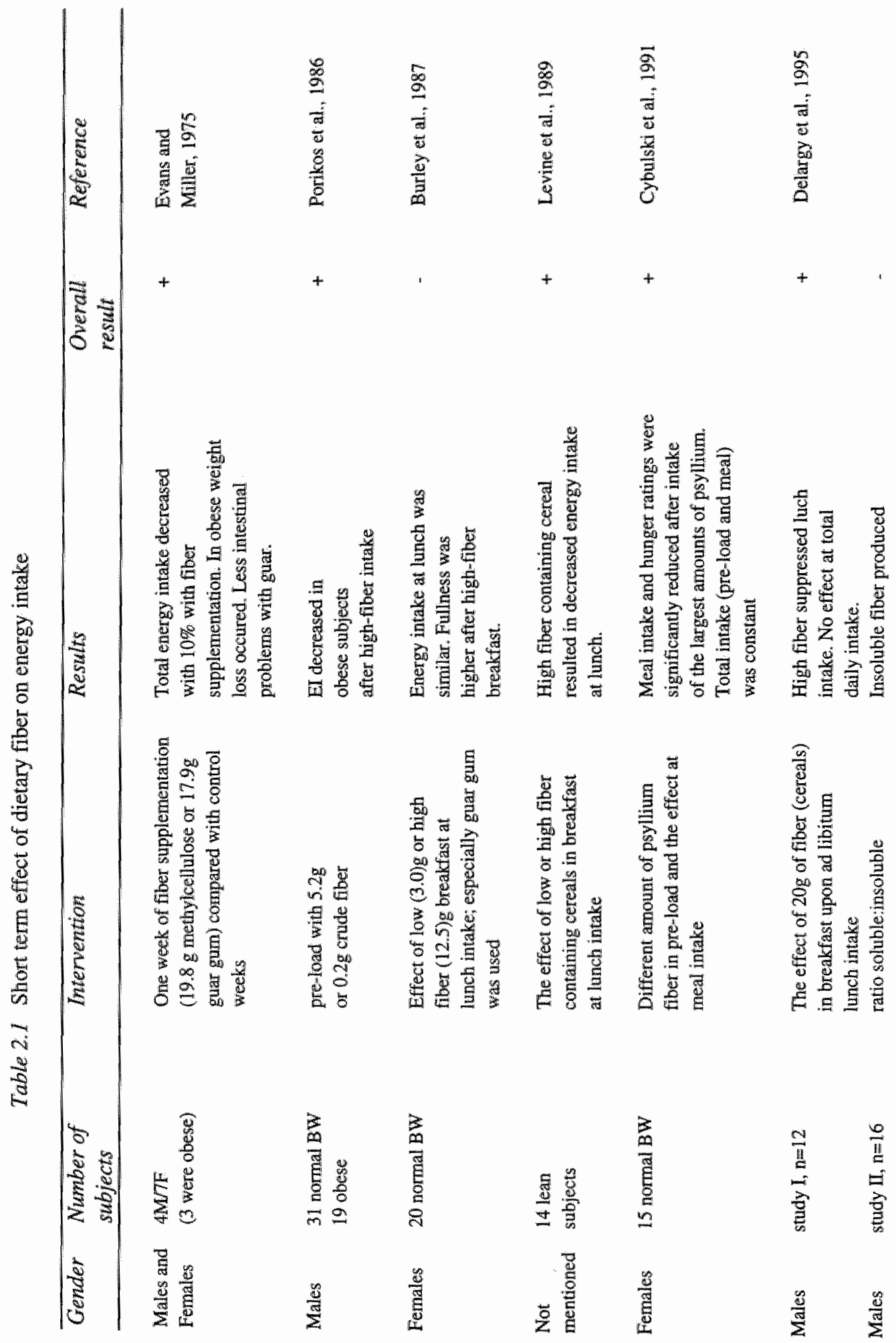


Dietary fiber and body weight control.

焉各

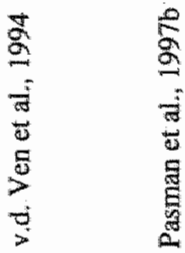

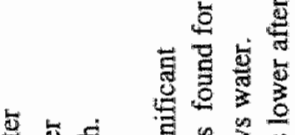

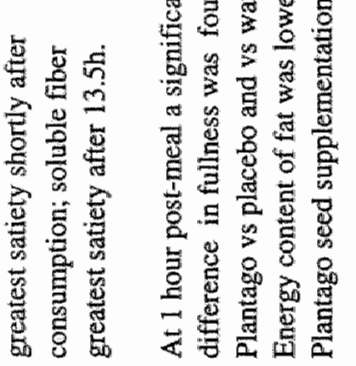

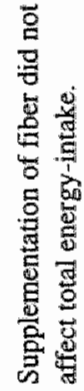

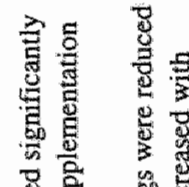

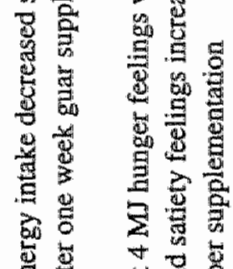

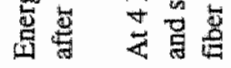

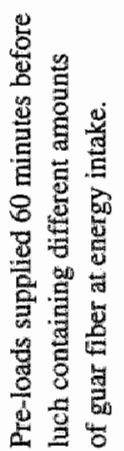

鬲苟
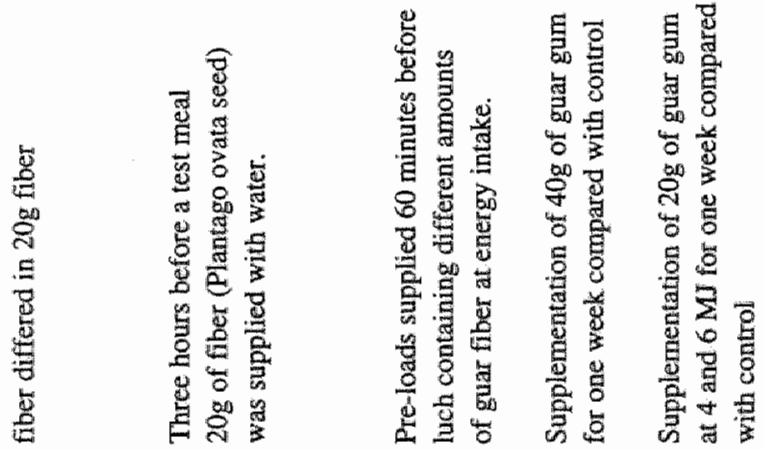

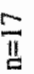

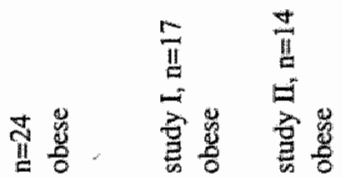

量

I

咅

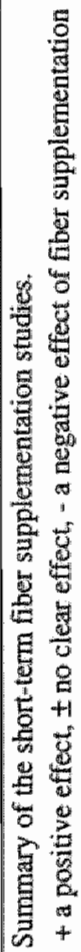


1983; Krotkiewski, 1984; Rigaud et al, 1987; Pasman et al., 1997b). Pasman and coworkers found in two short-term studies that the guar gum supplement used in weight-reduced women effectivelly resulted in a lowered energy-intake, increased satiety scores and decreased hunger scores (Pasman et al., 1997b). Two short-term studies listed in table 2.1 showed no effect of fiber containing pre-loads at EI. Burley and colleagues (1987) using soluble and insoluble fiber and guar in their bread found no differences in EI at lunch when a high fiber breakfast (12.5g) was consumed as a pre-load or a low-fiber breakfast ( $3.0 \mathrm{~g}$ ). Also van de Ven and coworkers (1994) using varying amounts of guaran (5-10-15g) as a pre-load before lunch, found no effect at meal intake.

The overview of studies presented by Róssner (1992) showed mostly a hunger reducing effect of fiber and an increase in satiety rating. The visual analog rating scales mostly used for measurement of these subjective feelings have however not been properly validated and therefore open to criticism (Blundell and Burley, 1987; Rössner, 1992).

In general it was found that of the nine presented short-term intervention studies, two studies found no effect of fiber, but seven studies showed a lowered energy intake, increased satiety scores and lowered hunger scores. Fiber seems therefore a promising food supplement for weight maintenance.

\section{Long-term fiber supplementation}

Supplementation of fiber has been performed mostly for short periods of time. In table 2.2 long-term fiber supplementation studies have been listed, and only three studies lasted longer than one year. In the two shortest studies shown in table 2.2 beneficial effects of guar gum supplementation was found at body weight (BW) (Krotkiewsky, 1984; Tuomilehto et al., 1980). Krotkiewsky found in his study a better weight reducing effect of guar gum when compared to wheat bran (subjects lost during the guar gum supplemented weeks on average $0.94 \pm 0.2 \mathrm{~kg}$ week ${ }^{-1}$ and during the wheat bran supplemented weeks on average $0.64 \pm 0.1$ $\mathrm{kg}$. week $\mathrm{k}^{-1}$ ). In the study of Tuomilehto (1980) a significant effect of $15 \mathrm{~g}$ of guar gum supplementation was found at BW. A $2.5 \mathrm{~kg}$ decrease in BW was observed in the fiber supplemented, normal weight females although they were instructed to keep their usual diet. In longer-term studies however the results of fiber supplementation with respect to BW do not seem so clear. Only Uusitupa and colleagues (1989), supplementing 15 grams of guar gum for 13 months, found a significant decrease in $\mathrm{BW}$ of $1.6-2.4 \mathrm{~kg}$. In the study of Simons (1982; $18 \mathrm{~g}$ of guar gum for 12 months) and Pasman (1997a; $20 \mathrm{~g}$ of guar gum for 14 months) no beneficial effect of fiber supplementation at weight control was found.

The lowered energy intake found in different short-term studies may be an acute effect and disappear when fiber is supplemented for a long period of time, because of habituation (Florent et al., 1985; Pasman et al., 1997a). Intestinal adaptation found to fiber supplementation might result in ineffectiveness of the fiber at energy intake and hunger and satiety feelings. Inclusion of fiber in normal food products resulting in a high-fiber diet is a way of studying the effect of fiber under free living conditions. Effects of long-term consumption of an ad libitum low-fat/high-fiber diet have been observed (Raben et al., 1995). A decrease in BW of $1.3 \pm 0.4 \mathrm{~kg}$ was found after 11 weeks consumption of a highfiber diet. The total EI was not different $(12.8 \pm 0.6 \mathrm{MJ}$ before the study vs $13.4 \pm 0.5$ during the intervention). However, energy percentage intake of fat decreased from $37.4 \pm$ 
Dietary fiber and body weighr control

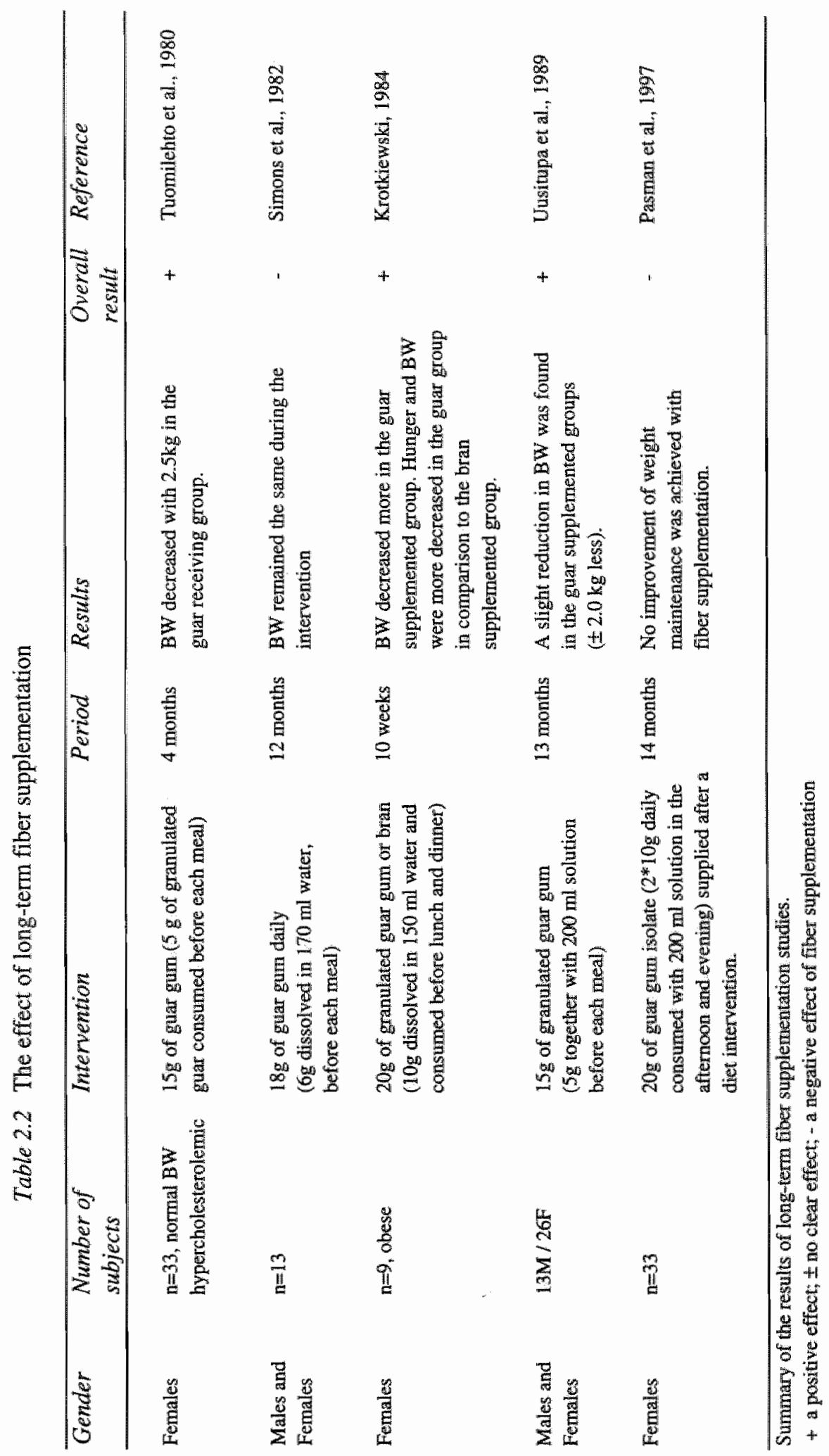


$1.3 \%$ to $25.6 \pm 0.2 \%$; energy percentage intake of carbohydrates increased from $44.7 \pm 1.0$ to $58.5 \pm 0.6 \%$; energy percentage protein intake remained the same, and fiber consumption increased during the intervention from $2.4 \pm 0.1 \mathrm{~g} . \mathrm{MJ}^{-1}$ to $3.9 \pm 0.1 \mathrm{~g} . \mathrm{MJ}^{-1}$. Although on average the absolute intake of fiber was already high ( $30.7 \mathrm{~g}$ per day), the increase to $52.3 \mathrm{~g}$ had still beneficial effects on weight control. However, also in this study it is not clear whether the positive effects of the diet at BW are caused by the lowered energy percentage fat intake or the increase in fiber consumption.

Of the listed five long-term fiber interventions three studies showed positive results with respect to weight loss. However, in the studies lasting more than 1 year, supplementation was only effective in one study (Uusitupa et al., 1989) and in 2 studies no differences were found in weight maintenance between fiber supplemented and control subjects (Simons et al., 1982; Pasman et al., 1997a). Therefore, the effects of long-term fiber supplementation at body weight control so far, is questionable.

\section{Fiber supplementation besides an energy restricted diet}

Studies examining the effect of fiber supplementation on weight loss are sometimes difficult to interpret. Besides a fiber supplement a restricted diet is often prescribed, therefore not only affecting energy intake by fiber supplementation, but compliance to the diet prescription too (Ryttig et al., 1989). The fiber is mostly added to a very low energy diet (VLED) to prevent constipation. Rössner showed already that, when listing the different studies from Ryttigs' thesis that additional fiber intake besides a low-calorie diet is effective (Rössner, 1992; also done by: Gatti, 1995) in most of the studies. Conflicting results with respect to fiber supplementation and diet prescription to weight loss has been found by Rössner too (see table 2.3). In 1987 a study was published stressing the importance of fiber (a mixture of wegetable, grain and citrus fruit fibers) (Rössner et al., 1987). In two studies additional weight loss was found when fiber was supplemented; in the first study (5g of fiber and 5.9 MJ daily ) a difference of $1.0 \mathrm{~kg}$ in weight loss was found and in the second study ( $7 \mathrm{~g}$ of fiber and $6.7 \mathrm{MJ}$ daily) a difference in weight loss of $2.1 \mathrm{~kg}$ was shown. However, supplementation of $6.5 \mathrm{~g}$ of mixed fibers (vegetable, citrus and grain fibers) besides a $6.7 \mathrm{MJ}$ diet did not result in different weight losses in normotensive fernales (Rössner et al., 1988). The amount of weight lost with placebo ( $4.4 \mathrm{~kg}$ ) was similar to the weight loss with the fiber supplement $(4.1 \mathrm{~kg}$ ). Also findings with fiber supplementation and a diet prescription of 5.9 MJ.day ${ }^{-1}$ by Hylander and Rössner (1983) showed reduced hunger ratings, but similar weight losses for the fiber supplemented and control group. Long-term fiber supplementation studies and an energy restricted diet showed conflicting results too. Supplementation of fiber tablets for long periods of time ( $>10$ weeks) showed differences in weight loss with controls when a diet of $4.2 \mathrm{MJ}$ and fiber tablets were prescribed (Solum et al., 1987; Ryttig et al., 1989). In the study of Solum (1987) $1.8 \mathrm{~kg}$ more weight was lost when $6 \mathrm{~g}$ of mixed fibers (cereals and citrus fruit) were consumed besides a diet providing $5.0 \mathrm{MJ}$.day ${ }^{-1}$ ( $8.5 \mathrm{~kg}$ in the fiber group $v s 6.7 \mathrm{~kg}$ in the placebo group). When the first 27 weeks of the 52 weeks lasting study of Ryttig and coworkers are compared (1989), a difference of $1.0 \mathrm{~kg}$ of weight was found between the fiber and control group. The diet prescribed was the same in both groups $\left(5 \mathrm{MJ}\right.$.day ${ }^{-1}$ for 11 weeks and $6.7 \mathrm{MJ}$.day ${ }^{-1}$ for the next 16 weeks). The weight loss at 27 weeks was $3.8 \pm 0.5 \mathrm{~kg}$ for the fiber group vs $2.8 \pm$ $0.9 \mathrm{~kg}$ for the control group, was still significantly higher. The mostly insoluble fibers used 


\section{Dietary filter and body wetght control}

(6-7g) therefore affected BW significantly. Further supplementation of the fibers to all subjects for 25 weeks under free living conditions (no diet prescribed) resulted in a further weight loss of $6.7 \mathrm{~kg}$ (Ryttig et al ${ }_{\circ}$ 1989). The reduced hunger ratings when fiber was added to a VLED might improve the compliance to the diet (Astrup et al., 1990). Adherence to a lowered energy intake level of $4 \mathrm{MJ}$ was also better achieved when $20 \mathrm{~g}$ of guar gum fiber was supplemented (Pasman et al., 1997b). Supplementation of fiber as a tool to improve compliance to a calorie restricted diet has been mentioned before (Solum et al., 1987; Ryttig et al., 1989; Carreilla et al., 1995).

With respect to weight control the increased fecal energy output as found after fiber supplementation may be another aspect of fiber that could have therapeutic value in the management of obesity as has been discussed above (Southgate and Durnin, 1970; Rigaud et al., 1987; Miles, 1992; Baer et al., 1997).

Supplementation of fiber combined with an energy restricted diet was effective in three of the six presented studies. An additional beneficial effect of fiber was found in subjects consuming fiber tablets and keeping a diet. The reduced hunger scores when fiber is supplemented has allso important clinical consequences. Compliance to the diet will improve when subjects are less hungry. Although addition of fiber to an energy restricted diet is useful to prevent constipation, the clinical significance with respect to increased weight loss remains under debate.

\section{Problems in experimental studies}

Interventions with fiber have to deal with the problem that it is hard to find a correct placebo for the fiber supplement (Heaton, 1992; Rössner, 1992; Rössner 1993). As Rössner stated it "there is no such thing as a placebo carrot" (Rössner, 1992; Rössner 1993). A placebo will] contain probably more energy than the fiber tested, explaining also a possible difference in body weight changes!

It is furthermore not clear whether fiber-rich diets are beneficial for weight loss or the related lowered fat intake causes weight loss/maintenance on a high-fiber diet (Jenkins et al., 1.988). As Sandström illustrates high-fibre diets with natural foods will also have a low fat content (Sandström, 1992) and will therefore have beneficial effects on other diseases than obesity. That is not necessarily the case when isolated fibre preparations are added to any type of diet. Eating behaviour resulting in fiber-rich diets might therefore be important in relation to body weight changes. The findings by the group of Astrup in Denmark support the finding that a low-fat/fiber rich diet is beneficial for weight loss and weight maintenance (Raben et al., 1995; Siggaard et al., 1996; Toubro et al., 1997).

Finally the results of studies using fiber pollymers or fiber concentrates cannot easily be extrapolated to whole foods, containing that type of fiber (Spiller, 1991). The fiber might well be less effective in its native form or be consumed normally in much lower amounts. So fiber polymers and concentrates give insight in some possible physiological functions, but additional studies with the food products containing that type of fiber are needed to find out whether these results can be duplicated (McPherson Kay, 1982). Full labeling and detailed information about the type of fiber used are therefore strongly recommended to fully understand the different actions of fiber (Spiller and Jenkins, 1986). 
Chapter 2

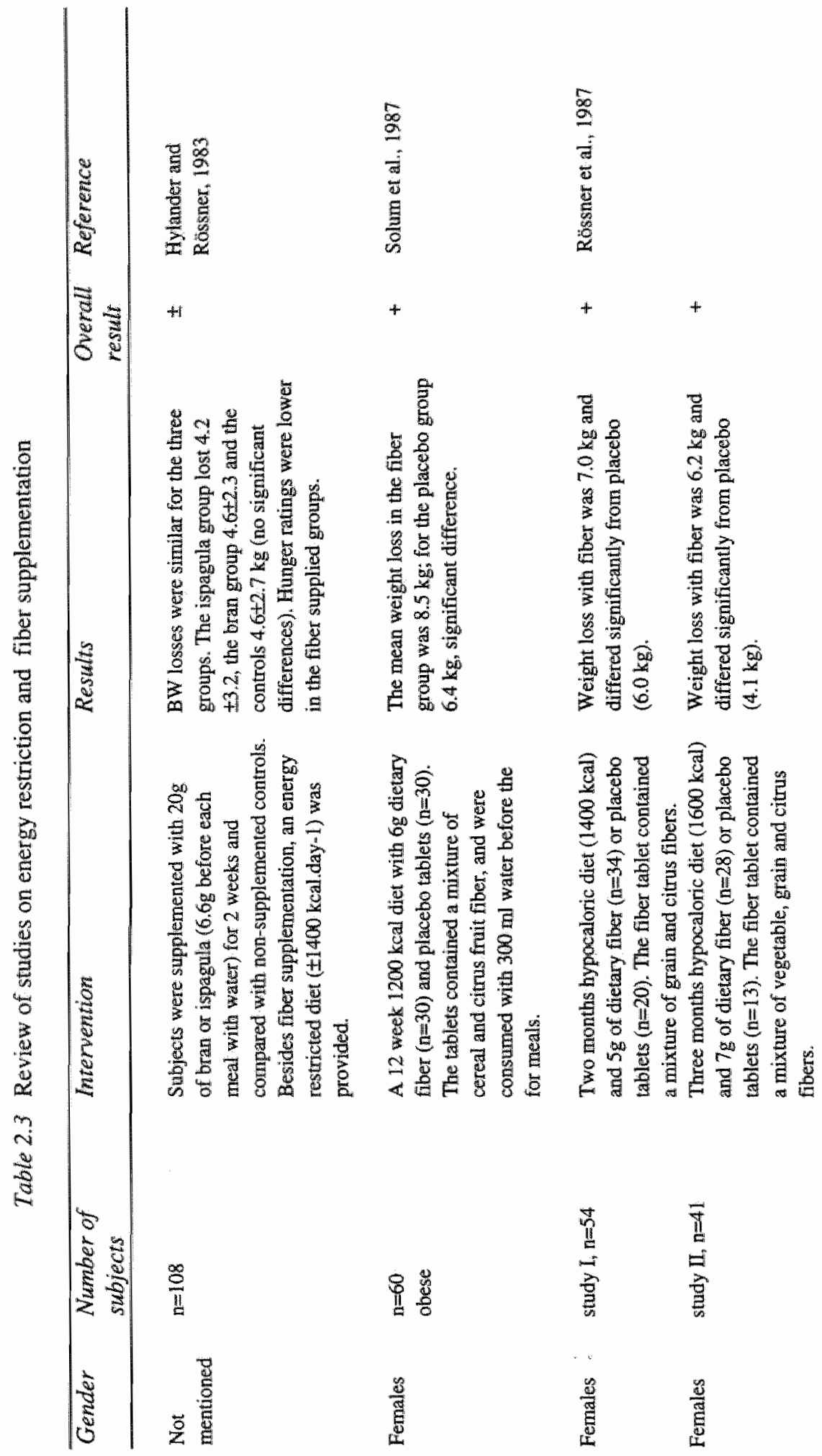


Dietary fiber and body weight control

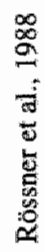

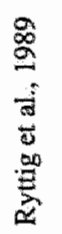

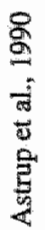

$+$

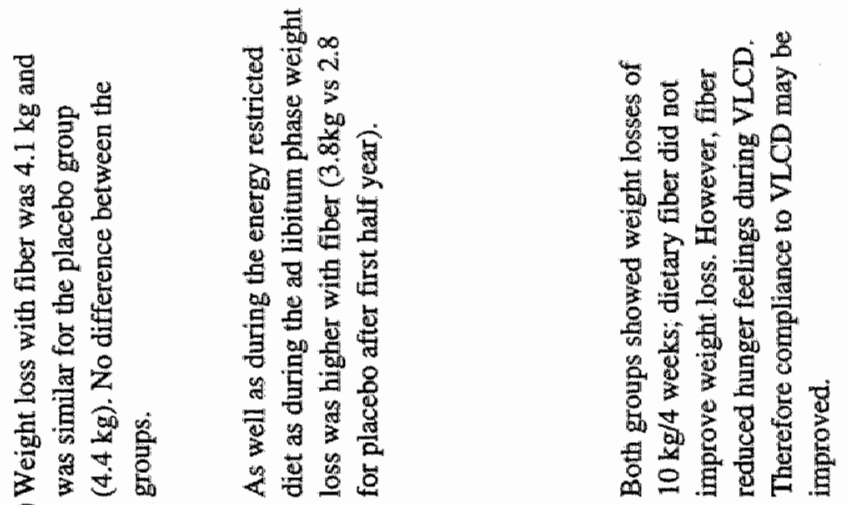

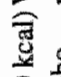

造

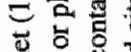

可总

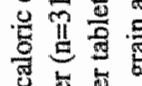

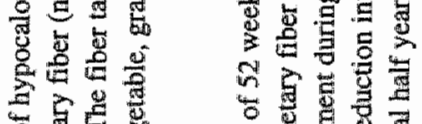

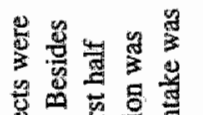

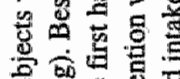

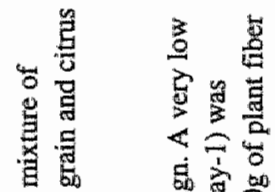

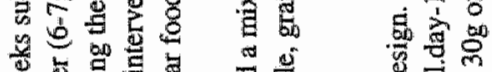

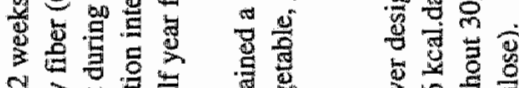

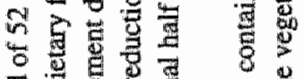

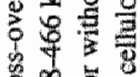

马ं

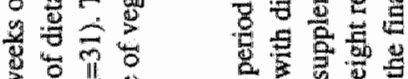

0 on

की

总总焉总

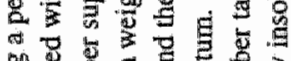

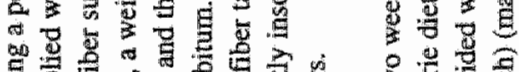

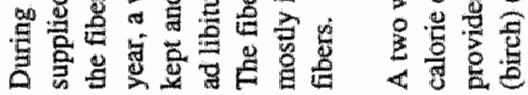

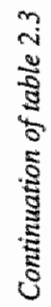

ii

î

곤

造

宽

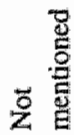


In conclusion, based upon the experimental studies the effect of dietary fiber at weight control is still under debate. In short-term studies mostly positive results of fiber with respect to energy intake were found. However, in long-term studies conflicting results have been reported, even in the same laboratories. More controlled, with especially clearly described fiber supplements or food interventions are needed. Furthermore, long-term interventions (of at least 1 year) need to be performed, when treatment of obesity is studied (Jéquier, 1987).

\section{Epidemiologic studies}

Burkitt already in 1969 reported about the relation between certain diseases in the Western society and the low dietary fiber intake. The changes in diet, and in particular removing unabsorbed fiber as is the case in modern food processing, was suggested to be the main cause for the gastro-intestinal diseases found in western society (Burkitt, 1969). Observations in Africa, for example in rural Bantustan, showed that intake of 580 grams of carbohydrates a day in comparison with the 140 grams of carbohydrates in the Western diets, resulted in less obesity as found in the Western societies (Lubbe, 1971; Heaton, 1973). Also Spiller reported in his book about dietary fiber that countries with a high-fiber consumption showed lower prevalence of obesity (Spiller, 1993; Bennett and Cerda, 1996). Cairella and colleagues even stated that there is epidemiologic evidence that a high prevalence of obesity in industrialized countries is associated with diets low in fibre content (Cairella et al., 1995). However, it is clear that in this type of comparisons there is a strong interaction with physical activity.

In epidemiologic studies like the Multiple Risk Factor Intervention Trial (MRFIT) study, or the Health Professionals Follow-up Study, dietary fiber intake has been studied in relation to obesity and coronary heart disease (Rimm et al., 1996; Stamler and Dolecek, 1997). In the MRFTT study it was found that a low energy density of the food consumed (low-fat/highfiber diets) was related to substantial weight loss (>6.8 kg) (Stamler and Dollecek, 1997). An increase in dietary fiber intake was found to be associated with greater weight loss during the six years study period (Stamler and Dolecek, 1997). The Health Professionals Follow-up Study examined the relation of dietary fiber intake and myocardial infarction (MI) (Rimm et al., 1996). It was clearly found that increased dietary fiber intake decreased the risk of coronary heart disease (Rimm et al, 1996), although Wynder and colleagues doubt whether fiber is an independent variable to protect against heart disease as suggested by Rimm and colleagues (Wynder et al., 1996). Their data further showed that the subjects in the highest quintile of fiber consumption (median: $28.9 \pm 6.7$ grams day $^{-1}$ ) were also the leanest subjects (BMI $\left.24.9 \mathrm{~kg} \cdot \mathrm{m}^{-2}\right)$ vs subjects in the lowest quintile of fiber intake $(12.4 \pm 2.0$ grams.day $\left.{ }^{-1}\right)$ had a higher BMI $\left(25.7 \mathrm{~kg} \cdot \mathrm{m}^{-2}\right)$.

An observational study in obese subjects showed an inverse relation between $B W$ and fiber intake (Alfieri et al., 1995). Three body weight groups (normal weight: $20.0<\mathrm{BMT}<27.0$; moderately obese: $27.1<\mathrm{BMI}<39.9$; and severely obese: $\mathrm{BML}>40.0$ ) were asked to record their food intake for three days. Fiber intake in the lean group was $18.8 \pm 9.3 \mathrm{~g}$; the moderately obese consumed $13.3 \pm 5.8 \mathrm{~g}$ and the severely obese $13.7 \pm 5.7 \mathrm{~g}$. Total fiber intake was found to be significantly higher in the lean group (Alfieri et al., 1995). The authors stressed that obese subjects should be made aware of the importance of a high fiber diet. Finally, Lovejoy and DiGirolamo found in a food survey executed in lean and obese subjects that the lean consumed on average significantly more fiber $(15.8 \pm 1.4 \mathrm{~g})$ than their obese counterparts (10.8 \pm 1.0 ) (Lovejoy and DiGirolamo, 1992). 
It is concluded that, although limited data is available, a high total fiber intake daily is important for control of body weight. Whether lean body weight is directly and independently related to fiber intake is not clear. A certain eating behaviour and consumption of a low fat diet when consuming a fiber-rich diet might be causing the lowered body weight too. Lissner reviewed the relation of fat intake and obesity based upon epidemiologic findings and concluded that mostly a positive relation was found (1995). Therefore the main factor affecting weight control, dietary fiber or a low-fat diet, needs to be studied in more detail to answer the question which factor mostly affects body weight.

\section{Comparison with other weight control food components}

Fiber supplements seem to be useful in short-term studies, but how effective is this treatment in comparison to other food component supplements? Another supplement that could affect body weight is caffeine. The thermogenic properties of dietary methylxanthines (often in combination with ephedrine) can raise energy expenditure in such a range that it could also be useful as a drug in the treatment of obesity (Astrup et al., 1991; Astrup et al., 1992; Dulloo and Miller, 1986; Dulloo et al., 1989). Administration of $100 \mathrm{mg}$ of caffeine 6 times during the day, when lean and post-obese subjects were in a respiration chamber, resulted in an increased energy expenditure during the day. Daily energy expenditure increased in lean volunteers with $627 \mathrm{~kJ}(150 \mathrm{kcal})$ and with $330 \mathrm{~kJ}(79 \mathrm{kcal})$ in post-obese volunteers (Dulloo et al., 1989). The $\pm 5 \%$ increase in energy expenditure found with caffeine makes it a potential drug for treatment of obesity.

Recently a combination of different food components at weight maintenance was studied in a long-term trial. Supplementation of $50 \mathrm{~g}$ of carbohydrates, $20 \mathrm{~g}$ of dietary fiber, $100 \mathrm{mg}$ of caffeine and $200 \mu \mathrm{g}$ of chromium-picolinate were given for 14 months to weight reduced women to study the effect at weight maintenance (Pasman et al., 1997c). Weight maintenance was compared with a group of women who only received $50 \mathrm{~g}$ of carbohydrates and a control group without supplementation. No differences in weight regain were found between the three groups studied; in all three groups $66 \%$ of the weight lost was regained in the weight maintenance phase. This study again illustrates that compounds effective in a laboratory setting might become ineffective under free living conditions, especially when supplemented for a long period of time (Pasman et al., 1997c).

A fiber related food product mycoprotein, is produced by continuous fermentation of Fusarium graminearum (Turnbull et al., 1993). The type of fiber present in mycoprotein is largely insoluble B-glycan ( $\pm 65 \%)$ and the remainder is chitin. The product can be used as a meat replacer (Quorn ${ }^{\circledR}$ ). The effect of mycoprotein at energy intake and appetite was examined in a short-term study (Turnbull et al., 1993). Two test meals, one containing chicken and one containing mycoprotein, were supplied to normal weight, young women. Although the energy intake with the meals was the same, subjects consumed at the test days less energy after the mycoprotein meal (3.1 MJ.day-1 vs $4.1 \mathrm{MJ}^{-1}$ day $^{-1}$ after the chicken meal). This effect at energy intake even persisted at the next day (6.0 MJ.day ${ }^{-1}$ following mycoprotein vs 7.2 MJ.day-1 following chicken). These short-term results, although promising, cannot be extrapolated to long-term, because adaptation could occur besides other factors of importance in free living subjects (Turnbull et al., 1993).

Other thermogenic food compounds besides methylxanthines have been studied, mostly in animals. Pungent ingredients like ginger and spices (mustard and red pepper for example) have been found to increase oxygen consumption in isolated hindlimb muscle of the rat 


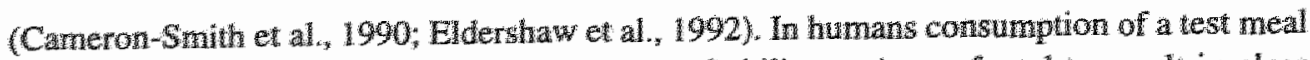
wh or whow spices (3g of mustard and $3 \mathrm{~g}$ of chil sause) was found to resul in clear

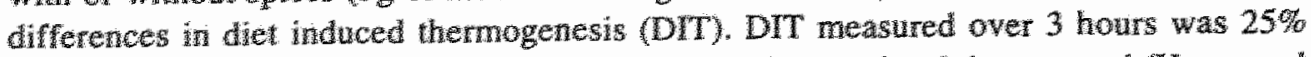
hivher after consumption of apiced meal in comparison to the plativest meal (Henry and Emery, 1986). This substantal increase in themogenesis deserves further study whthespect to mechanism of action and in relation 10 body weight control.

More complex interyentrons replacing macronutrients with substututes wave ben studied thoroughly in relation to body weight control. This subject will not be discussed, because if rell out of the scope of thing review.

For all wod compounds mentioned the effect at waight control is not yet clear. Mast studies. described were short-term studies, which like the fiber studies, showed promising results wh respect to weight control; a reduction in energy intake, increased satiety scores and reduced hunger scores. However, as we found for fiber, long-term studies need to be carried out to examine whether the positive effects found of the compounds described above, have real chinical significance with respect to weight comtrol. Adaptation and compensatory mechanisms using the compounds in long-term studies may affect weight control, resulting in no beneficial effects.

The mpact of a long-term intervention should also be taken into account. Addition of one simple supplement or changing food intake completely, affects subjects in their free living conditions differently. Therefore supplementation of one food component supplement seems to be an easier solution for body weight intervention, athough change in diet is a more natural way of implementüg fiber. Differences could already be expected from supplement and food products studies with the same type of fiber, because the fiber is probably processed differently in the body.

Studies incomporating fiber in normal food products, or prescribing fiber-rich diets showed promising results with respect to body weight (Raben et al, 1995; Siggaard et a1., 1996). It show dherefore be stimulated to improve the national food consumption to the nutritional guidelines. The average intake of $15-20$ grams of fiber a day should be increased to 30 grams a day ( 3 grams/ MJ). The reason for a positive effect of fiber supplementation on energy intake and weight loss, could be several: displacement of nutrients, the lowered energy density of food and/or the increased volume of food eaten, as has been discussed in this review.

\section{Conclusions}

The experimental and epidemiologic data presented in this review of dietary fiber are mostly positive in short-term studies, but conflicting results were found in long-term interventions with respect to weight control. A high fiber intake is recommended for lowering of energy intake, by the different actions mentioned. "To prevent habituation and low compliance with a fiber supplement, subjects are advised to consume fiber-rich food products, to increase their normal fiber intake. Subjects/populations consuming fiber-rich diets were found to have lowered body weights. Increasing fiber intake to 30 grams a day is a nutritional guideline that should be stressed as a public goal by increasing consumption of vegetables and fruits. The type of fiber, soluble or insoluble does not seem to be important for weight control. The facilitating effect of fiber at low-energy diets further stress the importance of fiber 


\section{Dielary fiber and body weight control}

supplementation for certain groups of subjects, under certain conditions. Also subjects not consuming fiber-rich food, because they do not think these food products are palatable fiber supplements are advised. Studies investigating implementation of a high-fiber diet at weight control under free living conditions and for a long period of time need to be studied. A highfiber diet could be studied by administration of fiber supplements/tablets or by prescribing high-fiber diets. Both designs should be tested to examine the most effective and beneficial way of increasing fiber intake.

\section{References}

Albrink MJ. Dietary fiber, plasma insulin, and obesity. Am J.Clin.Nutr.31: \$277-S279, 1978

Alfieri MAH, Pomerleau J, Grace DM, Anderson L. Fiber intake of normal weight, moderately obese and severely obese subjects. Obes. Res. 3: 541-547, 1995

Anderson JW. Physiological and metabolic effects of dietary fiber. Federation Proc.44: 2902-2906, 1985

Anderson JW. Fiber and health: An overview. Am.J.Gastroenterol.81, 892-897, 1986a

Anderson JW, Bryant CA. Dietary fiber: Diabetes and obesity. Am J.Gastroenterol.81: 898-906, 1986b

Astrup A, Vrist E, Quaade F. Dietary fiber added to very low calorie diet reduces hunger and alleviates constipation. Int.J.Obes. 14: 105-112, 1990

Astrup $A_{4}$ Toubro $S_{4}$ Cannon $S$, Hein $P$, Madsen J. Thermogenic synergism between ephedrine and caffeine in healthy wolunteers: A double-blind, placebo-controlled study. Metabolism 40: 323-329, 1991

Astrup A, Buemann B, Christensen NJ, Toubro S, Thorbek G, Victor OJ, Quaade $F$. The effect of ephedrine/caffeine mixture on energy expenditure and body composition in obese women. Preliminary report. Metabolism 41: 686-688, 1992

Baer DJ, Rumpler WV, Miles CW, Fahey GC. Dietary fiber decreases the metabolizable energy content and nutrient digestibility of mixed diets fed to humans. J.Nutr.127: $579-586,1997$

Barnard RJ, Wen SJ. Exercise and diet in the prevention and control of the metabolic syndrome. Sports Med.18: 218-228, 1994

Bennett WGi, Cerda JJ. Benefits of dietary fiber: Myth or medicine? Postgrad.Med.99: 153-175, 1996

Björwell $\mathrm{H}$, Rössner $\mathrm{S}$. Long-term effects of commonly available weight reducing programmes in Sweden. Int.J.Obes.11: 67-71, 1986

Blaak EE, Saris WHM. Health aspects of various digestible carbohydrates. Nutr.Res.15: 1547-1573, 1995

Blackburn NA, Redfern JS, Jarjis H, Holgate AM, Hanning I, Scarpello JH, Johnson IT, Read NW. The mechanism of action of guar gum in improving glucose tolerance in man. Clin.Sci.66:329-336, 1984

Blundell JE, Burley VJ. Satiation, satiety and the action of fibre on food intake. Int.J.Obes. 11(Suppl. 1), 19m 25,1987

Burkitt DP, Trowell HC. Refined carbohydrate foods and disease: the implications of dietary fiber. New York: Academic Press, 1975

Burkitt DP. Related disease - related cause? Lancet i: $1229-1231_{1} 1969$

Burley VJ, Leeds AR, Blundell JE. The effect of high and low-fibre breakfasts on hunger, satiety and food intake in a subsequent meal. Int.J.Obes.11(Suppl.1): 87-93, 1987

Cairella $\mathrm{G}$, Cairella M, Marchini $\mathrm{G}$. Effect of dietary fibre on weight correction after modified fasting. Eur.J.Clin.Nutr.49(Suppl.3): \$325-\$327, 1995

Cameron-Smith D, Colquhoun EQ, Ye J-M, Hettiarachchi JM, Clarck MG. Capsailicin and dilhydrocapsaucin stimulate oxygen consumption in the perfused rat hindlimb. Int.J.Obes. 14: 259-270, 1990

Cybulski KA, Lachaussée J, Kissileff HR. The threshold for satiating effectiveness of psyllium in a nutrient base. Physiol.Behav.51: 89-93, 1991

Delargy HJ, Burley VJ, O'Sullivan KR, Fletcher RJ, Blundell JE. Effects of different soluble: insoluble fibre ratios at breakfast on 24-h pattern of dietary intake and satiety. Eur.J.Clin.Nutr.49: 754-766, 1995

Dulloo $\mathrm{AG}$. Miller DS. The thermogenic properties of ephedrine/methylxanthime mixtures: human studies. Int.J Obes. 10: 467-481, 1986

Dulloo AG, Geissler CA, Horton $T$, Collins A, Miller DS. Normal caffeine conisumption: influence on thermogenesis and daily energy expenditure in lean and post-obese human volunteers. Am.J.Clin.Nutr.49: $44.50,1989$

Duncan KH, Bacon JA, Weinsier RL. The effects of high and low energy density diets on satiety, energyintake and eating time of obese and non-obese subjects. Am.J.Clin. Nutr.37: 763-767, 1983

Eastwood MA, Morris ER. Physical properties of dietary fiber that influence physiological function: a model for polymers along the gastrointestinal tract. Am.J.Clin.Nutr.55: 436-442, 1992 
Eldershaw TPD, Colquhoun EQ, Dora KA, Peng Z-C, Clark MG. Pungent prineiples of ginger (Zingiber officinale are thermogenic in the perfused tat hindlimb. IntJ.Obes. 16: 755-763, 1992

Evanis E, Miller DS. Bulking agents in the treatment of obesity. Nutr.Metab.18:199-203, 1975

Fleming SE. Influence of dietary fiber on the production, absorption, ar excretion of short chain fatty acids in humans. In: CRC Handbook of Dietary fiber in human nutrition. Ed. GE Spiller. CRC Press Boca Raton, Florida, second edition, $1993^{,} \mathrm{pg}$ : 387-412.

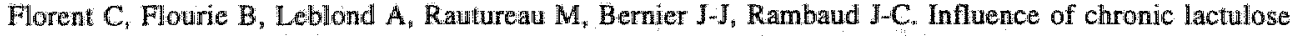
ingestion on the colonic metabolism of lactulose in man (an in viwo study). J.Clin. Invest.75: 608-613, 1985

Garnet DM, Wooley SC. Confronting the failure of behavioral and dietary treatments for obesity. Clin Psych.Rew. 11: 729-780, 1991

Gati E. Clinical effect of a dietary fibre supplement. A review. Eur.J.Clin.Nutr.49 (Suppl.3): S199-200, 1995

Goldstein DJ. Beneficial effects of modest weight loss. Int.J:Obes. 16, 397-415, 1992

Gurr MI, Asp N-G. Dietary fiber. ILSI Concise monograph.Ed. D. Kritchewsky, 2-nd edition, ILSI Press, Washington, USA, 1994

Hanilton CC. Anderson JW. Fiber and weight maintenance. J.Florida M.A.79: 379-381, 1992

Heaton KW. Food fibre as an obstacle to energy intake. Lancet ii: 1418-1421, 1973

Heaton KW. Dietary fiber in the prevention and treatment of gastro-intestinal disorders. In: Dietary fiber - A component of food. Ed. Schweizer TF, Edwards CA. London: Springer-Verlag, 1992, pg. 249-263

Henry CJK, Emery B. Effect of spiced food on metabolic rate. Human Nutr.Clim.Nutr.40C: 165-168, 1986

Holt $S, B$ rand $J$, Soweny $C$, Hansky $J$. Relationship of satiety to postprandial glycaemic, insulin and cholecystokinin responses. Appetite 18: 129-141, 1992

Holt SHA, Miller JB. Increased insulin responses to ingested foods are assaciated with lessened satiety. Appetite 24: 43-54, 1995

Hubert HB, Feinleib M, McNamara PM, Castelli WP. Obesity as an independent risk factor for cardiovascular disease: a 26-year follow-up of participants in the Framingham Heart Study. Circulation 67: 968-977, 1983

Hylander B, Rössner $\mathbf{S}$. Effects of dietary fiber intake before meals on weight lass and hunger in a weightreducing club. Acta Med.Scand.213, 217-220, 1983

Itallie TBv. Dietary fiber and obesity. Am.J.Clin.Nutr.31: \$43-S52, 1978

Jenkins DJA, Leeds AR, Gassull MA, Cochet $B$, Alberti KGMM. Decrease in postprandial insulin and glucose concentrations by guar and pectin. Ann.Int.Med. 86: 20-23, 1977

Jenkins DJA, Wolever TMS, Leeds AR, Gassull MA, Haisman P, Dilawari J, Goff D, Metz GL, Alberti KGMM. Dietary fibres, fibre analogues, and glucose tolerance: importance of viscosity. B.M.J.1: 1392 1394, 1978

Jenkins DJA, Jenkins AL, Wolever TMS, Rao AV, Thompson LU. Fiber and starchy foods: Gut function and implications in disease. Arn.J.Gastroenterol.81: 920-930, 1986

Jenkins DJA, Wolever TMS, Jenkins AL. Starchy foods and the glycenic index. Diab, Care 11: 149-159, 1988

Jenkins DJA, Jenkins AL, Wolewer TMS, Vuksan V, Rao AV, Thompson LU, Josse RG. Low glycemic index: lente carbohydrates and physiological effects of altered food frequency. Am.J.Clin.Nutr.59 (suppl): 706S-709S, 1994

Jisquier E. Energy, obesity, and body weight standards. Panel summary statements. Am.J.Clin.Nutr.45: 10351036,1987

Kromhout D. Body weight, diet, and serum cholesterol in 871 middle-aged men during 10 years of follow-up (the Zutphen Study J. Am.J.Clin.Nutr.38:591-598, 1983

Krotkiewski, M. Effect of guar gum on body-weight, thunger ratings and metabolism in obese subjects. Brit.J. Nutr.52:97-105, 1984

Krotkiewski M, Smith U. Dietary fibre in obesity. In: Dietary fibre perspectives - reviews and bibliography. Eds. Leeds AR, Avenell A. London: John Libby, 1985, pg. 61-67

Kuczmarski RJ, Flegall KM, Campbell SM, Johnson CL. Increasing prevalence of overweight among US adults. The national health and nutrition examination surveys, 1960 to 1991. JAMA 272: 205-211, 1994

Lean MEJ, James. WPT. Metabolic effects of isoenergetic nutrient exchange over 24 hours in relation to obesity in women. Int.J.Obes.12: 15-27, 1988

Leeds AR. Dietary tibre: mechanism of action. Int.J.Obes. 11(Suppl.1): 3-7, 1987

Leeds AR. Dietary fiber and obesity. In: Obesity. Chapter 58 (pg. 677-682). Ed. Björntorp P, Brodoff BN. Philadelphia: JB Lippincott Company, 1992 
Levine AS, Tallman IR, Grace MK, Parker SA, Billington CJ, Leviti MD. Effect of breakfast cereals on short-term food intake. Am.J.Clin.Nutr.50: 1303-1307, 1989

Lissner L, Heitmann BL. Review. Dietary fat and obesity: evidence from epidemiology. Bur.J.Clin.Nutr.49: $79-90,1995$

Lovejoy J, DiGirolamo M. Habitual dietary intake and insulin sensitivity in lean and obese adults. Am.J.Clin. Nutr.55: 1174-1179, 1992

Lubbe AM. Dietary evalluation. S.A.Med.J.45; 1289-1297, 1971

McPerson Kay R. Dietary fiber. J.Lipid Res. 23: 221-242, 1982

Meier R, Beglinger C, Schneider $H$, RowedderA, Gyr K. Effect of a liquid diet with and without soluble fiber supplementation on intestinal transit and cholecystokinin release in volunteers. J.Parent.Enter.Nutr. 17: $231-235,1993$

Miles CW. The metabolizable energy of diets differing in dietary fat and fiber measured in hunians. J.Nutr. 122: 306-311, 1992

Pasman WJ, Westerterp-Plantenga MS, Muls E, Vansant G, Ree Jv, Saris WHM. The effectiveness of longterm fiber supplementation on weight maintenance in weight-rectuced women. Int.J.Obes.21: $548-555$, $1997 \mathrm{a}$

Pasman WJ, Wauters M, Westerterp-Plantenga MS, Saris WHM. Effect of one week of fibre supplementation on hunger and satiety or energy intake. Appetite 29:77-87, 1997b

Pasman WJ, Westerterp-Plantenga MS, Saris WHM. The effectiveness of long-term supplenentation of carbohydrate, chromium, fiber and caffeine on weight maintenance. Int.J.Obes:(in press), 1997c

Poppitt SD. Energy density of diets and obesity. Int.J.Obes.19(Suppl.5): S20-S26, 1995

Porikos $K$, Hagamen S. Is fiber satiating? Effects of a high fiber preload on subsequent food intake of normal-weight and obese young men. Appetite 7: 153-162, 1986

Prentice AM, Jebb SA. Obesity in Britain: gluttony or sloth? B.M.J. 311: 437-439, 1995

Prentice AM, Poppitt SD. Importance of energy density and macronutrients in the regulation of energy intake. Int.J.Obes.20(Suppl.2): S18-S23, 1996

Raben A, Christensen NJ, Holst JJ, Astrup A. Decreased postprandial thermogenesis and fat oxidation but increased fullness after a high-fiber meal compared with a low-fiber meal. Am.J.Clin.Nutr.59: 1386-94, 1994

Raben A, Due Jensen N, Marckmann P, Sandström B, Astrup A. Spontaneous weight loss during 11 weeks' ad libitum intake of a low fathigh fiber diet in young, normal weight subjects. Int.J. Obes. 19: 916-923, 1995

Read $N_{1}$. French $S$, Cunningham $\mathrm{K}$. The role of the gut in regulating food intake in man. Nutr.Rev.52: 1-10, 1994

Riedy CA, Chavez M, Figlewicz DP, Woods SC. Central insulin enhances sensitivity to chollecystokinin. Physiol.Behav.58: 755-760, 1995

Rigaud D, Ryttig KR, Leeds AR, Bard D, Apfelbaum M. Effects of a moderate dietary fibre supplement on hunger rating, energy input and faecal energy output in young, healthy volunteers. A randomized, doubleblind, cross-over trial. Int.J. Obes. 11(Suppl.1): 73-78, 1987

Rigaud D, Ryttig $K R_{\text {r }}$ Angel LA, Apfelbaum M. Overweight treated with energy restriction and a dietary fiber supplement: a 6-month randomized, double-blind, placebo-controlled trial. Int.J.Obes. 14: 763-"769, 1990

Rimm EB, Ascherio A, Giovannucei E, Spiegelman D, Stampfer MJ, Willet WC Vegetable, fruit, and cereal fiber intake and risk of coronary heart disease among men. JAMA 275: 447-451, 1996

Roberfroid M. Dietary fiber, inulin, and oligofructose: a review comparing their physiological effects. Crit.Rev. Food Sc.Nutr. 33: 103-148, 1993

Rössner S, Zweigbergk Dv "Öhlin A, Ryttig K. Weight reduction with dietary fiber supplements. Results of two double-blind randomized studies. Acta Med.Scand.222: 83-88, 1987

Rössner S, Andersson I-L, Ryttig K. Effects of a dietary fibre supplement to a weight reduction programme on blood pressure. A randomized, double blind, placebo-controlled study. Acta Med.Scand.223: 353-7, 1988

Rössner S. Dietary fiber in the prevention and treatunent of obesity. In: Dietary fiber - A component of food. Chapter 15 (pg. 265-277). Ed. Schweizer TF, Edwards CA. London: Springer-Verlag, 1992.

Rössner S. Dietary fibre - no panacea (editorial). J.Int.Med.233: 433-434, 1993

Ryttig KR, Tellnes $G_{0}$ Hagh $L, B ø e ~ E$, Fagerthun $\mathbb{H}$. A dietary fibre supplement and weight maintenance. after weight reduction: a randomized, double-blind, placebo-controlled long-term triall, Int.J.Obes.13: 165171. 1989 
Sandström B. In: Dietary nber - A component of food. pg. 277. Ed. Schweizer TF, Edwards CA, London: Springer-Verlag, 1992

Seidell JC. Obesily in Europe. Obes.Res.3(suppl.2): 89s-93s; 1995

Siggaard R, Raben A, Astrup A. Weight loss during 12 weeks' ad libitum carbohydrate-rich diet in overweight and nonnal-weight subjects at a Danish work silte. Obes.Res.4: 347-356, 1996

Simons LA, Gayst $S$, Balasubramaniam $S$, Ruys $\mathbb{J}$. Long-term treatment of hypercholesterolaemia with a new pallatable formulation of guar gum. Atherosclerosis 45: 101-108, 1982

Solum TT, Rytig KR, Solum E, Larsen S. The influence of high-filbre diet on body weight, serum lipids and blood pressure in slightly overweight persons. A randomized, double-blind, placebo-controlled investigation with diet and fibre tablets (Dumovital). Int.J.Obes.11(Suppl. 1): 67-71, 1987

Southgate D, Englysit H. Dietary fibre: chemistry, physical properties. In: Dietary fibre, fibre-depleted foods and disease. Eds. Trowell $H_{*}$ Burkitt D, Heaton K. Academic Press Inc. London, 1985

Sparti A, Schutz $Y$, Di Vetta V. Pollet P, Milon $H_{s}$ Jéquier E. Effect of complex carbohydrates on 24 h nutrient oxidation. Int.J.Obes.21(Suppl.2): S18, 1997

Spiller GA, Jenkins DJA. Dietary fibre supplements, physiological and pharmacological aspects: a workshop report. In: Taylor TG, Jenkirs NK, eds. Proceedings of the XIII International Congress of Nutrition 1985. London: John Libby, pg. 184-185, 1986

Spiller GA. Beyond dietary fiber. Am.J.Clin.Nutr.54:615-617, 1991

Spiller GA. Suggestions for a basis on which to determine a desirable intake of dietary fiber. In: CRC Handbook of Dietary fiber in human nutrition. Ed. GE Spiller. CRC Press Boca Raton, Florida, second edition, pg: 351-354, 1993

Stamler J, Dollecek TA. Relation of food and nutrient intakes to body mass in the special intervention and usual care groups in the Multiple Risk Factor Intervention Trial. Arn.J.Clin.Nutr.65(suppl.1); \$366\$373, 1997

Stamler R, Stamler $\mathbb{1}$, Riedlinger WF, Algera G, Roberts RH. Weight and blood pressure. Findings in hypertension screening of 1 million Americans. JAMA 240: 1607 1610, 1978

Stevens J. Does dietary fiber affect food intake and body weight? J.Am.Diet.Assoc.88: 939-945, 1988

Stubbs RI, Ritz P, Coward WA, Prentice AM. Covert manipulation of the dietary fat to carbohydrate ratio and energy density: effect on food intake and energy balance in free-living men, feeding ad libitum. Am.J.Clin.Nutr.62: 330-337, 1995

Toubro S, Astrup A. Randonised comparison of diets for maintaining obese subjects' weight after major weight loss: ad lib, low fat, high carbohydrate diet v fixed energy intake. B.M.J. 314: 29-34, 1997

Trowell H. Southgate DAT, Wolever TMS, Leeds AR, Gassull MA, Jenkins DJA. Dietary fiber redefined. Lancet $1 ; 967,1976$

Trowell H. Dietary fibre, ischaemic heart disease and diabetes mellitus. Proc.Nutr.Soc.32: 151-157, 1973

Tuomilehto $J$, Voutilainen E, Huttunen $J$, Vinni S, Homan K. Effect of guar gum on body weight and serum lipids in hypercholesterolemic females. Acta Med.Scand.208: 45-48, 1980

Turnbull WH, Walton $J$, Leeds AR. Acute effects of mycoprotein on subsequent energy intake and appetite variables. Am.J.Cin.Nutr.58: 507-512, 1993

Turnbull WH, Thomas HG. The effect of a Plantago ovata seed containing preparation on appetite variables, nutrient and energy intake. Int.J.Obes. 19: 338-342, 1995

Uusitupa $M$, Siitonen $O$, Savolainen $K_{n}$. Silvasti $M$, Pentilä $I$, Parviainen $M$. Metabolic and nutritional effects of long-term use of guar gum in the treatment of non-insulin dependent diabetes of poor metabolic control. J.Clin.Nutr.49: $345-351,1989$

Ven MLHM wan de, Westerterp-Plantenga MS, Wouters L, Saris WHM. Effects of liquid preloads with different fructose/fibre concentrations on subsequent food intake and ratings of hunger in women. Appetite 23: $139-146,1994$

Wadden TA, Foster GD, Letizia KL. One-year behavioral treatment of obesity: comparison of moderate and severe caloric restriction and the effects of weight maintenance therapy. J.Consult.Clin.Psych.62: 165-
171,1994

Westerterp-Plantenga MS, Pasman WJ, Yedema MJW, Wijckmans-Duijsens NEG. Energy intake adaptation of food intake to extreme energy density of food by obese and nom-obese women. Eur.J.Clin.Nutr.50:
$401-407,1996$

Westerterp-Plantenga MS, Wijckmans-Duijsens NEG, Verboeketwan de Venne WPHG, de Graaf $K$, Weststrate JA, wan het Hof $\mathrm{KH}$. Diet-induced thermogenesis and satiety in humans after full-fat and reduced-fat meals. Physiol. Behav. 61: 343-349, 1997 


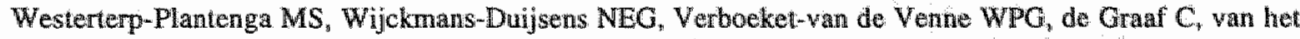
Hof KH. Westrate JA. Energy intake and body weight effects of six months reduced or full fall diets, as a function of dietary restraint. In J Obes.(in press), 1998

Wing RR, Jeffery RW. Effect of modest weight loss on changes in cardiovascular risk factors are there differences between men and women or between weight loss and maintenance? Int J.0bes. 19:67-73, 1995

Wollever TMS. Relationship between dietary fiber content and composition in toods and the glycemte index. Am.J.Clin.Nutr.51: $72-75,1990$

Wolever TMS, Jenkins DJA, Jenkins AL, Josse RC. The glycemic index: nethodology and clinical implications. Am.J.Clin.Nutr.54: 846-854, 1991

Woods MN, Gorbach SL. Influences of fiber on the ecology of the intestinal fora. In: CRC Handbook of Dietary fiber in human nutrition. Ed. GE Spiller. CRC Press Boca Raton, Florida, second edition. pg: $361-370,1993$

Wynder EL, Stellman SD, Zang EA. High fiber intake Indicator of a healthy lifestyle (Editoria). JAMA 275: $486-487,1996$ 


\title{
Chapter 3
}

\section{Effect of one week of fibre supplementation on hunger and satiety or energy intake}

\author{
W.J. Pasman*, M.A.J. WautersIl, M.S. Westerterp-Plantenga*\#, and W.H.M. Saris* \\ *Department of Human Biology, Maastricht University " Open University, Heerlen \\ WDepartment of Endocrinology and Human Nutrition, University Hospital, Antwerp
}

Appetite 29: 77-87, 1997

\begin{abstract}
The effect of one week of supplementation with a water-soluble fibre (guar gum) was studied in obese women who had lost weight. In study 1 ( $n=17$; mean \pm sem: age $38.5 \pm 2.3$ yrs; weight $86.8 \pm 2.3 \mathrm{~kg}$; BMT $32.2 \pm 0.9 \mathrm{~kg} \cdot \mathrm{m}^{-2}$ ) energy intake and hunger and satiety scores were assessed under free-living conditions. In study 2 ( $n=14$; age $44.5 \pm 1.8 \mathrm{yrs}$; weight $78.8 \pm 3.1 \mathrm{~kg}$; BMI $29.0 \pm 0.9 \mathrm{~kg} \cdot \mathrm{m}^{-2}$ ) energy intake was fixed at $6 \mathrm{MJ}^{-d a y^{-1}}$ (their normal energy intake at that time) or $4 \mathrm{MJ}^{-d a y^{-1}}$ (low energy intake). In both studies, the effect of one week of fibre supplementation $(40 \mathrm{~g}$ in study 1 and $20 \mathrm{~g}$ in study 2) was compared with no supplementation. In study 1 , mean energy intake decreased significantly from $6.7 \pm 0.4 \mathrm{MJ}$ to $5.4 \pm 0.2 \mathrm{MJ}$ daily after fibre supplementation, while hunger and satiety scores did not change. At a low energy intake level of $4 \mathrm{MJ}$ given in study 2 , hunger scores were significantly decreased after fibre supplementation. No changes were seen in hunger and satiety scores during fibre supplementation at $6 \mathrm{MJ}$. The reduction in energy intake by soluble fibre under free living conditions and the hunger-reducing effect of fibre at the low energy intake level (4 MJ) suggests that fibre may be useful in the treatment of obesity, by facilitating compliance to low energy intake.
\end{abstract}

\section{Introduction}

Successful weight maintenance is important because long-term weight reduction can be of considerable benefit to health in obese subjects by lowering risk factors for cardiovascular and other diseases (Goldstein, 1992; Wing and Jeffery, 1995). So far the results from weight maintenance studies are very disappointing, with long-term success rates below 1020\% (Garner and Wooley, 1991). (Dex)fenfluramine (Wurtman et al., 1985), caffeine (Dulloo et al., 1989), or a caffeine/ephedrine supplement (Astrup et al., 1991) have been shown to be useful agents with respect to maintenance of body weight. Bulking supplements such as dietary fibre increase feelings of fullness (Evans and Miller, 1975; Leeds, 1987; Raben et al., 1994) and augment satiating effects (Spiller, 1993; Ryttig et al., 1989) and so reduce energy intake and body weight. Interventions with a high and low fibre meal, shortterm and long-term interventions (breakfast - Burley et al., 1987; breakfast - Delargy et al., 1995; all meals - Duncan et al., 1983; pre-loads before meals - Porikos and Hagamen, 1986; van de Ven et al., 1994; long-term supplementation - Ryttig et al., 1989; Rigaud et al., 1990; 
Krotkiewski, 1984) all showed decreased hunger feelings and decreased energy intake when fibre was added.

Comparisons of the different fibre studies is however not easy. Variables like subjects (men or women; lean or obese), type of intervention (meal or pre-loads), laboratory or free living conditions, type of fibre used (soluble or insoluble), fibre dosage supplemented and duration of supplementation (short-term or long-term) are of importance for a good interpretation of the results found in the studies as is thoroughly discussed by Blundell and Burley (1987) and by Todd and coworkers (1990). Both emphasized that the type of administration used, an isolated fibre administered before a meal or administration of fibre via normal food products, like bread, as well as the water solubility of the fibre used, should be reported (Blundell and Burley, 1987; Todd et al., 1990; Delargy et al:, 1995).

Besides fibre specifications, the level of energy intake at which fibre supplementation takes place is of importance. In a study by Duncan and colleagues (1983) the satiating effect of fibre was investigated. Subjects were allowed to eat till satiation with different energy density diets (high and low energy density diet with low and high fibre contents resp.). Despite the same reported levels of satiation, energy intake was lower in the high fibre diet than it was in the low fibre diet (1570 vs $3000 \mathrm{kcal})$. The concept of time-energy displacement based on the hypothesis that prolonged eating time at a high fibre diet will induce satiety at a low energy intake level was therefore supported (Duncan et al., 1983). When a fixed low level of energy intake is consumed, it was found that $30 \mathrm{gram}$ of plant fibre daily, effectively reduced hunger feelings (Astrup et al., 1990). They compared the hunger feclings during a very low energy diet (VLED) with a VLED without fibre supplementation. Their finding showed that fibre supplementation is applicable in the field of obesity. No differences were found in weight losses between the fibre supplemented and non-fibre supplemented group, but the reduced hunger feelings in the fibre supplemented group may improve compliance to the VLED (Astrup et al., 1990). Supplementation of a bulking agent such as fibre could therefore be of interest for the possibility to maintain a decreased energy intake in order to prevent weight gain. However, usefulness of fibre supplementation in the long-term to achieve weight maintenance under non-restricted conditions is not clear (Evans and Miller, 1975; Hylander and Rössner, 1983; Rigaud et al.,
1990)

In this study we used a partially hydrolyzed form of guar gum fibre in powder form, which enabled us to give a high dosage of fibre daily, because it could be dissolved in drinks. In the present study the fibre isolate was dissolved in a water-orange juice solution. Guar gum, obtained from the endosperm of the Indian cluster bean Cyamopsis tetragonolobus, is a galactomannan, which in contact with water forms a highly viscous gel (Todd et al, 1990 ). Guar gum was used because it delays gastric emptying (Anderson, 1986; Todd et al., 1990) de Ven et al, 1994), increased satiety (Leeds, 1987) and decreased energy intake (Evans and Miller, 1975). Because most of the studies carried out with fibre are short-term interventions of only one day, we investigated whether supplementation with guar gum fibre under free living conditions decreased energy intake and / or hunger and satiety feelings at the end of one week of supplementation. In a second study the effect of fibre supplementation were studied at normal $(6 \mathrm{MJ})$ and low $(4 \mathrm{MJ})$ levels of energy intake. 


\begin{abstract}
Methods
Subjects

In the first study 17 women participated (mean \pm sem: age $38.5 \pm 2.3$ yrs; weight $86.8 \pm 2.3$ $\mathrm{kg}$; height $1.64 \pm 0.01 \mathrm{~m}$; BMI $32.2 \pm 0.9 \mathrm{~kg}^{-2} \mathrm{~m}^{-2}$. In the second study, 14 female subjects took part (mean age $44.5 \pm 1.8 \mathrm{yrs}$; weight $78.8 \pm 3.1 \mathrm{~kg}$; height $1.63 \pm 0.02 \mathrm{~m}$; BMI 29.0 $\pm 0.9 \mathrm{~kg} \cdot \mathrm{m}^{-2}$ ), four of whom had participated in study 1 . All subjects were studied 3 months after losing approximately $10 \mathrm{~kg}$ of body weight during a 2 -month treatment with very low energy diet for their obesity. This post-weight loss period was selected since it was hypothesized that subjects should be more vulnerable to weight gain after VLED. The studies were approved by the Ethics Committee of the Maastricht University and all subjects gave their written informed consent.
\end{abstract}

\title{
Study design
}

\section{Study 1}

The effect of fibre supplementation on energy intake and on ratings of hunger and satiety was compared with a normal, non-supplemented fibre condition. Subjects were studied for two periods of one week. During both weeks, subjects were asked not to eat between their three main meals. In one week, subjects' diet was supplemented with 20 grams of fibre twice daily and the other week was considered as control with no intervention. The fibre supplement was randomised across subjects between the first and second weeks. During the last three days of the week, the food intake was recorded in a food diary.

\section{Procedure}

Subjects were instructed to eat their normal main meals and to refrain from snacks in between meals during both weeks. Instead of snacks, subjects were asked to consume an orange juice solution at $15.30 \mathrm{~h}$ in the afternoon and at $20.00 \mathrm{~h}$ in the evening. During the non-supplemented week plain orange juice was consumed, whereas during the fibre supplemented week 20 gram of fibre was dissolved in the orange juice solution (40g of fibre daily). Energy intake (from coffee, tea or soft drinks) in between the main meals was zero giving the opportunity to study the effect of fibre supplementation on the amount ingested during the main meals and at hunger and satiety scores. Feelings of hunger and satiety were scored using rating scales (see below). Fibre supplementation was not blinded. Supplementation of the sachets with fibre enabled the subjects to prepare their drink everywhere.

\section{Food intake diary}

Food intake was recorded for the last three days of the study weeks in a food intake diary. Personal instruction was given in advance by a trained dietitian. After returning the diaries a final check completed the information to reduce underreporting. Portion size and household attributes were examined to give a good indication of the amount of food consumed. Food consumption was converted into energy and macronutrient intake using a computer programme based upon a nutrient file compiled from the Dutch food composition table (NEVO, 1989).

Rating scales

Hunger and satiety were scored at fixed times during the day on 100-mm lines anchored at the ends with "very hungry" and "not hungry at all" or "very satiated" and "not satiated at all". The times of rating were before $(7.00 \mathrm{~h})$ and after $(7.30 \mathrm{~h})$ breakfast, in between meals in 


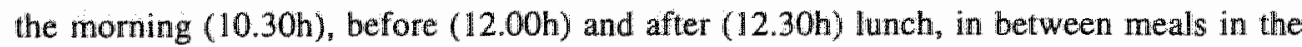
afternoon (15.30h), before (18.00h) and after (18.30h) dinmer and in the evening (20.30h).

\section{Fibre supplementation}

Subjects were randomly assigned to start either with or without fibre supplementation. Fibre was consumed for four days prior to the 3-day measurement period to allow the subjects to get used to supplementation. The fibre was a water-soluble fraction and partially hydrolyzed guar gum (Benefiber , Sandoz Nutrition, Minneapolis). A total of 40 grams was consumed: 20 grams of fibre twice daily, dissolved in orange juice. The subjects thad to prepare the orange juice solution $(200 \mathrm{ml})$ with $20 \mathrm{~g}$ of fibre in the afternoon and in the evening by themselves. The composition of the drink when fibre was added was: energy $308 \mathrm{~kJ}, 1.0 \mathrm{~g}$ protein, no fat, $17.4 \mathrm{~g}$ of carbohydrate, $1.6 \mathrm{~g}$ of orange fibre and $20 \mathrm{grams}$ of guar gum.

\section{Study 2}

Study design

Two fixed levels of energy intake were compared when fibre was supplemented us a nonsupplemented situation. During four weeks, subjects were exposed in random order to four different conditions. Two fixed energy intake levels (4 and $6 \mathrm{MJ}$ ) were compared with fibre supplementation and without fibre supplementation. Each condition was carried out for one week, during the last three days on which feelings of hunger and satiety were scored.

Procedure

The energy intake level was fixed at $4 \mathrm{MJ}$ and $6 \mathrm{MJ}$, using different complete menus. Several options for breakfast, lunch and dinner and drinks to be consumed between meals, were completelly prescribed. Subjects were able to choose and prepare their favorite food items, but were asked to stick to the prescribed amounts of food and to the given recipes, to maintain the energy intake levels. The macronutrient composition and energy content of each menu was the same. Within each level the total energy intake was obtained with the breakfast, lunch and dinner suggestions made. Supplementation of fibre was carried out by solving 2 times daily 10 grams of fibre in orange juice. The drink was consumed in the aftermoon (15.30h) and in the evening (20.00h). Fibre supplementation was randomised as was the energy intake level across subjects among the 4 weeks; one week at the $4 \mathrm{MJ}$ level and for one week at the $6 \mathrm{MJ}$ level with or without fibre. During the last three days of the week with fibre supplementation and without fibre supplementation, hunger and satiety scores were studied.

\section{Menu method}

The energy intake level was kept fixed at $4 \mathrm{MJ}$ and $6 \mathrm{MJ}$ using different complete menus. The $4 \mathrm{MJ}$ menu contained 21 percentage of energy (En\%) from protein, 24 En\% fat, $55 \mathrm{En} \%$ carbohydrate and 19 grams of dietary fibre. The 6 MJ menu contained 19 En\% protein, 28 En $\%$ fat, 53 En $\%$ carbohydrate and 21 grams of dietary fibre. Breakfast, lunch and dinner and in between drinks were completely prescribed on paper, qualitatively and quantitatively, to enable the subjects to prepare their meals at home. Subjects could choose daily between different menus and the main meals could also be switched from one menu to the other within one energy intake level, so that subjects were relatively free to choose their favorite food items. Within each energy intake level the total energy intake was obtained with the breakfast, lunch and dinner suggestions made. Compliance to the menus prescribed was checked. Subjects were asked to write down on the menu which food items were not eaten, or were consumed in larger quantities. The fixed levels of energy intake were based upon the 
food intake diaries of these post-weight loss subjects. Because the subjects were in a postweight loss phase ( 3 months after a very low energy diet) they were not able to consume the amount normally necessary for weight maintenance. The analyses of their food intake diaries showed a mean energy intake of $5.4 \mathrm{MJ}$ at 2 months after the VLED. This value is very low, especially when related to their resting metabolic rate (data not shown), and underreporting could be a realistic explanation (Pannemans and Westerterp, 1993). In a pilot experiment the $7 \mathrm{MJ}$ energy intake level (based upon resting metabolic rate and activity level) was tested. Because the subjects complained about the quantity of food that had to be consumed with 7 $\mathrm{MJ}$, we decided to lower the energy intake level to $6 \mathrm{MJ}$. Because a clear discrepancy in energy intake level is necessary to show effects on feelings of hunger and satiety (and an effect of fibre) the low energy intake level was set at $4 \mathrm{MJ}$ instead of the proposed $5 \mathrm{MJ}$.

Rating scales

Hunger and satiety feelings were scored during the day at fixed times on a $100-\mathrm{mm}$ line (see study 1). In the second study two further assessments of hunger and satiety were made. In the aftemoon and in the evening subjects were asked to score hunger and satiety feelings before and after consumption of the orange juice (+/-fibre) solution (15.00h and 20.00h).

Fibre supplementation

The type of fibre supplemented in the second study was the same as in the first study. The amount supplemented differed; in the second study subjects consumed 2 times 10 gram of Benefiber ${ }^{\circledR}$ daily, instead of 20 grams two times daily as performed in study 1 . In study 2 fibre supplementation was not blinded either. Supplementation of the sachets with fibre enabled the subjects to prepare their drink everywhere.

Data analysis

A two-way Anova (repeated measurements) was used to test for differences between the fibre and non-supplemented fibre conditions at the different time points (not the mean values). The data are presented as mean and standard errors of the mean (sem).

\section{Results \\ Study 1}

Energy intake was significantly lower when fibre supplement was eaten for three days than on three non-supplemented days (fibre intake mean \pm sem $20 \pm 8$ grams daily). When an additional 40 grams of fibre was consumed daily, energy intake (averaged over three days) was significantly lower (5.4 $\pm 0.24 \mathrm{MJ})$ than on the control days $(6.7 \pm 0.39 \mathrm{MJ})$ (fig.3.1), $\mathrm{F}(1,48)=8.32, \mathrm{p}<0.05$. Hunger and satiety scores averaged for each time point over three days were the same for fibre and non-supplemented days (fig. 3.2), hunger $F(1,73)=0.007$, $\mathrm{p}>0.9$, satiety $\mathrm{F}(\mathbb{1}, 73)=2.67, \mathrm{p}=0.11$. Two subjects complained about flatulence during the fibre supplemented week. 


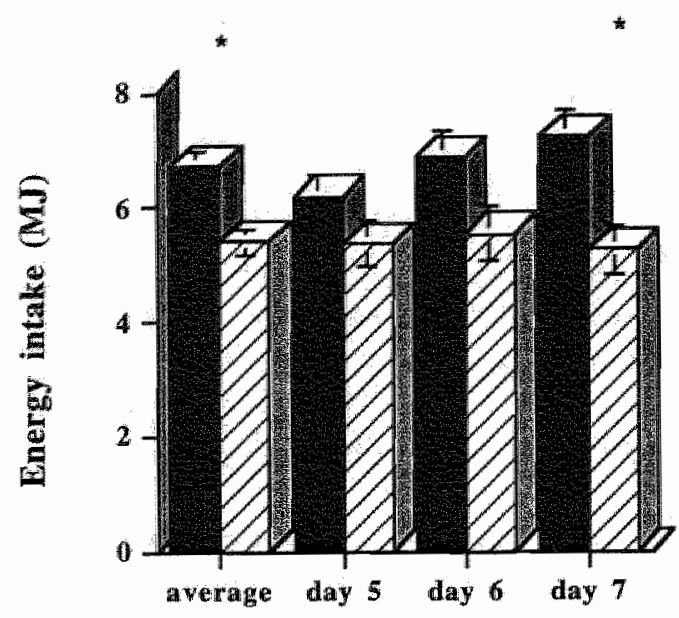

Fig. 3. $/$ Mean daily energy intake (MJ) over 3 days of 17 post-obese females on non-supplemented days (filled bars) and on dlays with 20 grams of fibre supplement twice daily (hatched bars) in study 1 .

$* p<0.05$
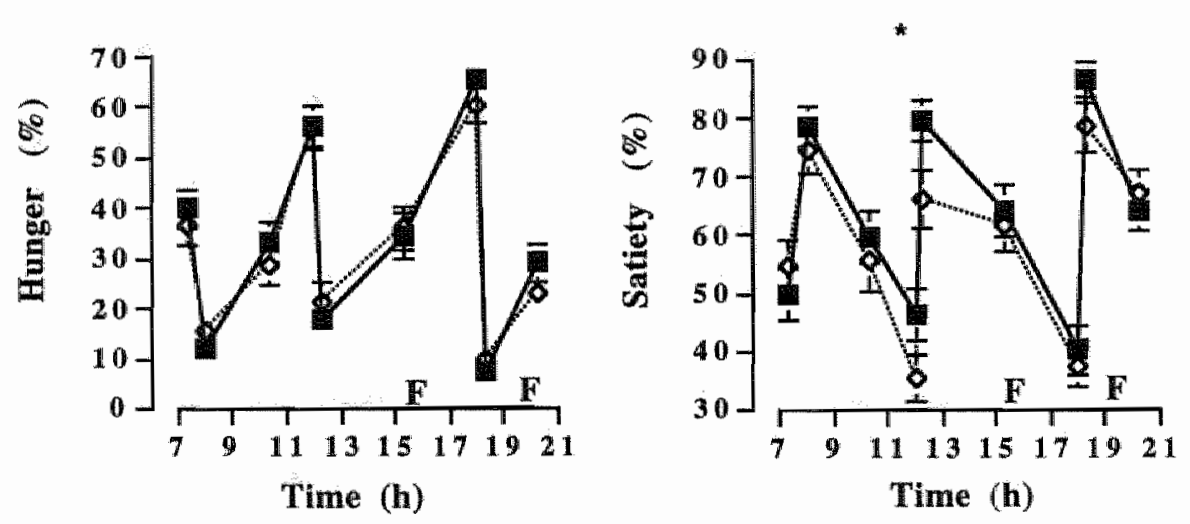

Fig. 3.2 Hunger scores (left) and satiety scores (right) averaged for the three days without supplement (filled squares) and with fibre supplementation (open diamonds) in study 1. Consumption of fibre indicated by $\mathbb{F} . * p<0.05$

\section{Study 2}

Reported food intake at the $6 \mathrm{MI}$ level was (mean \pm sem) $5.68 \pm 0.07 \mathrm{MJ}$ and at the $4 \mathrm{MJ}$ level $3.98 \pm 0.03 \mathrm{MJ}$. Hunger scores were significantly lower on the $6 \mathrm{MJ}$ menu than on the 4 MJ menu without fibre supplementation, $F(1,65)=3.94, p=0.05$. Hunger (fig.4.3) and satiety (fig.4.4) scores were the same with and without fibre supplementation at the $6 \mathrm{MJ}$ level, $\mathbb{F}(1,51)=0.26, p=0.61$. At the low energy intake level of $4 \mathrm{MJ}$, hunger scores and satiety scores were not significantly different according to a two-way Anova $F(1,73)=0.88$, $p=0.35$ for hunger, and for satiety $F(1,70)=1.85, p=0.18$. Data sets were however not fully complete for Anova-analysis, and therefore a paired t-test was performed to investigate differences between time points. The time points that differed significantly for hunger were: $7.00 \mathrm{~h}(\mathrm{t}=3.42, \mathrm{p}<0.01) ; 12.00 \mathrm{~h}(\mathrm{t}=2.33, \mathrm{p}<0.05) ; 20.00 \mathrm{~h}(\mathrm{t}=2.38, \mathrm{p}<0.05)$ and $20.30 \mathrm{~h}$ 
$(t=2.23, p<0.05)$. For satiety the time points that differed significantly were: $7.00 \mathrm{~h}(t=3.34$, $\mathrm{p}<0.01) ; 12.00 \mathrm{~h}(\mathrm{t}=2.50, \mathrm{p}<0.05)$ and $20.30 \mathrm{~h}(\mathrm{t}=2.10, \mathrm{p}<0.05)$.

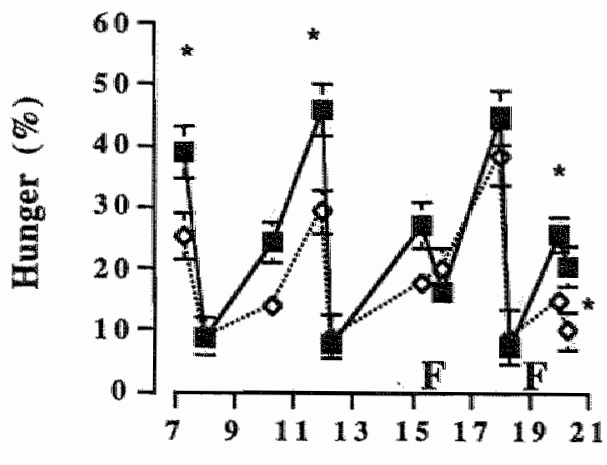

Time (h)

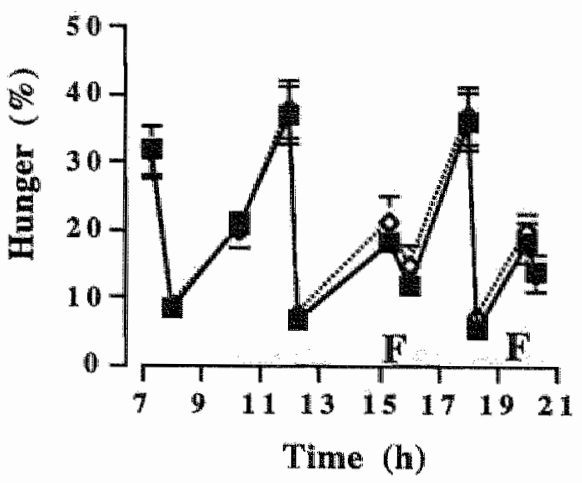

Time (h)

Fig.3.3 Hunger scores (n=13) at energy-intake levels of $4 \mathrm{MJ}$ (left) and $6 \mathrm{MJ}$ (right) averaged for the three days without supplement (filled squares) and for the three fibre-supplemented days (open diamonds) in study 2. Consumption of fibre indicated by $\mathbb{F}_{*} * p<0.05$
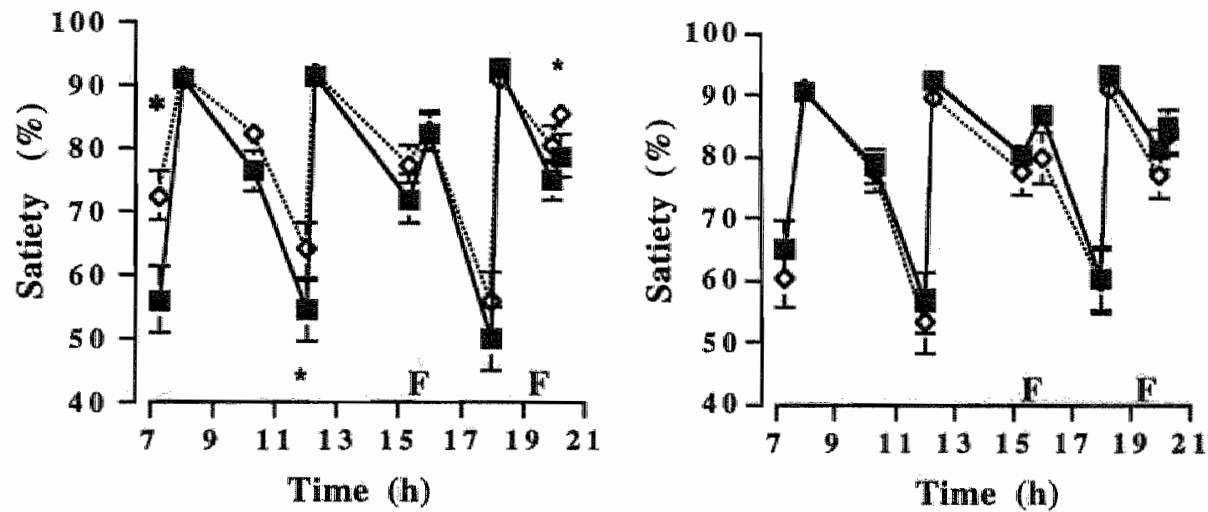

Fig.3.4 Satiety scores $(\mathrm{n}=13)$ at energy-intake levels of $4 \mathrm{MJ}$ (left) and $6 \mathrm{MJ}$ (right) averaged for the three days without supplement (filled squares) and for the three fibre-supplemented days (open diamonds) in study 2. Consumption of fibre indicated by $\mathrm{F}_{*}^{*} \mathrm{p}<0.05$

\section{Discussion}

The reduced energy intake with fibre supplementation under free living conditions and the lowered hunger scores and increased satiety scores at a fixed low level of energy intake, are the main findings of the two studies. The fibre supplement used was safe and easy to consume in high amounts, and could be dissolved by the subjects everywhere.

Study 1

In the present study a reduction of $19 \%$ in energy intake was found for freely feeding obese females when fibre intake was increased from the normal $20 \pm 8$ grams daily to $56 \pm 7$ grams. Evans and Miller (1975) reported a reduction in energy intake of $10 \%$ on average for 
all subjects and a reduction of $30 \%$ for the obese subjects $(n=3)$, when 10 gram of guar gum fibre was taken wice daily for one week. The subjects were instructed to consume the fibre with a glass of water half an hour before the main meal in contrast to our study were subjects consumed the fibre supplement in between main meals. Because both studies found lowering of energy intake it suggests that timing is not that important for an effective decrease in energy intake. Our results are based on 17 obese women ws 3 obese (no gender reported) in the study of Evans and Miller (1975). As in our study their subjects could eat ad libitum, under free living conditions. However, there food intake diaries was based upon weighed food intakes, resulting in better energy intake calculations, but having the negative effect that subjects might become more aware of their food consumption and consequently lower their intake. Duncan and colleagues (1983) also found lowered energy intake with high fibre containing diets in laboratory situations. Krotkiewski (1984) found lowered body weights in the obese women participating in a ten week supplementation trial of 20 grams of guar gum fibre. They probably lowered their energy intake although the subjects were under free living conditions. Our results confirm his findings and add that spontaneous food consumption is significantly lower with fibre supplementation.

Srudy 2

The finding in the second study that fibre supplementation effectively reduced hunger scores and increased satiety scores at the $4 \mathrm{MJ}$ level is promising with respect to long-term weight mantenance. Reduced hunger feelings during a VLED as reported by Astrup and colleagues (1990) when subjects were supplemented with fibre, may improve compliance to the VLED. The comparable hunger and satiety ratings found at the $6 \mathrm{MJ}$ level suggests that our subjects were already fully satiated and not hungry at all, at this in casu relatively high level of energy intake. Additional fibre supplementation is then of no benefit. Three months prior to these two studies described, all subjects had participated in a VLED. Supplementation of a bulking agent such as fibre could therefore be of special interest to these post-weight loss subjects, for a better compliance to a low energy intake and for maintenance of a decreased energy intake in order to prevent weight gain.

We can conclude that fibre supplementation is effective to realise a low energy intake level spontaneously without hunger feelings. It further appears to be rather successful to keep a fixed reduced energy intake level, when tibre is supplied.

\section{Methodological remarks}

The hunger and satiety scores in this study show a clear discrepancy in the case of normal weight subjects. Lean counterparts have a wider range in hunger scores and score higher (40-100 $\mathrm{mm}$ ) (van de Ven et al., 1994) than the subjects in this study (10-45 mm). The postweight loss phase might be an explanation for the exaggerated satiety and suppressed hunger responses. Different responses between obese and lean subjects also have been mentioned in other studies (Evans and Miller, 1975; Porikos and Hagamen, 1986; Duncan et al., 1983), suggesting that this group of subjects might benefit most of fibre supplementation.

The fibre isolate used in the present studies enabled us to administer a high dosage of fibre daily. The sachets with guar gum powder were easy to take away and could be dissolved in drinks. "The supplement proved to be a practical and safe way to increase fibre intake daily in freely feeding subjects.

A new method for intake of a fixed amount of food was used, the menu method, described in study 2. In comparison with food administration or the double portions technique, for control of energy intake, the method described was a wery practical way of feeding subjects 
at a fixed energy level under free living conditions. Subjects were able to choose almost freely and use normal food items. The menu method is less thime consuming for the investigators and subjects. The laboratory setting is not necessary, giving a more reliable response of hunger and satiety scores than under laboratory conditions. In comparison with the double portion technique, the menu method is not laborious. Especially for relatively short-term studies of 1 day to $1-2$ weeks this menu method could be used, because the compliance was very high $(95-99 \%)$. Applicability in the long-term however has to be investigated.

In conclusion, the reduction in energy intake by fibre under free living conditions and the hunger-reducing effect of fibre at the low energy intake level (4 MJ) suggests that soluble fibre may be useful in weight maintenance, if it can be ingested daily in the long-term, by facilitating compliance to low energy intake.

\section{References}

Andersion JW. Fiber and health: An overview. Am.J.Gastroenterol. 81: 892-897, 1986

Astrup A, Vrist $E_{\mathrm{r}}$ Quaade F. Dietary fiber added to very low calorie diet reduces hunger and alleviates constipation. Int.J.Obes. 14: 105-112, 1990

Astrup A, Toubro S, Cannon S, Hein P, Madsen J. Thermogenic synergism between ephedrine and caffeine in healthy volunteers: A double-blind, placebo-controlled study. Metabolism 40: 323-329, 1991

Blundell JE, Burley VJ. Satiation, satiety and the action of fibre on food intake. Inv.J.Obes. 11 (Suppl.1): 19. 25,1987

Burley VJ, Leeds AR, Blundell JE. The effect of high and low-fibre breakfasts on hunger, satiety and food intake in a subsequent meal. Int.I.Obes.11 (Suppl.1): 87-93, 1987

Delargy HJ, Burley VJ, O'Sullivan KR, Fletcher RJ, Blundell JE. Effects of different soluble: insoluble fibre ratios at breakfast on 24-h pattern of dietary intake and satiety. Eur.J.Clin.Nutr.49: 754-766, 1995

Dulloo AG, Geissler CA, Horton T, Collins A, Miller DS. Normal caffeine consumption: influence on thermogenesis and daily energy expenditure in lean and post-obese human volunteers. Am.I.Clin. Nutr.49: 44-50, 1989

Duncan KH, Bacon JA, Weinsier RL. The effects of high and low energy density diets on satiety, energyintake and eating time of obese and non-obese subjects. Am.J.Clin.Nutr.37: 763-767, 1983

Evans E, Miller DS. Bulking agents in the treatment of obesity. Nutr.Metab. 18: 199 - 203, 1975

Garner DM, Wooley SC. Confranting the failure of behavioral and dietary treatments for obesity. Clin. Psychal.Rev.11: 729-780, 1991

Goldstein, DJ. Beneficial effects of modest weight loss. Int.J.Obes. 16: 397-415, 1992

Hylander B, Rössner S. Effects of dietary fiber intake before meals on weight loss and hunger in a weightreducing club. Acta Med.Scand.213: 217-220, 1983

Krotkiewski M. Effect of guar gum on body-weight, hunger ratings and metabolism in obese subjects. Brit.J.Nutr.52: $97-105,1984$

Leeds AR. Dietary fibre: mechanism of action. Int.J.Obes.11(Suppl.1): 3-7, 1987

Nederlandse Voedingsstoffenbestand (NEVO). Dutch nutrient database 1989/1990. Zeist, The Netherlands: Stichting NEVO (in Dutch), 1989

Pannemans DLE, Westerterp KR. Estimation of energy-intake to feed subjects at energy balance as verified. with doubly labelled water: a study in the elderly. Eur.J.Clin.Nutr.47: 490-496, 1993

Porikos K, Hagamen S. Is fiber satiating? Effects of a high fiber preload on subsequent food intake of normal-weight and obese young men. Appetite 7: 153-162,1986

Raben A, Christemsen NJ, Holst JJ, Astrup A. Decreased postprandial thermogenesis and fat oxidation but increased fullness after a high-fiber meal compared with a low-fiber meal. Am.J.Clin.Nutr.59: 1386-94, 1994

Rigaud D, Ryttig KR, Angel LA, Apfelbaum M. Overweight treated with energy restriction and a dietary fibre supplement: a 6-month randomized, double-blind, placebo-controlled trial. Int.J.Obes.14: 763-769, 1990

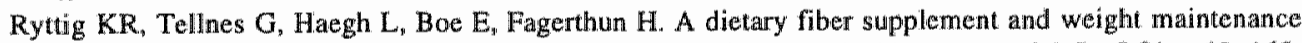
after weight reduction: a randomized, double-blind placebo-controlled long-term trial. Int.J.Obes. 13: 165171,1989 
Spiller GA. Handbook of dietary fiber in human mutrition (second edition). CRC Press, Florida, 1993

Todd PA, Benfield P, Goa KL. Guar Gum. A rewiew of its pharmacological properties, and use as a dietary adjunct in hypercholesterolaemia. Drugs 39: $917-928,1990$

van de Ven MLHM, Westerterp-Plantenga MS, Wouters L, Saris WHM. Effects of liquid preloads with different fructose/fibre concentrations on subsequent food intake and ratings of hunger in women. Appetite 23: 139-146, 1994

Wing RR, Jeffery RW. Effect of modest weight loss on changes in cardiovascular risk factors: are there differences between men and women or between weight loss and maintenance? Int.J.Obes. 19: 67-73, 1995

Wurtmain $I$, Wurtman $R$, Mark $B$, Tsay $R$, Gilbert $W$, Gordon $J$. Dexfenfluramine selectively suppresses carbohydrate snacking by obese subjects. Int J.Eat.Disord.4: 89-99, 1985 


\title{
Chapter 4
}

\section{The effectiveness of long-term fiber supplementation on weight maintenance in weight-reduced women}

\author{
W.J. Pasman" ${ }^{*}$ M.S. Westerterp-Plantenga*\#, E. MulsI, G. VansantI, J. van Ree and \\ W.H.M. Saris* \\ * Department of Human Biology and \& Department of General Practice, Maastricht \\ University, \#pen University, Heerlen, The Netherrlands \\ IDepartments of Endocrinology, Metabolism and Nutrition and Clinical Chemistry, \\ University Hospital Gasthuisberg, Leuven, Belgium
}

Int.J.Obes.21:548-555, 1997

\begin{abstract}
Objective: To investigate whether fiber supplementation is effective in weight-reduced subjects for maintenance of weight-loss in the long-term.

Design: Longitudinal, randomly assigned intervention study with supplementation of 20 grams of water soluble fiber (guar gum) daily for 14 months after an energy-restricted period of 2 months (VLED).

Subjects: 31 female, obese subjects (age: $41.4 \pm 7.4$ yrs; BMI $33.2 \pm 3.7 \mathrm{~kg} . \mathrm{m}^{-2}$ ); 20 subjects were supplemented with fiber and 11 subjects served as a control group.

Measurements: Body weight (BW), blood lipids and blood pressure, anthropometry, and eating behavior were measured before the VLED (0), after VLED (2), and at 4, 10 and 16 months.

Results: The fiber group with at least $80 \%$ compliance (group A) and the control group showed the same weight regain response after VLED. The fiber consuming group with 50$80 \%$ compliance (group B) differed with respect to relapse. The rate and amount of $\mathrm{BW}$ regain was significantly higher for group B. After 14 months BW of group B had returned to baseline levels, whereas group $\mathrm{A}$ and the control group showed a tendency to a lower $\mathrm{BW}$ than at baseline $(\mathrm{p}=0.09)$. No effect of fiber supplementation was found at blood lipids, blood pressure and energy intake. Eating behavior characteristics changed during the intervention and might explain differences in weight maintenance.

Conclusion: No effect was found of 14 months fiber supplementation at weight maintenance in weight-reduced subjects. Guar gum intake did not result in reduction of blood pressure, cholesterol and suppression of energy intake.
\end{abstract}

\section{Introduction}

Weight loss interventions have been shown to be successful but results in the long-term are

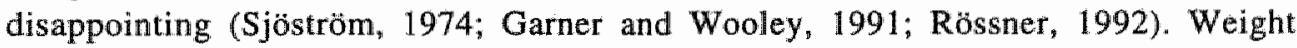
maintenance studies so far showed that successful weight maintainers exercised, were well motivated, managed stress well, used social support, and knew the type and quantity of food that was consumed (Kayman et al., 1990; DuPue et al., 1995). Because weight maintenance 
is achieved when energy intake and energy expenditure are balanced, interference of the type and quantity of food consumed seems to be the easiest way of changing energy balance. Studies with bulking agents like fibers were carried out to investigate whether supplementation of fiber resulted in decreased food intake. Fibers were found to be effectively increasing feelings of fullness (Evans and Miller, 1975; Leeds, 1987; Raben et al., 1994) and had a satiating effect (Ryttig et al., 1989; Spiller, 1993). This could result in a decreased energy-intake. Since it is also known that obese and especially severely obese subjects consume less fiber than their lean counterparts, supplementation of dietary fiber might be effective in reducing energy intake and therefore result in weight loss or weight maintenance (v.Itallie 1978; Alfieri et al., 1995).

In the present study a water soluble fiber guar gum is used to study the effect at weight maintenance. Guar gum, obtained from the endosperm of the Indian cluster bean Cyamopsis tetragonolobus, is a galactomannan, which in contact with water forms a highly viscous gel (Todd et al., 1990). We used an enzymatically modified guar gum. This water soluble fiber hydrolysate has been reported to have the same effects as its native form (Homann et al., 1994). It is reported that fiber has a major effect on blood pressure and cholesteroll levells (Anderson, 1986). Fiber should also improve the insulinemic response (Blackburn et al., 1984). The improved insulinemic response as a result of fiber supplementation could by itself be a useful physiological response to prevent obesity and weight gain (Anderson, 1986). We already found an effect of the guar gum supplement in a short-term intervention study at energy intake and hunger and satiety feelings (Pasman et al., 1994). The lowered energy intake found and increased satiety feelings reported, might be beneficial for weight maintenance in the long-term (Evans and Miller, 1975; Krotkiewski, 1984; Rigaud et al., 1990).

In this study the effect of long-term fiber supplementation (14 months) will be shown in 31 weight-reduced females, with respect to body weight maintenance, cholesterol and blood pressure, while energy intake and eating behavior characteristics are taken into account.

\section{Study design}

\section{Methods}

Maintenance of body weight after 2 months of a very low energy diet (VLED; 2 MJ.day-1) was studied for 14 months. The fiber intervention was studied in one group of subjects by supplementation of 20 grams of water soluble fiber daily (guar gum) and one control group; randomization was executed after the VLED period. Before (month 0 ) and after the VLED period (month 2) measurements were carried out. During the weight maintenance phase these measurements were repeated at 4,10 and 16 months. A written informed consent was obtained from each subject at the start of the study. The study was reviewed and approved by the Medical Ethical Committee of the Maastricht University.

\section{Subjects and drop-out information}

The VLED period was started with 48 female obese subjects. 41 subjects completed the VLED-period. Seven females dropped out of the study during the VLED period, because they were not able to follow the strict VLED regime. Two subjects lost less than $5 \mathrm{~kg}$ of body weight (BW) during the VLED and were excluded (set a priori as a measure of compliance to the VLED) $(n=39)$. The subjects were randomly assigned to a fiber supplemented group ( $n=25)$ and a non-treated group $(n=14)$. During the weight maintenance phase 8 subjects dropped-out and a complete data set was obtained of 31 subjects. One 
subject was not able to come for the test at month 10 , therefore she has been left out of the analysis. One subject became pregnant and another subject had a spinal cord operation. Five subjects stopped participation because of personal circumstances. The data presented in this study are based upon 31 female subjects (age $41.4 \pm 7.4$ yrs; height: $1.64 \pm 0.06 \mathrm{~m} ; \mathrm{BW}$ $88.7 \pm \sqrt{0.4 \mathrm{~kg}}$ ). The 17 subjects that dropped-out of the study had similar baseline characteristics (age $36.7 \pm 10.7$ yrs; height: $1.65 \pm 0.06 \mathrm{~m} ; \mathrm{BW} 86.6 \pm 10.5 \mathrm{~kg}$ ).

\section{Fiber supplementation}

Subjects supplemented with fiber were asked to consume 10 gram of guar gum fiber twice daily (20 grams in total). The fiber supplement was an enzymatically modified guar gum (Bemefiber ${ }^{(8)}$, Sandoz Nutrition, Minneapolis, US). The partially hydrolyzed fiber has still the same characteristics as its native form (Homann et al., 1994). Subjects were asked to consume 10 grams of fiber in the afternoon and 10 grams in the evening. The fiber supplement was dissolved in $200 \mathrm{ml}$ solution like water, coffee or orange juice to facilitate fiber intake. No placebo for this fiber supplement was available.

\section{Measurements}

Subjects came to the lab after an overnight fast at $8.00 \mathrm{~h} \mathrm{am}$, by car or public transport to minimize physical activity at $0,2,4,10$ and 16 months.

\section{Blood analysis}

At all test days, fasted blood samples were obtained (10 $\mathrm{ml}$ EDTA plasma and $10 \mathrm{ml}$ serum) of the subjects. Blood plasma was mixed with EDTA to prevent clotting, and immediately centrifuged. Serum was obtained by centrifugation of blood after one hour at room temperature. Plasma and serum samples were stored at $-80^{\circ} \mathrm{C}$ until further analysis. Plasma glucose was determined by means of a hexokinase method (Cobas Bio, Roche Diagnostics, Hoffmann-La Roche, Basle, Switzerland). Plasma insulin was measured using a double antibody radioimmunoassay for human insulin (Kabi Pharmacia Diagnostics AB, Uppsala, Sweden). For determination of free fatty acids we used plasma (Cobas Fara, Wako, NEFA C, Wako Chemicals, Neuss, Germany). Free glycerol and total glycerol concentrations were determined with a kit of Boehringer (Cobas Bio, Mannheim, Germany). Total cholesterol, LDL and HDL cholesterol, apo-a1, apo-b and Lp(a) were determined as described by Muls and coworkers (1993).

\section{Anthopometry}

Anthropometric data obtained at each test were; body weight (BW), height , body fat percentage and waist-hip ratio (WHR). The deuterium dilution technique was used for measurement of body composition in this study (Schoeller et al., 1980). Subjects were asked to collect an urine sample in the evening just before drinking the deuterium enriched water sollution. After consumption of this enriched water no more water and food was consumed. The next morning subjects came after an overnight fast to the lab for the measurement session. Ten hours after drinking the water solution another urine sample was collected. The degree of dilution of the deuterium isotope is a measure for total body water of the subject (Marken Lichtenbelt et al., 1994).

\section{Energy intake}

The amount of food consumed during the 16 month study period was calculated with analysis of the completed food-intake diary. Subjects were asked to write down everything that was consumed (meals, drinks and snacks) at two normal week days and one weekend day at every time point of the study. The diaries were analysed with the Dutch food table (Becel, 1989) and the accessory computer program. 


\section{Eating behavior}

Eating behavior was analyzed with a dutch translation of the Three Factor eating behavior questionnaire (TFEQ) (Stunkard and Messick, 1985) after each test day (WesterterpPlantenga et al., 1990). Cognitive restrained and unrestrained eating behavior (Factor 1 score), disinhibition (Factor 2) and the hunger factor (Factor 3 ) were scored. Body weight fluctuation was checked with the Herman and Polivy questionnaire (Herman and Polivy, $1980)$.

Compliance to fiber intake during the weight maintenance phase

The fiber supplemented subjects were asked to consume 2 sachets of ten grams of fiber daily. Actual fiber intake was checked by questionnaire when subjects were asked to report the amount of fiber consumed during a week and counting of returned sachets. Based upon this information 2 subgroups were classified. One group of subjects consumed more than $80 \%$ of the supplemented amount of fiber (group A; $n=10$ ) and group B consumed between $50-80 \%$ of the required amount of fiber $(n=10)$. The data in this repont is presented for 3 subgroups; group $A$ and $B$, and the control group $C(n=11)$.

Because the subdivision in fiber supplementation was made after completion of the study baseline characteristics were compared statistically to exclude differences that were already present at the start. No statistical differences were found for baseline data (table 4.1 ) and therefore these groups can be regarded as similar for these characteristics.

Stratistics

Data are presented as mean and standard deviation (sd). Statistics were performed with a two-way Anova for repeated measures to study differences over time and with respect to the factor fiber supplementation. Changes in parameters measured with respect to the initial walue were calculated as a percentage of the initial value to correct for differences in initial level of the parameter at the start of the experiment. Statistical significance was set at $p<0.05$.

\section{Results}

The physical characteristics of the subjects before the study (table 4.1) were not statistically different among the 3 groups. Weight maintenance and weight relapse for the three groups are presented in fig. 4.1 which illustrates the weight gained in the different groups at 16 months. Nine of the ten subjects from group B had relapsed $50 \%$ or more of the weight lost during the VLED. In group A 6 out of 10 subjects had regained $50 \%$ or more and for the control group 7 out of 11 subjects regained $50 \%$ or more. On average the percentage of regain was at 16 months: $65 \%( \pm 65 \%$ ) for group $\mathrm{A} ; 123 \%$ ( $\pm 63 \%$ ) for group $\mathrm{B}$ and $61 \%$ $( \pm 66 \%$ ) for the control group. Although there is a wide spread variation in weight regain, this difference in relapse between the three groups was almost significant $(F(2,30)=2.926$; $\mathrm{p}=0.07$ ). Expressed as change with respect to the initial value, changes in body weight are shown in fig.4.2. "The amount of regain of BW was higher for group B compared to group $A$ and the control group at 4 months $(p=0.08)$ and was significantly higher at 10 months (fig.4.2). The percentage BW at 16 months was for group $\mathrm{A}$ and the control group lower than at the beginning of the study $(p=0.09)$ and was equal with the initial $B W$ for group $B$ (fig.4.2). 
Table 4.1 Baseline characteristics

\begin{tabular}{|c|c|c|c|c|c|}
\hline Parameter & All & group A & group $\mathbf{B}$ & Contiroll & $p$ \\
\hline mumber & 31 & 10 & 10 & 11 & \\
\hline age (yrs) & $41.4(7.4)$ & $44.8(7.3)$ & $38.9(7.0)$ & $40.5(7.1)$ & 0.18 \\
\hline $\mathrm{BW}(\mathrm{kg})$ & $88.7(10.4)$ & $89.8(12.0)$ & $87.0(5.9)$ & $89.4(12.6)$ & 0.82 \\
\hline height (m) & $1.64(0.06)$ & $1.62(0.06)$ & $1.64(0.05)$ & $1.65(0.09)$ & 0.70 \\
\hline $\mathrm{BMI}\left(\mathrm{kg} \cdot \mathrm{m}^{-2}\right)$ & $33.2(3.7)$ & $33.9(2.8)$ & $32.7(3.6)$ & $32.9(4.7)$ & 0.75 \\
\hline BPsys ( $\mathrm{mm} \mathrm{Hg}$ ) & $135(17)$ & $145(23)$ & $129(16)$ & $133(10)$ & 0.12 \\
\hline BPdia (mm Hg) & $94(11)$ & $96(14)$ & $90(9)$ & $96(7)$ & 0.34 \\
\hline W/HI & $0.83(0.05)$ & $0.85(0.04)$ & $0.82(0.06)$ & $0.84(0.06)$ & 0.63 \\
\hline Body fat $(\%)$ & $43.0(4.1)$ & $42.6(4.4)$ & $43.7(3.6)$ & $42.6(4.5)$ & 0.78 \\
\hline Sag. dia (cm) & $23.8(2.2)$ & $24.0(2.4)$ & $23.6(1.3)$ & $23.7(2.7)$ & 0.91 \\
\hline
\end{tabular}

The data of all 31 subjects before the study are presented and compared for the three groups. In group $A$ the subjects consumed $>80 \%$ of the fiber supplied. In group $B$ the subjects consumed between the $50-80 \%$ of the fiber supplied. The control' group did not receive a supplement. Mean and standard deviations are presented. The p-yalues of the Anova-factor analysis are presented.

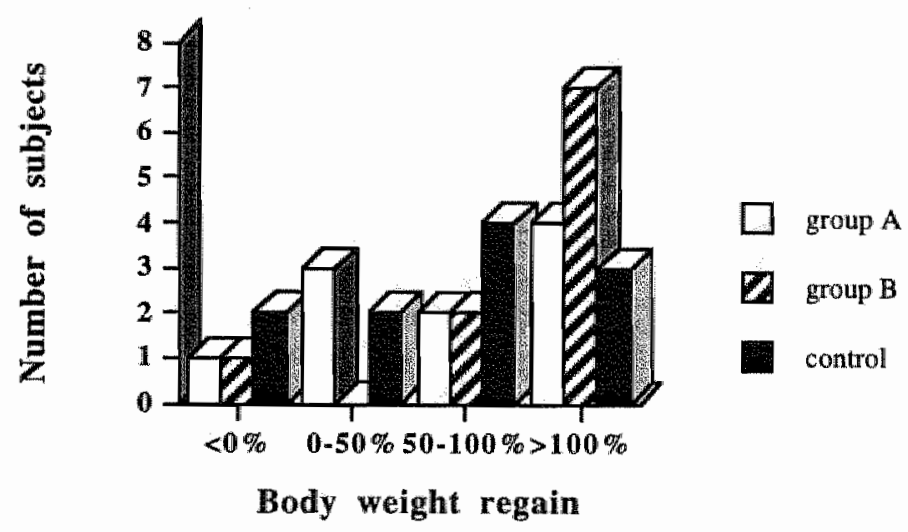

Fig.4.1 Weight regain is presented as a percentage of the amount of weight lost during VLED. The VLED untervention resulted in a significant weight loss for all three groups. The amount of weight lost during the VLED was set at $100 \%$. The number of subjects of the three groups that gained different amounts of $\mathrm{BW}$ are presented.

Body weight, body mass index, body fat percentage and waist-hip ratios measured at different time points are presented in table 4.2 . Only body fat percentage was significantly higher at 16 months after the VLED period in the fiber B group than in the control group. Blood pressure did not change significantly with fiber supplementation (data not shown). Baseline data of blood parameters are presented in table 4.3 , and during the course of the study no differences were found between the groups. Blood cholesterol, glucose and insulin levels were not affected by fiber supplementation. 


\section{Chapter 4}

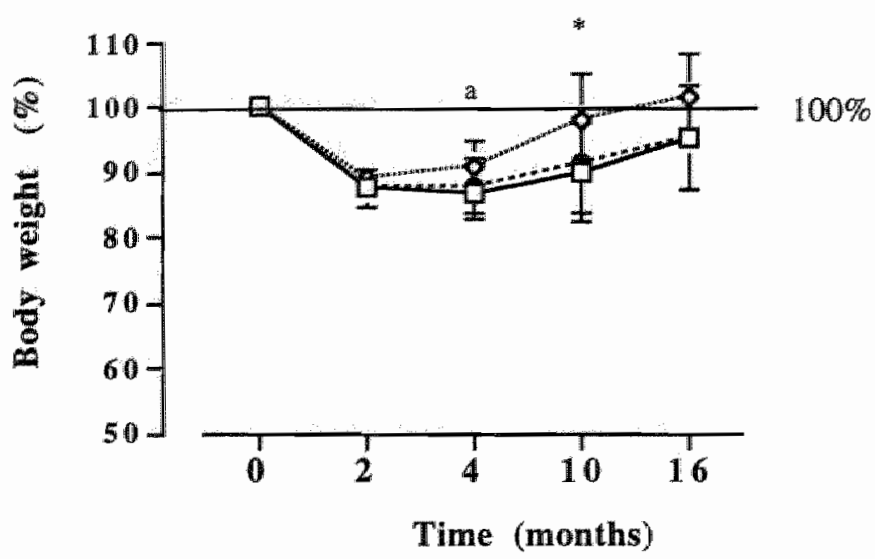

Fig. 4.2 The changes in body weight are expressed as percentage of the initial value for group A (open squares), group B (open diamonds) and for group C (filled circles). The mean and standard deviation are presented at different time points measured, for the three groups. The rate of regain is faster for the fiber B group than for the fiber $A$ and control group. a=fiber B differed at $p=0.08$ from group $A$ and control group. ${ }^{*} \mathrm{p}<0.05$ significant difference between fiber $B$ and fiber $A$ and the control group.

Table 4.2 Anthropometric data

\begin{tabular}{|c|c|c|c|c|c|c|}
\hline Month & 0 & 2 & 4 & 10 & 16 & $\mathrm{p}$ \\
\hline \multicolumn{7}{|c|}{ Body weight (kg) } \\
\hline A & $89.8(12.0)$ & $78.6(10.2)$ & $78.0(10.6)$ & $80.9(12.5)$ & $85.6(13.1)$ & * \\
\hline B & $87.0(5.9)$ & $77.3(6.1)$ & $79.2(7.4)$ & $85.3(9.8)$ & $88.4(10.1)$ & * \\
\hline $\mathrm{c}$ & $89.4(12.6)$ & $78.3(10.6)$ & $78.4(10.4)$ & $81.1(10.6)$ & $85.0(12.0)$ & * \\
\hline \multicolumn{7}{|c|}{$\mathrm{BMI}\left(\mathrm{kg} \cdot \mathrm{m}^{-2}\right)$} \\
\hline$A$ & $33.9(2.8)$ & $29.7(2.3)$ & $29.5(2.6)$ & $30.5(3.6)$ & $32.3(3.7)$ & * \\
\hline B & $32.7(3.6)$ & $29.0(3.3)$ & $29.8(3.8)$ & $32.0(4.8)$ & $33.2(5.0)$ & * \\
\hline $\mathrm{C}$ & $32.9(4.7)$ & $28.8(3.8)$ & $28.9(3.7)$ & $29.9(4.0)$ & $31.4(5.1)$ & * \\
\hline \multicolumn{7}{|c|}{ Body fat $\%(\%)$} \\
\hline$A$ & $42.6(4.4)$ & $37.3(3.7)$ & $36.2(2.7)$ & $38.5(4.4)$ & $42.1(3.3)$ & * \\
\hline B & $43.6(3.8)$ & $38.7(5.8)$ & $38.2(6,3)$ & $39.9(5.7)$ & $44.6(4.5)^{a}$ & $*$ \\
\hline $\mathrm{C}$ & $42.6(4.5)$ & $36.4(6.0)$ & $34.6(5.9)$ & $35.7(5.1)$ & $38.9(5.1)$ & * \\
\hline \multicolumn{7}{|l|}{ WHR } \\
\hline A & $0.85(0.04)$ & $0.82(0.06)$ & $0.81(0.05)$ & $0.82(0.04)$ & $0.82(0.04)$ & * \\
\hline B & $0.82(0.06)$ & $0.80(0.05)$ & $0.81(0.04)$ & $0.81(0.06)$ & $0.83(0.05)$ & * \\
\hline C & $0.84(0.06)$ & $0.79(0.05)$ & $0.81(0.05)$ & $0.81(0.05)$ & $0.83(0.04)$ & * \\
\hline
\end{tabular}

Data of 31 subjects are presented at different time points. Mean and standard deviations are presented. For all anthroponetric data presented the differences over time were significant, which are indicated by *. Between groups only body fat percentage at 14 months differed significantly between group $B$ and the control group (a). 
Table 4.3 Blood parameters

\begin{tabular}{|c|c|c|c|c|}
\hline Parameter & Group A & Group B & Control & $\mathrm{p}$ \\
\hline Gincose (mmol. $\left.L^{-1}\right)$ & $5.1(0.6)$ & $5.0(0.4)$ & $5.0(0.6)$ & 0.90 \\
\hline Insulin (mU.L $\left.\mathrm{L}^{-1}\right)$ & $13.2(4.2)$ & $12.9(4.4)$ & $12.9(6.9)$ & 0.99 \\
\hline Total Chollesterol (mmol $L^{-1}$ ) & $5.7(0.5)$ & $6.1(0.9)$ & $5.2(0.8)$ & 0.04 \\
\hline High Density Lipoprotein (mmol. $\mathrm{L}^{-1}$ ) & $1.3(0.3)$ & $1.5(0.3)$ & $1.5(0.7)$ & 0.49 \\
\hline Low Density Lipoprotein $\left.\left(\mathrm{mmol}^{-1}\right)^{-1}\right)$ & $3.6(0.7)$ & $3.6(1.0)$ & $3.0(0.7)$ & 0.17 \\
\hline Apoprotein-AI (mg.d. $\left.\|^{-1}\right)$ & $119.8(19.9)$ & $143.8(24.9)$ & $122.7(44.0)$ & 0.19 \\
\hline Apoprotein-B (mg.dl-1) & $85.3(13.1)$ & $85.8(17.6)$ & $71.2(14.2)$ & 0.07 \\
\hline Lipoprotein(a) (mgadi ${ }^{-1}$ ) & $243(351)$ & $230(192)$ & $180(242)$ & 0.86 \\
\hline
\end{tabular}

Baseline blood parameters are shown for the three groups. Total cholesterol, HDL and LDL data are presented (mean $\pm \mathrm{sd}$ ) in mmol.. $\mathrm{I}^{-1}$, Apoprotein-A1, Apoprotein-B and Lipoprotein (a) in mg.d-1 ${ }^{-1}$. The blood glucose and insulin data are also shown. The p-yalues of the Anova-factor analysis are presented.

The mean energy intake levels of the three groups changed significantly over time from $6.8 \pm$ 2.2 MJ at baseline to 5.3 $\pm 1.7 \mathrm{MJ}$ after VLED, and showed a tendency for differences in energy intake between groups $(F(2,23)=3.05, p=0.07)$. At 16 months only group A showed a lower energy intake $(5.8 \pm 1.8 \mathrm{MJ})$ than the other 2 groups $(7.0 \pm 2.2 \mathrm{MJ}$ for group $\mathrm{B}$ and $6.6 \pm 1.5 \mathrm{MJ}$ for group $\mathrm{C}$ ) but this was not significantly different. Group $\mathrm{A}$ also showed lower energy intake levels $(5.8 \pm 1.8 \mathrm{MJ})$ compared with baseline $(7.2 \pm 3.3 \mathrm{MJ})$; this difference was however not significant $(\mathrm{p}=0.11)$.

Eating behavior characteristics were of special interest because the deviation in two groups in the fiber supplemented group, by means of degree of compliance, was thought to be related to eating behavior characteristics. The variation in these factors between the subjects, also within each group, resulted in comparable eating behavior characteristic scores. In table 4.4 the restraint score (factor 1 ), the emotional/control score (disinhibition=factor 2 ) and the hunger related scores (factor 3) are presented. Only group A showed at month 16 significantly increased restraint scores from baseline ( $(0): 10.2 \pm 2.7$ vs (16): $13.7 \pm 4.0)$. In this group the factor 3 scores at the end of the study were also significantly lower at 16 months ((0): $5.3 \pm 3.1$ vs (16) 3.2 \pm 3.2 ). These changes in scores were not found for group $\mathrm{B}$ and the control group. Changes in eating behavior characteristics over the whole study period were not related to compliance of fiber intake. Changes in eating behavior factors were also studied in relation to the amount of weight gain for that period (change in factor and body weight from start of the study to month 2 (1); from start to month 4 (2); from start to month 10 (3); and from start to month 16 (4)). When the whole group was studied, significant relations were found between the amount of change in factor 1-score and the change in $\mathrm{BW}$. This was found for the period from month 0 to month $4\left(\mathrm{r}_{2}=0.51\right)$; from month 0 to month $10\left(r_{3}=0.60\right)$ and from month 0 to month $16\left(r_{4}=0.49\right)$. None of these relations were found with the other factors for the whole group. When the groups were analysed separately the main result was the significant relation in group A between the amount of change in factor 2 and the amount of body weight change $\left(r_{1}=0.70 ; r_{2}=0.71\right.$; $r_{3}=0.73 ; r_{4}=0.18$ ). The last period was not significant. These relations were not seen for the other two groups. 


\section{Chapter 4}

Table 4.4 Eating behavior characteristics

\begin{tabular}{cllllll}
\hline Monuh & 0 & 2 & 4 & 10 & 16 & $p$ \\
\hline TFEQ-Factor 1 & & & & & & \\
A & $10.3(2.7)$ & $14.7(2.7)$ & $17.2(2.3)^{a}$ & $14.1(3.9)$ & $13.7(4.0)$ & $*$ \\
B & $9.0(4.8)$ & $1.4 .2(4.0)$ & $13.0(5.6)$ & $10.8(5.0)$ & $9.1(5.6)$ & $*$ \\
C & $9.4(5.3)$ & $14.5(3.4)$ & $14.5(4.1)$ & $12.8(4.8)$ & $10.8(4.9)$ & $*$ \\
TFEQ-Factor 2 & & & & & \\
A & $8.1(4.0)$ & $5.8(4.3)$ & $5.6(3.6)$ & $6.0(4.6)$ & $6.6(3.9)$ & NS \\
B & $8.8(2.4)^{b}$ & $7.4(3.9)$ & $7.3(3.4)$ & $8.6(2.9)^{b}$ & $8.4(2.6)$ & NS \\
C & $5.7(3.0)$ & $5.8(3.2)$ & $5.1(3.0)$ & $5.1(2.7)$ & $6.0(3.4)$ & NS \\
TFEQ-Factor 3 & & & & & & \\
A & $5.4(3.1)$ & $3.0(2.5)$ & $3.2(2.1)$ & $4.0(3.7)$ & $3.2(3.2)$ & $*$ \\
B & $6.9(2.9)$ & $4.0(4.1)$ & $5.1(4.3)^{b}$ & $5.9(3.5)$ & $6.1(4.1)$ & $*$ \\
C & $4.1(3.3)$ & $3.0(2.7)$ & $2.0(2.1)$ & $2.6(2.5)$ & $4.0(2.8)$ & 0.08
\end{tabular}

Factor 1,2 and 3 scores of the Stunkard and Messick Three Factor Eating Behavior Questionnaire (TFEQ) (1985) of the three groups are presented at all time points. Significant differences over time are presented $(*)$ and between groups. $a$ : difference with $\mathrm{p}=0.06$ between group $\mathrm{A}$ and control group, $b$ : difference with $\mathrm{p}=0.07$ between group $B$ and control group

\section{Discussion}

\section{Weight maintenance}

In the present study no effect of 20 grams of guar gum supplementation per day was found in long-term weight maintenance, blood pressure, blood cholesterol or any other relevant parameter investigated. The control group showed the same physiological changes as the fiber supplemented groups. Weight maintenance was even better achieved in the control group than in the fiber B group; 4 subjects of group $A ; 1$ subject of group $B$ and 4 of the control subjects were able to prevent weight regain below $50 \%$ of the weight lost during VLED.

Other long-term fiber supplementation studies (table 4.5) show conflicting results with respect to body weight changes when fiber was supplemented. In this study we used a partially hydrolyzed fiber, which was not very well dissolvable after processing. The normally bitter taste of the guar gum fiber was gone, and gel-forming did not occur in the solution. The amount of fiber supplemented (20 grams of fiber daily) was the same, or even higher, as was used in other studies (table 4.5). Comparison with other fiber supplemented studies requires additional information about the diet instructions given.

In our study subjects were eating ad libitum in the weight maintenance phase, to investigate the sole cffect of the fiber supplement under nomal free living conditions, when on average already 18-19 grams of dietary fiber was consumed. In the studies of Rössner, Ryttig, and Rigaud and coworkers, besides a fiber supplement an energy restricted diet of 5-6 MJ.day-1 was prescribed (Rössner, 1987; Ryttig et al., 1989; Rigaud et al., 1990). The restricted energy intake by itself could result in a lowered BW, but addition of fiber was still more effective. Ryttig and coworkers further reported that at the end of their study subjects were also allowed to eat ad libitum. The fiber supplement was still effective and resulted in a further decrease of BW (Ryttig et al., 1989).

Differences in fiber preparation used could also be an explanation for differences in results found. The study of Uusitupa and colleagues (Uusitupa et al, 1989) is comparable with our study with respect to the amount of fiber supplemented, fiber type and duration of 
supplementation. The consumption of their granules before each meal (dissolved in a drink) might be more effective directly at the consumption of the main meal and result in a lowered energy intake and finally weight loss. Also the amount of solution used for dissolving the fiber might result in different results, affecting feelings of fullness and satiation as an interfering factor. In the study of Tuomilehto and coworkers (1980) the fiber granules were also supplied before each meal. The 15 grams of guar gum in total daily significantly decreased body weight in 4 months with $2.5 \mathrm{~kg}$. In our study subjects consumed the fiber dissolved in a solution in the afternoon and in the evening, between the main meals to reduce energy intake from snacks. In contrast to earlier findings in a short-term study, our fiber supplement did not seem to be effective for long-term maintenance of energy balance. The ineffectiveness of the fiber supplement of our study at body weight is comparable with Simons (1982). Their study was mainly focused upon the cholesterol lowering effect of fiber, but they also reported that body weight did not change significantly after 12 months treatment with 18 grams of fiber.

Table 4.5 Long-term fiber supplementation studies

\begin{tabular}{|c|c|c|c|c|c|c|c|}
\hline N/Sex & Amount & Fiber & Period & $\mathrm{BW}$ & $\mathrm{BP}$ & Chol. & Reference \\
\hline \multicolumn{8}{|c|}{ diet and fiber supplementation } \\
\hline $97 f$ & $6 \mathrm{~g}$ & insoluble & $12 \mathrm{mo}$ & $d$ & diad & $?$ & Ryttig (1989) \\
\hline $41 f$ & $7 \mathrm{~g}$ & insoluble & 3 mo & $d$ & diad & $?$ & Rössner (1987) \\
\hline $41 \mathrm{f} / 1 \mathrm{~m}$ & $7 \mathrm{~g}$ & insolublle & $6 \mathrm{mo}$ & $\mathrm{d}$ & $=$ & $?$ & Rigaud (1990) \\
\hline \multicolumn{8}{|c|}{ fiber supplenentation } \\
\hline $26 \mathrm{f} / 13 \mathrm{~m}$ & $15 \mathrm{~g}$ & guar gum & $13 \mathrm{mo}$ & $d$ & $d$ & $7 \%$ & Uusitupa (1989) \\
\hline $8 \mathrm{f} / 9 \mathrm{~m}$ & $18 \mathrm{~g}$ & guar gum & $12 \mathrm{mo}$ & $=$ & 7 & $15 \% \mathrm{~d}$ & Simons (1982) \\
\hline $32 f$ & $15 \mathrm{~g}$ & guar gum & $4 \mathrm{mo}$ & $d$ & $?$ & no & Tuomilehto(1980) \\
\hline $31 f$ & $20 \mathrm{~g}$ & guar gum & $14 \mathrm{mo}$ & $=$ & $=$ & $=$ & Pasman \\
\hline
\end{tabular}

Outline of several long-term fiber supplementation studies. Study characteristics in number of subjects, subject gender ( $m=$ male; $f=f e m a l e)$, amount of fiber supplemented, type of fiber, duration of the study, effect found at body weight (BW), blood pressure (BP) and at cholesterol (chol.) are presented. Abbreviations/symbols used: $\mathrm{d}=$ decreased; $=$ no effect; ? no information available; $\mathrm{BP}$ dia $=$ diastolic blood pressure.

\section{Free living conditions}

In the present study subjects were not restricted or advised with respect to energy intake and energy expenditure. Fiber supplementation as the sole intervention to be effective for weight maintenance when subjects are free liwing, would be very difficult. Social events, work, family and other aspects of life interfere with food consumption. Complete changes in behavior with respect to food intake and exercise seem to be necessary for successful weight maintenance or prevention of weight gain (Wing, 1995). Studies that investigated the needs of successful weight maintainers showed that exercise, motivation, social support, and knowledge of food are important factors (Kayman et al., 1990; Garner and Wooley, 1991; DuPue et al., 1995). Supplementation of fiber, an aspect of healthy food consumption, might be too weak. More factors should be stimulated for effective weight maintenance.

A problem with a long-term intervention is the duration of the study. Subjects are not able to fulfil a certain strategy well, when not supervised strictly. Already after 10 months we found 
poor weight maintenance results (Pasman et al, 1995). Habituation and compliance are of importance in long-tem intervention studies.

Another possible explanation for the fact that no effect of fiber was found at weight maintenance, could be the level of energy intake. In a short-term fiber supplementation study we found that fiber supplementation was effective at an energy intake level of $\pm 5 \mathrm{MJ}$.day ${ }^{-1}$ (Pasman et al. 1994). The energy intake in the present study was not high, but could be above the "effective" level. In this study probably 8-9 MJ.day ${ }^{-1}$ was consumed (based upon the measured resting metabolic rate (data not shown) and an assumed physical activity index of 1.4. resulting in a percentage of underreporting of $33 \%$, a figure that has been reported before for obese (Pannemans and Westerterp, 1993). Astrup and colleagues (1990) also found that fiber supplementation was effective at low energy intake levels , because compliance to a very low energy diet intervention improved when fiber was supplemented. Reduced hunger scores and increased satiety scores enabled subjects to fulfil the diet intervention (Astrup et al, 1990). The first three studies as presented in table 4.5 of Ryttig, Rossner and Rigaud and colleagues further support the effectiveness of fiber supplementation when energy intake is below the $6 \mathrm{MJ}_{\text {day }}{ }^{-1}$ (Rössner, 1987; Ryttig et al., 1989; Rigaud et al., 1990).

\section{Habituation}

Habituation to fiber intake may be an explanation for the fact that no effect of the fiber was found. Habituation to fiber intake might end up in no further changes or effects as was also seen in the study of Simons (1982). In their study the main changes in cholesterol were found in the first 3 months of the study. The following 10 months no further changes were seen. We showed in an earlier study that supplementation of fiber for one week, resulted in significantly lowered energy-intake and increased satiety feelings at already low energy intake levels (Pasman et al., 1994). In the present study subjects had difficulties with consequent fiber consumption, because the effect on hunger and satiety was not felt as clear as in the beginning (habituation). From colonic metabolism studies it is already known that bacterial mass and activity is higher after chronic load of nonabsorbable sugars (Florent et al., 1985). Alternating intake of fiber to prevent habituation, as suggested by Flatt (pers.comm., 1994), might result in stronger effects of fiber.

\section{Eating behavior}

In the present study not only fiber supplementation is a factor that could effect weight maintenance, (change in) eating behavior is also an influencing factor. The results of this study suggest that a change in cognitive restraint score (F1) is related to weight change. The larger the change in cognitive restraint, ie the change in attitude towards eating, the better the subjects are able to maintain body weight, as was reported before in our lab (Kempen et al., 1995). The decrease in factor 2 score (disinhibition, emotional eating and control) is effective for maintenance of body weight in the long-term for group A. This decrease in disinhibition mirrors compliance, and coincides with better weight maintenance in group $A$ than in group B (fig.4.1). The control group showed the same weight regain pattern as group A did, but no changes in factor 2 scores, probably because they were not subjected to an intervention and there was no reason for a change in disinhibition. The small changes in factor 1 and factor 2 scores in group B mirror the poor compliance of this group.

\section{General conclusion}

The supplementation of the water soluble fiber did not result in a better weight maintenance of the fiber supplemented subjects. Not only fiber intake is an important factor for weight 
control, eating behavior, activity level, social circumstances, etc. are all influencing body weight. An addition of 20 grams of fiber daily might be overruled by other factors in a longterm project with free living subjects where social factors are involved. The level of energy intake (up to $5 \mathrm{MJ}^{-d a y^{-1}}$ ) at which fiber supplementation would have been effective, concluded from our previous short-term study, was not maintained. So, in the long-term, fiber might be effective together with a 4-5 MJ.day ${ }^{-1}$ energy intake, a high compliance rate, and prevented habituation by means of irregular intake.

\section{References}

Alfieri MA.H, Pomerleau J, Grace DM, Anderson L. Fiber intake of normal weight, moderately obese and severelly obese subjects. Obes.Res.3: $541-547,1995$

Anderson JW. Fiber and health: An overview. The Am.J.Gastroenterol.81: $892-897,1986$

Astrup A, Vrist E., Quaade F. Dietary fiber added to very low calorie diet reduces hunger and alleviates constipation. Int. I.Obes.14: 10S-112, 1990

Becel, Nederlandse Voedingsstoffenbestand (NEVO). Dutch nutrient database 1989/1990. Zeist, The Netherlands: Stichting NEVO (in Dutch), 1989.

Blackburn NA, Redfern JS, Jarjis H, Holgate AM, Hanning I, Scarpello JHB, Johnson IT, Read NW. The mechanism of action of guar gum in improving glucose tolerance in man. Clin.Sc.66: 329-336, 1984

DuPue JD, Clark MM, Ruggiero L, Medeiros ML, Pera V. Maintenance of weight loss: a needs assessment. Obes.Res.3:241.248, 1995

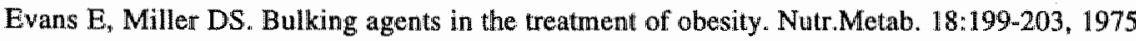

Florent $\mathrm{C}$, Flourie B, Leblond A, Rautureat $\mathrm{M}$, Bernier J-I, Rambaud J-C. Influence of chronic lactulose ingestion on the colonic metabolism of lactulose in man (an in vivo study). J.Clin.Invest.75:608-613, 1985

Garner DM, Wooley SC. Confronting the failure of behavioral and dietary treatments for obesity. Clin.Psych. Rev.11: 729-780, 1991

Herman CP, Polivy J. Restrained eating. In: Stunkard A (ed.): Obesity, W.B.Saunders, Philadelphia, pg:208225,1980

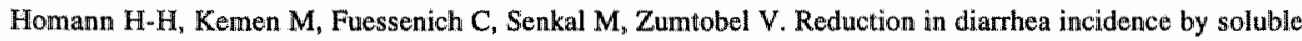
fiber in patients receiving total or supplemental enteral nutrition. J.Par.Ent.Nutr.18: 486-490, 1994

Itallie, TB v. Dietary fiber and obesity. Am.J.Clin.Nutr.31: S43-S52, 1978

Kayman S, Bruvold, W, Stern J. Maintenance and relapse after weight loss in women: behavioral aspects. Am.J.Clin.Nutr.52: 800-807, 1990

Kempen KPG, Westerterp-Plantenga MS, Wijckmans-Duijsens NEG, Saris WHM. Cognitive restraint predicts amount of weight cycles and failure in obese subjects. Int.J.Obes.19(Suppl.2): 28, 1995

Krotkiewski M. Effect of guar gum on body-weight, hunger ratings and metabolism in obese subjects. Br.J.Nutr.52: 97-105, 1984

Leeds AR. Dietary fibre: mechanism of action. Int.J.Obes.11(Suppl.1): 3-7, 1987

Marken Lichtenbelt WD wan, Westerterp $\mathrm{KR}_{n}$, Wouters $\mathrm{L}$. Deuterium dilution as a method for determining total body water: effect of test protocol and sampling time. Br.J.Nutr.72: 491-497, 1994

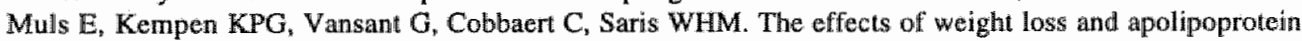
E polymorphism on serum lipids, apolipoproteins $\mathrm{A}-\mathbb{I}$ and $\mathrm{B}_{\text {, }}$ and lipoprotein(a). Int.J.Obes. 17: 711 -716, 1993

Pannemans DLE, Westerterp KR. Estimation of energy intake to feed subjects at energy balance as verified with doubly labelled water: a study in the elderly. Eur.J.Clin Nutr.47: 490-496, 1993

Pasman WJ, Westerterp MS, Saris. WHM. Adaptation of hunger and satiety feelings and/or energy intake to fiber supplementation. Int.J.Obes.18(Suppl.2): 123,1994

Pasman WJ, Saris WHM, Westerterp-Plantenga MS. The effect of fiber supplementation on long-term weight maintenance. Int.J Obes. 19(Suppl.2): 155, 1995

Raben A, Christensen NJ, Holst JJ, Astrup A. Decreased postprandial thermogenesis and fat oxidation but increased fullness after a high-fiber meal compared with a low-fiber meal. Am.J.Clin.Nutr.59: 1386-94, 1994

Rigaud D, Ryttig KR, Angel LA, Apfelbaum M. Overweight treated with energy restriction and a dietary fibre supplement: a 6-month randomized, double-blind, placebo-controlled trial. Imt.J.Obes. 14: 763-769. 1990 


\section{Chapter 4}

Rössner $\mathrm{S}_{*}$ Zweigbergk Dv, Ohlin $\mathrm{A}_{2}$ Rytig K. Weight reduction with dietary fiber supplements. Results of wo double-blind randomjzed studies. Acta Med.Scand.222: 83-88, 1987

Rojssner $\$$. Factors determining the long-term outcome of obesity treatment. In: Björntorp $P$, Brodoff $B N$, ed.: Obesity, I.B. Lippincot Company, Philadelphia, pg: 712-719, 1992

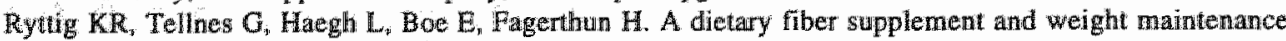
after weight reduction: a randomized, double-blind placebo-controlled long-term trial. IntJ.Obes.13: 165171,1989

Schoeller DA, Santen E v, Peterson DW, Diez W, Jaspan J, Klein PD. Total body water measurement in humans with ${ }^{18} \mathrm{O}$ and ${ }^{2} \mathrm{H}$ labeled water. Am.J.Clin.Natr.33: 2686-2693, 1980

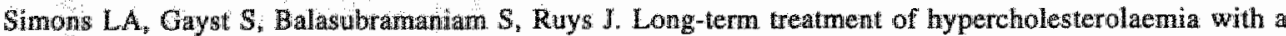
new palatable fornulation of guar gum. Artherosclerosis 45: 101-108, 1982

Sjowstron $\mathrm{L}$. Can the relapsing patient be identified? In: Björntorp, Cairella, Howard (eds.): Recent advances in obesty research: III. Proceedings of the third International Congress on Obesity. Libbey: London, pp $85-93,1974$

Spiller GA, Handbook of dietary fiber in human nutrition. CRC Press, Inc.: Boca Raton, USA, 1993

Stunkard $\mathrm{AJ}$, Messick. S. The three-factor cating questionnaire to measure dietary restraint, disinhibition, and hunger. J.Psychosom. Res. 29: 71-83, 1985

Todd PA, Benfield P, Goa KL. Guar Gum. A review of its pharmacological properties, and use as a dietary adjunct in bypercholesterolaemia. Drugs 39: 917-928, 1990

Twomilehto J, Voutilainen $E_{y}$ Hutturen J, Vinni $S$, Homan $K$. Effect of guar gum on body weight and serum lipids in hypercholesterolemic females. Acta Med.Scand.208: 45-48, 1980

Uusitupa $M$, Silitonen $D$, Sawolainen $K$, Silvasti M, Pentilä I, Parviainen M. Metabolic and nutritional effects of long-term use of guar gum in the treatment of non-insulin dependent diabetes of poor metabolic control. J:Clin.Nutr.49: 345 351, 1989

Westerterp-Plantenga MS, Westerterp KR, Nicolson NA, Mordant A, Schoffelen PFM, ten Hoor F. The shape of the cumulative food intake curwe in humans, during basic and manipulated meals. Physiol Behav.47: 569-576, 1990

Wing RR. Changing diet and exercise behaviors in individuals at risk for weight gain. Obes.Res.3(suppl.2): $277 \mathrm{~s}-282 \mathrm{~s}, 1995$ 


\title{
Chapter 5
}

\section{The effectiveness of long-term supplementation of carbohydrate, chromium, fiber and caffeine on weight maintenance}

\author{
W.J. Pasman ${ }^{*}$, M.S. Westerterp-Plantenga ${ }^{* \#}$, and W.H.M. Saris ${ }^{*}$ \\ *Maastricht University, Maastricht, \#Open University, Heerlen, The Netherlands
}

Int.J.Obes. 21: 1143-1151, 1997

\begin{abstract}
Objective: To investigate whether supplementation of carbohydrate, chromium, dietary fiber and caffeine is effective for maintenance of weight-loss in the long-term.

Design: A longitudinal, double-blind, randomly assigned intervention study of 16 months with supplementation of 50 grams of carbohydrates (CHO), $200 \mu \mathrm{g}$ chromium-picolinate (Cr-Pic), 20 grams of soluble fiber and $100 \mathrm{mg}$ caffeine (CHO+) or 50 grams of plain CHO for 16 months besides a very low energy diet (VLED) during the first two months.

Subjects: 33 Female, obese subjects (age: $34.8 \pm 7.0$ yrs; BW: $85.5 \pm 10.0 \mathrm{~kg}$; BMI $31.2 \pm$ $3.7 \mathrm{~kg} \cdot \mathrm{m}^{-2}$ ) participated; 13 subjects were supplemented with $\mathrm{CHO}+; 11$ subjects were supplemented with $\mathrm{CHO}$ and 9 subjects served as a control group.

Measurements: Body weight, body composition, energy intake and blood parameters were measured before the VLED (0), after the VLED at 2 months (2), and at 4, 10 and 16 months. Results: The amount and course of relapse of BW was equal for the supplemented and control groups. The average regain at 16 months (the weight gained as a percentage of the total weight loss during the VLED) was $66.1 \pm 81.2 \%$, and was not different between the groups. No differences in body composition were found between the groups at 16 months. The CHO supplements resulted in significantly elevated En\% intake daily of $\mathrm{CHO}$ in both supplemented groups, although this did not result in less regain. Pearson correlation analysis for all subjects revealed that the more fat was consumed the more regain was found at 16 months ( $r=0.41, p<0.05)$. A high $\mathrm{CHO}$ consumption was correlated with less regain ( $r=-$ $0.40, \mathrm{p}=0.05$ ). Furthermore, chromium intake did not result in significant changes in blood parameters and body composition.

Conclusion: Although additional supplementation of $\mathrm{CHO}$, chromium, dietary fiber and caffeine intake did not affect BW, the En\% CHO daily was increased significantly. Our results indicate that a high En\% intake of $\mathrm{CHO}$ and a low En\% intake of fat daily is beneficial for prevention of weight regain.
\end{abstract}

\section{Introduction}

A low-fat diet, exercise and social support are important factors for successful weight maintenance (Kayman et al., 1990; DePue et al., 1995). However, results of long-term weight maintenance studies have been disappointing (Garner and Wooley, 199》; Rössner, 1992), indicating that incorporation of these success factors in normal life is difficult. An increasing number of studlies have indicated that obesity could take place as a result of 
overconsumption of fat, resulting in an overconsumption of energy (Lissner et. al., 1987; Dreon et al., 1988; Romieu et al., 1988; Barnard and Wen, 1994). Besides this, development of obesity could result from insulin resistance and hyperinsulinaemia, without consumption of excess calories (Barnard and Wen, 1994). Maintenance of increased levels of fasted adipose tissue lipoprotein lipase (LPL) and an increased response of adipose tissue LPL at insulin support the fast uptake and storage of fatty acids, resulting in weight gain (Eckel, 1992). Insulin resistance has therefore been suggested to be an adaptation to prevent ongoing weight gain, when energy intake/fat intake is high and energy expenditure is low (Eckel, 1992; Barnard and Wen, 1994).

Studies with ad libitum intake of energy with a high carbohydrate (CHO) energy percentage (En\%), like performed by Toubro and Astrup (1997), suggest that a change in macronutrient composition is essential for weight maintenance (Flatt, 1987; Astrup and Raben, 1995; Blaak and Saris, 1995). Besides a better weight maintenance, lowering of insulin resistance has been suggested to take place with lowering of the En\% fat to a high-carbohydrate diet, probably especially with complexed carbohydrates (Fukagawa et al, 1990; Barnard and Wen, 1994; McCarty, 1995). The high dietary fiber content of the diet would affect the hunger and satiety feelings in such a way that less energy will be consumed (Evans and Miller, 1975; Spiller, 1993).

Lowering of insulin resistance has further been suggested by McCarty (1993) with supplementation of chromium, since chromium potentiates the action of insulin. Furthermore, supplementation of chromium has been reported to have positive effects at blood lipid profiles (Mertz, 1993). Patients with insulin resistance syndrome, often suffer of dyslipidaemia and chromium supplementation would therefore effect both disorders (Lee and Reasner, 1994; Godsland and Stevenson, 1995). Besides stimulation of glucose-uptake, amino-acid uptake is stimulated by insulin too (Felig, 1984; Evans, 1989a; Evans, 1989b). A lowering of the insulin resistance would result in a higher amino-acid uptake. This anabolic effect of chromium has been reported to result in increase of lean body mass and lowering of fat mass (Evans, 1989a; Evans, 1989b).

The food elements carbohydrate, chromium and dietary fiber were suggested in relation to a

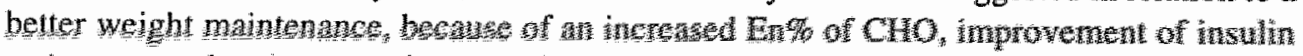

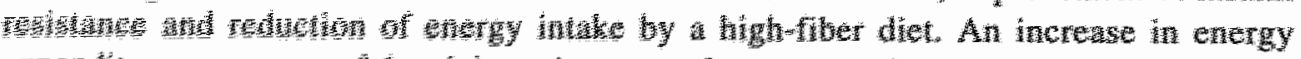

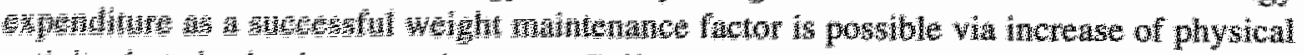

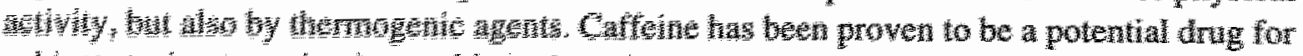

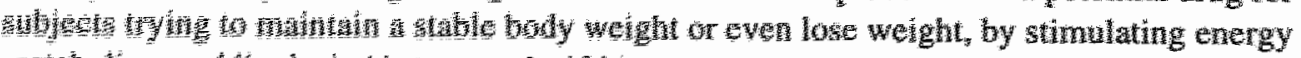

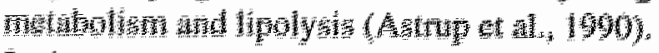

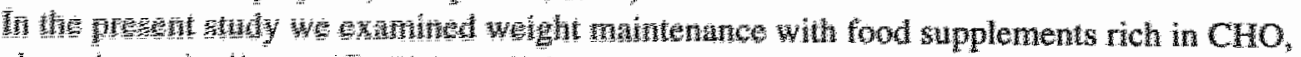

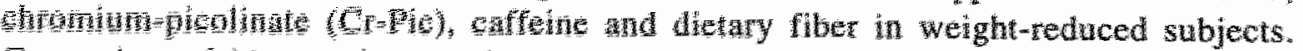

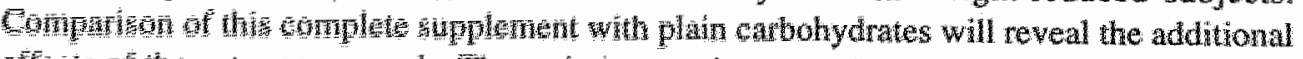

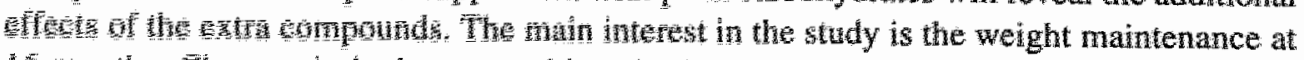

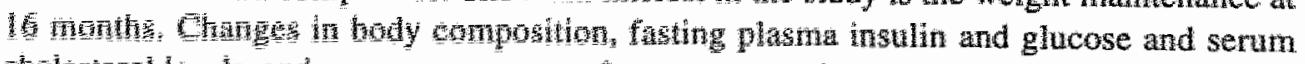
cholght

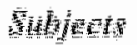

\section{Methods}

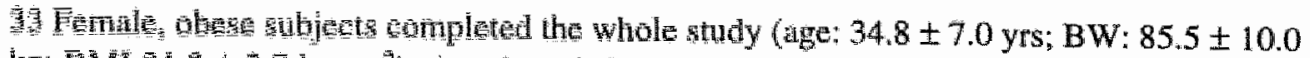

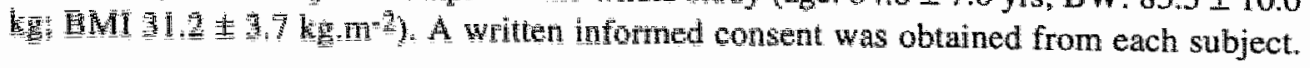


The study protocol was reviewed and approved by the Medical Ethical Committee of the Maastricht University.

\section{Drop-out information}

At the start of the study 49 subjects participated. Ten females dropped out of the study during the very low energy diet (VLED) period, because they were not able to follow the strict diet regime. 39 Subjects completed the VLED. 3 Subjects dropped out of the 16 month weight maintenance phase at 5 months, because of personal reasons. At 10 months again 3 subjects dropped out; 2 were not able to complete the tests and 1 complained about the supplement. Comparison of the baseline characteristics of the subjects who dropped out of the study with those who completed the study did not reveal any significant differences.

\section{Study protocol}

The subjects took part in a VLED intervention for eight weeks in order to lose weight. The VLED (Modifast ${ }^{\circledR}$, Novartis Nutrition, Bern, Switzerland) was supplied in three sachets daily which were dissolved with water, to obtain a milk-shake or dessert. Total energy intake during VLED was 2 MJ daily. The maintenance of body weight after VLED was followed for 16 months. The food supplement intervention during this period consisted of a carbohydrate, chromium-picolinate, soluble fiber (Benefiber ${ }^{\circledR}$ "Novartis Nutrition, Bern, Switzerland), caffeine supplement $(\mathrm{CHO}+)$, or supplementation with plain carbohydrates (CHO). The control group did not receive any intervention. Subjects were randomly assigned to a supplement or control group, and a double-blind administration of the supplement was carried out. Before ( 0 months) and after the VLED period ( 2 months) measurements were carried out. During the weight maintenance phase these measurements were repeated at 4,10 and 16 months. The study design is presented in fig.5.1.
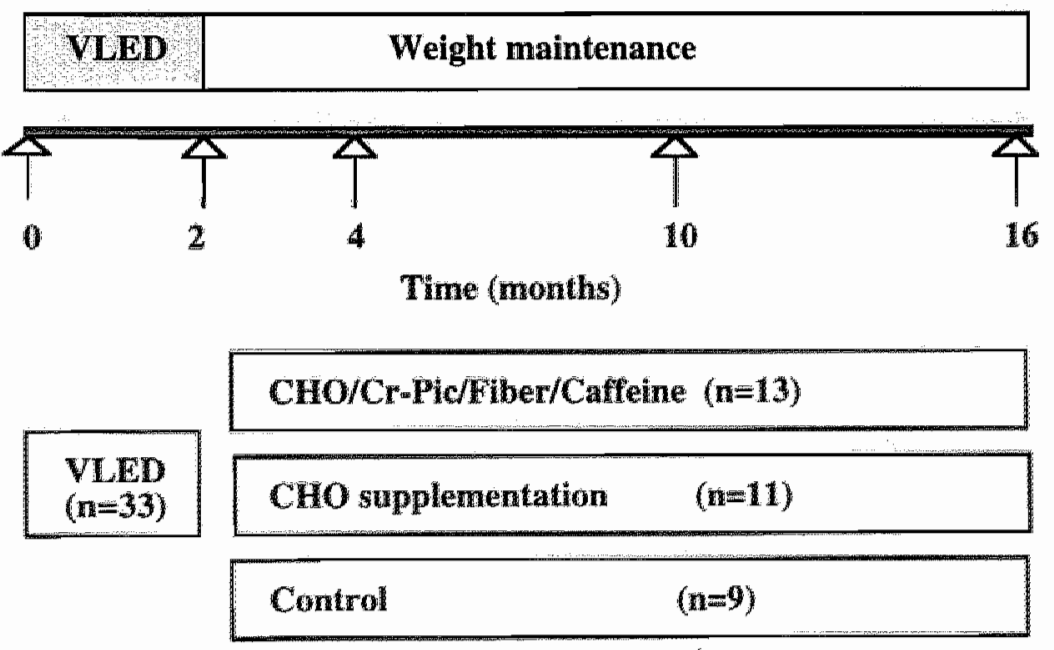

Fig. 5.1 Study design of the long-tern food supplementation study. Already during the 2 monthe of very low energy diet (VLED), 2 groups were supplemented daily with 2 different kinds of supplements $(\mathrm{CHO}+$ and plan $\mathrm{CHO})$. Measurements were perforned before the VLED $(0$ months), after the VLED (2 months), and at 4,10 and 16 months. 


\section{Food supplements}

The two supplements used differed in composition. The $\mathrm{CHO}+$ supplement contained 50 grams of carbohydrate ( $42 \%$ glucose and $58 \%$ maltodextrines), $200 \mu g$ chromiumpicolinate, 20 grams of soluble fiber (Benefiber ${ }^{(0)}$ ) and $100 \mathrm{mg}$ of caffeine. The CHO contained 50 grams of carbohydrates ( $42 \%$ glucose and $58 \%$ maltodextrines).

The supplement had to be dissolved with $250 \mathrm{ml}$ water to obtain a fresh juicy lemonade (flawors: peach, lemon and apple). The food supplements were prepared by Novartis Nutrition (Bern, Switzerland). The supplements were consumed once daily. Subjects were instructed to use this supplement in the afternoon to replace the usual in between drink such as a cup of tea or coffee and/or a fat containing snack.

\section{Measurements}

Subjects came to the lab after an overnight fast at $8.00 \mathrm{~h}$ am at $0,2,4,10$ and 16 months for different measurements.

\section{Blood analysis}

At all test days, fasted blood samples were obtained ( $10 \mathrm{ml}$ EDTA plasma and $10 \mathrm{ml}$ serum) of the subjects. Blood plasma was mixed with EDTA to prevent clotting, and immediately centrifuged. Serum was obtained by centrifugation of blood after one hour at room temperature. Plasma and serum samples were stored at $-80^{\circ} \mathrm{C}$ until further analysis. Plasma glucose was determined by means of a hexokinase method (Cobas Bio, Roche Diagnostics, Hoffmann-La Roche, Basle, Switzerland). Plasma insulin was measured using a double antibody radioimmunoassay for human insulin (Kabi Pharmacia Diagnostics AB, Uppsala, Sweden). Total cholesterol (CHOD-PAP method; Monotest cholesterol, Boehringer Mannheim, Mannheim, Germany), HDL cholesterol (precipitation method; Monotest cholesterol, Boehringer Mannheim, Mannheim, Germany) and triacylglycerols (GPOTrinder; Sigma Diagnostics, St. Louis) were analyzed enzymatically. LDL cholesterol concentration was calculated by using the Friedewald equation (Friedewald et al., 1972).

\section{Anthropometry}

Body weight (BW) was measured on a digital balance accurate to $0.1 \mathrm{~kg}$ (Sauter D-7470, Ebingen, Germany). Height was measured to the nearest $0.1 \mathrm{~cm}$ using a wall-mounted stadiometer (Seca, model 220, Hamburg, Germany). The body mass index (BMI) was calculated by weight and height $\left(\mathrm{kg} \cdot \mathrm{m}^{-2}\right)$. The distribution of fat was investigated by measuring waist and hip circumferences, the wailst-hip ratio (WHR) and the sagittal diameter. The waist circumference was measured at the smallest circumference between the rib cage and the ileac crest, with the subject in standing position. The hip circumference was measured at the level of the widest circumference between the waist and the thighs. The WHR was calculated by dividing the waist circumference by the hip circumference. For determination of the sagittal diameter, the distance between the abdomen and the back, a stadiometer was used with a subject in supine position.

Bio-impedance spectrometry

Multiple frequency bio-electrical impedance analyses was measured with a Xitron 4000 Multi-Frequency Bio-Impedance Analyzer (Xitron Technologies, San Diego). This device uses a four-electrode arrangement and measures reactance and phase angle of a conductor to injection of an alternating electric current. Tracets MP3000 (LecTec Corporation, Minnetonka, MN) electrodes were used. The applied frequency ranged from $1 \mathrm{kHz}$ to 1.35 MHz. Measurements were made while the subjects were lying comfortably on a polysterene mattress, with their legs slightly abducted to ensure no contact between the thighs. The arms 
relaxed at the side to prevent contact with the trunk. The electrodes were positioned at conventional locations on hand and foot. Measurements were made one-sited at the right site of the body. The calculations of FFM and FM were performed with Triton $4000 B$. Extracellular water (ECW) and intracellular water (ICW) were predicted from the general mixture theory. This implies that we used a formula that directly callculates the water compartments from resistance values, assuming specific resistance of $\mathrm{ECW}$ and $1 \mathrm{CW}$. The specific resistances used for women was extracellularl $y=146.4$ and intracellularl $y=947$; these values were obtained from an independent dataset of our laboratory (Marken Lichtenbelt et al., 1994; Marken Lichtenbelt et al., 1997).

\section{Energy intake}

The amount of food consumed during the 16 month study period was calculated with analysis of the completed food-intake diary. Subjects were asked to write down everything that was consurned (meals, drinks and snacks) at two normal week days and one weekend day at every time point of the study. After returning the diaries the portion size and household attributes were examined to give a good indication of the amount of food consumed. The diaries were analysed with the Dutch food table (Becel, 1989) and the accessory computer program.

\section{Compliance to supplement intake during the weight maintenance phase}

The supplemented subjects were asked to consume I sachet daily. Actual intake was checked by lists of supplement intake and counting of the returned sachets. The 24 supplemented subjects liked the supplement and hardly forgot consumption. Compliance was $86 \pm 15 \%$ on average for the $\mathrm{CHO}+$ group and $84 \pm 18 \%$ for the $\mathrm{CHO}$-group.

\section{Statistics}

Data are presented as mean and standard deviation ( $\pm \mathrm{sd}$ ). A two-way ANOVA with repeated measurements was used to compare differences in parameters across the groups over time. Changes in parameters measured with respect to the initial value were calculated as a percentage of the initial value. Statistical significance was set at $\mathrm{p}<0.05$.

Power analysis (power 0.80) was performed a priori based upon data of a previous supplementation study (Pasman et al., 1997a). A difference in regain between groups of $60 \%$ and a standard deviation of $60 \%$ revealed that we needed 3 groups of 12 subjects for our study. Based upon a drop-out estimation of \pm 10 subjects we started with 49 subjects.

\section{Results}

The physical characteristics of the subjects before the intervention are presented in table 5.1. For the anthropometric parameters measured (BW, WHR, sagittal diameter, body fat percentage, FFM and FM) two-way ANOVA analysis revealed significant differences over time for all parameters, but no differences among the three groups. Subjects lost on average $9.0 \pm 2.4 \mathrm{~kg}$ during the VLED (no differences between groups). Body weight decreased on average to $89.5 \pm 2.7 \%$ of the initial body weight. The changes in body weight are presented in fig.5.2, which illustrates weight fluctuation in the different groups during the study. The amount and course of changes in BW was equal for the supplemented and control groups. At 16 months of the study all three groups had still significantly lower BW than at month 0 . The classification of subjects according to the amount of weight regained at 16 months (as a percentage of the weight lost during the VLED) is shown in fig.5.3. The average regain at 16 months was $66.1 \pm 81.2 \%$, and was similar for the groups $(51.1 \pm$ $109.0 \%$ for $\mathrm{CHO}+; 68.1 \pm 55.2 \%$ for $\mathrm{CHO}$ and $85.5 \pm 55.8 \%$ for the control group). 
Leaving one subject of the $\mathrm{CHO}+$ group out of the analysis because of ongoing weight loss during the weight maintenance phase, resulted in a percentage of $76.6 \pm 62.7$ at 16 months for the $\mathrm{CHO}+$ group. In fig. 5.3 it is shown that $31 \%$ of the $\mathrm{CHO}+\mathrm{group}, 36 \%$ of the CHO group and $21 \%$ of the control group regained less than $50 \%$ of the weight lost.

Table 5.1 Baseline characteristics

\begin{tabular}{|c|c|c|c|}
\hline & $\mathrm{CHO}+$ & $\mathrm{CHO}$ & Control \\
\hline Number & 13 & 11 & 9 \\
\hline Age (yrs) & $36.2(7.0)$ & $32.6(7.4)$ & $35.6(6.5)$ \\
\hline Height (m) & $1.69(0.02)$ & $1.63(0.07)$ & $1.65(0.03)$ \\
\hline Weight (kg) & $86.3(8.5)$ & $85.5(13.5)$ & $84.2(7.7)$ \\
\hline $\mathrm{BMI}\left(\mathrm{kg} \cdot \mathrm{m}^{-2}\right)$ & $30.4(0.89)$ & $32.1(4.6)$ & $31.2(3.5)$ \\
\hline WHR & $0.81(0.04)$ & $0.81(0.05)$ & $0.82(0.06)$ \\
\hline Sagg $(\mathrm{cm})$ & $20.3(1.7)$ & $21.2(2.6)$ & $20.7(1.6)$ \\
\hline BPsys(mm Hg) & $125.1(12.3)$ & $125.1(14.9)$ & $134.4(16.5)$ \\
\hline BPdia $(n m \mathrm{Hg})$ & $83.0(9.7)$ & $85.1(13.6)$ & $86.9(11.3)$ \\
\hline glucose $\left(\right.$ mmol $\left.L^{-1}\right)$ & $5.10(0.46)$ & $5.29(0.15)$ & $5.31(0.53)$ \\
\hline insulin $\left(\mu \mathrm{U}_{\mathrm{m}} \mathrm{ml}^{-1}\right)$ & $10.3(3.6)$ & $13.4(5.2)$ & $13.9(4.6)$ \\
\hline
\end{tabular}

The data of all 33 subjects before the study are presented and compared for the three groups. No significant differences were found in physical characteristics. Mean and standard deviations (in parentheses) are presented. BMI: Body Mass Index; WHR: Waist-Hip Ratio; BDsys: systolic blood pressure; BDdia: diastolic blood pressure.
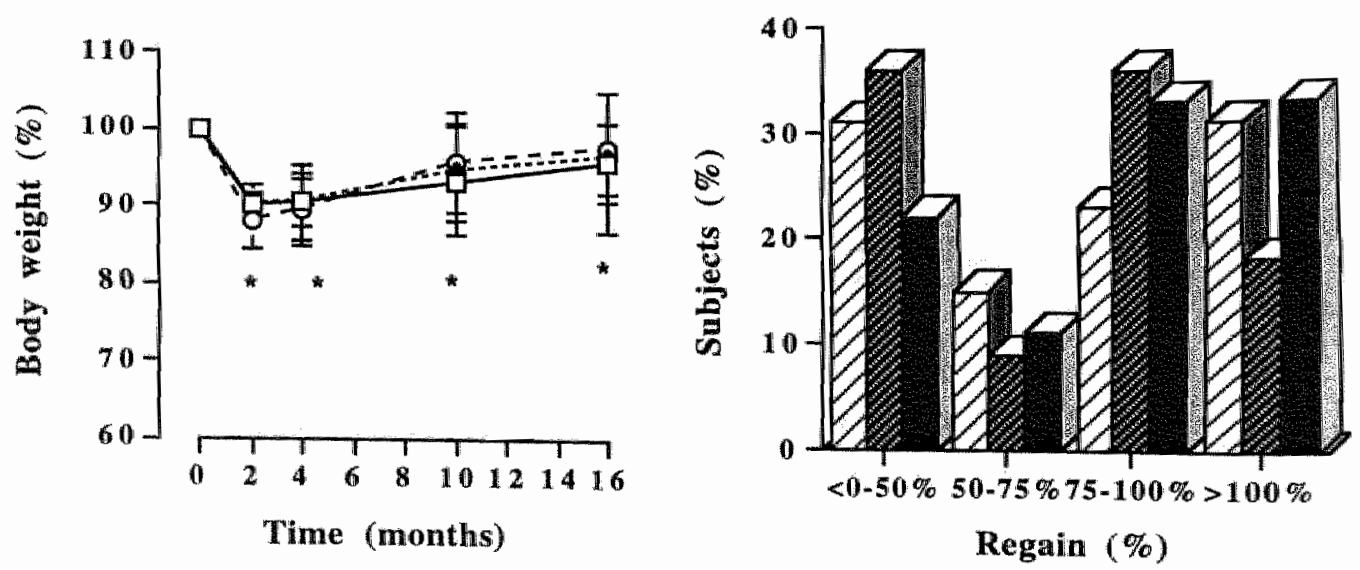

Fig. 5.2 (left the changes in body weight arre expressed as a percentage of the initial value. The mean and standard deviation are presented at different time points measured, for the CHO+ group (open squares), CHO group (filled diamonds) and control-group (open cincles).

Fig. 5,3 (right) Weight regain is presented as a percentage of the amount of weight lost during VLED. The VLED intervention resulted in a significant weight loss for all three groups. The amount of weight liost during the VLED was set at $100 \%$. The percentage of subjects of the three groups that gained different amounts of $\mathrm{BW}$ are presented for the $\mathrm{CHO}+$ group (light hatched bars), CHO-group (dark 
Fat free mass (FFM) and fat mass (FM), as was measured with bio-impedance, are presented in fig.5.4. No differences in body composition were found between the groups. although clear differences were found over time. FFM was at 16 months still significantly lower compared to baseline values. For FM this was not found; although BW was still lower at 16 months, FM was already completely the same as at the beginning of the study (see fig.5.4).

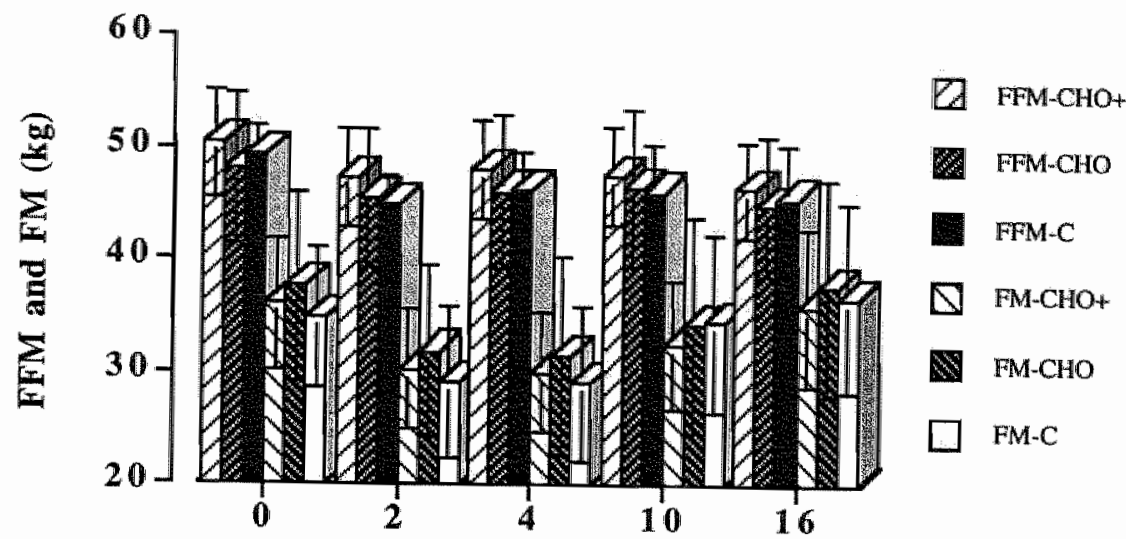

Time (months)

Fig.5.4 The absolute amount of fat free mass and fat mass are shown for the CHO + group (light hatched bars), CHO-group (dark hatched bars) and control group (unicoloured bars) at the different time points of the siudy.

Serum cholesterol data and fasted plasma glucose and insulin levels are presented in table 5.2. No influence of CHO supplementation or the additional compounds was found, meaning that there were no differences among the 3 groups in this study. Comparable changes over time were found for the three groups caused by the VLED intervention. Because an extra intake of 50 grams of CHO daily would affect mácronutrient composition of the diet, the energy intake and composition are shown (table 5.3). The El differed significantly over time, but was similar in the three groups. Significant differences in CHO energy percentage (En\%) intake were found between the two supplemented groups and the control group; En\% CHO intake was significantly higher during the supplenented phase in the $\mathrm{CHO}+(52.0 \mathrm{En} \%$ of $\mathrm{CHO})$ and $\mathrm{CHO}$ group (50.3 En\% CHO) compared with the control group (42.9 En\% CHO) (two-way ANOVA; $<<0.01$ among groups). Pearsoncorrelation analysis revealed that overall, for the whole group, the more En\% of CHO was ingested daily (average intake at 10 and 16 months) the less regain took place ( $r=0.40$, $\mathrm{p}=0.05$ ) (fig.5.5a). When corrected for energy-intake a partial correlation coefficient for CHO intake and body weight regain of -0.40 was found ( $\mathrm{p}<0.05$ ). For the average fat intake at 10 and 16 months a positive relation with regain of BW was found as is showa in fig. $5.5 b ; r=0.41 \quad(p<0.05)$. Correction for energy-intake revealed a partal correlation coefficient of 0.40 of fat intake and body weight ( $p<0.05$ ). Relative changes in SW were also significantly correlated with the En\% of CHO and fat intake at 10 and 16 months. The En\% of $\mathrm{CHO}$ intake and relative changes in $\mathrm{BW}$ at 10 and 16 months was $r=-0.54(\mathrm{p}=0,01)$ 


\section{Chapter 5}

and $r=-0.42(\mathrm{p}<0.05)$, respectively, indicating that a higher En\% of $\mathrm{CHO}$-intake is correlated with less changes in $\mathrm{BW}$. For En\% fat intake positive relations were found; at 10 months $r=0.45(p<0.05)$ and at 16 months $r=0.49(p<0.05)$.

Table 5.2 Blood parameters

\begin{tabular}{|c|c|c|c|c|c|}
\hline & Month 0 & Month 2 & Month 4 & Month 10 & Month 16 \\
\hline \multicolumn{6}{|c|}{ Total cholesterol (mmol.L-1)* } \\
\hline $\mathrm{CHO}+$ & $51 \pm 1.1$ & $4.5 \pm 0.8$ & $5.1 \pm 0.9$ & $5.3 \pm 11.2$ & $5.3 \pm 0.9$ \\
\hline $\mathrm{CHO}$ & $4.9 \pm 0.9$ & $4.3 \pm 1.0$ & $4.8 \pm 1.0$ & $4.9 \pm 1.0$ & $5.0 \pm 1.0$ \\
\hline contral & $5.9 \pm 0.5$ & $4.9 \pm 0.5$ & $5.3 \pm 0.5$ & $5.9 \pm 1.0$ & $6.0 \pm 0.8$ \\
\hline \multicolumn{6}{|c|}{ HDL (minol.L-1)* } \\
\hline $\mathrm{CHO}_{+}$ & $1.3 \pm 0.5$ & $1.3 \pm 0.2$ & $4.5 \pm 0.2$ & $1.7 \pm 0.3$ & $1.6 \pm 0.3$ \\
\hline $\mathrm{CHO}$ & $1.3 \pm 0.3$ & $1.1 \pm 0.3$ & $1.4 \pm 0.2$ & $1.6 \pm 0.4$ & $1.4 \pm 0.2$ \\
\hline control & $1.5 \pm 0.3$ & $1.4 \pm 0.3$ & $1.4 \pm 0.3$ & $1.6 \pm 0.3$ & $1.6 \pm 0.4$ \\
\hline \multicolumn{6}{|c|}{ LDL (mmoil. $\left.\operatorname{LL}^{-1}\right) *$} \\
\hline $\mathrm{CHO}+$ & $3.3 \pm 1.1$ & $2.9 \pm 0.8$ & $3.4 \pm 1.0$ & $3.3 \pm 1.0$ & $3.3 \pm 0.9$ \\
\hline CHO & $3.2 \pm 0.7$ & $2.8 \pm 0.8$ & $3.1 \pm 0.9$ & $3.1 \pm 0.9$ & $3.3 \pm 1.0$ \\
\hline control & $3.9 \pm 0.4$ & $3.1 \pm 0.4$ & $3.5 \pm 0.6$ & $3.9 \pm 0.8$ & $3.8 \pm 0.6$ \\
\hline \multicolumn{6}{|c|}{ Glucose (mmol:L' $\left.{ }^{1}\right)^{*}$} \\
\hline $\mathrm{CHO}+$ & $5.1 \pm 0.5$ & $4.7 \pm 0.4$ & $4.9 \pm 0.4$ & $4.9 \pm 0.4$ & $4.7 \pm 0.4$ \\
\hline $\mathrm{CHO}$ & $5.3 \pm 0.5$ & $4.8 \pm 0.4$ & $5.0 \pm 0.4$ & $4.9 \pm 0.3$ & $4.7 \pm 0.3$ \\
\hline control & $5.3 \pm 0.5$ & $4.8 \pm 0.4$ & $4.9 \pm 0.5$ & $4.9 \pm 0.3$ & $4.7 \pm 0.5$ \\
\hline \multicolumn{6}{|c|}{ Insulin (mmol. $\left.\mathrm{L}^{-1}\right)^{*}$} \\
\hline $\mathrm{CHO}+$ & $10.3 \pm 3.6$ & $9.0 \pm 2.8$ & $10.0 \pm 3.1$ & $11.1 \pm 3.1$ & $9.4 \pm 1.9$ \\
\hline $\mathrm{CHO}$ & $13.5 \pm 5.2$ & $10.1 \pm 3.9$ & $11.8 \pm 5.1$ & $11.9 \pm 4.8$ & $10.1 \pm 3.0$ \\
\hline control & $13.9 \pm 4.6$ & $8.8 \pm 2.7$ & $9.3 \pm 2.0$ & $12.6 \pm 3.5$ & $10.5 \pm 4.1$ \\
\hline
\end{tabular}

Serum cholesterol levels are shown for the three groups. Total cholesterol, HDL and LDL data are presented for the three groups in mmol. $\mathrm{L}^{-1}$. Glucose and insulin data are also presented in mmol...-1. Mean and standard deviations are presented. significant difference over time $(\mathrm{p}<0.05)$ 


\section{Long-term weight maintenance}

Table 5.3 Energy intake and macronutrient composition

\begin{tabular}{|c|c|c|c|c|c|}
\hline & Month 0 & Month 2 & Month 4 & Month 10 & Month 16 \\
\hline \multicolumn{6}{|l|}{ EI (MJ day $\left.{ }^{-1}\right)^{*}$} \\
\hline $\mathrm{CHO}+$ & $8.6 \pm 2.9$ & $6.6 \pm 1.7$ & $6.8 \pm 1.3$ & $7.4 \pm 2.1$ & $8.0 \pm 1.8$ \\
\hline $\mathrm{CHO}$ & $8.9 \pm 2.1$ & $7.7 \pm 2.1$ & $8.3 \pm 1.2$ & $9.0 \pm 2.1$ & $8.1 \pm 1.5$ \\
\hline Control & $9.1 \pm 3.2$ & $5.6 \pm 1.9$ & $6.6 \pm 2.5$ & $6.6 \pm 1.7$ & $7.6 \pm 1.9$ \\
\hline \multicolumn{6}{|c|}{ Protein $\left(\mathrm{En} \% \%^{*}\right)^{*}, \#$} \\
\hline $\mathrm{CHO}+$ & $15.3 \pm 3.1$ & $17.0 \pm 2.4$ & $15.7 \pm 2.3$ & $14.4 \pm 2.1$ & $14.9 \pm 2.0$ \\
\hline $\mathrm{CHO}$ & $13.8 \pm 1.3$ & $13.8 \pm 2.5$ & $13.4 \pm 2.7$ & $11.8 \pm 1.7$ & $13.1 \pm 1.8$ \\
\hline Control & $14.9 \pm 3.9$ & $21.3 \pm 5.3$ & $17.3 \pm 3.3$ & $15.5 \pm 2.0$ & $14.8 \pm 3.4$ \\
\hline \multicolumn{6}{|l|}{ CHO (En\%) } \\
\hline $\mathrm{CHO}_{+}$ & $41.1 \pm 4.3$ & $53.6 \pm 5.8$ & $52.9 \pm 5.4$ & $52.7 \pm 4.6$ & $48.8 \pm 4.4$ \\
\hline $\mathrm{CHO}$ & $45.8 \pm 6.9$ & $52.1 \pm 4.3$ & $49.6 \pm 3.6$ & $49.4 \pm 4.2$ & $50.3 \pm 5.0$ \\
\hline Control & $39.1 \pm 7.1$ & $41.8 \pm 7.4$ & $43.6 \pm 8.2$ & $44.1 \pm 8.8$ & $42.0 \pm 8.1$ \\
\hline \multicolumn{6}{|l|}{ Fat (En\%) } \\
\hline $\mathrm{CHO}+$ & $40.9 \pm 6.2$ & $28.4 \pm 6.8$ & $29.0 \pm 5.7$ & $31.3 \pm 4.3$ & $34.7 \pm 4.2$ \\
\hline $\mathrm{CHO}$ & $37.9 \pm 5.3$ & $32.2 \pm 3.5$ & $35.3 \pm 3.6$ & $38.4 \pm 3.7$ & $36.0 \pm 5.6$ \\
\hline Control & $39.4 \pm 5.6$ & $30.5 \pm 8.3$ & $32.4 \pm 9.2$ & $35.3 \pm 9.0$ & $37.1 \pm 7.1$ \\
\hline \multicolumn{6}{|l|}{ Alcohol $(\mathrm{En} \%) \#$} \\
\hline $\mathrm{CHO}+$ & $2.7 \pm 3.6$ & $1.0 \pm 1.3$ & $2.4 \pm 2.7$ & $1.7 \pm 2.0$ & $1.6 \pm 2.6$ \\
\hline $\mathrm{CHO}$ & $2.5 \pm 3.8$ & $1.9 \pm 2.8$ & $1.6 \pm 2.0$ & $0.3 \pm 0.7$ & $0.6 \pm 1.1$ \\
\hline Control & $6.6 \pm 7.1$ & $6.4 \pm 8.3$ & $6.7 \pm 7.1$ & $5.2 \pm 5.0$ & $6.1 \pm 6.3$ \\
\hline \multicolumn{6}{|c|}{ Fiber (g.day $\left.{ }^{-1}\right)^{*}$} \\
\hline $\mathrm{CHO}+$ & $14.8 \pm 3.7$ & $32.4 \pm 1.6$ & $33.8 \pm 3.5$ & $33.1 \pm 4.0$ & $35.3 \pm 4.4$ \\
\hline $\mathrm{CHO}$ & $12.7 \pm 4.1$ & $12.4 \pm 4.5$ & $12.4 \pm 3.9$ & $14.2 \pm 4.8$ & $12.2 \pm 4.0$ \\
\hline Control & $14.5 \pm 5.5$ & $12.2 \pm 4.0$ & $12.8 \pm 3.3$ & $14.0 \pm 4.5$ & $14.5 \pm 3.9$ \\
\hline
\end{tabular}

Mean energy intake (MJ.day ${ }^{-1}$ ) of 24 completed food intake diaries are presented at different time points of the study for the three groups. * significant difference over time $(\mathrm{p}<0.05)$; \# significant difference between groups $(\mathrm{p}<0.05)$ 

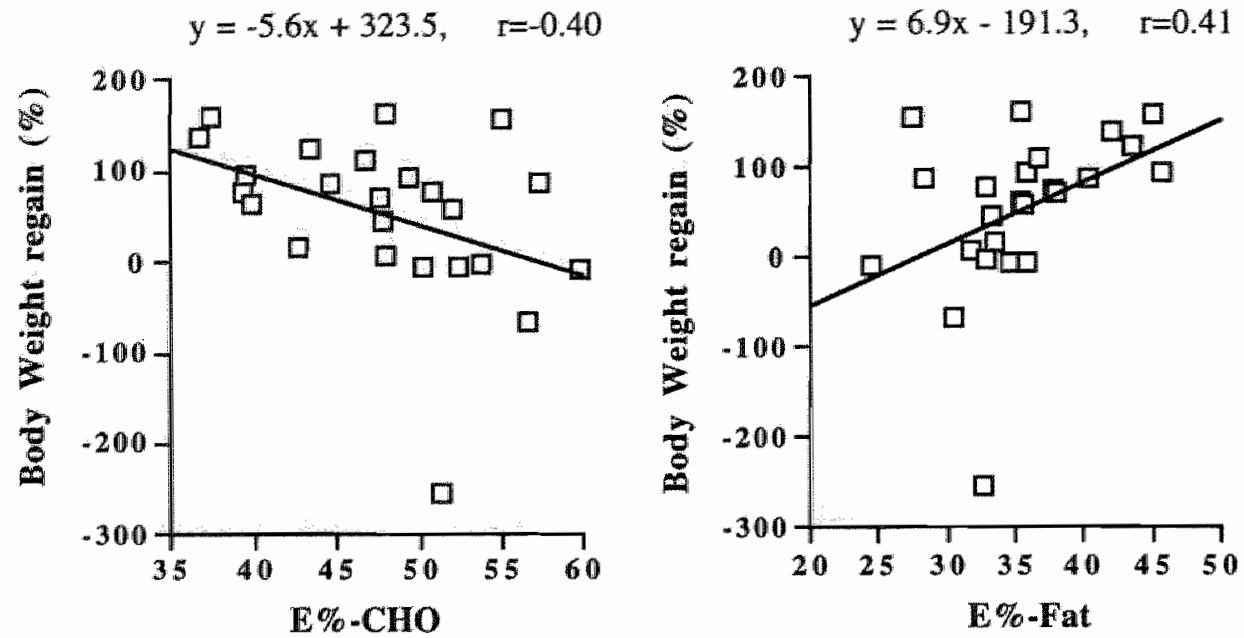

Fig. 5.5 The relation between the total En\% CHO intake daily and regain of body weight at 16 months is shown for the whole group (fig.5.5a: left). The negative relation found indicates that the more $\mathrm{CHO}$ were consumed, the less regain was found. The relation between the total En\% fat intake daily and regain of body weight at 16 months is shown for the whole group (fig.5.5b: right). Regain was higher when more fat was consumed.

\section{Discussion}

In this study an attempt was made to improve weight maintenance success over a 14 month period by means of a food supplement in order to increase the $\mathrm{CHO}$, fiber, caffeine and chromium content of the diet. All components have a potential capacity to facilitate weight maintenance. The results did not show a beneficial effect at weight maintenance, al though the increased En of CHO of the whole day was related to lowered weight regain. It can however not be ruled out that the number of subjects participating in our study was too small. Based upon results of weight maintenance with fiber supplementation (Pasman et al., 1997 a) we calculated that with a power of 0.80 a difference in regain of $60 \%$ could be detected, with this number of subjects. The results of the study indicate that the supplement affectiveness was far below the calculated power.

Weight maintenance and macronutrient intake

The $\mathrm{CHO}$-containing supplements used in the present study did not result in weight maintenance. Studies with replacement of fat with carbohydrates (CHO) have been carried out to manipulate lipid balance. In ad libitum food intake studies an energy percentage of 55\% (Shah et al., 1994; Siggaard et al., 1996; Toubro and Astrup, 1997) have shown positive outcomes at weight maintenance and weight loss. The theory of Flatt, that fat storage will not take place when $F Q>R Q$, illustrates that a high $C H O$ diet will improve weight maintenance (Flatt, 1987; Flatt, 1993). This theory is supported by our findings that, when all subjects were studied as one group because no differences in regain of BW were found between the groups, the En\% of $\mathrm{CHO}$ intake was negatively related with $\mathrm{BW}$-regain. 
The more CHO were consumed, the less regain took place. Calculated from the regression line, no regain took place when $57 \mathrm{En} \%$ of $\mathrm{CHO}$ were consumed. Fat-intake was positively correlated with BW-regain; more En\% of fat intake showed more regain of BW (En\% intake of fat of $28 \%$ revealed no regain) . No relation between total energy intake and regain of $\mathrm{BW}$ at 16 months was found. Partial regression analysis revealed still significant correlation coefficients between the macronutrient intake and $\mathrm{BW}$ regain. These results support the theory that macronutrient composition is of importance in addition to total energy intake consumed daily (Prewitt et al., 1991; Astrup and Raben, 1995; Siggaard et al., 1996; Toubro and Astrup, 1997). This result agrees with the general finding that high-fat diets result in obesity (Lissner et al., 1987; Raben and Astrup, 1996). The fact that supplementation of $\mathrm{CHO}$ as we performed in this study is not effective for weight maintenance, but overall increased $\mathrm{CHO}$-intake and lowered fat-intake is related to less $\mathrm{BW}$ regain, seems to suggest that supplementation of one food element is not the solution for maintenance of a stable BW. The total food consumed during the day, especially under free living conditions, is of more importance. It should therefore be emphasized that normal food consumption during the day should contain low-fat and $\mathrm{CHO}$-rich food products for beneficial effects at weight maintenance.

Body composition

In the studies described by Evans, showing an effect of $\mathrm{Cr}$-Pic supplementation on body composition, the body fat percentages were determined with skin folds measurements (Evans, 1989a; Exans, 1989b). Knowing the inaccurateness of this method in obese subjects (Gray et al., 1990; Kooy et al., 1992), we studied body composition by bio-impedance. No differences in body fat percentage was found between the three groups as a consequence of Cr-Pic supplementation. Our results are in agreement with Trent and Thieding-Cancel (1995) who studied the effect of $400 \mu \mathrm{g}$ of $\mathrm{Cr}$-Pic at body composition. Although they used a higher dosage of $\mathrm{Cr}$-Pic that is suggested to be more effective particularly in men, no effect at body fat percentage was found. Other studies used hydrodensitometry, known as a quallitative good method for body composition determination (Lukaski, 1987). Densitometry was used by Clancy et al. (1994) and Hallmark et al. (1996) who also found no effect of 200 $\mu \mathrm{g}$ of $\mathrm{Cr}$-Pic supplementation besides fitness training of 9 and 12 weeks respectively at body composition.

Calculation of the Body Composition Improvement-score (BCI-score) as performed by Kats and coworkers (1996) to study the effect of Cr-Pic supplementation, did not result in differences between the groups in this study. Our results are in contrast with the results of Kaats and colleagues (1996) who found positive changes in body composition after 72 days of supplementation of 200 and $400 \mu \mathrm{g}$ of Cr-Pic. The addition of fat mass losses and increases in fat free mass resulted in negative BCI-scores for all groups in the present study ( $\mathrm{CHO}+:-3.9 \pm 4.3 ; \mathrm{CHO}:-3.2 \pm 4.2$; Control: $-5.6 \pm 3.5$ ), indicating that the intervention in the long-term resulted in an impaired body composition. Therefore the anabolic effect of chromium remains under debate.

Effectiveness of Cr-Pic at blood parameters

Although positive effects of chromium supplementation have been found with respect to glucose tolerance (Mertz, 1993), the results of our study indicate that supplementation with Cr-Pic was not effective at fasted glucose and insulin levels. A possible explanation would be that the subjects participating in this study were not $\mathrm{Cr}$-deficient (as discussed below). With respect to the lipid metabolism Mertz reported that 4 of 8 studies found no and 4 studies 
found positive effects of chromium supplementation at cholesterol (Mertz, 1993). Although the effect of supplementation is not clear yet Newman already reported in 1978 that serum chromium levels was significantly lower in patients with coronary artery disease (CAD) (Newman et al, 1978). Serum chromium was even suggested to be a clinical parameter for prediction of future $C A D$. The effect of chromium supplementation at $C A D$ is however not answered with these findings.

Several explanations why no specifie effect of $\mathrm{Cr}$-Pic supplementation was found are possible. The first and most important possible explanation could be that the participating subjects had no insulin resistance and were not chromium-deficient. The fasted plasma glucose and insulin levels of our subjects were not pathological (plasma glucose $<8$ mmol. $\mathrm{L}^{-1}$ and plasma insulin $\left.<20 \mathrm{mU} . \mathrm{L}^{-1}\right)$. This was further supported by the finding that the area under the curves (AUC) of the oral glucose tolerance tests (OGTT), performed in the two supplemented groups (data not shown), did not change at all with supplementation of $\mathrm{CHO}+$ or CHO. In the United States based upon results with self-selected diets it is assumed that $90 \%$ of the population have deficient chromium-intake $(<50 \mu \mathrm{g}$ daily) (Anderson and Kozovsly, 1985). This will however not necessarily mean that the risk factor for impaired glucose tolerance is increased. Uusitupa and coworkers found that although elderly subjects in Finland consumed on average less than $30 \mu \mathrm{g}$.day ${ }^{-1} \mathrm{of} \mathrm{Cr}$, this was not found to be an important risk factor for impaired glucose tolerance. Long-term supplementation of $160 \mu \mathrm{g}$ of $\mathrm{Cr}$ per day was not effective for normalization of glucose and insulin metabolism (Uusitupa et al., 1992).

Compliance of the supplement intake was thoroughly checked and appeared to be high $(85 \%)$ and is therefore ruled out as a possible explanation for finding no effects of supplementation. The chelating agent for chromium, picolinic acid, has been studied by Evans $(1989 \mathrm{a} ; 1989 \mathrm{~b})$ and was suggested to be the best chelating agent for $\mathrm{Cr}$. The dosage of Cr-Pic supplemented in this study ( $200 \mu \mathrm{g}$ daily $\sim 4 \mu \mathrm{mol} \mathrm{Cr}$ daily) was in the same range as used in other studies, that for example proofed to be effectively lowering cholesterol (Mertz, 1993), triglyceride levels (Lee and Reasner, 1994), improve insulin sensitivity (Mertz, 1993), and had beneficial effects at body composition (lowering of fat mass and increase of fat free mass) (Evans, 1989a; Evans, 1989b; Kaats et al., 1996). Therefore the dosage of chromium supplemented was not the limitation in this study, however the combination of $\mathrm{Cr}-\mathrm{Pic}$ with other mutrients (like $\mathrm{CHO}$ and dietary fiber) could be, resulting in a lowered uptake of $\mathrm{Cr}$-Pic.

Of the other ingredients conflicting results have been found before. Although caffeine is known for its thermogenic effect and stimulation of thermogenesis (Toubro et al., 1993), this was not always found (Astrup et al., 1990). The same is true for the ingredient dietary fiber. Dietary fiber was found to be effective as a supplement in short-term studies (Pasman et al., 1997b), however in our previous long-term fiber supplementation study no beneficial effects were found with respect to weight maintenance (Pasman et al., 1997a).

Conclusion

Supplementation of $\mathrm{CHO}$, in combination with $\mathrm{Cr}-\mathrm{Pic}$, dietary fiber and caffeine or plain $\mathrm{CHO}$, has no beneficial effect at weight maintenance in the long-term. No changes in body composition, glucose, insulin and cholesterol were found, suggesting that supplementation was not effective under free living conditions. However, overall En\% of CHO-intake and fat-intake were significantly correlated with BW-regain, indicating that macronutrient 
composition of the diet influences regain of $\mathrm{BW}$. Altention should be given to the macronutrient composition of the total food consumed during the day, to stimulate $\mathrm{CHO}$-rich and low-fat food consumption in normal daily life.

\section{References}

Anderson RA, Kozovsly AS. Chromium intake, adsorption and excretion of subjects consuming self-selected diets. Am.J.Clin.Nutr.41: 1177-1183, 1985

Astrup A, Toubro S, Cannon $S$, Hein P, Breum L, Madson J. Caffeine: a double-blind, placebo-controlled study of its thermogenic, metabolic, and cardiovascular effects in healthy volunteers. Am.J.Clin.Nutr. 51: 759-767, 1990

Astrup A, Raben A. Carbohydrate and obesity. Int.J.Obes.19 (Suppl. 5): S27-S37, 1995

Barnard RJ, Wen SJ. Exercise and diet in the prevention and control of the metabolic syndrome. Sports Med.18: 218-228, 1994

Becel, Nederlandse Voedingsstoffenbestand (NEVO). Dutch nutrient database 1989/1990. Zeist, The Netherlands: Stichting NEVO (in Dutch), 1989

Blaak EE, Saris WHM. Health aspects of various digestible carbohydrates. Nutr.Res.15: 1547-1573, 2995

Clancy SP, Clarckson PM, DeCheke ME, Nosaka K, Freedson PS, Cunningham JJ, Valentine B. Effects of chromium picolinate supplementation on body composition, strength, and urinary chromium loss in football players. Int.J.Sport Nutr.4: 142-1.53, 1994

Dreon DM, Frey-Hewitt B, Ellsworth N, Williams PT, Terry RB, Wood PD. Dietary fat: carbohydrate ratio and obesity in middle-aged men. Am.J.Clin.Nutr.47: 995 1000, 1988

DuPue JD, Clark MM, Ruggiero L, Medeiros ML, Pera V. Maintenance of weight loss; a needs assessment. Obes.Res. 3: 241-248, 1995

Eckel RH. Insulin resistance: an adaptation for weight maintenance. Lancet 340: 1452-1453, 1992

Evans E, Miller DS. Bulking agents in the treatment of obesity. Nutr.Metab.18:199-203, 1975

Ewans GW. The effect of chromium picolinate on insulin controlled parameters in humans. Int.J.Biosocial. Med.Research 11: 163-180, 1989(a)

Evans GW. The picolinates - How they help build muscle writhout steroids - and their other heal th benefits. In: RA Passwater, E Mindell, eds. A good health guide. Connecticut: Keats Publishing, Inc. New Canaan, pg:1-24, 1989(b)

Felig $P$. Insulin is the mediator of feeding-related thermogenesis: insulin resistance and/or deficiency results in a thermogenic defect which contributes to the pathogenesis of obesity. Clin.Phys.4: 267-273, 1984

Flatt JP. Dietary fat, carbohydrate balance, and weight maintenance: effects of exercise. Am.J.Clin.Nutr.45: $296-306,1987$

Flatt JP. Dietary fat, carbohydrate balance, and weight maintenance. Ann.N.Y. Acad.Sci.683: 122-140, 1993

Friedewald WT, Levy RI, Fredrickson DS. Estimation of the concentration of low-density lipoprotein cholesterol in plasma, without use of the preparative ultracentrifuge. Clin. Chem.18: 499-502, 1972

Fukagawa NK, Anderson JW, Hageman G, Young VR, Minaker KL. High-carbohydrate, high-fiber diets increase peripheral insulin sensitivity in healthy young and old adults. Am.J.Clin.Nutr.52: $524-528,1990$

Garner DM, Wooley SC. Confronting the failure of behavioral and dietary treatments for obesity. Clin. Psych.Rev.11: 729-780, 1991

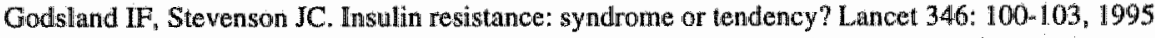

Gray DS, Bray GA, Bauer M, Kaplan K, Gemayel N, Wood R, Greenway F, Kirk S. Skinfold thickness measurements in obese subjects. Am.J.Clin.Nutr.51: 571-577, 1990

Hallmark MA, Reynolds TH, DeSouza CA, Dotson CO, Anderson RA, Rogers MA. Effects of chromium and resistive training on muscle strength and body composition. Med.Sci.Sports Exerc.28: 139-144, 1996

Kaats GR, Blum K, Fisher JA, Adelman JA. Effects of chromium picolinate supplementation on body composition: a randomized, double-masked, placebo-controlled study. Current Ther.Res.57: 747-756. 1996

Kayman S, Bruwold W, Stern J. Maintenance and relapse after weight loss in women: behavioral aspects. Am.J.Clin.Nutr. 52: 800-807, 1990

Kooy Kvd, Leenen R, Deurenberg P, Seidell JC, Westerterp KR, Hautvast JGAJ. Changes in fat-free mass in obese subjects after weight loss: a comparison of body composition measures. Int.J.Obes.16: 675-683, 1992

Lee NA, Reasner CA. Beneficial effect of chromium supplementation on serum triglyceride levels in NIDDM. Diab.Care 17: 1449.1452, 1994 
Lissner L, Levitsky DA, Strupp BJ, Kalkwarf HI, Ro DA. Dietary fat and the regulation of energy intake in human subjects. Am.J.Clin.Nutr.46: 886 892, 1987

Lakaski HC. Methods for the assessment of human body composition : traditional and new. Am.J.Clin.Nutr. 46: $537-556,1987$

Marken Lichtenbelt WD wan, Westerterp KR, Wouters L, Luijendijk, SCM. Validation of bioelectricalimpedance measurements as a method to estimate body-water compartments. Am.J.Clin. Nutr.60: 159166, 1994

Marken Lichteribelt WD van, Snel YEM, Brummer RJM, Koppeschaar HPF. Deuterium and bromide dilution, and bioimpedance spectrometry independently show that growth hormone-deficient adults have an enlarged extracellular water compartment related to intracellular water. J.Clin.Endocrin. Metab.82: 907 911,1997

McCarty MF. Insulinin resistance in mexican Americans - a precursor to obesity and diabetes? Med. Hypotheses 41: 308-315, 1993

McCarty MF. Reduction of free falty acids may ameliorate risk factors associated with abdominal obesity. Med. Hypotheses 44: 278-286, 1995

Mertz W. Chromium in thuman nutrition: a review. J.Nutr.123: 626 633, 1993

Newman HAI, Leighton RF, Lanese RR., Freedland NA. Serum chromium and angiographically determined coronary artery disease. Clin.Chem.24: 541-544, 1978

Pasman WJ, Westerterp-Plantenga MS, Muls E, Vansant G, wan Ree J, Saris WHM. The effectiveness of long-term fiber supplementation on weight maintenance in weight-reduced women. Int.J.Obes.21: 548$555,1997 \mathrm{a}$

Pasman WJ, Wauters M, Westerterp-Plantenga MS, Saris WHM. Effect of one week of fibre supplementation on hunger and satiety or energy intake. Appetite 29:77-87, 1997b

Prewitt TE, Schmeisser D, Bowen PE, Aye P, Dolecek TA, Langenberg P, Cole T, Brace, L. Changes in body weight, body composition, and energy intake in women fed high- and low-fat diets. Am.J.Clin.Nutr.54: 304-310, 1991

Raben A, Astrup A. Manipulating carbohydrate content and sources in obesity prone subjects: effect on energy expenditure and macronutrient balance. Int.J.Obes. 20: S24-S30, 1996

Romieu I, Willett WC, Stampfer MJ, Colditz GA, Sampson L, Rosner B, Hennekens CH, Speizer FE. Energy intake and other determinants of relative weight. Am.J.Clin.Nutr.47: 406-412, 1988

Róssner $S$. Factors determining the long-term outcome of obesity treatment. In: Björntorp $P$, Brodoff $B N_{\text {, }}$ ed.: Obesity, J.B. Lippincott Company, Philadelphia, 1992, pg: 712-719.

Shah $M$, McGovern $P$, French $S$, Baxter J. Comparison of a low-fat, ad libitum complex-carbohydrate diet with a low-energy diet in moderately obese women. Am.J.Clin.Nutr.59: 980-984, 1994

Siggaard R, Raben A, Astrup A. Weight loss during 12 weeks' ad libitum carbohydrate-rich diet in overweight and nomal-weight subjects at a Danish work site. Obes. Res.4: 347-356, 1996

Spiller GA. Handbook of dietary fiber in human autrition. CRC Press, Inc, second edition, Bocia Raton, USA, 1993

Toubro S, Astrup A, Breum L, Qyaade F. The acute and chronic effects of ephedrine/caffeine mixtures on energy expenditure and glucose metabolisim in humans. Int.J.Obes.17(Suppl.3): S73-S77, 1993

Toubro S, Astrup A. Randomised comparison of diets for maintaining obese subjects' weight after major weight loss: ad lib, low fat, high carbohydrate diet $v$ fixed energy intake. B.M.J.314: 29-34, 1997

Trent LK, Thieding-Cancel D. Effects of chromium picolinate on body composition. J.Sports Med.Phys. Fitness 35: 273-280, 1995

Uusitupa MIJ, Mykkanen $L_{s}$, Siitonen $O$, Laakso M, Sarlund $H$, Kolehmainen $P_{n}$ Råsänen $T$, Kumpulainen $\mathrm{J}_{\text {\# }}$ Pyörälä. Chromium supplementation in impaired glucose tolerance of elderly: effects on blood glucose plasma insulin, C-peptide and lipid levels. Br.J.Nutr.68: 209-216, 1992 


\title{
Chapter 6
}

\section{The effect of exercise training on long-term weight maintenance in weight-reduced men}

\author{
Wilrike J. Pasman", Wim H.M. Saris*, Erik MulsI, Greet Vansantll and Margriet S. \\ Westerterp-Plantenga *\# \\ * Maastricht University, Maastricht, Open University, Heerlen, The Netherlands \\ II Departments of Endocrinology, Metabolism and Nutrition and Clinical Chemistry, \\ University Hospital Gasthuisberg, Leuven, Belgium
}

Metabolism (Accepted)

\begin{abstract}
In this study we investigated whether endurance training is effective for successful weight maintenance in the long-term, after weight reduction.

15 Male, obese subjects (age: $37.3 \pm 5.2$ yrs; BW: $96.2 \pm 13.6 \mathrm{~kg} ; \mathrm{BMI}: 30.9 \pm 2.8 \mathrm{~kg} \cdot \mathrm{m}^{-2}$ ) participated in 16 months exercise intervention study. During the first 4 months all subjects trained 3-4 times weeklly, also keeping a very low energy diet (VLED) during the first 2 months. After the 4 months treatment period 7 subjects contimued training for 12 months (34 times.week ${ }^{-1}$ ) and 8 control subjects trained 1-2 times.week ${ }^{-1}$.

Regain (increase of a variable during the intervention period as a percentage of the 4 month treatment) of BW at 16 months was $64 \%$ ( $\pm 26 \%$ ) for the whole group (trained (T): $52 \pm$ $28 \%$ ws control $(\mathrm{C}): 74 \pm 20 ; \mathrm{p}=0.09$ ). The increase in absolute fat mass (FM) was significantly lower at 16 months for the trained group ( $\mathrm{T}_{:} 4.8 \pm 1.9 \mathrm{~kg}$ vs C: $9.0 \pm 3.3 \mathrm{~kg}$ ), as was regain of FM at 16 months (T: $61 \pm 24 \%$ vs $\mathrm{C}: 92 \pm 32 \% ; \mathrm{p}=0.05$ ). The amount of regain of the waist circumference, waist-hip ratio and sagittal diameter were correlated with the amount of training hours performed weekly ( $(\Delta$ waist $)=-0.55, p<0.05 ; \mathrm{r}(\Delta W H \mathrm{HR})=$ $0.50, p=0.06 ; \mathrm{r}(\Delta \mathrm{sag})=-0.53, \mathrm{p}<0.05)$. Physical fitness variables (maximal power output and oxygen uptake) were significantly increased in both groups at 4 months. The trained subjects maintained the high levels of physical fitness at 16 months, in contrast to the control group.

In conclusion, although BW regain was not significantly different in both groups, the trained showed less regain of fat mass and higher levels of physical fitness, factors related with lower risk factors for CVD, compared to the control group. Furthermore, the regain of FM which occured even in the exercising group suggests that maintenance of fat loss is extremely difficult.
\end{abstract}

\section{Introduction}

Obesity defined as a body mass index (BMI) $>30 \mathrm{~kg} \cdot \mathrm{m}^{-2}$, is known to be related to increased risks of cardiovascular diseases (CVD), hypertension and diabetes mellitus (Stamler et al., 1978; Hubert et al., 1983; Kromhout et al., 1983). The prevalence of obesity has increased in the United States (Kuczmarski et al., 1994), as well as in Europe (Seidell, 
1995). Weight loss intervention programs are usually successful, however results with respect to weight maintenance in the long-term are disappointing (Sjöström, 1974; Garner and Wooley, 1991; Rössner, 1992). Obesity is caused by a chronic positive energy balance. A positive energy balance is mainly caused by a positive lipid balance (Flatt, 1993). To accomplish weight reduction by a negative fat balance, obese subjects should limit their fat intake and/or increase fat oxidation (Tremblay and Buemann, 1995). Increased fat oxidation might be accomplished by means of exercise training. Bouchard and colleagues (1993) suggest that obese subjects should have an exercise prescription that results in long-term negative energy balance. This would be the case if endurance exercise of moderate intensity, of long duration and preferably performed on a daily basis would take place (Bouchard et all., 1993; Saris, 1996). Another beneficial effect of this type of exercise is the reduction of risk factors of CVD known to be related with obesity (Bouchard et al, 1993; Barnard and Wen, 1994; Katzel et al., 1995). Buemann and Tremblay reviewed the use of physical training as a nonpharmacological tool in the treatment of abdominal obesity and associated metabolic diseases (1996). With endurance training obese males show losses of visceral fat (Tremblay and Buemann, 1995). It is known that obesity, and upper-body obesity in particular, is related to increased cardiovascular risk factors like insulin resistance, hypertension and elevated plasma LDL-levels (Katzel et al., 1995; Weidner et al., 1995; Buemann and Tremblay, 1996). Moreover inactivity has been found to be correlated with increased risk of CVD (Blair et al., 1989). Therefore regular endurance exercise might not only increase fat oxidation, but also induce positive changes with respect to lowering of risk factors for CVD (Bouchard et al., 1993; Saris, 1996; Buemann and Tremblay, 1996). Based upon the afore mentioned poor success rates of weight maintenance in the long-term, we hypothesized that subjects with a recent weight loss are most vulnerable in regaining weight and the best subjects in studies of long-term intervention strategies to study weight maintenance. Therefore it is hypothesized in the present study that regular endurance exercise would be beneficial with respect to long-term weight maintenance in weight-reduced subjects and lowering of risk factors for cardiovascular diseases.

\section{Methods}

\section{Subjects}

16 Malle, obese subjects recruited by an advertisement in the local newspaper, participated in this study (age $37.3 \pm 5.2 \mathrm{yrs}$; $\mathbb{B W}: 96.5 \pm 13.6 \mathrm{~kg}$; BMI: $30.9 \pm 2.8 \mathrm{~kg} \cdot \mathrm{m}^{-2}$ ). The very low energy diet (VLED) was started with 16 male obese subjects. 15 subjects completed the VLED-period and one subject was not able to keep the strict diet regime and was therefore excluded from the protocol. A written informed consent was obtained from each subject at the start of the study. The study protocol was reviewed and approved by the Medical Committee of the Maastricht University.

Study design

All subjects took part in an endurance training program during the first 4 months of the study, that also included a very low energy diet (VLED) of 2 months, in order to lose weight. The VLED used provided $2 \mathrm{MegaJ}$ oule daily and was a protein-enriched formula diet (44 percentage of energy protein; 14 percentage of energy fat; 42 percentage of energy carbohydrate). The VLED was supplied in three sachets daily which were dissolved with water, to make a milk-shake or dessert. After two months the energy intake was free. All subjects took part in the endurance training program during the first 4 months of the study, 
to prevent a fast rebound after the VLED and to have a not significantly different starting point to study weight maintenance. They ran and cycled at a moderate intensity for at least one hour, 3-4 times a week and were professionally coached. After 4 months 7 subjects continued the training sessions at a triathlon club where they were able to swim, cycle and run in group sessions ( $3-4$ times. week $^{-1}$ ), supervised by a coach (trained group). Eight subjects served as a control group during the 12 months intervention period and trained on average 1-2 times a week. The study design is presented in fig. 1 .

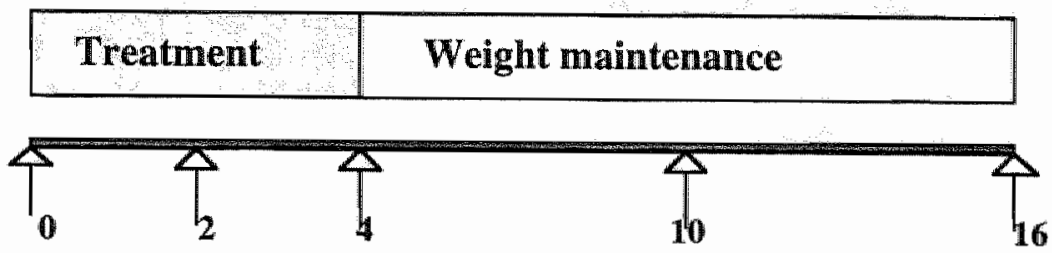

Time (months)

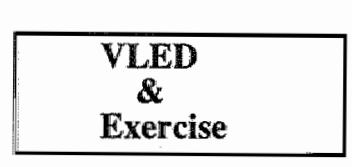

Exercise $(n=7), 3-4$ times a week

No treatment $(n=8)$

Fig.6.I Study design of the long-term exercise intervention study. All subjects participated in a training program during the first four months (3-4times weekly), the first 2 months of which they were on a VLED. After 4 months only one group continued the exercise training. Measurements were carried out at $0,2,4,10$ and 16 months as indicated by the arrows.

\section{Compliance to endurance training during the weight maintenance phase}

Compliance to training sessions was checked in multiple ways. A training diary was used for day-to-day activities and remarks (illness, injury, weather conditions, etc), by all participants. Besides the training diaries, questionnaires were filled in at the laboratory when measurements took place, to check frequency of training (amount of training hours a week) by all subjects. The investigator visited training sessions of the triathlon club frequently to examine compliance during the 12 month follow-up period. Compliance to the prescribed training sessions was $89 \pm 26 \%$ for the trained group in the intervention period.

\section{Measurement protocol}

After an overnight fast subjects came to the laboratory at $0,2,4,10,16$ months at 8.00 am for different measurements.

Resting Metabolic Rate

Resting metabolic rate was measured for 45 minutes at $8.00 \mathrm{~h}$ am. Subjects came to the lab by car or public transport to minimize physical activity. Oxygen consumption and carbon dioxide production were measured by means of an open circuit ventilated hood system (Human Biology, Maastricht, University Maastricht, The Netherlands). Measurement of energy expenditure was based upon the Weir formulas (Weir, 1949).

Blood analysis

At all test days, fasted blood samples were obtained ( $10 \mathrm{ml}$ EDTA plasma and $10 \mathrm{ml}$ serum) of the subjects. Blood plasma was mixed with EDTA to prevent clotting, and immediately centrifuged. Serum was obtained by centrifugation of blood after one hour at room 
temperature. Plasma and serum samples were stored at $-80^{\circ} \mathrm{C}$ until further analysis. Total cholesterol, LDL and HDL cholesterol, triglycerides; apo-al and apo-b were determined as described by Muls and coworkers (1993).

\section{Anthropometry}

Subjects were weighed on a digital balance accurate to $0.1 \mathrm{~kg}$ (Sauter D-7470, Ebingen, Germany). Height was obtained to the nearest $0.1 \mathrm{~cm}$ using a wall-mounted stadiometer (Seca, model 220, Hamburg, Germany). The body mass index (BMI) was calculated by BW*height ${ }^{-2}\left(\mathrm{~kg} \cdot \mathrm{m}^{-2}\right)$. The distribution of fat was investigated by measuring the waist and hip circumferences and calculation of the waist-hip ratio (WHR) and sagittal diameter. The waist circumference was measured at the smallest circumference between the rib cage and the ileac crest, with the subject in standing position. The hip circumference was measured at the level of the widest circumference between the waist and the thighs. The WHR was calculated by dividing the waist circumference by the hip circumference. For determination of the sagittal diameter (sag.ø), the distance between the abdomen and the back, a stadiometer was used with a subject in supine position.

The deuterium dilution technique was used for measurement of body composition in this study (Schoeller et al.., 1980). ${ }^{2} \mathrm{H}_{2} 0$ dilution was used to measure total body water (TBW). Subjects were asked to collect an urine sample in the evening just before drinking the deuterium enriched water solution. After consumption of this solution no further consumption was allowed. Ten hours after drinking the water solution another urine sample was collected. The dilution of the deuterium isotope is a measure for total body water of the subject (Marken Lichtenbelt et al., 1994). Deuterium was measured in the urine samples with an isotope ratio mass spectrometer (VG-Isogas Aqua Sira). TBW was obtained by dividing the measured deuterium dilution space by 1.04 (Schoeller et al., 1980). Fat free mass was calculated by dividing the TBW by the hydration factor 0.73 . By subtracting FFM from BW, fat mass (FM) was obtained. FM expressed as a percentage of BW revealled body fat percentage (BF\%).

\section{Physical fitness}

To investigate the effect of the training program on performance capacity (maximal oxygen uptake: $\mathrm{VO}_{2} \max$ ) and maximal power output (Wmax), an incremental exercise test was performed on an electromagnetically braked cycle ergometer (Lode, Groningen, The Netherlands). After a warm-up period of 9 minutes ( 5 minutes at $40 \mathrm{~W}$ and 4 minutes at 80 W) the workload was increased every minute with $20 \mathrm{~W}$ until exhaustion. The maximal power output was calculated using the total time cycled at the exercise test. The highest workload completed for 1 minute (Wcompleted) and the number of seconds $(X)$ that the final increase of $20 \mathrm{~W}$ was maintained, were added, according to the following formula: Wmax = Wcompleted $+((X / 60) * 20)$. Criteria for maximal performance were forced ventilation, leveling off of oxygen uptake or a respiratory exchange ratio (RER) above 1.1. The oxygen uptake during the test was measured continuously, using a computerized open system (Oxycon Beta, Mijnhardt, Bunnik, The Netherlands).

Statistics

A two-way Anova with repeated measurements was used to compare variables across the groups. Data are presented as means and standard deviation ( $\pm \mathrm{sd}$ ). Changes in variables measured were expressed as a percentage of the baseline value. Pearson-correlations were calculated between training hours and regain of BW; regain of FM; waist circumference; 
sagittal diameter; Wmax and $\mathrm{VO}_{2}$ max. For all statistics the significance level was set at $\mathrm{p}<0.05$.

\section{Resullts}

Baseline characteristics are shown in table 1. No significant differences were found between the groups in physical characteristics before the study. At 4 months, when the two groups appeared, physical characteristics were even more similar. BW at 4 months was $82.0 \pm 10.8$ $\mathrm{kg}$ for the trained ws $85.6 \pm 13.8 \mathrm{~kg}$ for the controls (NS). BMI was $26.3 \pm 2.2 \mathrm{~kg} \cdot \mathrm{m}^{-2}$ for the trained w $27.3 \pm 2.2 \mathrm{~kg} \cdot \mathrm{m}^{-2}$ for the controls (NS). Sagittal diameter was $18.1 \pm 1.5 \mathrm{~cm}$ at 4 months for the trained and $18.9 \pm 1.9 \mathrm{~cm}$ for the controls (NS). Body fat percentage was also not significantly different at 4 months $(21.8 \pm 3.8 \%$ for the trained $v s 24.1 \pm 4.2 \%$ for the control group).

Table 6.l Baseline characteristics of the 15 male subjects

\begin{tabular}{llll}
\hline & Trained & Control & $\mathrm{p}$ \\
\hline Number & 7 & 8 & \\
Age (yrs) & $38.0(3.9)$ & $36.6(6.3)$ & $\mathrm{NS}$ \\
BW (kg) & $93.1(14.5)$ & $99.5(12.9)$ & $\mathrm{NS}$ \\
height $(\mathrm{m})$ & $1.76(0.07)$ & $1.77(0.13)$ & $\mathrm{NS}$ \\
BMI $\left(\mathrm{kg} \cdot \mathrm{m}^{-2}\right)$ & $29.8(3.0)$ & $31.8(2.3)$ & NS \\
WHR & $0.95(0.04)$ & $0.96(0.04)$ & NS \\
Sagittal $(\mathrm{cm})$ & $22.7(2.2)$ & $24.8(2.2)$ & NS \\
Body fat $(\%)$ & $28.0(3.4)$ & $31.0(3.0)$ & NS \\
\end{tabular}

Data of 15 male, obese subjects before the study are presented. No statistical significant (NS) differences were found in baseline characteristics between both groups. Means and standard deviations (in parentheses) are presented.

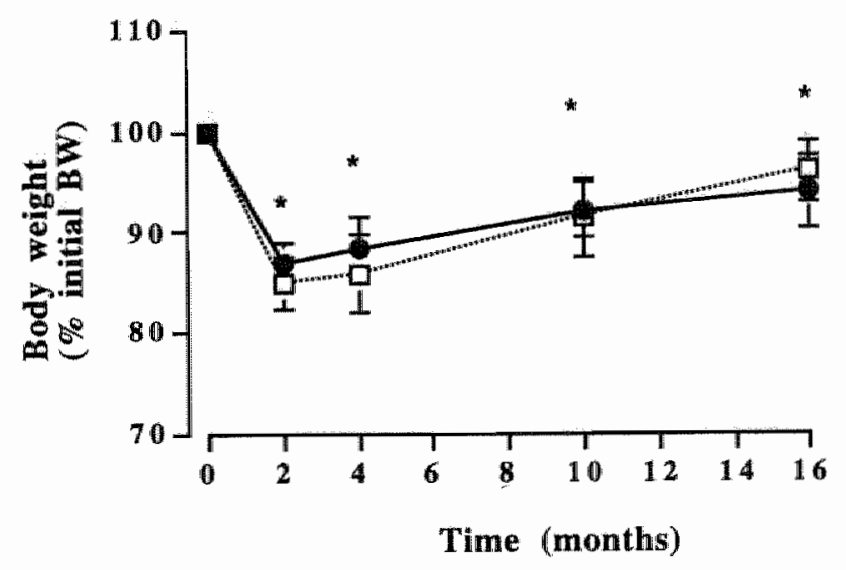

Fig.6.2 The changes in body weight are expressed as a percentage of the initial value. The mean and standard deviation are presented at different time points measured for the trained group (filled circles) and the control group (open squares). * denote significant differences compared to baseline BW for both groups 


\section{Chapter 6}

\section{Body weight and fat mass changes}

Changes in relative BW (expressed as a percentage of the baseline value) are presented in fig 6.2 for the trained and the control group. No differences were found between the two groups over the whole study period with respect to absolute $B W$ or relative $B W$.

Over time significant changes were found in relative $\mathbb{B W}$ for both groups. The weight lost during the four month treatment period was not significantly different between both groups; the trained lost $11.1 \pm 4.5 \mathrm{~kg}$ and the control group lost $13.9 \pm 2.8 \mathrm{~kg}$. The relative $B W$ at 16 months $(94.0 \pm 3.6 \%$ for the trained $v s 96.0 \pm 3.0 \%$ for the control) was still significantly lower for both groups $v$ the beginning of the study (fig.6.2).

When the amount of weight lost during the 4 month treatment period was set at $100 \%$ and regain of weight during the 12 months follow-up is expressed as a percentage of the treatment-loss, 3 subjects in the trained group were able to regain less than $50 \%$ at 16 months $v s 1$ subjects of the control group. Seven out of 8 subjects of the control group regained more than $50 \%$ of the weight-lost $v s 4$ out of 7 in the trained group. Overall regain of body weight at 16 months was $64 \%( \pm 26 \%$ ) for the whole group ( $52 \pm 28 \%$ for the trained vs $74 \pm 20 \%$ for the control; $t(1,13)=-1.84, \mathrm{p}=0.09$. There was no significant correlation between training hours per week and regain of $\mathrm{BW}$ at 16 months $(r=0.41$; $\mathrm{p}=0.13$ ).

The changes in fat free mass ( $\triangle F F M$ ) and in fat mass ( $\triangle F M)$ are shown in fig.6.3 for the treatment period ( $0-4$ months) and the intervention period (4-16 months). Regain of FM during the intervention period was significantly lower for the trained group $v s$ the control group. At 16 months regain of FM was $4.8 \pm 1.9 \mathrm{~kg}$ FM corresponding to $61 \pm 24 \%$ regain of FM for the trained compared to $9.0 \pm 3.3 \mathrm{~kg} \mathrm{FM}$, corresponding with $92 \pm 32 \%$ regain of FM for the controls.

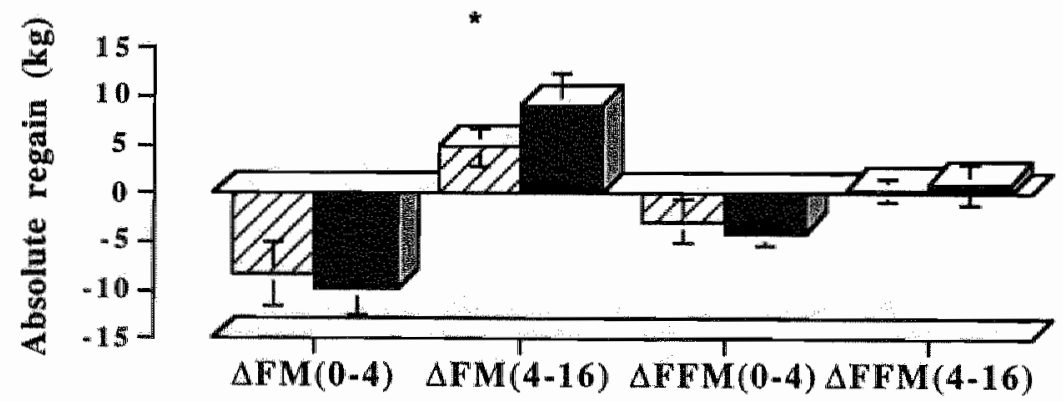

\section{Changes in body composition}

Fig. 6.3 "The changes of FFM and FM during the treatment period (0-4 months) and during the intervention period (4-16 months) are presented for the trained group (hatched bars) and control group (filled bars).

Physical fitness

In table 6.2 the results of the maximal performance tests are presented. At 4 months comparable increases in maximal power output and maximal oxygen uptake were measured for both groups. The increase in physical fitness at 4 months was significantly higher compared with baseline for both groups ( 34 and $41 \%$ increase for Wmax.kg-1 BW and 30 and $36 \%$ for $\mathrm{VO}_{2}$ max. $\mathrm{kg}^{-1} \mathrm{BW}$, for the trained and control group resp.). A significantly 
higher Wmax was found at 10 and 16 months for the trained group compared to the control group. The $\mathrm{VO}_{2}$ max was also higher at 10 months $(\mathrm{p}<0.05)$ and at 16 months $(\mathrm{p}=0.07)$ for the trained group. In fig.6.4 the changes in $\mathrm{Wmax}$ and $\mathrm{VO}_{2}$ max are presented as percentages of baseline and as a percentage of the performance at 4 months. During the intervention period (4-16 months) the trained group maintained their increased levels of physical fitness, while the control group showed poorer performances at 16 months compared with 4 months. The difference in $\mathrm{Wmax}$ at 10 and 16 months was significant between the groups.

Table 6.2 Physical titness

\begin{tabular}{|c|c|c|c|c|c|}
\hline Month & 0 & 2 & 4 & 10 & 16 \\
\hline \multicolumn{6}{|c|}{$W_{\max }\left(W \cdot k g B W^{-1}\right)$} \\
\hline $\mathrm{T}$ & $2.7(0.3)$ & $3.4(0.5)$ & $3.6(0.2)$ & $3.4(0.3)^{*}$ & $3.4(0.3)^{*}$ \\
\hline $\mathrm{C}$ & $2.6(0.2)$ & $3.1(0.3)$ & $3.7(0.4)$ & $3.2(0.2)$ & $2.9(0.2)$ \\
\hline \multicolumn{6}{|c|}{$\mathrm{VO}_{2} \max \left(\mathrm{ml} \cdot \mathrm{min}^{-1} \cdot \mathrm{kg} \mathrm{BW}^{-1}\right)$} \\
\hline $\mathrm{T}$ & $32.7(3)$ & $40.8(5)$ & $42.6(3)$ & $39.2(4)^{*}$ & $39.0(4)^{*}$ \\
\hline C & $31.3(5)$ & 39.1 (4) & $42.3(5)$ & $34.7(3)$ & $35.3(2)$ \\
\hline
\end{tabular}

Absolute data of maximall power output (Wmax) and maximal oxygen uptake (VO2max) are shown for the trained group $(T)$ and the control group $(C)$ at different time points. $* p<0.05$ between groups; ${ }^{*} p=0.07$ between groups

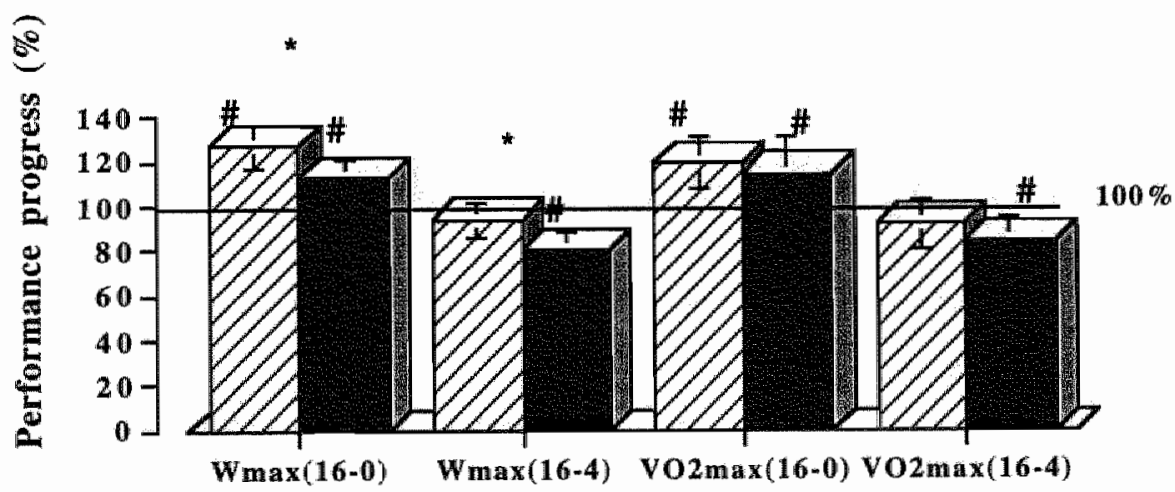

Changes in physical fitness

Fig.6.4 The maximal power output (Wmax) and maximal oxygen uptake (VO2max) at 16 months are presented as a percentage of the performance delivered at 0 months at the start of the study or at 4 months. The trained group (hatched bars) and the control group (filled bars) are presented. * denotes significant differences between the two groups, \# significant difference from $100 \%$.

\section{Cardiovascular risk factors}

Parameters of interest for CVD such as blood pressure and blood cholesterol, did not differ between the groups as a consequence of the exercise training. However, due to the treatment 


\section{Chapter 6}

period the systolic and diastolic blood pressure decreased significantly. Diastolic blood pressure decreased on average from $95.3 \pm 10.1 \mathrm{~mm} \mathrm{Hg}$ to $87.4 \pm 9.3 \mathrm{~mm} \mathrm{Hg}$ at 4 months. The diastolic blood pressure was still decreased at 16 months for both groups $(88.2 \pm 9.4$ mm Hg). The systolic blood was significantly decreased at 4 months $(132.0 \pm 12.8 \mathrm{~mm} \mathrm{Hg}$ vs $125.5 \pm 13.7 \mathrm{~mm} \mathrm{Hg}$ ). At 16 months the systolic blood pressure had retumed to baseline values $(130.1 \pm 13.0 \mathrm{~mm} \mathrm{Hg})$.

In table 6.3 baseline cholesterol data of the two groups are shown. Significant changes over lime were found for all cholesterol fractions caused by the VLED program, but not as a consequence of the training intervention. Over time the cholesterol data returned to baseline values in both groups. Because of initial differences in cholesterol levels between the groups, interpretation of the data is difficult.

Table 6.3 Cholesterol data

\begin{tabular}{|c|c|c|c|c|}
\hline Month & & 0 & 4 & 16 \\
\hline \multirow[t]{2}{*}{ Total Cholesterol } & $\mathrm{T}$ & $6.9 \pm 1.9^{*}$ & $6.0 \pm 1.0^{\#}$ & $6.3 \pm 1.3$ \\
\hline & $\mathrm{C}$ & $5.0 \pm 1.4$ & $4.7 \pm 1.6$ & $5.1 \pm 1.4$ \\
\hline \multirow[t]{2}{*}{ HDL } & $\mathrm{T}$ & $1.1 \pm 0.2$ & $1.3 \pm 0.2$ & $1.2 \pm 0.2^{\#}$ \\
\hline & $\mathrm{C}$ & $1.0 \pm 0.3$ & $1.2 \pm 0.4$ & $1.0 \pm 0.2$ \\
\hline \multirow[t]{2}{*}{ LDLL } & $\mathrm{T}$ & $4.7 \pm 1.6^{*}$ & $4.1 \pm 1.0^{*}$ & $4.4 \pm 1.2^{*}$ \\
\hline & C & $2.9 \pm 1.1$ & $2.8 \pm 1.1$ & $3.1 \pm 0.9$ \\
\hline \multirow[t]{2}{*}{ Triglycerides } & $\mathrm{T}$ & $1.6 \pm 0.9$ & $0.8 \pm 0.3$ & $1.1 \pm 0.5$ \\
\hline & $\mathrm{C}$ & $1.7 \pm 0.5$ & $1.0 \pm 0.3$ & $1.6 \pm 0.6$ \\
\hline \multirow[t]{2}{*}{ Apo-A1 } & $\mathrm{T}$ & $126.8 \pm 19.4$ & $142.7 \pm 19.0$ & $131.0 \pm 17.7$ \\
\hline & $\mathrm{C}$ & $114.6 \pm 28.3$ & $126.3 \pm 35.2$ & $119.3 \pm 20.2$ \\
\hline \multirow[t]{2}{*}{ Apo-B } & $\mathrm{T}$ & $104.2 \pm 28.5^{*}$ & $90.0 \pm 20.0^{f}$ & $100.2 \pm 25.0^{\#}$ \\
\hline & $\mathrm{C}$ & $74.3 \pm 22.8$ & $66.4 \pm 21.9$ & $78.4 \pm 20.7$ \\
\hline
\end{tabular}

Total cholesterol, Figh Density Lipoprotein (HDL), Low Density Lipoprotein (LDL), and triglyceride data (mmol. $\mathrm{L}^{-1}$ ) and Apoprotein-Al and Apoprotein-B (mg.dl-1) are shown for the trained (T) and the control (C) group at baseline (month 0 ), at 4 months and 16 months. Means, standard deviations and statistical significance are presented. * $p<0.05$ between groups; \# $p<0.1$ between groups

Body fat distribution (abdominal or gluteal) was investigated by examination of the waist circumference, WHR and the sagittal diameter. The amount of regain of the variables was significantly negatively correlated with the amount of weekly training hours performed $(\mathrm{r}(\Delta$ waist $)=-0.55, \mathrm{p}<0.05 ; \mathrm{r}(\Delta \mathrm{WHR})=-0.50, \mathrm{p}=0.06 ; \mathrm{r}(\Delta \mathrm{sag} . \emptyset)=-0.53, \mathrm{p}<0.05)$.

Resting Metabolic Rate

With respect to the RMR no differences were seen as a result of exercise training. Both groups showed not significantly different RMR values at 16 months as measured before the study $\left(87 \pm 7 \mathrm{~kJ} \mathrm{~min}^{-1}\right.$.FFM ${ }^{-1}$ and $88 \pm 6$ for the trained; $90 \pm 12 \mathrm{~kJ} \cdot \mathrm{min}^{-1}$.FFM ${ }^{-1}$ and $91 \pm$ 10 for the control, at the start and at the end of the study, respectively).

Regain of body weight and fat mass

\section{Discussion}

The major finding of this study was that exercise training did not result in much better weight maintenance compared with controls. However, regain of FM was significantly lower in the trained group (exercise: 3-4 times a week, at least for 1 hour, at a moderate intensity). The 
results indicate that less regain of FM took place, the more training hours were carried out. This finding illustrates that exercise seems to have a weight-controlling aspect, as was found in studies analyzing the success factor for long-term weight maintenance (Hartman et al., 1993; Harris et al., 1994; Ewbank et al., 1995). In a long-term study of van Dale and coworkers (1996) the weight maintenance of the subjects exercising after a weight-loss intervention was $23 \%$ and much lower than the diet or diet-exercise group. No regain of fat mass was found in the exercise group. This study and the review of Stefanick (1993) about the weight controlling aspect of exercise support our findings that exercise is effective for reducing weight regain in the long-term. An additional energy expenditure of $1500 \mathrm{kcal}$ per week should be sufficient for effective weight maintenance (Pavlou et al., 1989; Hartman et al., 1993). However in some studies a maintenance program was used, that besides exercise subjects were informed weekly in group settings about nutrition, eating behaviour and tips for low-fat cooking (Pavlou et al., 1989; Hartman et al., 1993). In a study of Ewbank and colleagues (1995) the subjects were weighed 2 years post VLED, when subjects were left free. When grouped to the amount of exercise performed weekly they found at 2 years regain levels corresponding to our results (72\% compared with $63 \%$ found on average in this study). Especially in the group of subjects that performed exercise 5 times a week (in total \pm $2300 \mathrm{kcal}$ ) even less regain was found (24\%) (Ewbank et al., 1995).

Although different reports have prescribed the mechanisms for the weight-controlling aspects of exercise (Saris, 1996), it still remains striking that the exercise group also regained FM. It seems to be difficult to maintain the lowered BW achieved after the 4 months treatment. The above mentioned studies stress the importance of a high frequency of exercise weekly, and participation in group sessions (high compliance and strenuous exercise). The explanation for an increase in BW and FM in our study in spite of the regular intense exercise performance could be several. The daily energy intake might be more increasing than energy expenditure, as has already been found for females (Westerterp et al., 1992). In our study the frequency of training might be too low for weight maintenance; different studies report that activities should be incorporated in daily life, at a daily basis (Bouchard et al., 1993; Davidson et al., 1993; Hartman et al., 1993; Harris et al., 1994; Ewbank et al., 1995). Another possible explanation for the weight regain found in this study could be that insufficient oxidation of fat has lead to a positive lipid balance when fat intake is high, resulting in the long-term in weight gain (Tremblay and Buemann, 1995). Tremblay and Buemann further suggested that beneficial effects of exercise can not be maintained on a long-term basis if the new exercise and food habits are not incorporated in the lifestyle of the individuals (Tremblay and Buemann, 1995). Long-term effects of exercise training seem to be small and are rapidly suppressed with cessation of training (Bouchard et al., 1993).

Physical fitness

In this study we found an increase of the maximal oxygen uptake $\left(\mathrm{VO}_{2}\right.$ max $)$ of $16 \%$ for both groups at 4 months. The trained group maintained that level of $\mathrm{VO}_{2} \max$ at 16 months in contrast to the control group. The increase in $\mathrm{VO}_{2} \max$ is comparable with increases in oxygen uptake found by Katzel and colleagues (1995). In their study subjects were asked to cycle 3 times a week for 45 minutes at 70-80\% heart rate reserve for 9 months (Katzel et al., 1995). The increased maximal power output of the trained group further illustrates that endurance training resulted in a better physical fitness compared with the maximal power output of the control. The relatively high $\mathrm{VO}_{2} \max$ at 16 months for the control group, indicates that changes caused by the 4-month training period were still at a higher level 


\section{Chapter 6}

compared to the start of the study. It is possible that adaptation to exercise training had occurred and was partially maintained during the intervention period even with a low frequency of training (once a week). The significantly increased $\mathrm{VO}_{2} \max$ as we found in this study for both groups, has been reported to be positively correlated with the a higher insulin sensitivity. This suggests again that training had beneficial health effects (Barnard and Wen, 1994; Clausen et al., 1996).

\section{Cardiovascular risk factors}

In the present study no differences in blood pressure and cholesterol, cardiovascular risk factors were found, as a result of the training program. Blood pressure and cholesteroll data were reduced after the VLED treatment, but retumed to baseline values during the long-term intervention, as was found before (Saris et al., 1992). Another important risk factor for CVD is the waist circumference (or WHR) or the sagittal diameter (Hodgson et al., 1994). In several studies the relation of abdominal fat distribution with exercise was reported (Krotkiewski and Björntorp, 1986; Bouchard et al., 1993; Tremblay and Buemann, 1995; Weidner el al., 1995; Buemann and Tremblay, 1996). In this study we found negative correlations between the weekly amount of training hours and waist circumference and also for sagittal diameter, suggesting that exercise effectively prevented regain of upper-body fat. The change in waist circumference, WHR and sagittal diameter were significantly higher for the control group at 16 months. In men upper-body obesity is more common than in women, and a preferential mobilization of abdominal fat with exercise has been found before (Bouchard et al., 1993). Björntorp has already stated in different studies that abdominal obesity, with hypertrophic cells, can mobilize fat easier than peripheral fat sites (Björntorp. 1978). B-Adrenergic stimulation which takes place during exercise increases fat mobilization in the abdomen effectively. Furthermore, lowering of the filling state of the fat cells in the abdomen reduces insulin resistance. Insulin resistance is another important risk factor for CVD (Björntorp, 1978; Krotkiewski and Björntorp, 1986). In this study the results indicate a decrease in abdominal fat in the trained group and an improvement of the risk factor profile for the trained.

\section{Resting metabolic rate}

In this study no changes in RMR were found between the two groups as a consequence of the exercise training. The decrease in RMR after the VLED found in this study was already reported before (Shah and Jeffery, 1991). At the end of the study the RMR was similar for both groups as at the start of the study. The hypothesized effect of exercise at RMR, an increase in RMR, as was found before (Tremblay et al, 1988; Westerterp et al., 1991), could contribute to weight loss or weight maintenance. However, also a decrease in RMR has been found as a consequence of endurance training (Phinney, 1988; Heymsfield, 1989; Tremblay, 1997). A reduced RMR has been found to correlate with weight gain (Ravussin et al., 1988; Bouchard et al., 1993). The regain of body weight and fat mass found in the present study could therefore be partly explained by the lowered RMR after the diet intervention. However, at the end of the study no differences between groups and no differences with initial RMR was found, suggesting that in the long-term other factors affected weight gain too. Therefore, the effect of training at RMR is still unclear.

Conclusion

In this study we found that although regain of BW was not significantly different in both groups, the trained had less regain of fat mass. Significantly less regain of waist circumference, WHR and sagittal diameter took place, the more training hours a week were 
performed. Higher levels of physical fitness and less regain of FM and abdominal fat as found in the trained group are positive factors related with lower risk factors for CVD. However, the regain of FM in the trained group suggests that maintenance of fat loss is extremely difficult, even with a relatively intensive exencise program.

\section{References}

Barnard RJ, Wen SJ. Exercise and diet in the prevention and control of the metabolic syndrome. Sports Med.18: 218-228, 1994

Björntorp P. Physical training in the treatment of obesity. Int J.Obes.2: 149-156, 1978

Blair SN, Koh1 HW, Paffenberger RS Jr.., Clark. DG, Cooper KH, Gibbons LW. Physical fitness and allcause mortality; a prospective study of healthy men and women. JAMA 262: 2395-2401, 1989

Bouchard C Deprés J-P, Tremblay A. Exercise and obesity. Obes.Res. 1: 133-147, 1993

Buemann B, Tremblay A. Effects of exercise training on abdominal obesity and related metabolic complications. Sports Med.21: 191-212, 1996

Clausen JO, Borch-Johnsen K, Ibsen H, Bergman RN, Hougaard $P_{n}$ Winther K, Pedersen O. Insulin sensitivity index, acute insulin response, and glucose effectiveness in a population-based sample of 380 young healthy caucasians. Analysis of the impact of the gender, body fat, physical fitness, and life-style factors. J.Clin.Invest.98: 1195-1209, 1996

Dale D van, Saris WHM, ten Hoor F. Weight maintenance and resting metabolic rate $18-40$ months after a diet/exercise treatment. Int. J.Obes. 14: 347-359, 1990

Davidson RCR, Grant S. Is walking sufficient exercise for health? Sports Med.16: 369-373, 1993

Ewbank PP, Darga LL, Lucas CP. Physical activity as a predictor of weight maintenance in previously obese subjects. Obes. Res. 3: 257-263, 1995

Flatt JP. Dietary fat, carbohydrate balance and weight maintenance. Ann.N.Y.Acad Sci.683: 122*140, 1993

Garner DM, Wooley SC. Confronting the failure of behavioral and dietary treatments for obesity. Clin.Psych. Rev.11: 729-780, 1991

Harris $\mathrm{JK}_{\mathrm{r}}$ French SA, Jeffery RW, McGovern PG, Wing RR. Dietary and physical activity correlates of long-term weight loss. Obes.Res.2: 307-313, 1994

Hartman WM, Stroud $M$, Sweet DM, Saxton J. Long-term maintenance of weight loss following supplemented fasting. Int.J.Eat.Dis. 14: 87-93, 1993

Heymsfield SB, Casper K, Hearn J, Guy D. Rate of weight loss during underfeeding: relation to level of physical activity. Metabolism 38: 215-223, 1989

Hodgson $\mathrm{MM}$, Wahlquist ML, Balazs NDH, Boxall JA. Coronary athero-sclerosis in relation to body fatness and its distribution. Int.J.Obes.18: 41-46, 1994

Hubert HB, Feinleib M, McNamara $\mathrm{PM}_{4}$ Castelli WP. Obesity as an independent risk factor for cardiovascular disease: a 26-year follow-up of participants in the Framingham Heart Study. Circulation 67: 968-977, 1983

Katzel LI, Bleecker ER, Colman EG, Rogus EM, Sorkin JD, Goldberg AP. Effects of weight loss vs aerobic exercise training on risk factors for coronary disease in healthy, obese, middle-aged and older men. IAMA 274: 1915-1921, 1995

Kromhout D. Body weight, diet, and serum cholesterol in 871 middle-aged men during 10 years of follow-up (the Zutphen Study). Am.J.Clin.Nutr.38: 591-598, 1983

Krotkiewski M, Björntorp P. Muscle tissue in obesity with different distribution of adipose tissue. Effects of pliysical training. Int.J.Obes.10: 331-341, 1986

Kuczmarski RJ, Flegal KM, Campbell SM, Johnson CL. Increasing prevalence of overweight among US adults. The national health and nutrition examination surveys, 1960 to 1991. JAMA 272: 205-211, 1994.

Marken Lichtenbelt WD van, Westerterp KR, Wouters L. Deuterium dilution as a method for determining total body water: effect of test protocol and sampling time. Br.J.Nutr. 72: 49॥-497, 1994

Muls E, Kempen KPG, Vansant G, Cobbaert C, Saris WHM. The effects of weight loss and apolipoprotein E polymarphism on serum lipids, apolipoproteins A-I and B, and lipoprotein(a). Int.J.Obes. 17: 711-716, 1993

Pavlou KN, Whatley JE, Jannace PW, DiBartelomeo JJ, Burrows BA, Duthie EAM, Lerman RH. Playsical activity as a supplement to a weight-loss dietary regimen. Am.J.Clin.Nutr.49: 1110-1114, 1989

Phinney SD, LaGrange BM, O'Connell M, Danforth E. Effects of aerobic exercise on energy expenditure and nitrogen balance during very low calorie dieting. Metabolism 37: 758-765, 1988 


\section{Chapter 6}

Ravussin E, Lillioja $S$, Knowler WC, Christin L, Freymond $D$, Abbott WGH, Boyce V, Howard BV, Bogardus C. Reduced rate of energy expenditure as a risk factor for body weight gain. N.Eng.J.Med. 318: $467-72,4988$

Rösstner S. Faetors determining the long-term outcome of obesity treatment. In: Björntorp, P. and Brodoff, B.N., ed.: Obesity. J.B. Lippincott Company, Philadelphia, pg:712-719, 1992

Saris WHM, Koenders MC, Panmemans DLE, Baak wan MA. Outcome of a multicenter outpatient weightmanagement program including very-low calorie diet and exercise. Arn.J.Clin.Nutr.56:294S-296S, 1992

Saris WHM. Physical activity and body weight regulation. In: Bouchard, C and Bray, G.A., ed.: Regulation of body weight: Biological and biohavioral mechanisms. Iohn Wiley \& Sons Ltd., pg. 135-148, 1996

Schoetler DA, Santen E v, Peterson DW, Diez W, Jaspan J, Klein PD. Total body water measurement in humans with ${ }^{18} \mathrm{O}$ and ${ }^{2} \mathrm{H}$ labeled water. Am.J.Clin.Nutr.33: 2686-2693, 1980

Seidell JC. Obesity in Europe. Obes. Res.3(suppl.2); 89 $-93 \mathrm{~s}, 1995$

Shah $M_{\text {. Jeffery }}$ RW. Is obesity due to overeating and inactivity or to a defective metabolic rate? A review. Ann. Behav.Med.13: 73-81, 1991

Sjowström L. Can the relapsing patient be identified? In: Björntorp, Cairella, Howard (eds.): Recent advances in obesity research: III. Proceedings of the third International Congress on Obesity. Libbey: London,pg: $85-93,1974$

Stamler R, Stamler $\mathrm{J}_{4}$ Riedlinger WF, Algera $\mathrm{G}$, Roberts RH. Weight and blood pressure. Findings in hypertension screening of 1 million Americans. JAMA 240:1607-1610, 1978

Stefanick ML. Exercise and weight control. Exerc.Sport Sci.Rev.21: 363-396, 1993

Tremblay $A$, Nadeau A, Fourier $G$, Bouchard $C$. Effect of a three-day interruption of exercise training on resting metabolic rate and glucose-induced thermogenesis in trained individuals. Int.J.Obes.12:163-168, 1988

Tremblay $A_{n}$ Buemann B. Exercise-training, macromutrient balance and body weight control. Int.J.Obes. 19: $79-86,1995$

Tremblay A, Poehlman ET, Deprés J-P, Theriault $G_{w}$ Danforth E, Bouchard C. Endurance training with constant energy intake in identical twins: changes over time in energy expenditure and related hormones. Metabolism 46: 499-503, 1997

Weidner MD, Gavigan KE, Tyndall GL, Hickey MS, McCammon MR, Houmard JA. Which anthroponetric indices of regional adiposity are related to the insulin resistance of aging? Int.J.Obes.19: 325-330, 1995

Weir, JB de V. New Methods for calculating metabolic rate with special reference to protein metabolism. J Physiol 109: 1-9, 1949

Westerterp KR, Saris WHM, Soeters PB, Winants Y, ten Hoor F. Physical activity and resting metabolic rate. Med Sci.Sports Exerc. 23: 166-170, 1991

Westerterp KR, Meijer GAL, Janssen EME, Saris WHM, ten Hoor F. Longaterm effect of physical activity on energy balance and body composition. Br.J.Nutr.68: 21-30, 1992 


\title{
Chapter 7
}

\section{The effect of exercise training on leptin levels in obese males}

\author{
W.J. Pasman*, M.S. Westerterp-Plantenga\#* and W.H.M.Saris* \\ *Department of Human Biology, Maastricht University, \#Open University, Heerlen
}

Am.J.Physiol.(Endocrin.Metab.) (In press)

\begin{abstract}
The effect of endurance training on plasma leptin levels was investigated in 15 male, obese subjects in a weight loss and exercise program (age: $37.3 \pm 5.2 \mathrm{yrs}$; BW $96.5 \pm 13.6 \mathrm{~kg}$; BMI $29.8 \pm 3.0 \mathrm{~kg} \cdot \mathrm{m}^{-2}$ ). After four months of treatment containing a very low energy diet (VLED) and endurance exercise training (3-4 times weekly; 1 hour sessions; moderate intensity), two groups were formed. One group continued the exercise sessions (trained subjects; $n=7$ ) and one group stopped with the exercise program (control; $n=8$ ). Measurements of anthropometry, aerobic power, and fasted blood samples were executed at fixed time points $(0,2,4,10$, and 16 months).

With partial regression analysis, keeping changes in insulin and body fat percentage constant, it was shown that hours of exercise training was significantly correlated with changes in leptin levels, during the 16 months period $(r=0.56 ; p<0.05)$. Changes in insulin levels were significantly related to the changes in leptin levels $(r=0.47 ; p<0.05)$, which was less for changes in body fat percentage $(r=0.42 ; p=0.07)$. During the VLED, the change in insulin concentration was affecting leptin levels significantly $(r=0.79)$, the latter was not found for changes in body fat percentage.

It is concluded that endurance exercise training decreased plasma leptin levels, independently of changes in plasma insulin levels and body fat percentage.
\end{abstract}

\section{Introduction}

The isolation of the $a b$ gene in mice by the group of Friedman (Zhang et al., 1994) has renewed interest in body weight regulation and the pathophysiology of human obesity. The $o b$ gene product leptin is secreted from adipocytes and it is postulated that leptin acts as a humoral long-term feedback signal to the central nervous system and in particular to the satiety centre in the hypothalamus (Campfield et al, 1995; Stephens et al., 1995; RohnerJeanrenaud and Jeanrenaud, 1996). Ob/ob mice, not producing leptin, responded to high levels of (injected) leptin with decreased food intake, a decrease in body weight (BW), an increase in energy metabolism and normalization of glucose and insulin concentrations (Halaas et al., 1995; Pelleymounter et al., 1995). In human studies it was found that obese subjects have high leptin concentrations which might indicate that they are resistant to leptin. Several potential defects have been suggested such as: 1 . a defect in the blood-brain barrier transport, 2. a defect in the leptin-receptor in the brain, or 3. a defect in the coupling with neuropeptide Y resulting in altered food-intake (Rohner-Jeanrenaud and Jeanrenaud, 1996). 
The relation between fat mass and leptin which is also found in humans (Considine et al., 1996) might be affected by mechanisms acting on fat mass. The insulin hormone is thought to be of importance in this control mechanism (Cusin et al., 1995; McGarry, 1995). Feeding and starvation (increase and a decrease of fat mass respectively) have been found to affect leptin and insulin levels (Considine et al., 1995; Maffei et al., 1995). It has been suggested that insulin can be viewed as an up - and down regulator of $a b$ gene expression as was shown in lean rats (Cusin et al., 1995), whereas only up-regulation was present and functional in obese animals. Circumstantial evidence suggests a role for the adipocyte in the genesis of insulin resistance. Recent work of Cohen and colleagues (1996) suggested that secretion of leptin by an enlarged store of adipose tissue, may cause insulin resistance, because of insulin-antagonizing effects of leptin (Cohen et al., 1995; Taylor et al., 1996).

Not much information is available about the effect of long-term exercise on the relation of body fat and leptin. Since it is known that exercise can be of therapeutic value for diabetic patients, because of an increase in insulin sensitivity (Clausen et al., 1996), the question arises which the effect of exercise on the leptin-insulin interaction might be. Is an exercise intervention effective in relation to obesity by means of an adaptation of leptin levels related to changes in body fatness?

In this study the effect of an exercise intervention after a weight loss treatment is studied in relation to long-term weight maintenance in male obese subjects. Changes in body weight (BW) and body fat percentage, insulin and leptin concentrations were examined in relation to training status of the subjects. It is hypothesized that long-term endurance training might reduce leptin levels in relation to body fatness, possibly mediated by insulin.

\section{Subjects}

\section{Methods}

In this study 15 sedentary, obese males participated (age: $37.3 \pm 5.2$ yrs; body mass index (BMI) $29.8 \pm 3.0 \mathrm{~kg} \cdot \mathrm{m}^{-2}$; body weight (BW) $96.5 \pm 13.6 \mathrm{~kg}$ ). Physical characteristics of the subjects before the study are given in table 1 . Subjects were medically examined by a physician before they entered the study. The experimental procedures and potential risks of the study were explained both verbally and in writing. A written informed consent was obtained from each subject at the start of the study. The study was approved by the Ethics Committee of the Maastricht University.

Study design and protocol

All subjects started a very low energy diet (VLED), a protein-enriched formula diet, providing 2 MegaJoule daily (44 percentage of energy protein; 14 percentage of energy fat; 42 percentage of energy carbohydrate) for 2 months in addition to a training program of four months. The exercise performed consisted of moderate intensity exercise bouts of one hour, 3-4 times a week. After the VLED, the training sessions were continued for another 2 months, to prevent a fast regain of the weight lost. After these four months two groups were formed; one group continued the training sessions ( $n=7$ ) and one group stopped training $(n=8)$. The last group served as a control group and performed sports activities less than once a week, as before the intervention. Physical characteristics (the same as presented in table 1) were not significantly different between the trained and the control group at four months.

The group that continued training, trained with a local triathlon club where they could train under supervision at a moderate to severe intensity all three events of the triathlon 
(swimming-cycling-running). They could also train by themselves, thereby not restricting them to certain training hours (because of shift-work some subjects were otherwise not able to train).

\section{Compliance}

Compliance to training sessions was checked in multiple ways. A training-diary was used for day-to-day activities and remarks (illness, injury, weather conditions, etc). Questionnaires at the time of measurement to check frequency of training (amount of training hours a week) and visitations of the investigator to training sessions were also performed to investigate compliance. Compliance to the prescribed training sessions was $89 \pm 26 \%$ for the trained group during the intervention period.

\section{Measurements}

After an overnight fast subjects came to the laboratory at $0,2,4,10$ and 16 months after starting the study at 8.00 am for different measurements.

\section{Anthropometry}

Subjects were weighed on a digitall balance accurate to $0.1 \mathrm{~kg}$ (Sauter D-7470, Ebingen, Germany). Height was obtained to the nearest $0.1 \mathrm{~cm}$ using a wall-mounted stadiometer (Seca, model 220, Hamburg, Germany). The body mass index (BMI) was calculated by $B W^{*}$ height ${ }^{2}\left(\mathrm{~kg}^{-2} \mathrm{~m}^{-2}\right)$. The distribution of fat was investigated by measuring the waist and hip circumferences and calculation of the waist-hip ratio (WHR) and sagittal diameter. The waist circumference was measured at the smallest circumference between the rib cage and the ileac crest, with the subject in standing position. The hip circumference was performed at the level of the widest circumference between the waist and the thighs. The WHR was calculated by dividing the waist circumference by the hip circumference. For determination of the sagittal diameter (sag. $\emptyset$ ), the distance between the abdomen and the back, a stadiometer was used with a subject in supine position.

The deuterium dilution technique was used for measurement of body composition in this study (Schoeller et al., 1987). ${ }^{2} \mathrm{H}_{2} \mathrm{O}$ dilution was used to measure total body water (TBW). Subjects were asked to collect an urine sample in the evening just before drinking the deuterium enriched water solution. After consumption of this solution no further consumption was allowed. Ten hours after drinking the water solution another urine sample was collected. The dilution of the deuterium isotope is a measure for total body water of the subject (van Marken Lichtenbelt et al., 1994). Deuterium was measured in the urine samples with an isotope ratio mass spectrometer (VG-Isogas Aqua Sira). TBW was obtained by dividing the measured deuterium dilution space by 1.04 (Schoeller et al., 1987). Fat free mass (FFM) was calculated by dividing the TBW by the hydration factor 0.73 . By subtracting FFM from BW, fat mass (FM) was obtained. FM expressed as a percentage of $\mathrm{BW}$ revealed body fat percentage (BF\%).

\section{Blood analysis}

At all test days fasted blood samples were obtained $(10 \mathrm{ml}$ EDTA-blood and $10 \mathrm{ml}$ serum) of the subjects. Subjects were instructed not to perform strenuous exercise the day prior to the test day, and train at least 12 hours before blood sampling. The time period between the last exercise bout and blood sampling was always at least 12 hours. Blood plasma was mixed with EDTA to prevent clotting, and immediately centrifuged. Serum was obtained by centrifugation of blood after one hour at room temperature. Plasma and serum samples were stored at $-80^{\circ} \mathrm{C}$ until further analysis. Plasma insulin was measured using a double antibody radioimmunoassay for buman insulin (Kabi Pharmacia Diagnostics AB, Uppsala, Sweden). 
Leptin analysis was performed with a radioimmunoassay (Linco Research Inc., St. Charles, Missouri, USA), based upon a study of Maffei and colleagues (1995). The within-assay analytical coefficient of variation of the RIA kit ranged from 3.4-8.5\% and the interassay coefficient of variation ranged from 3.6-6.2\%. The within subject of variation for repeated sampling was $2.9 \pm 2.4 \%$, whereas the between-subject coefficient of wariation was $65.6 \%$. The values measured all were in the range of detection (range $0.5-100 \mathrm{ng} \cdot \mathrm{ml}^{-1}$ ). All determinations of leptin levels were run in a single assay to eliminate interassay variation. Insulin and leptin were both determined in duplicate.

\section{Maximal performance test}

To investigate the effect of the training program on performance capacity (maximal oxygen uptake: $\mathrm{VO}_{2} \mathrm{max}$ ) and maximal power output ( $\mathrm{Wmax}$ ), an incremental exercise test was performed on an electromagnetically braked cycle ergometer (Lode, Groningen, The Netherlands). After a warm-up period of 9 minutes ( 5 minutes at $40 \mathrm{~W}$ and 4 minutes at 80 W) the workload was increased every minute with $20 \mathrm{~W}$ until exhaustion. The maximal power output was calculated using the total time cycled at the exercise test. The highest workload completed for 1 minute (Wcompleted) and the number of seconds (X) that the final increase of $20 \mathrm{~W}$ was maintained, were added, according to the following formula: Wmax = Weompleted+ $\left((\mathrm{X} / 60)^{*} 20\right)$. Criteria for maximal performance were forced ventilation, leveling off of oxygen uptake or a respiratory exchange ratio (RER) above 1.1. The oxygen uptake during the test was measured continuously, using a computerized open system (Oxycon Betta, Mijnhardt, Bunnik, The Netherlands).

\section{Data analysis}

In the text, tables and. figures data are presented as means \pm standard deviation (sd). In the present study the effect of 12 months of endurance training on leptin concentration in weightreduced males was examined. The data measured at 10 and 16 months was therefore averaged and the change in variable $(\Delta)$ was compared with the change in variable during the four month treatment. Regain of the parameter during the intervention period (4-16) is expressed as a percentage of the treatment period $(0-4)$. However, factors known to be related with leptin such as insulin concentration and body fat percentage, could disturb the relation between exercise and leptin. This relation found should therefore be studied by means of partiall regression analysis, to correct for changes in insulin concentration and body fat percentage. The amount of variance explained by the factors leptin, insulin and body fat percentage then can be evaluated with multiple regression analysis.

Statistical analysis

Differences between the group that trained continuously and the group which had stopped training after 4 months were tested nonparametrically by using the Mann-Whitney test. Partial correlation coefficients (pcc) were calculated by use of residual sum of squares of multiple (RSS2) and simple regression analysis (RSS1) ( $($ (RSS1-RSS2)/RSS1)). Multiple regression analysis was used to calculate the amount of explained variance of the variables. For all statistics performed statistical significance was set at $\mathrm{p}<0.05$.

\section{Results}

Physical characteristics of the 15 male participants are presented in table 7.1. No significant differences were found in baseline characteristics between the trained and the control group. At 4 months physical characteristics appeared to be similar too (data partly shown in table 7.2). 
Weight loss and exercise in relation to leptin

Table 7.1 Physical characteristics of the obese males before the study

\begin{tabular}{|c|c|c|}
\hline & Trained $(\mathrm{m}=7)$ & Control $(n=8)$ \\
\hline Age (yns) & $38.0(3.9)$ & $36.6(6.3)$ \\
\hline BW (kg) & $93.1(14.5)$ & $99.5(12.9)$ \\
\hline Height $(\mathrm{m})$ & $1.76(0.07)$ & $11.77(0.13)$ \\
\hline $\mathrm{BMI}\left(\mathrm{kg} \cdot \mathrm{m}^{2}\right)$ & $29.8(3.0)$ & $31.8(2.3)$ \\
\hline WHR & $0.95(0.04)$ & $0.96(0.04)$ \\
\hline Sag $(\mathrm{cm})$ & $22.7(2.2)$ & $24.8(2.2)$ \\
\hline $\mathrm{BF} \%(\%)$ & $28.0(3.4)$ & $31.0(3.0)$ \\
\hline Wmax (Wattkg BW-1) & $2.7(0.3)$ & $2.6(0.2)$ \\
\hline $\mathrm{VO}_{2} \max \left(\mathrm{mlmin}^{-1} \mathrm{~kg} \mathrm{BW}-1\right)$ & $32.8(3,2)$ & $31.3(4.8)$ \\
\hline
\end{tabular}

BMI: body mass index; WHR: wast-hip ratio; Sag. maximal power output; VO2max: maximal oxygen uptake.

Table 7.2 The effect of the exercise intervention at physical parameters

\begin{tabular}{|c|c|c|c|c|c|c|}
\hline Month & 0 & 2 & 4 & 10 & 16 & \\
\hline$B W(t)$ & $93.1(14.5)$ & $80.7(11.2)$ & $82.0(10.8)$ & $85.7(11.9)$ & $87.3(12.5)$ & abodfghi \\
\hline BW(c) & $99.5(12.9)$ & $84.7(12.6)$ & $85.6(13.8)$ & $91.2(14.4)$ & $95.6(12.7)$ & abcdlghij \\
\hline BMT(0) & $29.8(3.0)$ & $25.9(2.2)$ & $26.3(2.2)$ & $27.5(2.6)$ & $28.0(2.9)$ & abodfghi \\
\hline BMI(c) & $31.8(2.3)$ & $27.0(2.0)$ & $27.3(2.2)$ & $29.1(2.4)$ & $30.6(2.4)$ & abedfghij \\
\hline Fat $\%(t)$ & $28.0(3.4)$ & $21.8(4.1)$ & $21.8(3.8)$ & $25.0(3.8)^{8}$ & $25.9(3.8) \mathrm{T}$ & abodfghi \\
\hline Fat $\%(c)$ & $31.0(3.0)$ & $25.6(4.0)$ & $24.1(4.2)$ & $29.1(3.7)$ & $31.3(2.2)$ & abfighi \\
\hline WHR(t) & $0.95(0.04)$ & $0.89(0.03)$ & $0.87(0.04)$ & $0.90(0.05)$ & $0.92(0.04)^{9}$ & abcdgij \\
\hline WHR(c) & $0.96(0.04)$ & $0.91(0.03)$ & $0.89(0.03)$ & $0.93(0.04)$ & $0.98(0.04)$ & $\operatorname{abcgij}$ \\
\hline Sag. $(t)$ & $22.7(2.2)$ & $18.1(1.4)$ & $18.1(1.5)$ & $18.9(1.5)$ & $19.4(1.6) 1$ & abedgi \\
\hline Sag $\theta(c)$ & $24.8(2.2)$ & $18.9(1.6)$ & $18.9(1.9)$ & $20.4(1.9)$ & $22.2(2.0)$ & abedfghij \\
\hline Insulin(t) & $16.6(\mathbb{1 5} .1)$ & $9.0(3.2)$ & $10.7(7.1)$ & $13.5(7.7)$ & $12.1(5.6)$ & a \\
\hline Insulin(c) & $15.4(5.1)$ & $6.9(2.8)$ & $10.1(3.8)$ & $16.0(7.2)$ & $11.9(5.3)$ & abfgh \\
\hline Leptin(t) & $9.3(4.5)$ & $2.8(0.8)$ & $4.8(1.8)$ & $5.6(2.5)^{\mathrm{a}}$ & $7.2(2.2)^{\mathrm{a}}$ & abcdefgi \\
\hline $\operatorname{Leptin}(\mathrm{c})$ & $11.9(5.5)$ & $3.4(1.6)$ & $5.5(3.2)$ & $89(3.8)$ & $11.0(3.4)$ & abcfghi \\
\hline
\end{tabular}

Significant differences $(p<0.05)$ between moments are indicated with initials: anonth 0 ws 2 , b month 0 vo 4; c month 0 ws 10; d month 0 ws 16 ; month 2 ws 4 ; f nonth 2 ws 10 ; 8 month 2 ws 16 ; honth 4 vs 10 ; month 4 ws $16 ; j$ month 10 ws $16 ;$ il $p<0.05$ (berween groups); $p=0.06$ (between groups)

\section{Training intervention}

The effectiveness of the training intervention studied, is examined by comparison of the training status of the two groups. In table 7.3 the maximal oxygen uptake and maximal power output measured at the maximal performance test are presented for the 2 groups, expressed per $\mathrm{kg} \mathrm{BW}$. The training status variables maximal oxygen uptake and maximal power output were equal at the beginning of the study and at 2 and 4 months. The group that continued the training sessions showed significantly higher power output levels and maximal oxygen uptake at 10 and 16 months. Based upon these differences found in training status we can compare these groups, and study the effect of differences in training status. 


\section{Chapter 7}

Table 7.3 The effect of the exercise intervention at training status

\begin{tabular}{|c|c|c|c|c|c|c|}
\hline Month & 0 & 2 & 4 & 10 & 16 & \\
\hline$W_{\max }(t)$ & $2.7(0.3)$ & $3.4(0.5)$ & $3.6(0.2)$ & $3.4(0.3))^{4}$ & $3.4(0.3)^{2}$ & \multirow{2}{*}{$\begin{array}{l}\text { abod } \\
\text { abedeghi }\end{array}$} \\
\hline$W \max (c)$ & $2.6(0.2)$ & $3.1(0.3)$ & $3.6(0.4)$ & $3.2(0.2)$ & $2.9(0.1)$ & \\
\hline $\mathrm{VO}_{2}(t)$ & $32.7(3)$ & $40.8(5)$ & $42.6(3)$ & $39.2(3)^{11}$ & $39.0(4)$ & \multirow{2}{*}{$\begin{array}{l}\text { abodgh } \\
\text { abdfgh }\end{array}$} \\
\hline Von(c) & $313(5)$ & $39.2(4)$ & $42.6(5)$ & $35.0(3)$ & $35.3(3)$ & \\
\hline
\end{tabular}

Maximal performance and maximal oxygen uptake at different time points. Wmax: maximal power output at the bicycle ergometer test (Watt.kg $\mathrm{BW}^{+11}$ ); $\mathrm{VO}_{2}$ : maximal oxygen consumption (ml.(kg BW.min) ${ }^{-1}$ ). Significant differences $(p<0,05)$ between moments are indicated with initials: ${ }^{2}$ month 0 us 2 , b month 0 vs

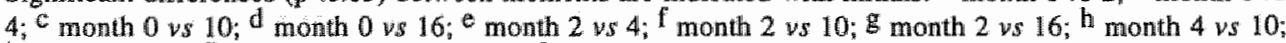
i month 4 ws $16 ;$ Il $<<0.05$ (between groups); \& $\mathrm{p}=0.09$ (between groups)

\section{Anthropometry and blood parameters}

In table 7.2 the variables BW, BMI, BF\%, WHR and sag. $\varnothing$ are shown for the entire period for the trained and control group. BF\% determined with the deuterium dilution technique was significantly lower, for the trained compared to the control group at 16 months (at 10 months: $\mathrm{p}=0.06$ ). Significant differences were also found between the groups with respect to WHR at 16 months. The leptin concentration decreased for both groups during the VLED (02 months) from $10.7 \pm 5.1$ to $3.1 \pm 1.3 \mathrm{ng} \cdot \mathrm{ml}^{-1}$ for all subjects (no differences between the two groups). During the intervention period leptin concentration changed significantly, and was different between the two groups at 10 and 16 months. For the insulin concentrations no differences were found between the groups over the entire period.

Regain of waist, WHR and sag. $\emptyset$ during the intervention period ( $\triangle 4-16)$ was significantly less for the trained compared to the control group (fig.7.1). Significantly less regain of waist, WHR and sagittal diameter was found for the trained compared to the control group.

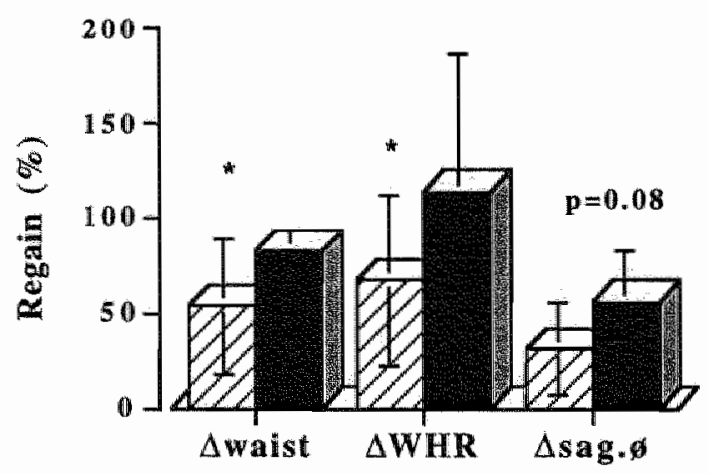

Fig.7.1 Regain of anthropometric parameters at 16 months (the increase is expressed as a percentage of the amount lost during the 4 month treatment). The increase in waist ( $\Delta$ waist), WHR ( $\triangle W H R$ ) and increase in sagittal diameter ( $\Delta$ sag. are presented for the trained (hatched bars) and the control group (filled bars). Statistical significance was set at $\mathrm{p}<0.05$ (*). 


\section{Relation of insulin, $B F \%$ and exercise with leptin}

The relation between $\mathrm{BF} \%$ and leptin was studied by relating the change in $\mathrm{BF} \%$ during the 2 months VLED with the change in leptin concentration over the same period. Partial regression analysis revealed that the change in $\mathrm{BF} \%$ was not correlated with the changes in leptin (pcc=0.27, n.s.). However, the change in insulin was correlated with the changes in

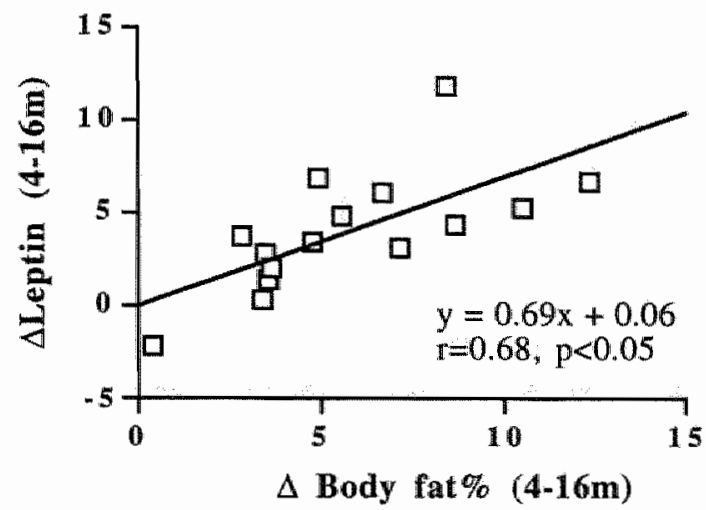

Fig.7.2 Relation between change in body fat percentage during the intervention (4-16 months) and change in leptin concentration (open squares). The regression line and correlation are presented.

leptin concentration ( $\mathrm{pcc}=0.79, \mathrm{p}<0.01$ ). The change in $\mathrm{BF} \%$ during the intervention period (44-16) was however significantly correlated with the change in leptin concentration during this same period $(r=0.68, p<0.05$ ) (fig.7.2).

Already with simple regression analysis a relation was found between maximal oxygen uptake (per $\mathrm{kg} \mathrm{BW}$ ) and leptin levels with training (on average over the 4 time points $\mathrm{r}=-0.57$ $\pm 0.1, p<0.05)$. Before the training intervention no such relation was found $(r=-0.08$, $\mathrm{p}=0.79$ ). The effect of training on plasma leptin levels was analyzed using partial regression analyses (table 7.4).

Table 7.4 Partial correlation coefficients

Partial correlation

Corrected for

r

$\mathrm{p}$

$\begin{array}{lllr}\triangle \text { insulin } & \Delta \text { fat } \% & 0.47 & <0.05 \\ \triangle B F \% & \Delta \text { instin } & 0.42 & 0.07 \\ \text { hours exercise } & \Delta \text { fat \% and } \Delta \text { insulin } & 0.56 & <0.05\end{array}$

Partial regression analysis of the effect of changes in insulin ( $\Delta$ insulin) changes in body fat $\%(\Delta B F \%)$ and hours of exercise training at changes in leptin levels during the study intervention are presented.

Changes in insulin, body fat percentage and amount of training hours per week of all subjects were analysed in relation to leptin levels measured, when corrected for possible interactions. As found for changes during the VLED, changes in leptin levels over the entire period were related to changes in insulin ( $\mathrm{pcc}=0.47, \mathrm{p}<0.05$ ). During this time period a trend for changes in body fat percentage affecting leptin changes was also found $(\mathrm{pcc}=0.42$, $\mathrm{p}=0.07$ ). Analysis of the influence of training hours when the change in body fat percentage 
and the change in inswlin were kept constant showed a pcc of $0.56(\mathrm{p}<0.05)$, indicating that traning was an independent factor correlated with changes in leptin levels. Multiple regression analysis of 2 variables ( $\Delta$ insulin and $\Delta$ bodyfat $\%$ ) explained $44 \%$ of the variance of leptin. Inclusion of the amount of training hours resulted in a significant increase in explained variation to $61 \%$.

\section{Discussion}

\section{Exercise}

The main result of this study is the independent effect of training on leptin concentration. So far no studies are known in humans in which an effect of exercise training on leptin levels is reported independent of body fatness and insulin "levels. Because the trained group had significantly lowered leptin levels after one year of exercise training, we analyzed the independent effect of training on leptin levels, when corrected for the changes in insulin and body fat percentage during the long-term exercise intervention. The amount of training hours a week correlated significantly with the changes found in leptin levels. Recently it was found that sex steroid hormones too were independent of body fat, related to leptin levels (Elbers et al., 1997).

Because it is known that some obese subjects overestimate their physical activity (Lichtman et al., 1992), the training sessions were continuously visited by the investigator (WP) and training diaries were frequently examined, to make sure that reliable training data was obtained. The relation found between training hours and leptin may suggest that exercise effectively resulted in reduced leptin secretion or an elevated elimination of leptin. This effect was not found at 10 months of the study, indicating that the difference in training status between the two groups was not as clear as after 16 months. Our findings could not be explained by the pulsatile leptin secretion recently reported by Licinio and coworkers (1997), because we sampled blood at the same standardized moments of the day. Our findings are supported by the results of Hickey and coworkers who reported that male trained distance runners also had reduced leptin levels (Hickey et al., 1996). In another study Hickey and colleagues found a reduction in serum leptin levels in female subjects after a 12 week training intervention, which was not found in the participating males (Hickey et al., 1997). This might indicate that the duration of the training intervention is of importance, especially for malles. The $17.5 \%$ reduction in serum leptin level as was found by Hickey et al. was less than the reduction of $23 \%$ in our study. A study of Kohrt and colleagues in elderly women (aged 60-72 yr) further indicate that women as a response to exercise show lowered leptin levels (Kohrt et al., 1996). The $23 \%$ reduction in leptin levels found in that training group was similar as found in the male population in the present study. Low levels of leptin were also found in highly-trained women ws controls by Ryan and Elahi (1996). All results support the suggestion that training lowers leptin levels. Hickey and coworkers suggest that the gender specific response to training is based upon the difference in insulin-resistance between males and females; males being the most insulin resistant might need more time and a greater stimulus to respond with lowered leptin levels (Hickey et al., 1997). According to Kohrt and coworkers the reduction in leptin concentration is an indirect consequence of exercise; the reduction in fat mass, caused by training seemed to be the main factor related to leptin (Kohrt et al., 1996). This is in contrast with the findings in the present study. We found after correction of the relation of leptin with body fat percentage and insulin still a clear relation with the amount of training performed a week. Perhaps the clear difference in 
exercise protocol in the studies (intensity and duration per training session in the present study were higher and longer) and the participating subjects (male, middle-aged subjects $w s$ elderly females in Kohrts' study) can explain the differences found in the relation of training and leptin. The recently published results of Pérusse and coworkers (1997) and Ostlund and coworkers (1996) also stress the relation between leptin and exercise via the changes in body fat. The much longer training period in the present study (16 months ws 4-5 months) might explain the independent effect of training found in the present study, while Perusse and coworkers found that after correction for fat mass no effect of exercise was seen (Pérusse et al., 1997). As mentioned above at 10 months no independent effect of training was found, so duration might be an important factor. The difference in BMI of the male subjects at the start of the study $\left(25.5 \pm 5.0 \mathrm{~kg} \cdot \mathrm{m}^{-2}\right)$ (Pérusse et al., 1997) in comparison to the subjects participating in the present study $\left(29.8 \pm 3.0 \mathrm{~kg} \cdot \mathrm{m}^{-2}\right)$ might further stress that exercise in obese subjects normalizes leptin levels, resulting in more pronounced effects in obese subjects. In the study of Ostlund (1996) however 106 subjects aged between 60-70 yr were included, thus only a low range of the $\mathrm{VO}_{2}$ max was examined.

Data of trained rats showed that endurance training significantly decreased the ob gene expression (Friedman et al., 1996; Zachwieja et al., 1996). Insulin sensitivity and fat cell size were postulated to be important regulators of $o b$ protein mRNA expression (Zachwieja et al., 1996). The regulation is complex, because exercise training not only influences obesity but also insulin resistance as well as body composition (Colman et al., 1995; Buemann and Tremblay, 1996). These three variables are mutually related. All findings together suggest that exercise and leptin levels are causaly related, although a spurious relation or confounding factors like a negative energy balance, that could disturb the relation cannot be ruled out. Our data support the relation, but does not inform us about cause and effect.

There might be another possibility that could explain the differences in leptin found in the trained and control group after 16 months of exercise training. It has already been found that leptin is bound by plasma proteins (Sinha et al., 1996). A change in ratio of leptin free or bound at plasma proteins might result in more or less active leptin action. The total amount of leptin could be stable but the ratio of bound and free leptin, and thereby the activity of leptin, might be changed by exercise training. Differences in the ratio of free and bound free fatty acids (FFA) for example, has already been found for trained $v s$ untrained subjects by Turcotte and coworkers (1992).

\section{Insulin and BF\% during VLED and long-term intervention}

In the present study we found that 2 months of energy restriction resulted in significantly lowered leptin levels in both groups as was found by others (Maffei et al., 1995; Considine et a1., 1996). The VLED intervention resulted also in a change in the relation between body fat percentage and leptin levels. In the body fat range of $15 \%$ to $40 \%$ a decrease in body fat after VLED is accompanied with lower leptin concentrations than measured before the energy restricted period. Partial regression analysis showed that changes in insulin levels during the energy restricted period were significantly correlated with changes in leptin levels and that changes in body fat percentage were not related to changes in leptin levels. Also a simple regression analysis between body fat percentage and leptin (directly after VLED at month 2) showed that these variables were not related, which could be explained by the negative energy balance (extreme negative energy balance because of the VLED). This dissociation of 
serum leptin concentration and body fat content was recently also shown by Scholz and coworkers (1996). They concluded that long-term hypocaloric diet uncouples the relation of leptin of changes in body fat (Scholz et al., 1996). The low levels of leptin as we found after

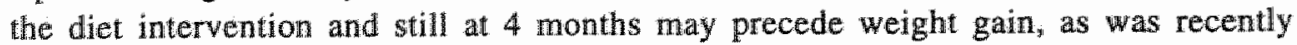
suggested by Ravussin and coworkers (1997). A lower production of leptin by the adipose tissue may play a role in the pathophysiology of obesity, but could also indicate that the sensitivity of the tissue to leptin has increased, and that leptin concentration has therefore been adapted. Further studies are needed to find out whether lowered leptin levels in blood are useful markers for the development of obesity.

At 4 months of the present study the subjects were weight stable and most probably no negative energy balance was present. Therefore the differentiation between the groups from that time point onwards could only be related to exercise level and not to energy restriction. Partial regression analysis revealed that $\Delta$ insulin affected $\Delta$ leptin, during VLED, indicating that insulin and leptin are related also when corrected for body fat percentage. The change in insulin significantly affected leptin levels, but in the long-term also the change in body fat percentage influenced leptin levels. The change in BF\% over 1 year of training and change in leptin during the interwention period was related. Together with the lowered leptin levels for the trained group, it is concluded that the regulation of insulin and leptin are interrelated, although the mechanism and direction behind this remains to be elucidated. Recently it was hypothesized that insulin would act as an up - and down regulator of leptin in lean rats, and in obese rats only the up-regulation works (Cusin et al., 1995). Zheng and coworkers (Zheng et al 1996) reported that ob mRNA is up-regulated by insulin infusion in abdominal adipose tissue of a fasted rat. Insulin would be directly involved with the expression of ob mRNA at a transcriptional level as was found in cultured mature fat cells (Leroy et al., 1996). Our data support the hypothesis that insulin might have a regulatory role in obese males, because after correction of body fat percentage still clear relations of insulin exists with leptin. However, the direction of regulation, insulin regulating leptin or leptin regulating insulin is still unclear, although Cohen and coworkers recently suggested that in vitro insulin is modulated by leptin (Cohen et al, 1996; Taylor et al 1996). This interaction of insulin and leptin warrants further study.

\section{Body fat percentage or body fat distribution?}

In the present study a relation between body fat percentage (BF\%) and body fat mass (FM) with leptin was found (on average $r=0.76, p<0.05$ for body fat $\%$ at all time points measured; with FM on average $r=0.83, \mathrm{p}<0.05$ ) (data not shown). This strong relation was already found by others (Lönngvist et al.,1995; Considine et al., 1996). The differences in body fat percentage between the trained and control group at 16 months might be a consequence of the training sessions performed as has been shown before (Westerterp et al, 1992). The body composition differences are of importance since no significant differences in body weight and body mass index were found at 16 months. Therefore the differences in body composition between the two groups could be of importance with respect to differences in leptin levels found.

However, fat distribution measured by waist-hip ratio or sagittal diameter differed significantly at the end of the study between the two groups. In the present study we found significant differences during the intervention period in waist circumferences, sag. $\varnothing$ and WHR between the two groups. The increased values for the control group might indicate that 
the extra regain of fat mass in the control group is probably located in the waist region. Simple regression analysis also revealed significant correlations between the change in waist, $\Delta$ WHR and $\Delta$ sag. with the change in leptin during the exercise intervention period $(r=0.58$, $\mathrm{p}<0.05 ; \mathrm{r}=0.69, \mathrm{p}<0.05 ; \mathrm{r}=0.59, \mathrm{p}<0.05$, respectively). These results are in accordance with Buemann and Tremblay (1996) who reported that exercise training is negatively correlated with WHR. Mauriège and colleagues also supported the hypothesis that the abdominal fat depot is decreased by training (Mauriège et al., 1996). Buemann and Tremblay further reported that upper body obese patients responded to exercise with increased insulin sensitivity (1996). Exercise can thus via lowering of percentage of body fat and fat accumulation in the waist region increase insulin sensitivity, and perhaps via a regulation with insulin result in decreased leptin levels, which would be in favour of a role of the fat distribution. Regional differences in catecholamine-induced lipolysis (Arner et al., 1990) and site-specific differences in ob gene expression reported in rats (Zheng et al., 1996), support the hypothesis that leptin production might be site specific. This is further supported by the results of Ryan and Elahi (1996) who found that WHR not, but other measures for abdominal obesity (trunk fat by DXA, abdominal subcutaneous fat and sagittal diameter) were, as in the present study, significantly related with leptin. However, Ostlund and coworkers recently showed that there was no independent effect of fat distribution at leptin levels measured (1996). Correction for body fat percentage resulted in disappearance of the negative correlation found between WHR and leptin (Ostlund et al., 1996). In that study the majority of subjects were females (120 females vs 84 males), which is in contrast to the homogeneous group of male subjects in the present study. The abdominal fat distribution found in males might be less obvious in a mixed population in contrast to our group of subjects. Furthermore the differences in age range in the present study (28-46 yr) us 18-80 yr in the study of Ostlund et al. (1996) might explain the differences found with fat distribution and leptin.

Based upon these findings in the literature and our own data we conclude that the localization of the main fat depot might have consequences for the regulation of leptin metabolism.

\section{Conclusion}

It is concluded that exercise training decreased plasma leptin levels, independently of changes in plasma insulin lewels and body fat percentage. In addition to training, the changes in body fat percentage and moreover changes in insulin seem to be affecting the regulation of leptin levels.

\section{References}

Arner P, Hellströ̀n L, Wahremberg H, Brönnegård M. Beta-adrenoceptor expression in human fat cells from different regions. J.Clin.Invest.86:1595-1600, 1990

Buemann B. Tremblay A. Effects of exercise training on abdominal obesity and related metabolic complications. Sports Med.21: 191-212, 1996

Campfield L, Smith FJ, Guisez $X$, Devos R, Burn P. Recombinant mouse ob protein: Evidence for a peripheral signal linking adiposity and central neural networks. Science 269:546-549, 1995

Clausen JO, Borch-Johnsen $K$, Ibsen $H_{*}$ Bergman RN, Hougaard P, Winther $K$, Pedersen $O$. Insulin sensitivity index, acute insulin response, and glucose effectiveness in a population-based sample of 380 young healthy caucasians. Analysis of the impact of the gender, body fat, physical fitness, and life-style factors. J.Clin.Invest.98: 1195-1209, 1996

Cohen B,Novick D, Rubinstein M. Modulation of insulin activities by leptin. Science 274: 1185 1188, 1996 


\section{Chapter 7}

Colman E, Katzel LI, Rogus E, Coon P, Muller D, Goldberg AP. Weighi loss reduces abdominal fat and improves insulin action in middle-aged and older men with impaired glucose tolerance. Metabollism 44: 1502-1508, 1995

Considine RV, Sinha MK, Heiman ML, Kriauciunas A, Stephems TW, Nyce ML, Ohannesian JP, Marco CC. Mckee LJ, Bauer TL, Caro JF. Serum immunoreactive-leptin concentrations in normall weight and obese humans. N.Engl.J.Med.334: 292-295, 1996

Cusin $I_{n}$ Sainsbury A, Doyle $P_{n}$ Rohner-Jeanrenaud $F_{*}$ Jeanrenaud $B$. The $a b$ gene and insulin. A relationship leading to clues to the understanding of obesity. Diabetes 44 : 1467-1470, 1995

Etbers IMH, Asscheman H, Seidell JC, Frölich M, Meinders AE, Gooren LJG. The effect of cross-Sex fhormonal treatment on serum leptin levels in trainssexuals. Int.J.Obes.21(suppl.2): S14, 1997

Friedman JE, Aulak KS, Ferrara CM, MoCune SA, Park S, Sherman WM. Exercise training decreases expression of obesity gene $(o b)$ in adipose tissue of obese SHHF/Mcc-fa rats. The FASEB journal 10: p.A 186 , abstract 1074,1996

Hallaas J, Gajiwala KS, Maffei M, Cohen SL, Chait BT, Rabinowitz D, Lallone RL, Burley SK, Friedman JM. Weight-reducing effects of the plasma protein encoded by the obese gene. Science 269:543-546, 1995

Hickey MS, Considine RV, Israel RG, Mahar TL, McCammon MR, Tyndall GL, Houmard JA, Caro JF. Leptin is related to body fat content in male distance runners. Am.J.Physiol.271(Endocrin. Metab. 34): E938-E940, 1996

Hickey MS, Houmard JA, Considine RV, Tyndall GL, Midgette JB, Gavigan KE, Weidner ML, McCammon MR, Israell RG, Caro JF. Gender-dependent effects of exercise training on serum leptin levels in humans. Am.J.Physiol.272 (Endocrin. Metab.35): E562-E566, 1997

Kolhrt WM, Landit M, Birge SJ. Serum leptin levels are reduced in response to exercise training, but not homone replacement therapy, in older women. J.Clin.Endoctin. Metab.81: 3980-3985, 1996

Leroy P, Dessolin S, Villageois P, Moon BC, Friedman JM, Ailhaud G, Dani C. Expression of ob gene in adipose cells. Regulation by insullin. J.Biol.Chem.271: 2365-2368, 1996

Lichtman SW, Pisarska $K$, Berman ER, Pestone M, Dowling $\mathrm{H}_{0}$ Offenbacher $\mathrm{E}_{\mathrm{s}}$ Weisel $\mathrm{H}_{\mathrm{w}}$ Heshka S, Matthews DE, Heymsfield SB. Discrepancy between self-reported and actual caloric intake and exercise in obese subjects. N.Engl.J.Med.327: 1893-1898, 1992

Licinio J, Mantzoros $C_{n}$ Negrao AB ${ }_{n}$ Cizza G, Wong M-L, Bongiomo PB, Chrousos GP, Karp B, Allen C, Fier IS, Gold PW. Human leptin levels are pulsatile and inversely related to pituitary-adrenal function. Nature Med. 3: 575-579, 1997

Lönnquist $\mathbb{F}_{n}$ Arner $\mathrm{P}$, Nordfors $\mathrm{L}$, Schalling $\mathrm{M}$. Owerexpression of the obese $(o b)$ gene in adipose tissue of human obese subjects. Nature Med. 1: 950-953, 1995

Maffei M, Halaas J, Ravussin E, Pratley RE, Lee GH, Zhang Y, Fei H, Kim S, Lallone R, Ranganathan S, Kern PA, Friedman JM. Leptin levels in thuman and rodent: measurement of plasma leptin and $o b$ RNA in obese and weight-reduced subjects. Nature Med.1: 1155-1161, 1995

McGarry JD. Does leptin lighten the problem of obesity? Current Biology 5: 1342-1344, 1995

Marken Lichtenbelt WDV, Westerterp KR, Wouters L. Deuterium dilution as a method for determining total body water: effect of test protocol and sampling time. Br.J.Nutr.72: 491-497, 1994

Mauriege P. Prud'homme D, Marcotte M, Yoshioka M, Tremblay A, Deprés JP. Chronic adaptation of adipose tissue metabolism to endurance training: existence of regional differences. Int.J.Obes. 20 (Suppl.4): 66, 1996

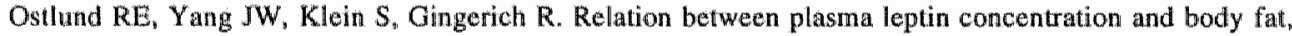
gender, diet, age, and metabolic covariates. J.Clin.Endocrinol.Metab.81: 3909-3913, 1996

Pelleymounter MA, Cullen MJ, Baker MB, Hecht R, Winters D, Boone T, Collins F. Effects of the obese gene product on body weight regulation in objab mice. Science 269:540-543, 1995

Pérusse L, Collier $G$, Gagnon J, Leon AS, Rao DC, Skinner IS $S_{n}$ Wilmore JH, Nadeau A, Zimmel P, Bouchard C. Acute and chronic effects of exercise on leptin levels in humans. J.Appl.Physiol.83: 5-10, 1997

Ravussin E, Pratley RE, Maffei M, Wang H, Friedman JM, Bennet PH, Bogardus C. Relatively low plasma leptin concentrations precede weight gain in Pima Indians. Nature Med.3: 238-240, 1997

Rohner-Jeanrenaud F, Jeanrenaud B. Obesity, leptin and the brain. N.Engl.J.Med. 334: 324-325, 1996

Ryan AS, Elahi D. The effects of acute hyperglycemia and hyperinsulinemia on plasma leptin levels: its relationships with body fat, visceral adiposity, and age in women. J.Clin.Endocrinol.Metab.81: 44334438,1996 


\section{Weight loss and exercise in relation to leptin}

Schoeller DA, Jones PJH. Measurement of total body water by isotopic dilution: a unified approach to calibrations. In Ellis, K.J.s S. Yasumura and W.D. Morgan (eds). In who body composition studies. London, Institute of Phys. Sc. in Medicine pp 131-136, 1987

Scholz GH, Englaro P, Thiele I, Scholz M, Klusmann T, Kellner K, Rascher W, Blum WF. Dissociation of serum leptin concentration and body fat content during long term dietary intervention in obese individuals. Horm.Metab.28: 718-723, 1996

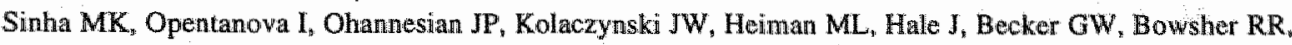
Stephens TW, Caro JF. Evidence of free and bound leptin in thuman circulation. Studies in lean and obese subjects and during short-term fasting. J.Clin.Invest.98: 1277-1282, 1996

Stephens TW, Basinski $M_{0}$ Bristow PK, Bue-Valleskey JM, Burgett SG, Craft L, Hale $\mathrm{J}_{*}$ Hoffmann I, Hisiung HM, Kriauciunas A, Mackellar W, Rosteck Jr PR, Schoner B, Smith D, Tinstey FC, Zhang X$Y$, Heiman $M$. The role of neuropeptide $Y$ in the antiobesity action of the obese gene product. Nature 377: $530-532,1995$

Taylor SI, Barr V, Reitman M. Does leptin contribute to diabetes caused by obesity? Science 274. 11.51. 1152,1996

Turcotte LP. Richter EA, Kiens B. Increased plasma FFA uptake and oxidation during prolonged exercise in trained ws untrained humans. Am.J.Physiol.262(Endocrinol. Metab. 25): E791-E799, 1992

Westerterp KR, Meijer GAL, Janssen EME, Saris WHM, ten Hoor F. Long-term effect of physical activity on energy balance and body composition. Br.J.Nutr.68: 21-30, 1992

Zachwieja $J J$, Harris RBS, Smith SR. Voluntary wheel running normalizes insulin resistance and reduces ob mRNA expression in adipose tissue of Osborne-Mendel rats. The FASEB journal 10 : p.A218, abstraci 1257,1996

Zhang Y, Proenca R, Maffei M, Barone M, Leopold L, Friedman IM. Positional cloning of the mouse obese gene and its human homologue. Nature 372:425-432, 1994

Zheng D, Jones JP, Usala SJ, Dohm GL. Differential expression of $o b$ mRNA in rat adipose tissue in response to insulin. Biochem.Biophys.Res.Commun.218:434-437, 1996 


\title{
Chapter 8
}

\section{The effect of exercise training on $24 \mathrm{~h}$ substrate utilization}

\author{
W.J. Pasman* ,M.S. Westerterp-Plantenga*\# and W.H.M.Saris* \\ * Maastricht Uniwersity, Maastricht, \#pen University, Heerlen, The Netherlands
}

Am.J.Physiol.(Endocrin.Metab.) (Submitted)

\begin{abstract}
The effect of exercise training and macronutrient composition of the diet on $24 \mathrm{~h}$ substrate oxidation was studied in 12 male, obese subjects (age $36.3 \pm 5.1 \mathrm{yrs} ; \mathrm{BW}: 94.6 \pm 13.9 \mathrm{~kg}$; BMI: $30.8 \pm 3.0 \mathrm{~kg} \cdot \mathrm{m}^{-2}$ ). A 16 months exercise intervention study was executed, including a very low energy diet (VLED) of 2 months at the start of the study. Substrate oxidation was measured during a standardized $36 \mathrm{~h}$-stay at energy balance in the respiration chamber at the start of the study ( 0 months), at 4,10 and 16 months. In the respiration chamber subjects were randomly assigned to a high-fat (Hi.F) diet (60 En\% fat) or a reduced-fat (Red.F) diet (30 En\% fat). Also 15 lean, well-trained subjects (age 36.7 \pm 7.1 yrs; BW: $72.2 \pm 5.9 \mathrm{~kg}$; BMT: $22.3 \pm 1.7 \mathrm{~kg} \cdot \mathrm{m}^{-2}$ ) were measured once in the respiration chamber for $36 \mathrm{~h}$ according to the same protocol for comparison of the data of the obese group.

At any time point in the chamber, independent of the diet consumed, the 24 h carbohydrate (CHO) balances were mostly negative (range +31 to -88 grams.day ${ }^{-1}$ ) and the fat balances mostly positive (range -26 to +38 grams.day $^{-1}$ ) for the obese as well as for the lean group. In the lean group the $24 \mathrm{~h}$ CHO balance was even more negative for both types of diet (range -103 to -185 grams.day ${ }^{-1}$ ). For both diets a difference of 70 grams of $\mathrm{CHO}$ was found at 16 months compared with 4 months, and an increase in fat balance of 33 grams during the same time period, already indicating that fat oxidation was not improved with endurance training. Effect of the cycling activity in the respiration chamber at substrate oxidation was examined by comparing oxidation during the first and second night. CHO oxidation was not significantly different between the first and second night. However, fat oxidation was found to be significantly increased at a Hi.F diet $(\mathrm{p}<0.05)$; the more fat was supplied, the higher the fat oxidation.

In conclusion: a 1.6 months endurance training increased the reliance on carbohydrate oxidation and did not increase fat oxidation, when studied for $24 \mathrm{~h}$.
\end{abstract}

\section{Introduction}

Maintenance of body weight (BW) is achieved when energy intake and energy expenditure are balanced via manipulation of the type and quantity of food consumed or level of physical activity (Flatt, 1995a). Over the last decade a number of studies have suggested that a positive energy ballance, causing obesity, is mainly a result of a positive lipid balance (Abbott et al., 1988; Schutz et al., 1989; Ravussin and Swinburn, 1992; Flatt, 1993), caused by decreased physical activity and an increased consumption of high-fat diets (Barnard and Wen, 1994; Prentice and Jebb, 1995; Seidell and Flegal, 1997). To accomplish fat balance, 


\section{Chapter 8}

oxidation of fat should be stimulated (by exercise or drugs) and/or fat intake should be decreased (low-fat diet) (Bouchard et al., 1993; Tremblay and Buemann, 1995; Flatt, 1995b). In normal weight subjects exercise training has been found to result in increased fat oxidation during rest and exercise (Turcotte et al., 1992; Kiens et al., 1993; Martin et al., 1993; Brooks and Mercier, 1994; Calles-Escadón, 1996). In contrast to normal weight subjects, obese subjects were found to have an impaired fat oxidation (Blaak et al., 1994). Consumption of a high-fat diet will therefore easely result in a positive fat balance, and in the end in an increase in body weight (Schutz et al., 1989; Saris, 1996). Obese subjects are therefore adviced to eat a low-fat diet and perform endurance type of exercise to reduce the positive fat balance and prevent weight gain (Larson et al ${ }_{\star ., 1}$ 1995; Bouchard, 1996). The increased capacity to oxidize fat as found in normal weight subjects after a training intervention, could be an useful mechanism for maintenance of body weight for obese subjects after a weight reduction period. However, does exercise training affect fat oxidation in the same way in weight-reduced obese subjects as in lean subjects?

To answer this question we undertook the following study. After a four months period of weight reduction and weight stabilization by means of a very low energy diet (VLED) and a physical activity program with obese men, a 12 month exercise intervention study was executed to investigate changes in $24 \mathrm{~h}$ substrate oxidation. The substrate balances were examined by means of $24 \mathrm{~h}$ measurements in a respiration chamber. It was further hypothesized that stimulation of fat oxidation in weight-reduced obese caused by the exercise intervention would improve the fat balance even when a high-fat diet is consumed. We therefore studied the effect of a high-fat diet ( $\mathrm{Hi} . \mathrm{F}$ diet; 60 energy percent of fat) and a reduced fat diet (Red.F; 30 energy percent of fat) at substrate oxidation. To obtain insight into the maximal effect of training at substrate oxidation, the results of the obese group were compared with a lean, well-trained group of athletes which was measured once in the respiration chamber, according to the same protocol.

\section{Methods}

\section{Subjects}

15 Male, obese subjects participated in this study (age $37.3 \pm 5.2 \mathrm{yrs}, \mathrm{BW}: 96.5 \pm 13.6 \mathrm{~kg}$; BMI: $30.9 \pm 2.8 \mathrm{~kg} \cdot \mathrm{m}^{-2}$ ). The very low energy diet (VLED) was started with 16 male obese subjects. One subject was not able to keep the strict diet regime. Halfway the study, three subjects were not able to continue the training program. Therefore data of 12 obese subjects are presented (age $36.3 \pm 5.1$ yrs; BW: $94.6 \pm 13.9 \mathrm{~kg} ; \mathrm{BMI}: 30.8 \pm 3.0 \mathrm{~kg}^{-2}$ ). For comparison of the $24 \mathrm{~h}$ substrate oxidation data during the standardized respiration chamber protocol, we also measured 15 very well-trained athletes (age $36.7 \pm 7.1 \mathrm{yrs} ; \mathrm{BW}$ : $72.2 \pm$ $5.9 \mathrm{~kg} ; \mathrm{BMI}: 22.3 \pm 1.7 \mathrm{~kg} \cdot \mathrm{m}^{-2}$ ), matched for age. On average the well-trained athletes trained $12.1 \pm 7.4 \mathrm{~h}$ a week, and had a training history of $19.6 \pm 7.7$ years. All trained athletes participated in cycling or triathlon competition. A written informed consent was obtained from each subject at the start of the study. The study protocol was reviewed and approved by the Medical Committee of the Maastricht University.

Srudy design

The obese subjects kept a VLED (Modifast ${ }^{*}$, Novartis Nutrition, Switzerland) for 2 months in order to lose weight. The VLED was supplied in three sachets daily which were dissolved with water, to make a milk-shake or dessert. Total energy intake during VLED was 2 MJ daily. All subjects took part in the endurance training program during the first 4 months of 
the study, of which the first two months were a VLED. Intensity and performance time of the training were gradually build up and after one month training the subjects ran and cycled at a moderate intensity for at least one hour, 3-4 times a week and were coached by the investigator. This training intervention was performed by all subjects to prevent a fast rebound after the VLED and to have a similar starting point to study substrate utilization at 4 months. After 4 months the training sessions were continued at a triathlon club where they were able to swim, cycle and run in group sessions (3-4 times.week $\left.{ }^{-1}\right)$, supervised by a coach. Respiration chamber measurements were performed before the study (month 0), after the diet and first exercise period (month 4), at 10 and 16 months.

Compliance to endurance training during the weight maintenance phase

Compliance to training sessions was checked in multiple ways. A training diary was used for day-to-day activities and remarks (illness, injury, weather conditions, etc). Besides the training diaries, questionnaires were filled in at the laboratory when measurements took place, to check frequency of training (amount of training hours a week) by all subjects. The investigator (WP) visited training sessions of the triathlon club weekly to examine compliance from 4 to 16 months. Of the 15 participating subjects, three stepped out of the training program during the 12 months follow-up, 5 subjects trained once to twice a week, and 7 subjects were able to keep the training frequency at a high level, three times a week or more.

\section{Physical fitness}

One week before the respiration chamber experiment was carried out subjects executed a maximal performance test (an incremental exercise test) on an electromagnetically braked cycle ergometer (Lode, Groningen, The Netherlands) to estimate maximal power output ( $W$ max). After a warm-up period of 9 minutes ( 5 minutes at $40 \mathrm{~W}$ and 4 minutes at $80 \mathrm{~W}$ ) the workload was increased every minute with $20 \mathrm{~W}$ until exhaustion. The maximal power output was calculated using the total time cycled at the exercise test. The highest workload completed for 1 minute (Wcompleted) and the number of seconds $(X)$ that the final increase of $20 \mathrm{~W}$ was maintained, were added, according to the following formula: Wmax = Wcompleted+ $((X / 60) * 20)$. Criteria for maximal performance were forced ventilation, leveling off of oxygen uptake or a respiratory quotient (RQ) above 1. 1. The oxygen uptake during the test was measured continuously, using a computerized open system (Oxycon Beta, Mijnhardt, Bunnik, The Netherlands).

\section{Body composition}

The deuterium dilution technique was used for measurement of body composition in this study (Schoeller et al., 1980), ${ }^{2} \mathrm{H}_{2} \mathrm{O}$ dilution was used to measure total body water (TBW). Subjects were asked to collect an urine sample in the evening just before drinking the deuterium enriched water solution. After consumption of this solution no further consumption was allowed. Ten hours after drinking the water solution another urine sample was collected. The dilution of the deuterium isotope is a measure for total body water of the subject (Marken Lichtenbelt et al., 1994). Deuterium was measured in the urine samples with an isotope ratio mass spectrometer (VG-Isogas Aqua Sira). TBW was obtained by dividing the measured deuterium dilution space by 1.04 (Schoeller et al., 1980). Fat free mass was calculated by dividing the TBW by the hydration factor 0.73 . By subtracting FFM from BW, fat mass (FM) was obtained. FM expressed as a percentage of BW revealed body fat percentage (BF\%). 


\section{Respiration chamber experiments}

\section{Measurement protocol}

Al 4 fixed time points of the study (at month $0,4,10$ and 16 months) subjects stayed in the respiration chamber for 36 hours. Subjects were randomly assigned to a high-fat diet (Hi.F) ( $n=6$ in the obese group; $n=8$ in the well-trained group) or a reduced-fat diet (Red.F) $(n=6$ in the obese group; $n=7$ in the well-trained group) in the respiration chamber. Food intake was carefully callbrated to the estimated energy expenditure, in order to achieve $24 \mathrm{~h}$ energy balance. The type of diet was kept constant during the respiration chamber days throughout the study. At the first evening the estimation of energy expenditure (EE) to feed subjects in energy balance (EB) was based upon the equations of Harris \& Benedict (1919) and a physical activity factor of 1.5 (for the obese group) or 1.7 (for the well-trained group) for free living conditions. After the first night the measured sleeping metabolic rate (SMR) was used and based upon this value and the amount of work delivered that day in the respiration chamber, the subjects were fed in order to achieve EB. During their stay in the respiration chamber subjects were asked to cycle one hour at $40 \%$ of their W max twice (at $10.00 \mathrm{~h}$ and at $15.00 \mathrm{~h})$. Efficiency of cycling of the subjects was set at $21 \%$ and during the warming-up and cooling-down they cycled for 5 minutes at a fixed work load of $60 \mathrm{~W}$.

\section{Respiration chamber conditions}

Energy expenditure was calculated from oxygen consumption and carbon dioxide production as measured in a respiration chamber (Schoffelen et al ${ }_{*,}$ 1984). This chamber measures 14 $\mathrm{m}^{3}$ and is furnished with a bed, chair, table, TV, radio, telephone, computer, cycle ergometer, wash bowl and toilet facilities. Contact between the subjects and investigator was possible via an intercom or telephone and through a window in the door. Food trays and specimen bottles were introduced or withdrawn from the chamber through small airtight hatches. The temperature in the chamber during day-time $(7.00 \mathrm{~h}-23.00 \mathrm{~h})$ was maintained between $20-22{ }^{\circ} \mathrm{C}$ and during the night (23.00h-7.00h) lowered to a comfortable sleeping temperature $\left(18-19^{\circ} \mathrm{C}\right)$.

The respiration chamber is an airtight room connected to an open circuit ventilated indirect calorimeter. The room is ventilated with fresh air at $120 \mathrm{~L} \cdot \mathrm{min}^{-1}$. The ventilation rate was measured with a dry gasmeter (G4, Schlumberger, The Netherlands). The concentration of oxygen and carbon dioxide was measured using a paramagnetic $\mathrm{O}_{2}$ analyser (type $\mathrm{OA} 184 \mathrm{~A}$, Servomex, England) and an infra-red $\mathrm{CO}_{2}$ anallyser (URAS $3 \mathrm{G}$, Hartman \& Braun, Germany). Ingoing air was analysed once every $15 \mathrm{~min}$ and outgoing air once every $5 \mathrm{~min}$. The gas sample to be measured was selected by a computer which also stored and processed the data. Respiratory quotient (RQ) and $\mathrm{EE}$ were calculated from $\mathrm{O}_{2}$ consumption and $\mathrm{CO}_{2}$ production according to the formulas of Weir (1949). Oxidation of CHO and fat was calculated using the equations of Brouwer (1957). The assumption was made that protein intake and oxidation were equal under these conditions in the respiration chamber as was seen before in our lab (Schoffelen et al., 1984; Brouns et al.,1989; Verboeket-van de Venne, 1994).

Fat oxidation (g.day $\left.{ }^{-1}\right)=1.718 * \mathrm{VO}_{2}-1.718 * \mathrm{VCO}_{2}-0.315 * \mathrm{P}$

CHO oxidation (g.day $\left.{ }^{-1}\right)=4.17 * \mathrm{VCO}_{2}-2.965 * \mathrm{VO}_{2}-0.390 * \mathrm{P}$

where $\mathrm{VO}_{2}$ is the oxygen consumption (L.day ${ }^{-1}$ )

$\mathrm{VCO}_{2}$ is the carbon dioxide production (L.day $\left.{ }^{-1}\right)$

$P$ is the protein oxidation (g.day ${ }^{-1}$ ) 
The physical activity of the subjects in the chamber was monitored by means of a radar system, based on the Doppler principle (Advisor DU 160, USA).

\section{High-fat and reduced-fat diet}

During their stay in the respiration chamber subjects were either fed a high-fat (Hit.F) diet or a reduced-fat (Red.F) diet at each occasion. Exchange of macronutrients was carried out for CHO and fat. The Hi.F-diet contained 15 energy $\%$ of protein; 60 energy $\%$ of fat and 25 energy $\%$ of CHO. The amount of fiber was 0.8 gram per $M$ I and the P/S ratio was 0.17 . The Red.F-diet contained 15 energy $\%$ of protein; 30 energy $\%$ of fat and 55 energy $\%$ of CHO. The amount of fiber per MJ was $1.2 \mathrm{gram}$ and the $\mathrm{P} / \mathrm{S}$ ratio 0.46 .

The meals were served at $8.00 \mathrm{~h}$ (breakfast); at $13.00 \mathrm{~h}$ (lunch) and at $18.00 \mathrm{~h}$ (dinner). The composition of the macronutrients for each meal was similar as the composition of the diet over the whole day. Breakfast contained $25 \%$ of the total energy intake (E); lunch contained $35 \%$, and dinner was composed of $40 \%$ of the total EI. The meals were prepared with common food items like bread, cheese, jelly, sausage, milk, pasta, etc. Each food item was weighed to the nearest gram on a precise balance. In between the main meals subjects were allowed to drink water, tea or coffee without sugar and milk (only sweeteners were allowed), to prevent energy intake between the main meals.

$24 \mathrm{~h} \mathrm{EE}$ and $\mathrm{RQ}$ were calculated from $0.00 \mathrm{~h}$ to $0.00 \mathrm{~h}$ the next day. $\mathrm{EB}$ was determined by subtracting $24 \mathrm{~h} \mathrm{EE}$ from energy intake (EI). Macronutrient composition and total EI was calculated using the Dutch food composition table (Becel, 1989). The food quotient (FQ) defined as the ratio of $\mathrm{CO}_{2}$ produced to $\mathrm{O}_{2}$ consumed during the oxidation of a representative sample of the diet (Flatt, 1987), was calculated using the following equations (Jéquier et al., 1987):

$\mathrm{O}_{2}$ consumption $\left(\mathrm{L}\right.$. day $\left.^{-1}\right)=\left(0.966^{*}\right.$ protein intake $)+(2.019 *$ fat intake $)+(0.829 * \mathrm{CHO}$ intake), and $\mathrm{CO}_{2}$ production $\left(\mathrm{L}\right.$.day $\left.{ }^{-1}\right)=\left(0.774^{*}\right.$ protein intake $)+(1.427 *$ fat intake $)+$ $(0.829 * \mathrm{CHO}$ intake), where the intake of protein, fat and $\mathrm{CHO}$ is expressed in grams per day. Correction based upon the Atwater factors were performed before calculation of the $\mathrm{VO}_{2}$ and $\mathrm{VCO}_{2}$ of the $\mathrm{FQ}$ (for protein, fat and $\mathrm{CHO}$ the factors are $0.909,0.948$ and 0.953 respectively, to correct for differences in digestibility). The computer program used for calculation of EI already corrected the weighed food items itself.

\section{Activity protocol}

In the respiration chamber a strict activity protocol was kept, to prevent inactivity. Subjects were waked at $7.15 \mathrm{~h}$ and were asked to sleep at $23.00 \mathrm{~h}$. In between they cycled at $10.00 \mathrm{~h}$ and at $15,00 \mathrm{~h}$ for 1 hour. During daytime subjects were allowed to move freely, to sit, lie down, telephone, listen to the radio and watch television, however sleeping and other exercise activities than prescribed, were not allowed.

Absolute and relative workload

Due to the training program the individual maximal acrobic capacity and power output increased during the course of the study. Therefore the relative work load cycled in the respiration chamber $(40 \% \mathrm{Wmax}$ ) changed. To compare substrate oxidation at a same absolute work load the subjects were asked at the last time point (=month 16) to stay in the respiration chamber for $60 \mathrm{~h}$. 9 Subjects were willing to participate in this part of the study. At the first day the normal procedure was performed (feeding subjects in energy balance and cycling at a relative work load of $40 \%$ Wmax). During the second day exactly the same conditions regarding energy balance and absolute workload were imposed as measured during the first chamber measurement at month 0 . This second day stay enabled us to 
compare substrate utilization changes caused by training and weight loss at an absolute work load.

\section{Data analysis}

Four major questions with respect to $24 \mathrm{~h}$ energy and substrate balances were studied:

1. Long-term training effect. The effect of training in the obese group was examined using an exercise protocol in the respiration chamber with a relative work load of $40 \% \mathrm{Wmax}$. Comparison of the starting condition of weight maintenance (month 4: after weight loss and first training period) $(n=12)$ with the final weight maintenance measurements were analysed with paired $t$-tessts.

2. Effect of training and initial weight loss. The effect of training in the obese group after a weight reduction period was examined using an exercise protocol in the respiration chamber with an absolute work load based on $40 \%$ Wmax at baseline. The measurement at baseline (month 0 ) and the second day of month $16(n=9)$ were compared with paired t-tests.

3. Macronutrient composition of the diet. The effect of diet supplied in the respiration chamber (Hi.F vs Red.F) was analysed by comparison of the RQ and FQ of the diets $(\mathrm{n}=12)$ with paired t-tests at different time points of the study.

4. Training status. The obese group at 16 months of training was compared with the lean group to find out whether the training intervention had changed substrate utilization in the obese subjects towards the direction of the lean, well-trained subjects. Differences were analysed with unpaired t-tests.

In the text, tables and figures data are presented as mean and standard deviation $(\mathbb{t} \mathrm{sd})$.

\section{Physical characteristics}

\section{Results}

Physical characteristics of the obese and the well-trained group are presented in table 8.1. No differences in physical characteristics within both groups receiving a Hi.F or Red.F diet were found. Physical characteristics of the well-trained group differed, as expected, significantly for almost all physical variables from the obese group; subjects were only matched for age (table 8.1). At the end of the study the obese group that received a Hi.F-diet in the respiration chamber trained on average $2.1 \pm 2.3 \mathrm{~h}$. week ${ }^{-1}$ which was similar for the Red.F-diet receiving group, $2.0 \pm 2.1$ h.week ${ }^{-1}$. The amount of training hours a week of the obese subjects was significantly increased compared with the sedentary status at the beginning of the study. Of the well-trained subjects the Hi.F-diet group trained $13.3 \pm 9.7$ hours a week and had a training history of $18.8 \pm 8.9$ years. The Red.F-diet group trained $10.9 \pm 3.8$ hours a week and had a training history of $20.6 \pm 6.7$ years.

Because of the weight loss of $13.7 \pm 3.0 \mathrm{~kg}$ after 8 weeks VLED (range $8.2-18.5 \mathrm{~kg}$ ) no respiration chamber measurement was performed at that time point, because the influence of the weight loss would overrule the effect of exercise training.

\section{Long-term training effect}

The effect of training at substrate oxidation for the Hi.F and Red.F obese group by comparison of month 4 and month 16, is shown in table 8.2. Both groups were in EB at 4 and 16 months. The relative work load of $40 \% \mathrm{~W} \max$ was at 4 months $117 \pm 12 \mathrm{~W}$ and 122 $\pm 19 \mathrm{~W}$ for the Hi.F and Red.F-diet recieving group, resp. (no significant differences). At 16 months the work load cycled in the chamber was $113 \pm 15 \mathrm{~W}$ and $114 \pm 24 \mathrm{~W}$ for the Hi.F and Red.F diet group, resp (again no significant differences). The reliative work load was not significantly different over time. Negatiwe CHO balances were found for both diets, 
Table 8.1 Physical characteristics of the obese and well-trained subjects

\begin{tabular}{|c|c|c|c|c|}
\hline & $\begin{array}{l}\text { Obese } \\
\text { Hi.F dijet }\end{array}$ & Red F diet & $\begin{array}{l}\text { Well-trained } \\
\text { Hi.F diet }\end{array}$ & Red.F diet \\
\hline Nomber & 6 & 6 & 8 & 7 \\
\hline Age (yrs) & $36.8(5.0)$ & $35.8(5.6)$ & $35.9(7.6)$ & $36.6(7.2)$ \\
\hline $\mathrm{BW}(\mathrm{kg})$ & $94.6(12.4)$ & $94.5(16.6)$ & $72.0(5.2)$ & $72.4(7.1)$ \\
\hline hoight (m) & $1.76(0.07)$ & $1.74(0.15)$ & $1.81(0.03)$ & $1.79(0.04)$ \\
\hline $\mathrm{BMI}\left(\mathrm{kg} \cdot \mathrm{m}^{-2}\right)$ & $30.6(3.1)$ & $31.0(3.3)$ & $21.9(1.5)$ & $22.7(2.0)$ \\
\hline W/H ratio & $0.95(0.05)$ & $0.95(0.04)$ & $0.84(0.04)$ & $0.85(0.05)$ \\
\hline Sagitt的 $1(\mathrm{~cm})$ & $23.5(2.7)$ & $23.4(2.1)$ & $15.8(0.6)$ & $16.5(1.0)$ \\
\hline Body fat $(\%)$ & $29.5(2.2)$ & $28.8(4.6)$ & $12.9(1.6)$ & $15.5(3.2)$ \\
\hline$W \max (W)$ & $245(22)$ & $253(49)$ & $355(35)$ & $339(34)$ \\
\hline $\mathrm{VO}_{2} \max \left(\mathbb{L} \cdot \min ^{-1}\right)$ & $2.9(0.3)$ & $3.1(0.7)$ & $4.4(0.6)$ & $4.5(0.4)$ \\
\hline
\end{tabular}

The mean baseline physical characteristics of the 12 obese subjects and of the 15 well-trained subjects (standard deviations are presented in parentheses).

Table 8.2 Energy and substrate balances for the obese group

\begin{tabular}{|c|c|c|c|c|}
\hline & \multicolumn{2}{|l|}{ Hi.F diet $(n=6)$} & \multicolumn{2}{|l|}{ Red F diet $(n=6)$} \\
\hline & 4 months & 16 months & 4 months & 16 months \\
\hline EDB & $-0.03 \pm 0.32$ & $-0.01 \pm 0.48$ & $-0.36 \pm 0.70$ & $-0.29 \pm 0.98$ \\
\hline $\mathrm{RQ}$ & $0.800 \pm 0.017^{a b}$ & $0.825 \pm 0.008^{b}$ & $0.862 \pm 0.009^{2}$ & $0.887 \pm 0.024$ \\
\hline $\mathrm{FQ}$ & $0.787 \pm 0.003^{a b}$ & $0.789 \pm 0.002^{b}$ & $0.869 \pm 0.001^{\mathrm{a}}$ & $0.871 \pm 0.002$ \\
\hline$\triangle \mathrm{CHO}$ & $-17.9 \pm 41.8^{a b}$ & $-87.8 \pm 26.3^{b}$ & $+30.8 \pm 39.6^{a}$ & $-40.3 \pm 58.1$ \\
\hline$\Delta(\triangle C H O)$ & \multicolumn{2}{|c|}{$-69.9 \pm 39.2$} & \multicolumn{2}{|c|}{$-71.1 \pm 67.2$} \\
\hline$\Delta$ fat & $+5.6 \pm 24.8^{a b}$ & $+38.4 \pm 12.7^{b}$ & $-25.7 \pm 11.2^{\mathrm{a}}$ & $+8.7 \pm 37.4$ \\
\hline$\Delta(\Delta$ fati $)$ & \multicolumn{2}{|c|}{$+34.4 \pm 35.4$} & \multicolumn{2}{|c|}{$+32.8 \pm 16.3$} \\
\hline
\end{tabular}

$24 \mathrm{~h} \mathrm{~EB}, \mathrm{RQ}$ and FQ, and substrate balances (mean $\pm \mathrm{sd}$ ) when fed a Hi.F-diet and a Red.F-diet, at 4 months and 16 months ( $\Delta$ : difference between the substrate balances at 16 and 4 months). The energy balance (EB) is presented in $\mathrm{MJ}_{\text {.day }}{ }^{-1}$ and the carbohydrate balance $(\Delta \mathrm{CHO})$ and fat balance $(\Delta \mathrm{fat})$ in grams day ${ }^{-1} . \Delta(\Delta \mathrm{CHO})$ and $\Delta(\Delta$ fat $)$ are the changes in $C H O$ and fat balance resp. fron 4 to 16 months. $p<0.05$ within the diet over" trme (4 months vs 16 months). $\mathrm{b}$ p 0.05 between diels (Hi F vis Red.F diet)

especially at 16 months. For both diets a difference of 70 grams of CHO in comparison to the month 4 measurement was found. During the training intervention the fat balance became even more positive (an increase of 33 grams), already indicating that fat oxidation was not improved.

\section{Training and weight loss}

The effect of training and weight loss was examined by comparison of $24 \mathrm{~h}$ energy balanice and substrate balance at baseline (month 0 ) and at the second $24 \mathrm{~h}$ respiration chamber day of the month 16 measurement. The subjects exercised throughout the day at the same absolute work load (Hi.F group: $n=5,102 \pm 6 \mathrm{~W}$; Red.F group, $n=4,106 \pm 17 \mathrm{~W}$ ) determined at month 0 . In addition to a similar work load a comparable negative energy ballance was imposed $(-1.0 \mathrm{MJ})$ at 16 months as measured at 0 months. The negative $\mathrm{EB}$ at 0 months was due to the fact that actual $\mathrm{EE}$ was higher than the estimated EE, which was used for calculation of the amount of food supplied in the chamber. Therefore an inadequate amount of food was supplied, resulting in a negative EB. Despite this negative EB, the CHO and fat 
balances of both diets indicated that subjects still relied mostly at CHO. The results measured at month 0 and month 16 (second day) with a fixed work load are in accordance with the results presented in table 8.2, for the chamber experiments with relative work loads ( $\Delta$ (Hi.F vs Red.F): $\triangle \mathrm{CHO}:-16.0 \pm 36.0$ vs $-70.0 \pm 25.8$ g.day $^{-1}$, $\mathrm{p}<0.05 ; \Delta$ fat : $6.4 \pm 21.8$ vs 34.9 \pm 22.5 g.day $\left.{ }^{-1}, \mathrm{p}<0.1\right)$. The difference in $\mathrm{CHO}$ balance $(\Delta(\Delta \mathrm{CHO})$ at month 16 (second day) and the month 0 measurement of $-54 \mathrm{~g}$ of $\mathrm{CHO}$ per $24 \mathrm{~h}$ indicates that for the same protocol more CHO was oxidized at month 16 . The difference in fat balances $(\Delta(\Delta$ fat $)$ $(+28 \mathrm{~g})$ also indicate that subjects oxidized even less fat than at the start of the study, and that $24 \mathrm{~h}$ fat oxidation was not stimulated after one year of endurance training.

Macronutrient composition of the diet

The effect of the macronutrient composition of the diet at substrate oxidation is presented in fig.8.1 for the obese group and the well-trained group. Comparison of the FQ of the diet and the measured RQ of the well-trained subjects show significant differences.

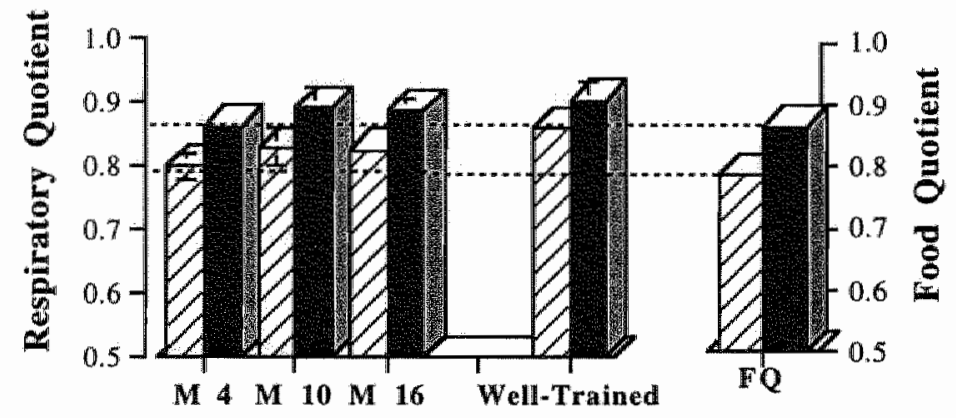

Obese

Fig.8.124h Respiratory quotients (RQ) and food quotient (FQ) (mean \pm sd) of the high-fat (hatched bars) and reduced fat (filled bars) diet at 4 months (M 4), at 10 months (M 10) and at 16 months (M 16$)$ for the obese group and of the once measured well-trained group. RQ of both diets between month 4 and month 10 differed significantly; and RQ of both diets between month 4 and month 16 differed significantly.

For both diets the $24 \mathrm{~h} \mathrm{RQ}$ value was higher than the FQ value at all time points for the obese group (range 0.01-0.04 for the Hi.F diet, significantly higher RQ at 10 and 16 months; range $0.00-0.02$ for the Red.F diet, RQ not significantly different from FQ). These differences were even more pronounced in the well-trained group; a difference in $R Q$ and $F Q$ of 0.07 was found for the Hi.F diet, and a difference of 0.04 for the Red.F diet $(\mathrm{p}<0.05$ ). The obese group showed changes in RQ in the course of the study in the direction of the well-trained group. However, the $24 \mathrm{~h}$ RQ values measured at 16 months were still significantly lower compared to the $24 \mathrm{~h} \mathrm{RQ}$ values of the well-trained group, at the Hi.F diet (Hi.F diet: RQ obese $0.83 \pm 0.01 v s$ trained $0.86 \pm 0.01$, p $<0.001$ ). For the Red.F diet the differences in RQ were not significant (Red.F diet: RQ obese $0.89 \pm 0.02 v s$ trained $0.90 \pm$ $0.03, \mathrm{NS}$ ). These findings are further illustrated in table 8.3. The obese group, although oxidizing more $\mathrm{CHO}$ at 16 months than at the start of the study, showed less CHO oxidation compared to the well-trained subjects. With a Hi.F diet the well-trained group apparentily oxidized significantly less fat compared to the obese group. 


\section{Training status}

To find out how the $24 \mathrm{~h}$ positive fat balances and negative CHO balances could arise, as found at month 16 (day 1) and especially for the lean, well-trained group (see table 8.3), the data were further analyzed by comparison of substrate oxidation during the first and second night (a $12 \mathrm{~h}$ measurement from $19.00 \mathrm{~h}-7.0 \mathrm{hh}$ ). In fig.8.2a the amount of $\mathrm{CHO}$ oxidation is presented for the Hi.F and Red.F diets in the obese group (at month 16) and the well-trained group for the first and second night in the respiration chamber. No differences between the

Table 8.3 Energy and substrate balances for the obese and well-trained group

\begin{tabular}{lcllll}
\hline & $\begin{array}{l}\text { Hi.F diet } \\
\text { OB (n=6) }\end{array}$ & WT $(n=8)$ & $\begin{array}{l}\text { Red.F diet } \\
\text { OB }(n=6)\end{array}$ & WT $(n=7)$ & \\
\hline EB & $-0.03 \pm 0.49$ & $+0.39 \pm 0.70$ & $-0.35 \pm 1.0$ & $-0.60 \pm 0.74$ & f \\
RQ & $0.825 \pm 0.01$ & $0.86 \pm 0.01$ & $0.887 \pm 0.02$ & $0.90 \pm 0.03$ & abcef \\
FQ & $0.789 \pm 0.002$ & $0.786 \pm 0.001$ & $0.871 \pm 0.002$ & $0.865 \pm 0.005$ & acdef \\
$\Delta \mathrm{CHO}$ & $-87.8 \pm 26.2$ & $-185.4 \pm 33.0$ & $-40.3 \pm 58.1$ & $-103.0 \pm 97.1$ & bdf \\
$\Delta$ fat & $+38.4 \pm 12.7$ & $+92.0 \pm 10.3$ & $+8.7 \pm 37.4$ & $+30.0 \pm 37.8$ & bdf
\end{tabular}

Energy and substrate balances (mean \pm sd) of the obese(OB) ws well-trained (WT) subjects when fed a Hi.Fdiet or a Red.F-diet. The trained have been measured once and the data presented of obese were measured after 16 months of training. The energy balance (EB) is presented in MJ.day ${ }^{-1}$ and the carbohydrate ballance $(\triangle \mathrm{CHO})$ and fat balance ( $\triangle \mathrm{fat})$ in grams day ${ }^{-1}$.

paired t-tests p<0.05: a: OB, Hi.F ws OB, Red.F; b: OB, Hi.F ws WT, Hi.F; $c$ : OB, Hi.F vs WT, Red.F; d: OB, Red.F vs WT, Hi.F; e: OB, Red.F vs WT, Red.F; f: WT, Hi.F ws WT, Red.F

first and second night were found in $\mathrm{CHO}$ oxidation with Anova-repeated measurements. For the fat oxidation however, as presented in fig.8.2b, the differences between the first and second night were significant $(p<0.05)$. An increase in fat oxidation was found in the Hi.Fgroups in the second night.

Because clear negative $\mathrm{CHO}$ balances were found for $24 \mathrm{~h}$ data and no differences were seen in $\mathrm{CHO}$ oxidation of night 1 compared to night 2 , a high amount of $\mathrm{CHO}$ had to be oxidized during the day. The main activity during the day was the 2 times 1 hour cycling activity at 40\% Wmax. In table 8.4 the total amount of $\mathrm{CHO}$ and fat oxidized during the two hour cycling activity are presented for the four groups. Significant differences in amount of CHO and fat oxidized were found between the Hi.F and Red.F diet, whereas training status (obese $w s$ well-trained group) did not result in differences in substrate oxidation (group 1 and 2 , and group 3 and 4 are not significantly different). 

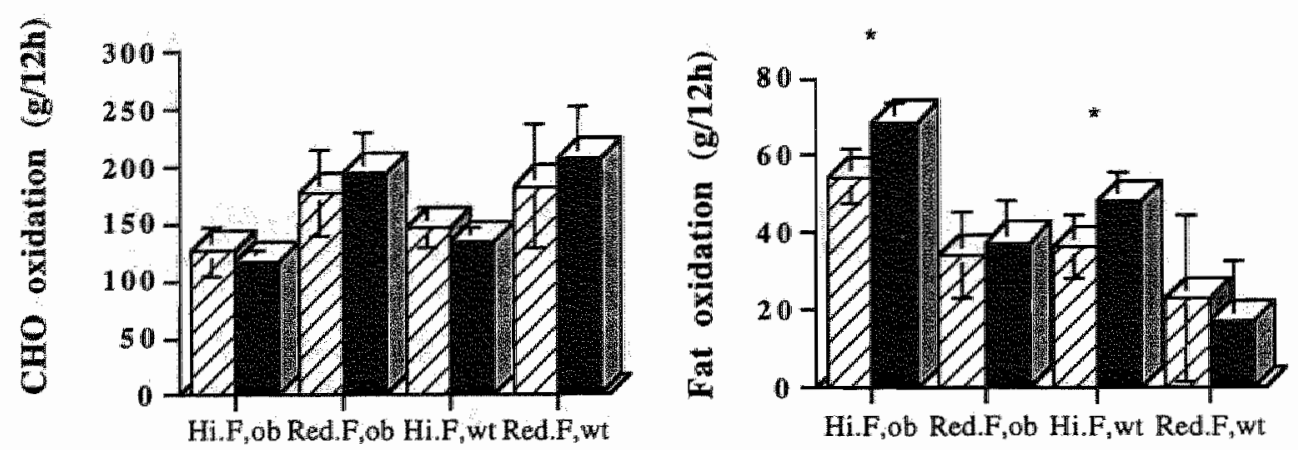

Substrate oxidation during the night

Fig. 8.2 The carbohydrate oxidation (fig.8.2a - left) measured during the first (hatched bars) and second night (filled bars) in the respiration chamber was measured from 19.00 PM to 7.00 AM. Carbohydrate oxidation (total over 12 hours) is presented for the obese group (ob) at 16 months and the welltrained (wt) group for the high-fat (Hi.F) and reduced-fat (Red.F) diet during the first (hatched bars) and the second night (filled bars). No differences in $\mathrm{CHO}$ oxidation were found between the first and second night.

The fat oxidation (fig. $8.2 \mathrm{~b}$ - right) measured during the first (hatched bars) and second night (filled bars) in the respiration chamber was measured from 19.00 PM to 7.00 AM. Fat oxidation (total over 12 hours) is presented for the obese group (ob) at 16 months and the well-trained (wt) group for the high-fat (Hi.F) and reduced-fat (Red.F) diet during the first (hatched bars) and the second night (filled bars). Significant differences in fat oxidation were found between the first and second night for the Hi.F-consuming groups (indicated with *).

Regression analysis to clarify the factors related to $\mathrm{CHO}$ and fat oxidation (during the first and second night), were executed. Body fat percentage and hours of training weekly were used as factors to explain the variance in fat oxidation in the first and second night. The relation between body fat $\%$ and fat oxidation increased in the second night $(r=0.33, p=0.09$ during the first night and $r=0.41, p<0.05$ during the second night). Hours of training a week was not related with fat oxidation. No relation was found between body fat percentage or hours of training with CHO oxidation.

Table 8.4 Substrate oxidation during cycling exercise

CHO oxidation

$143.1 \pm 24.5$

$169.9 \pm 35.1$

$196.1 \pm 46.8$

$198.6 \pm 35.6$

$*(\pi, b)$
Fat oxidation

$52.8 \pm 11.4$

$52.9 \pm 11.2$

$32.7 \pm 7.9$

$41.6 \pm 11.3$

$*(\mathrm{a}, \mathrm{c})$

The total CHO and fat oxidation during 120 minutes of cycling is presented for the Hi.F, obese group (Hi.F, ob); Hi.F, well-trained group (HiF, wt); the Red.F, obese group (Red.F, ob); and the Red.F, well-trained group (Red.F, wt). a: Hi.F, ob vs Red.F, ob; b: Hi.F, ob ws Red.F, wt: c: Red.F, ob ws Hi.F, wt 


\section{Substrate axidation}

\section{Discussion}

The important findings in the present study were the $24 \mathrm{~h}$ negative CHO balances and positive fat balances found under these experimental conditions for the obese group, even after participation in an exercise training program. The data presented, clearly indicate that the training intervention resulted in a higher reliance on CHO as the 24 h energy substrate in the course of the study. The results are supported by similar findings in a well-trained group, that indicate that life-long training results in increased $24 \mathrm{~h}$ CHO oxidation and less fat oxidation, during a $24 \mathrm{~h}$ protocol in the respiration chamber with $2 \mathrm{~h}$ of moderate exercise. The $24 \mathrm{~h}$ negative $\mathrm{CHO}$ balances and positive fat balances found in the present study are in contrast to the general consensus that endurance training stimulates fat oxidation during exercise (Turcotte et al., 1992; Kiens et al., 1993; Martin et al., 1993; Brooks and Mercier, 1994) and during rest (Bouchard et al., 1993; Calles-Escadón et al., 1996). The positive fat balances, even in the Red.F conditions, might indicate that the amount of fat supplied was too high or that fat oxidation was reduced. During the training intervention the fat balance became even more positive (an increase of 33 grams), already indicating that fat oxidation did not improve. The similar differences found in the CHO balance ( $70 \mathrm{gram}$ ) and the fat balance ( $33 \mathrm{gram}$ ) for both types of diets (table 2), indicate that a one year training program did not alter metabolic capacity to increase fat oxidation. With respect to the substrate oxidation results found in the present study, two important factors should be stressed. Firstly, the results are collected under strict energy balance (except for the month 0 and month $16 /$ second day). Secondly, the results presented are based upon $24 \mathrm{~h}$ data and include not only exercise performance data.

\section{CHO oxidation}

An explanation for the clear negative $\mathrm{CHO}$ balances (increased $\mathrm{CHO}$ oxidation) found, (table 3) could be the increase in absolute exercise performance (relative $40 \% \mathrm{Wmax}$ ). The increased energy expenditure has to be generated by more fuel, and could therefore explain, when an impaired fat oxidation is present, the increase in CHO oxidation. However, the results comparing the absolute work load at month 0 and month $16 /$ day 2 (see results section) showed a similar shift in substrate oxidation towards CHO. The work load cycled at the first $24 \mathrm{~h}$ respiration chamber day at month 16 was significantly higher $(15 \%)$ in comparison to the baseline $40 \%$ Wmax work load. This illustrates that it was worth while to differentiate between absolute and relative work load. The oxidation of substrates however did not differ significantly, and stressed again that the 16 months exercise intervention did not improve fat oxidation in the obese subjects. However, the finding that the well-trained subjects showed an even more pronounced $24 \mathrm{~h}$ CHO oxidation, might suggest that other regulatory mechanisms are involved when substrate oxidation is examined for a whole day. A separate examination of substrate oxidation during the night and of the cycling activities during the day, did not reveal a possible mechanism for the exaggerated CHO oxidation and showed no differences between the obese and well-trained group.

We are aware of only two other studies reporting an increase in CHO oxidation after an exercise intervention. In the first study post-obese women trained 2-3 times a week for 45$60 \mathrm{~min}$, for 3-4 months, outdoor running and cycling (Buemann et al, 1992). Although the intensity and frequency of the training sessions is lower in comparison to the present study, on average a comparison with our study is very well possible. Sleeping and $24 \mathrm{~h} \mathrm{RQ}$ were found to be significantly increased after the training intervention, and an increased CHO 
availability after training was suggested (Buemann et al., 1992). Also Westerterp and coworkers (1994) reported an inerease in RQ during the night. Untrained, normal weight male and female subjects participated in an endurance training intervention of 44 weeks, to complete a half-marathon. Overnight a change to relatively less fat and more CHO oxidation was found in the course of the training intervention (Westerterp et al., 1994). Their suggestion that training could result in an increased insulin sensitivity and therefore end-up with higher glycogen stores, agrees with the suggestion of Buemann that more CHO were available. Increased glycogen levels in trained ( 584 mmol.kg dry weight $^{-1}$ ) compared to untrained subjects (433 mmol.kg dry weight ${ }^{-1}$ ) have been found (Turcotte et al., 1992). Higher glycogen levels therefore might result in an increased $24 \mathrm{~h}$ CHO oxidation. Although the measurements in the present study were carried out under energy balance condition we would like to suggest that the increased CHO oxidation could be explained by lipogenesis in the muscle. Predominant depletion of intramuscular triglycerides (IMTG) during exercise has been found in trained subjects, suggesting that the greater utilization of fat during exercise is due to increased lipolysis of IMTG (Hurley et al., 1986). These stores need to be replenished, what could possibly be done via increased $24 \mathrm{~h}$ CHO oxidation. Lipogenesis might therefore explain the increased $24 \mathrm{~h}$ CHO oxidation found with training.

Macronutrient composition of the diet

Fat oxidation was increased in the groups that received a Hi.F-diet. Increased fat oxidation when Hi.F diets are supplied has been found before (Hill et al., 1991; Verboeket-van de Venne et al., 1994). This finding is in contrast with the result of Schutz, who observed no increased fat oxidation after addition of $106 \mathrm{~g}$ of fat to a meal (Schutz et al., 1989). The equicaloric exchange in macronutrients as carried out in our study might explain this difference. The theory of Flatt, that fat does not promote its own oxidation seems to be in conflict with our result (Flatt, 1987). A possible explanation for the fast adaptation of substrate oxidation to substrate intake could be the increased energy turnover due to the exercise bouts. The normally slow adaptation to a Hi.F-diet (7 days; Schrauwen et al., 1997) is perhaps accelerated because of the increased energy turnover. It was further found that body fat percentage was positively related to fat oxidation, indicating that the higher the body fat percentage the more fat was oxidized, as has been suggested before (Astrup et al., 1994; Schutz et al., 1995).

In the present study the Hi.F or Red.F diet given in the respiration chamber, was supplied to the subjects acutely. The diet consumed in the chamber was not supplied the days before at home, so no adaptation to the diet could take place. Daily food intake was recorded during the three days prior to the measurement to examine food intake and the possible effect at substrate oxidation in the chamber. No relation was found between the CHO-fat ratio of the diet prior to the chamber experiment and the substrate oxidation measured in the chamber (for CHO intake and CHO oxidation, $r=0.19, N S$; for fat intake and oxidation, $r=0.18, N S$ ). Therefore it is not likely that the type of food consumed prior to the respiration chamber measurement did affect substrate oxidation measured in the chamber.

The changes in substrate oxidation caused by training would preferably be studied with the data of the first measurement at month 0 , and compared with month 16 (day 1). Based upon the clear negative energy balance at the start however we decided to study the effect of training when subjects were in energy balance after weight loss (at month 4) and compare the results with the results obtained at month 16 (day 1). The second day of the month 16 measurement was carried out, to obtain the same negative energy balance and also the same 
absolute work load, to create an identical situation in order to study the effect of training over the complete 16 months period. These results confirmed the finding that endurance training resulted in increased $24 \mathrm{~h}$ CHO oxidation.

\section{Conclusion}

Endurance training did not result in an increased fat oxidation over $24 \mathrm{~h}$, as is often found for the training performance itself. Data of well-trained subjects supported the finding that during this $24 \mathrm{~h}$ protocol in the respiration chamber mostly CHO were oxidized. It was further found that the diet supplied in the chamber affected the substrate oxidized, resulting in increased fat oxidation at a high-fat diet and an increased CHO oxidation at a reduced fat diet. Future studies should analyze the discrepancy of substrate oxidation during exercise and $24 \mathrm{~h}$ substrate oxidation.

\section{References}

Abbott WGH, Howard BV, Christin L, Freymond D, Lillioja S, Boyce VL, Anderson TE, Bogardus C, Ravussin E. Short-tern energy balance: relationship with protein, carbohydrate, and fat balances. Am. J.Physiol.255 (Endocrin.Metab.18): E332-E337, 1988

Astrup A, Buemann B, Western P, Toubro S, Raben A, Christensen NJ. Obesity as an adaptation to a highfat diet: evidence from a cross-sectional study. Am.J.Clin.Nutr.59: 350-355, 1994

Barnard RJ, Wen SJ. Exercise and diet in the prevention and control of the metabolic syndrome. Sports. Med.18: 218-228, 1994

Becel, Nederlandse Voedingsstoffenbestand (NEVO). Dutch nutrient database 1989/1990. Zeist, The Netherlands: Stichting NEVO (in Dutch), 1989

Blaak EE, wan Baak MA, Kemerik GJ, Pakbiers MTW, Heiendal GAK, Saris WHM. B-Adrenergic stimulation of energy expenditure and forearm skeletal muscle metabolism in lean and obese men. Am.J.Physiol 267: E306-E315, 1994

Bouchard C, Deprés JP,Tremblay A. Exercise and obesity. Obes.Res.1: 133-147, 1993

Bouchard C. Can obesity be prevented? Nutr.Rev. 54: S125-S130, 1996

Brooks GA, Mercier J. Balance of carbohydrate and lipid utilization during exercise: the "crossover" concept. J.Appl.Physiol. 76: 2253-2261, 1994

Brouns F, Saris WHM, Beckers E, Adlercreutz $\mathbb{H}$, van de Vusse GJ, Keizer HA, Kuipers H, Menheere P, Wagenmakers AJM, ten Hoor F. Metabolic changes induced by sustained exhaustive cycling and diei manipulation. Int.J.Sports Med.10: S49-S62, 1989

Brouwer $\mathrm{E}$. On simple formulae for calculating the heat expenditure and the quantities of carbohydrate and fat oxidized in metabolism of men and animals, from gaseous exchange (oxygen intake and carbonic acid. output) and urine. Acta Physiol.Pharmacol. Neerlandica 6: 795-802, 1957

Buemann $B$, Astrup $A$, Christensen NJ. Three months aerobic training fails to affect 24 -hour entergy expenditure in weight-stable, post-obese women. Int.J.Obes.16: 809-816, 1992

Calles-Escandón J, Goran MI, O'Connell M, Sreekumaran Nair $K$, Danforth E. Exercise increnses fat ox.jdation at rest unrelated to changes in energy balance or lipolysis. Am.J.Physiol.270 (Endocrin. Metab. 33): E1009-E1014, 1996

Flat JP. Dietary fat, carbohydrate balance, and weight maintenance: effects of exercise. Am.J.Clin.Nutr.45: 296-306, 1987

Flat JP. Dietary fat, carbohydrate balance and weight maintenance. Ann.N.Y.Acad.Sci.683: 122-140, 1993

Flatt JP. McCollum Award Lecture, 1995: Diet, lifestyle, and weight maintenance. Am.J.Clin. Nutr.62: 820$836,1995 a$

Flatt JP. Integration of the overall response to exercise. Int.J.Obes. 19(Suppl.4): S31-S40, 1995b

Harris $J A$, Benedict $F G$. A biometric study of basal metabolism in man. Washington, Carnegie Institution, 1919

Hill JO, Peters JC, Reed GW, Schlundt DG, Sharp T, Greene HL. Nutrient balance in humans: effects of diet composition. Am. J.Clin.Nutr. 54: 10-17, 1991

Hurley BF, Nemeth PM, Martin WH, Hagberg IM, Dalsky GP, Holloszy JO. Muscle triglyceride utilization during exercise: effect of training. J.Appl.Physiol.60: 562-567, 1986

Jequier $E_{y}$ Acheson $\mathbb{K}_{\text {, Schutz }} \mathrm{Y}$. Assessment of energy expenditure and fuel utilization in man. Ann.Rev. Nutr.7: $187-208,1987$ 


\section{Chapter 8}

Kiens $\mathrm{B}$, Essen-Gustavsson $\mathrm{B}$, Christensen $\mathrm{NJ}$, Saltin $\mathrm{B}$. Skeletal muscle substrate utillization during submaximal exencise in man: effect of endurance training. J.Physiol.469:459 $47 \mathrm{~B}_{\mathrm{i}}, 1993$

Larson DE, Ferraro RT, Robertson D, Ravussin E. Energy metabolism in weight-stable postobese indiwiduals. Am.J,Clin.Nutr.62: 735-739, 1995

Marken Lichtenbelt WD van, Westerterp $K R$, Wouters $L$. Deuterium dilution as a method for determining total body water: effect of test protocol and sampling time. Br.J.Nutr.72:491-497, 1994

Martin WH, Dalsky GP, Hurley BF, Matthews DE, Bier DM,Hagberg MM, Rogers MA, King DS, Holloszy 10. Effect of endurance training on plasma free fatty acid turnover and oxidation during exercise. Am.J.Physiol.265 (Endocrin Metab. 28): E708-E714, 1993

Prentice AM, Jebb SA Obesity in Britain: gluttony or sloth? B.M.J. 311: 437-439, 1995

Ravussin E, Swinburn BA. Pathophysiology of obesity. Lancet 340: 404-408, 1992

Saris WHM. Physical activity and body weight regulation. In: Bouchard C, Bray GA, ed.: Regulation of body weight: Biological and biohsvioral mechanisms. John Wiley \& Sons Ltd., pg: 135-148, 1996

Schoeller DA, Santen E yan, Peterson DW, Diez W, Jaspan J, Klein PD. Total body water measurement in humans with ${ }^{18} \mathrm{O}$ and ${ }^{2} \mathrm{H}$ labeled water. Am.J.Clin.Nutr.33: 2686-2693, 1980

Schoffelen PFM, Saris WHM, Westerterp $\mathrm{KR}_{\text {, }}$ ten Hoor F. Ewaluation of an automated indirect calorimeter for measurement of energy balance in man, In: Van Es, A.J.H. (ed). Human energy metabolism: physical activity and energy expenditure measurements in epidemiological research based upon direct and indirect calorimetry. Euro-nut report 1094; 5: 51-54. Stichting Nederlands Instituut voor de Vaeding, Wageningen, The Netherlands, 1984

Schrauwen P. Marken Lichtenbelt WD van. Saris WHM, Westerterp KR. Changes in fat oxidation in response to a high-fat diet. Am.J.Clin.Nutr.66: 276-282, 1997

Schutz X. Flatt JP, Jéquier E. Failure of dietary fat intake to promote fat oxidation: a factor favoring the development of obesity. Am.J.Clin.Nutr.50: 307-314, 1989

Schutz Y. Abnormalities of fuel utilization as predisposing to the development of obesity in bumans. Obes.Res.3(suppl.2):173s-178s, 1995

Seidell JC, Flegal KM. Assessing abesity: classification and epidemiology. Brit.Med.Bull. 53: 238-252, 1997

Tremblay A, Buemann B. Exercise-training, macronutrient balance and body weight control. Int.J.Obes. 19: $79-86,1995$

Turcotte LP, Richter EA, Kiens B. Increased plasma FFA uptake and oxidation during prolonged exercise in trained vs untrained humans. Am.J.Physiol.262(Endocrinol. Metab. 25): E791-E799, 1992

Verboeket-van de Venne WPHG, Westerterp KR, ten Hoor F. Substrate utilization in man: effects of dietary fat and carbohydrate. Metabolism 43: 152-156, 1994

Weir JB de V. New Methods for calculating metabolic rate with special reference to protein metabolism. J. Physiol. 109: 1-9, 1949

Westerterp KR, Meier GAL, Schoffelen PFM, Jansen EME. Body mass, body composition and sleeping metabolic rate before, during and after endurance training. Eur.J.Appl.Phys.69: 203 208, 1994 


\title{
Chapter 9
}

\section{Predictors of weight maintenance}

\author{
W.J. Pasman*, W.H.M. Saris* and M.S. Westerterp-Plantenga**, \\ * Maastricht University, Maastricht, Open University, Heerlen, The Netherlands
}

Br.Med.J. (Submitted)

\begin{abstract}
In the present study predictors of weight maintenance were studied. Data of two long-term intervention studies in which female subjects participated were used in the analysis $(\mathrm{n}=67$; age $37.9 \pm 1.0$ yrs; BW $87.0 \pm 1.2 \mathrm{~kg}$; BMI $32.1 \pm 0.5 \mathrm{~kg} . \mathrm{m}^{-2}$; body fat $\% 42.4 \pm 0.5 \%$ ). Subjects were measured before a very low energy diet (VLED) (month 0), after the VLED of 2 months (month 2) and after a 14 months follow-up phase (at 16 months). The baseline measurements and the changes in variables caused by the diet intervention, were used to predict the changes in body weight (BW) in the follow-up phase $(\triangle B W(2-16)$ ).

Factor 2 of the Three Factor Eating Behaviour Questionnaire $(r=0.26)$, the change in resting metabolic rate (RMR) during the VLED $(r=0.28)$, the frequency of dieting prior to the study $(r=0.46)$, and weight $(r=0.51)$ and shape-concern $(r=0.47)$ scores of the Eating Disorder Examination Questionnaire (EDE-Q), were significantly positively correlated with $B W$ regain $\triangle B W(2-16)$. Multiple and stepwise regression analysis revealed that $50 \%(\mathrm{p}<0.001)$ of the variation in weight regain could be explained. The most powerful predictor was frequency of dieting prior to the study ( $\mathrm{p}<0.05$ ) and $\triangle R M R-24 \mathrm{~h}$ (step 3:0.42, $\mathrm{p}<0.05$ ) both contributed significantly in explained variation. Subjects with a frequent diet history showed significantly more weight regain compared to less frequent dieters $(8.8 \pm 1.0 \mathrm{~kg}$ w $5.1 \pm 0.8 \mathrm{~kg}$ resp., $<<0.01)$, and more disturbed eating behaviour. It was further found that although subjects with obese parents were significantly more weight concerned in comparison to subjects with lean parents (EDEweight: $3.1 \pm 0.3$ vs $2.4 \pm 0.3$ resp.), an almost significant difference in weight regain cluring follow-up was found (obese parents: $8.5 \pm 0.2 \mathrm{~kg} v \mathrm{~s}$ lean parents $5.1 \pm 1.5 \mathrm{~kg}$, $\mathrm{p}=0.06$ ).

Fifty percent of the variation in weight regain over a 14 month period could be explained by behavioural (frequency of dieting prior to the study and factor 3 of the TFEQ) and physiological ( $\triangle \mathrm{RMR}-24 \mathrm{~h}$ ) factors, showing that with relatively simple measures obese subjects at risk for weight regain can be identified.
\end{abstract}

\section{Introduction}

The prevalence of obesity has increased considerably in the United States and Europe in the last decade (Kuczmarski et al., 1994; Seidell, 1995). More and more subjects will therefore start a diet intervention to achieve a healthier body weight (BW). However, weight cycling and relapse of body weight are common features after a weight loss interwention (Garner and Wooley, 1991; National Task Force, 1994). It is therefore of clinical importance that we 
understand which parameters are related to regain of body weight after a weight-loss intervention. These parameters could be used as predictors of the degree of possible weight regain and enable us to support subjects who are at risk of relapse more intensively in order to prevent weight gain (Rôssner, 1997).

In the past a number of studies have addressed this issue. The postabsorptive respiratory quotient (RQ) had been found to predict relapse of BW (Froidevaux et al., 1993). After discontinuation of a low energy diet, an elevated postabsorptive RQ showed that the endogenous lipid oxidation is low, a condition favoring weight gain (Froidevaux et al., 1993). However, measurement of RQ and the prediction of weight change at that same time point with $\mathrm{RQ}$, is not effective. Measurement of a variable early in a weight loss program to predict weight changes later on are clinically more relevant since estimation of risk of weight regain should be used for the amount of support given to the subject. Resting RQ in weightstable subjects was also used as a predictor of weight regain in Pima Indians (men and women) (Zurlo et al., 1990). 24h Respiratory chamber data showed that subjects after a diet intervention are prone to weight regain, because of a low ratio of fat to CHO oxidation, which could result in a positive energy balance and subsequent weight gain. The higher the RQ measured, the more weight was regained (Zurlo et al., 1990; Ravussin et al., 1993). In The Baltimore Longitudinal Study on Aging, results of resting $R Q$ in relation to weight gain were presented in 775 non-obese males (Seidell et al., 1992). It was concluded that also for non-obese subjects a relatively high RQ was a predictor of weight gain, which might suggest the same mechanism for weight gain and weight regain. The resting metabolic rate (RMR) was also tested and was not found useful for prediction of relapse, although $\mathbb{R a v u s s i n}$ and colleagues reported a decade ago that this parameter is useful for prediction of weight changes (Ravussin et al., 1988; Seidell et al., 1992). Recently, a high RQ measured at the last day of a very low energy diet (VLED) of 28 days ( $R Q_{28}$ ) was found to predict weight regain at 1,3 and 6 months of follow-up (Valtuena et al., 1997). The measurement of $R Q$ was recommended as a simple and inexpeńsive predictor. An even more simple predictor was suggested by Kramer and coworkers, who found that the change in body weight during a diet intervention, is a good indicator for the estimation of weight changes in the long-term (Kramer et al., 1989).

Not only physiological, also psychological parameters have been studied for prediction of weight changes. Long-term weight maintenance could be predicted using the Stunkard and Messick (1985) Three Factor Eating Behaviour Questionnaire (Karlsson et al., 1994). The female obese subjects participating in their study of 24 months, showed changes in the disinhibition (Factor 2) score during dieting and in the weight maintenance phase, which could be used as a predictor for relapse (Karlsson et al., 1994). Others also found the TFEQ useful for relating eating behaviour to weight maintenance (Ganley, 1988; Pekkarinen et al., 1996). Westerterp-Plantenga and colleagues (1998) found that an increase of the cognitive restraint scores during a VLED was negatively correlated with weight regain and can thus be used as predictor for successful weight maintenance.

Based upon these findings found in literature the question arises whether the absolute values measured before or after an energy restricted period should be used for prediction of body weight regain or that changes in these parameters (caused by the energy restriction) are meaningful as predictors of relapse. Although Sjöström stated that it is not difficult to identify relapsing patients, because all dieters relapse (Sjöström, 1974), we examined whether physiological and/or psychological parameters could be used as predictors of degree 
of relapse. The aim of the present study was to evaluate the predictive value of available variables of two long-term weight maintenance studies, to get insigit into the factors that affect success of weight maintenance.

\section{Subjects}

\section{Methods}

In this study results of 2 long-term intervention studies were used for analysis of predictors of weight regain. Data of a long-term intervention with fiber supplementation (fiber study) (Pasman et al., 1997a) and a long-term intervention with a food supplement containing carbohydrates, fiber, caffeine and chromium (CHO-study) (Pasman et al., 1997b) were evaluated. In the fiber study 34 female obese subjects participated (age $41.0 \pm 1.3 \mathrm{yrs} ; \mathrm{BW}$ $88.5 \pm 1.7$; BMI $33.0 \pm 0.6 \mathrm{~kg}^{-2}$; body fat $\% 42.7 \pm 0.7 \%$ ) and in the CHO-study 33 female, obese subjects participated (age $34.8 \pm 1.2$ yrs; BW $85.5 \pm 1.7 \mathrm{~kg}$; BMI $31.2 \pm 0.7$ $\mathrm{kg} \cdot \mathrm{m}^{-2}$; body fat $\% 42.0 \pm 0.7 \%$ ). Data of the 67 subjects were pooled (age $37.9 \pm 1.0 \mathrm{yrs}$; BW $87.0 \pm 1.2 \mathrm{~kg} ;$ BMI $32.1 \pm 0.5 \mathrm{~kg} \cdot \mathrm{m}^{-2}$; body fat $\% 42.4 \pm 0.5 \%$ ). A written informed consent was obtained from each subject at the start of the original studies. The study protocols were reviewed and approved by the Medical Committee of the Maastricht University.

\section{Study design}

The subjects participated in a long-term intervention study to maintain body weight after a weight-loss period (a detailed description is presented elsewhere; Pasman et al. 1997a). Subjects kept a very low energy diet (VLED) for eight weeks. After the weight loss program a weight maintenance intervention of 14 months followed. During the intervention period of 14 months subjects were supplemented with 20 grams of fiber (fiber study) or a CHOcontaining food supplement (CHO-study) or subjects served as control.

\section{Measurements}

Before the VLED (0 months), after the VLED (2 months) and at the end of the study (16 months) physical measures and eating behaviour questionnaires were obtained. Subjects came to the lab after an overnight fast at $8.00 \mathrm{~h}$ am, by car or public transport to minimize physical activity.

Physiological parameters measured of importance for this study were: body weight (BW); Body Mass Index $\left(\mathrm{BMI}=\right.$ body weight height $\left.{ }^{-2}\right)\left(\mathrm{kg} \cdot \mathrm{m}^{2}\right)$; resting metabolic rate (RMR) and respiratory quotient (RQ), measured using an open-circuit ventilated hood system (Oxycon Beta, Jaeger, Breda, The Netherlands). The RMR measured (KJ.min-1) was calculated and presented as $24 \mathrm{~h}-\mathrm{RMR}$ (MJ day ${ }^{1}$ ).

Eating behaviour was analyzed with a dutch translation of the Three Factor Eating behaviour Questionnaire (TFEQ) (Stunkard and Messick, 1985). The first factor represents cognitive restrained eating, i.e. control of food intake by thought and will-power (restrained eating). The second factor measures emotional eating and disinhibition, an incidental inability to resist eating cues (disinhibition). The third factor examines the subjective feeling of hunger (hunger). The Herman and Poliwy questionnaire was used to investigate the frequency of dieting prior to the study. Frequency classification was; $1=$ never; $2=$ sometimes; $3=$ often; 4 = always (Herman and Polivy, 1980).

\section{Follow-up data}

Subjects of the fiber study and the CHO study were sent additional eating behaviour questionnaires after cessation of the study (4-24 months after the month 16 measurement). 


\section{Chapter 9}

The eating behaviour questionnaires sent were: the Eating Disorder Examination Questionnaire (EDE-Q) (Fairburn and Cooper, 1993; Fairburn and Beglin, 1994) and the Dutch Eating Behaviour Questionnaire (DEBQ) (van Strien et al., 1986) and the TFEQ. The $\mathrm{EDE}-\mathrm{Q}$ is used for examination of restrained eating, eating concern (pre-occupation with food), shape concern (importance of body shape) and weight concern (importance of body weight). The DEBQ, which is almost similar to the TFEQ, was used to investigate emotional eating, external cues and dieting related eating behaviour. The scores of the questionnaires were used to evaluate characteristic eating behaviour in respect to weight regain.

Number of subjects

Most of the data obtained in the long-term studies was based upon all subjects ( $n=67$ ). However, in one trial not all subjects were measured with the indirect ventilated hood system. Data related with RQ and RMR are therefore presented of 58 subjects. We further sent the questionnaires to all participating subjects, but they were returned only by 54 persons ( $81 \%$ ). Data of the EDE-Q and the DEBQ were of 54 subjects. The TFEQ and the Herman and Polivy questionnaire were used at the beginning of the long-term study and therefore obtained from all subjects. Because of this varying number of subjects, the number of subjects used in the different calculations will be shown continuously.

Statistics

The main aim of the study was to examine whether physiological and, or psychological parameters measured correlated with the absolute weight change during the 14 months intervention phase $(\triangle B W(2-16))$. This parameter could subsequently be used as a predictor. Simple regression analysis was performed to test these rellations. The significant correlations found were used together in a multiple regression analysis, to study the explained variance with the factors used. Stepwise regression analysis was performed to obtain the most powerful predictor.

Some items of the TFEQ and the HP questionnaire were used to obtain categories and examine these in relation to weight regain more closely. Frequency of dieting, smoking habit and obesity of parents were examined in categories. Unpaired t-tests were carried out to examine whether these categories showed differences in weight regain or physiological or psychological variables. Data presented in the text, figures and tables are given as mean $t$ sem.

\section{Results}

Because the frequency distribution of weight regain was similar for both long-term interventions, the women of the fiber study and the CHO-study were taken together as one group.

Physical and eating behavioural characteristics of all participating subjects before the VLED, after VLED and at 16 months are presented in table 9.1. All parameters changed significantly over time, because of the strict dietary regime, but parameters also returned to baseline levels at 16 months. Body weight at 16 months was still significantly lower than at the beginning of the study, but differed already significantly from month 2 . RMR changed because of the VLED, but was not significantly different at 16 months compared with month 0 . This was also found for RQ. Eating behaviour characteristic factor 1 not only changed during the diet intervention; at 16 months the scores were still significantly higher compared with month 0 . However, the scores had also decreased compared with month 2. Both factors 2 and 3 were 
at the end of the study not significantly different from month 2 , just after VLED. Only factor 2 was at 16 months not significantly different from month 0 .

Table 9.1 Physiological and psychological parameters at different time points of the study

\begin{tabular}{lllll}
\hline & Month 0 & Month 2 & Month 16 \\
\hline Physiological parameters & & & & \\
BW (kg) & $87.0 \pm 1.2$ & $77.3 \pm 1.1$ & $84.3 \pm 1.4$ & abc \\
24h-RMR (MJ day $\left.{ }^{-1}\right)$ & $6.94 \pm 0.11$ & $6.33 \pm 0.10$ & $6.94 \pm 0.11$ & ac \\
RQ & $0.83 \pm 0.01$ & $0.79 \pm 0.01$ & $0.84 \pm 0.01$ & a \\
& & & & \\
Eating behaviour parameters & $9.5 \pm 0.5$ & $13.8 \pm 0.5$ & $10.9 \pm 0.6$ & abc \\
SM - Factor 1 & $6.7 \pm 0.4$ & $5.5 \pm 0.4$ & $6.2 \pm 0.4$ & a \\
SM - Factor 2 & $5.0 \pm 0.4$ & $2.9 \pm 0.4$ & $3.5 \pm 0.4$ & ab \\
SM - Factor 3 & & & &
\end{tabular}

Significant differences are indicated with initials: a: month 0 vs month $2 \mathrm{p}<0.05$; b: month 0 vs month 16 $\mathrm{p}<0.05$; c: month 2 vs month $16 \mathrm{p}<0.05$.

In table 9.2 simple correlations of parameters with unsuccessful weight maintenance $(\approx$ weight regain) are shown. Significant relations with weight regain were found for initial BMI (before the study); the change in RMR during the VLED ( $\triangle R M R$ ) (fig.9.1); frequency of dieting prior to the study; and the shape and weight concern scores of the EDE-Q; and factor 2 of the TFEQ (table 9.2). A tendency with regain of BW was found for factor 3 of the TFEQ measured at the beginning of the study.

Table 9.2 Relationships between physical and psychological parameters and weight regain

\begin{tabular}{llll}
\hline & Number & Correlation & p \\
\hline BMI(0) & 67 & 0.24 & 0.05 \\
$\triangle R M R$ & 58 & 0.28 & 0.03 \\
Diet frequency & 67 & 0.46 & $<0.01$ \\
SM-Factor 2 & 66 & 0.26 & 0.03 \\
SM-Factor 3 & 66 & 0.23 & 0.065 \\
EDE-Shape & 54 & 0.47 & $<0.01$ \\
EDE-Weight & 54 & 0.51 & $<0.01$ \\
\hline
\end{tabular}




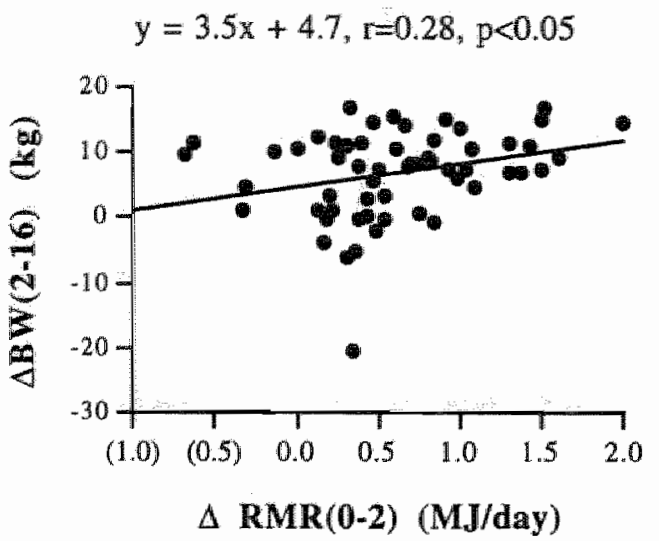

Fig.9.1 The relation between the change in RMR during the VLED (ARMR(0-2)) and the change in body weight in the weight maintenance phase $(\triangle B W(2-16))$ is shown. Data of 58 subjects are presented (black circles).

A multiple regression analysis (table 9.3) was carried out with the six variables that were significantly correlated with weight regain (see table 9.2); BMI(0), $\triangle R M R-24$, prior diet frequency, SM-Factor 2, SM-Factor 3, and EDE-weight concern score.

Table 9.3 Multiple regression analysis and stepwise regression analysis

\begin{tabular}{|c|c|c|c|c|c|}
\hline Predictor & Coefficient & S.E. & $\mathbf{F}$ & $r^{2}$ & $\mathrm{p}$ \\
\hline \multicolumn{6}{|l|}{ Multiple regression } \\
\hline Intercept & -1.32 & & & & \\
\hline $\mathrm{BMI}(0)$ & -2.35 & 0.28 & & & 0.41 \\
\hline Diet frequency & 2.33 & 0.99 & & & 0.02 \\
\hline$\triangle \mathrm{RMR}-24$ & 4.24 & 1.56 & & & 0.01 \\
\hline SM-Factor 2 & $\times 0.33$ & 0.33 & & & 0.32 \\
\hline SM-Factor 3 & 0.85 & 0.35 & & & 0,02 \\
\hline EDE-weight & 1.35 & 0.78 & & & 0.07 \\
\hline \multicolumn{6}{|l|}{ Stepuige regression } \\
\hline Intercept & -6.51 & & & & \\
\hline step 1: Diet frequency & 2.39 & 0.73 & 10.7 & 0.27 & $<0.05$ \\
\hline step 2: SM-Factor 3 & 0.75 & 0.31 & 5.92 & 0.32 & $<0.05$ \\
\hline step 3: $\triangle \mathrm{RMR}-24$ & 3.57 & 1.55 & 5.33 & 0.42 & $<0.05$ \\
\hline
\end{tabular}

The factors of table 2 were studied together in a multiple regression analysis. Stepwise regression afterwards nevealed the nost powerful predictor of weight regain.

EDE-shape concern was left out of the analysis because it is closely related to EDE-weight concern. Overall relation with weight regain was $r=0.71$, explained variation $r^{2}=0.50$, p $<0.0001$. In table 9.3 the individual coefficients, standard errors and probability are shown. Stepwise regression analysis revealed that the diet history prior to the study is the most powerful predictor for unsuccessful weight maintenance $\left(r^{2}=0.27\right)$. The Factor 3 score and $\triangle R M R-24$ increased the explained variation to 0.42 (see table 9.3). 
When the frequency of dieting was used as a category variable, 4 groups appeared. One group that had never dieted prior to intervention $(n=1)$; a group that dieted sometimes $(n=21)$; a group that had dieted often prior to the study ( $n=30)$; and one group that always dieted $(n=3)$. Because of the small number of subjects in subclass 1 and 4 , only subclass 2 and 3 were compared. This subjective variable was very effective to differentiate specific eating behaviour characteristics (table 9.4). Significantly more weight loss during the diet intervention was seen in the group that dieted 'often' (10.4 $\pm 0.5 \mathrm{~kg})$ compared to 'sometimes' dieters $(8.6 \pm 0.4 \mathrm{~kg})$. However, the 'often' dieters also regained significantly more weight in the weight maintenance phase (fig.9.2). This could perhaps be explained by the significantly higher $B W$ at the beginning of the study of the frequent dieters $(89.3 \pm 1.7$ $\mathrm{kg}$ vs $82.8 \pm 1.7 \mathrm{~kg}$ of the less frequent dieters). Although we found that weight loss during the VLED was correlated with initial BW $(r=0.51, p<0.01, n=67)$, no such relation of $B W(0)$ was found with weight maintenance. No relation was found in RQ measured after the VLED and the amount of weight regain from 2 to 16 months. The RQ after the VLED (at 2 months) was lower in the regular dieters compared with the less frequent dieters ( $p=0.06$ ). However, the lower RQ with increased fat oxidation in rest was not related with less weight regain in the weight maintenance phase. Eating behaviour scores were characteristic for both groups. At the EDE-Q all items were scored significantly higher for the group that often dieted in comparison to the less frequent dieters. For factor 1 and 2 of the TFEQ significantly increased scores were found for the regular dieters, as was found for the DEBQ, the emotion and dieting score. Factor 3 of the TFEQ and the extern score of the DEBQ between the groups were similar for both groups, indicating that dieting did not affect this aspect of eating behaviour.

Table 9.4 Frequency of dieting

\begin{tabular}{|c|c|c|c|}
\hline & Sometimes & Often & $\mathrm{p}$ \\
\hline$B W(0)$ & $82.8 \pm 1.7$ & $89.3 \pm 1.7$ & $<0.01$ \\
\hline$\triangle \mathrm{BWW}(0-2)(\mathrm{kg})$ & $8.6 \pm 0.4$ & $10.4 \pm 0.5$ & 0.01 \\
\hline$\triangle B W(2-16)(\mathrm{kg})$ & $5.1 \pm 0.8$ & $8.8 \pm 1.0$ & $<0.01$ \\
\hline RMR(O) (MJ.day $\left.{ }^{-1}\right)$ & $6.7 \pm 0.1$ & $7.1 \pm 0.2$ & 0.08 \\
\hline $\mathrm{RQ}(0)$ & $0.83 \pm 0.01$ & $0.83 \pm 0.01$ & 0.78 \\
\hline $\mathrm{RQ}(2)$ & $0.80 \pm 0.01$ & $0.78 \pm 0.01$ & 0.06 \\
\hline SM-Factor 1 & $6.7 \pm 0.7$ & $10.8 \pm 0.6$ & $<0.01$ \\
\hline SM-Factor 2 & $5.8 \pm 0.7$ & $7.7 \pm 0.5$ & $<0.02$ \\
\hline SM-Factor 3 & $4.7 \pm 0.6$ & $5.2 \pm 0.5$ & 0.44 \\
\hline EDE-Restraint & $1.2 \pm 0.2$ & $2.3 \pm 0.2$ & $<0.01$ \\
\hline EDE-EC & $0.8 \pm 0.2$ & $1.6 \pm 0.2$ & 0,02 \\
\hline EDE-Shape & $2.3 \pm 0.4$ & $3.7 \pm 0.3$ & $<0.01$ \\
\hline EDE-Weight & $2.1 \pm 0.3$ & $3.4 \pm 0.2$ & $<0.01$ \\
\hline DEBQ-Em & $2.4 \pm 0.1$ & $2.9 \pm 0.1$ & 0.02 \\
\hline DEBQ-Ex & $2.6 \pm 0.1$ & $2.6 \pm 0.1$ & 0.80 \\
\hline DEBQ-Diet & $3.1 \pm 0.1$ & $3.5 \pm 0.1$ & 0.02 \\
\hline
\end{tabular}

Physical and psychological scores of subjects who underwent a diet intervention "sometimes' ( $n=21$ ) or 'often' $(n=30)$ before the present study 


\section{Chapter 9}

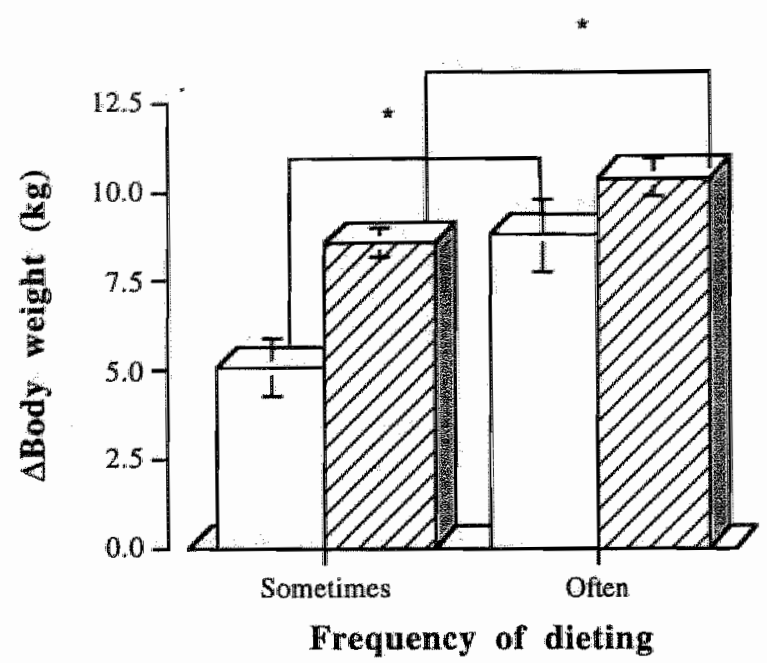

Fig. 9.2 The amount of weight gained in the weight maintenance phase ( $\triangle B W(2-16)$ ) (white bars) and weight lost during the diet intervention $(\triangle B W(0-2)$ ) (hatched bars) is shown for subjects who diet 'sometimes' $(n=21)$ and subjects who diet "often' $(n=30)$. A significant difference in weight regain was found (* $\left.{ }^{*}<0.05\right)$.

When the data were analyzed according to smoking habit, a significant difference in the amount of weight loss was found during the VLED. The smokers Jost significantly less weight $(8.2 \pm 0.6 \mathrm{~kg})$ compared to the non-smokers $(10.0 \pm 0.4)$, although there were no differerences in initial BW $(87.2 \pm 3.0 \mathrm{~kg}$ for the smokers, ws $85.7 \pm 1.5 \mathrm{~kg}$ for the nonsmokers; NS). This is in contrast with the finding that the decrease in RMR was lower for the smokers than the non-smokers, resulting normally in a higher energy balance discrepancy (fig.9.3).

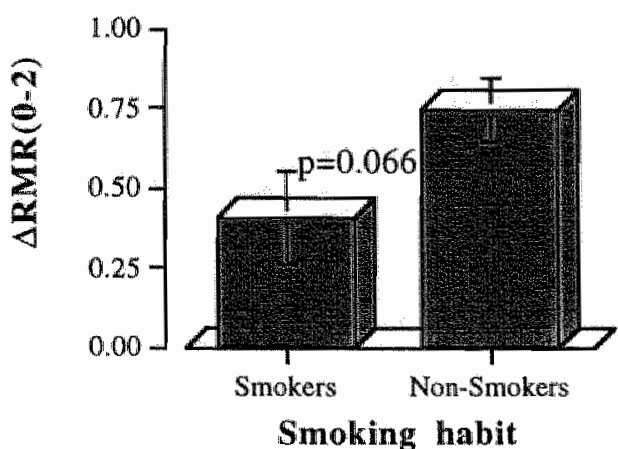

Fig.9.3 The change in RMR dwring the diet interwention is presented for the smokers $(n=13)$ and the nonsmokers ( $n=41$ ). An almost significant difference in decrease of the RMR was found between the groups.

In order to estimate the influence of the genetic background at weight maintenance, the data were analysed according to body weights of the parents. Subjects with obese parents (one or two) were found to regain more weight in the weight maintenance phase, when compared to subjects of lean parents ( $\mathrm{p}=0.06$ ) (fig.9.4). The weight loss during the VLED was not 
significantly different $(9.8 \pm 0.6$ w $9.3 \pm 0.5, p>0.05$, for the obese us lean parentssubjects, resp.). It was further found that the group with obese parents was significantly more preoccupied with their body weight (EDE-weight) (fig.9.4) than the group with lean parents, and a tendency for shape concern was found $(3.5 \pm 0.3$ vs $2.7 \pm 0.3, p=0.066$, for the obese vs lean parents-subjects, resp.). No other physiological or behavioural differences were found between the 'obese parents' and 'lean parents' groups.

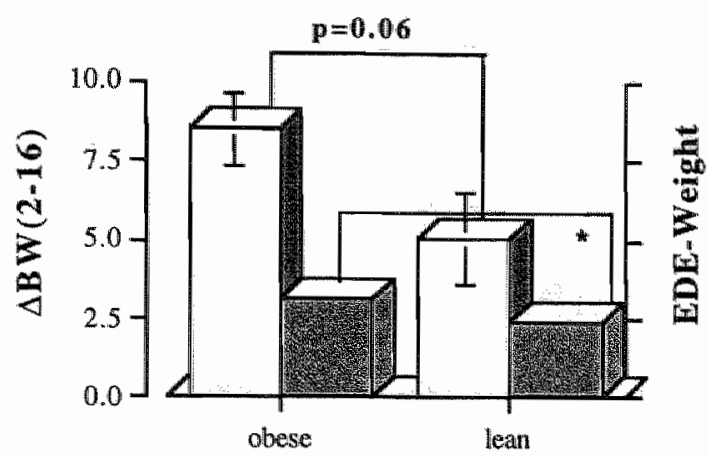

Parents

Fig.9.4 The amount of weight gained in the weight maintenance phase (white bars) and the BDE-Weight scores (filled bars) is presented for the group with obese parents ( $n=29)$ and for the group with lean parents $(\mathbf{n}=25)$.

\section{Discussion}

In the present study new predictors for weight maintenance were found. The most powerful predictor for weight regain after a diet intervention was the frequency of dieting prior to the study. Information about the frequency of dieting is easily determined using the Herman and Polivy restraint questionnaire (1980). The first question "How often are you dieting?" is further assessed in detail by the nine following questions. French and coworkers reported too that history of dieting is an effective predictor of weight gain in women (French et al., 1994). Two other important predictors for weight regain, factor 3 of the TFEQ and $\triangle R M R$ during the VLED, improved prediction of weight regain significantly. These three factors were found to be of main importance for an adequate prediction of unsuccessful weight maintenance.

Besides an increased amount of weight regain after more diet altempts, we also found differences in eating behaviour characteristics between the groups. Although the group that dieted 'often' showed more restraint eating behaviour, and was highly weight and shape concerned, more regain of body weight was found than in the group that 'sometimes' dieted. These data are in agreement with the results of Pekkarinen et al. (1996) and Karlsson et al. (1994). Psychological dysfunction at the beginning of the study, in combination with difficulties in resisting emotional and social eating cues (less control over their eating), would result in bad weight maintenance in the follow-up phase. The significantly higher body weight at the beginning of the study for the frequent dieters already indicate that weight regain had taken place after prior diet interventions.

Physiological predictors found in the present stady were the BMI before the study and the change in RMR during the VLED. Especially the BMI is an easy method for prediction of 


\section{Chapter 9}

weight maintenance later on. The relation of BMI with weight maintenance was not found for initial body weight. BMI and shape concern of the EDE-Q were significantly related $(\mathrm{r}=54 ; \mathrm{r}=0.30 ; \mathrm{p}<0.05)$, indicating that more obese persons were indeed more concerned about their body shape. The fact that BMI was related to weight regain, might be explained by the set-point theory (Keesey and Corbett, 1984; Kramer et al ", 1989; Harris, 1990). Kramer and colleagues thoroughly discussed the biological model of body weight setpoint (and thus BMI-setpoint, because the height remains the same), as an alternative explanation for maintenance failure (Kramer et al, 1989). The defense of body weight and body fat already predict return to baseline weight. The predictor suggested $(\triangle B W(0-2))$ was however not related to weight regain for our data. Kramer further hypothesized that frequency of dieting, in his biological set-point model, as well as in his social-learning model, subjects with a history of weight maintenance failure, can predict relapse (Kramer et al., 1989). This hypothesis is confirmed in our study.

The change in RMR during dieting was positively correlated with unsuccessful weight maintenance; the more RMR adapted to the negative energy balance due to the VLED, the more weight regain was found afterwards. This physiological result of dieting has been mentioned to be related with the loss in fat free mass (FFM). The relation between FFM and RMR before the VLED was in this study $r=0.76, p<0.0001$, and after the VLED $r=0.72$, p $<0.0001$. The changes in both variables during the VLED correlated less well; $r=0.21$, $\mathrm{p}=0.11$. It has also been suggested that the decrease in $\mathrm{RMR}$, makes subjects vulnerable for weight regain, because they become more efficient. However, this aspect of weight control is still under debate (Saris et al., 1989; Ravussin et al., 1993; Kempen, 1996).

The often reported predictor of weight regain, the $\mathrm{RQ}$, was not at any time point related with weight regain. The RQ measured just after VLED had also been used as a predictor of weight changes (Valtuena et al.,1997), but this was not confirmed in the present study. The RQ measured at 2 months VLED, was not related to weight regain. The RQ data did not suggest that a lowered fat oxidation will result in a fat imbalance and therefore end-up in weight gain, as was suggested by Seidell et al. (1992), Froidevaux et al. (1993), Zurlo et al. (1990) and Schutz (1995).

In the present study we further found clear simple correlations between the EDE shape and weight score with weight regain, however the multiple regression analysis revealed no significant contribution of the EDE-weight score. The score could perhaps be used as a predictor for weight changes in a long-term trial. It should be stressed that in our study the EDE-questionnaire was given after the long-term trial to identify the eating behaviour characteristics of the subjects. It is unknown whether the same results were obtained when these questionnaires were used before the long-term studies started. On the other hand, all subjects in this study had a dieting history, therefore the time point of completing the questionnaire may be of less importance.

The almost significant difference in weight regain berween subjects with lean or obese parents, suggests that this might be a very simple predictor of weight regain. Although the subjects with obese parents showed to be more weight and shape concerned than the subjects with lean parents, still more weight regain was found. The result showed that there is a genetic component not only contributing to body weight per se (Stunkard et al., 1986), but also to maintenance of body weight after weight loss. The predisposition to obesity is still prevalent after weight-loss, making weight maintenance difficult. 


\section{Predictors of weight maintemance}

In general, this stresses the importance of useful and simple predictors of weight regain and weight maintenance, to support subjects who are at risk for relapse of body weight. Other predictors of weight regain found in literature like insulin sensitivity (Ravussin et al., 1993; Wing, 1997); fat cell number (Sjostròm, 1974); or information of autonomous motivation for body weight control (locus of causality) (Williams et al., 1996) are less easy to obtain.

In the present study new and traditional predictors were related with weight changes after a diet intervention. Frequency of dieting prior to the study was found to be a powerful predictor of unsuccessful weight maintenance. The additional predictive information obtained from factor 3 of the TFEQ and $\triangle R M R$ showed that weight regain has to be explained by behavioural and physiological parameters.

\section{References}

Fairburn CG, Cooper Z. The Eating Disorder Examination (12th ed.). In: C.G. Fairburn and G.T. Wilson (Eds.). Binge eating: nature, assessment, and treatment. New York: Guilford Press, pg: 317-360, 1993

Fairburn CG, Beglin SJ. Assessment of eating disorders: Interview or self-reported questionnaire? Int.J.Eat.Dis.16: 262-270, 1994

French SA, Jeffery RW, Forster JL, McGovern PG, Kelder SH, Baxter JE. Predictors of weight change over two years among a population of working adults: the Healthy Worker Project. Int.J.Obes. 18: 145-154, 1994

Froidevaux $F$, Schutz $Y_{\text {"I }}$ Christin L, Jéquier E. Energy expenditure in obese women before and during weight loss, after refeeding, and in the weight-relapse period. Am.J.Clin.Nutr.57: 35-42, 1993

Ganley RM. Emotional eating and how it relates to dietary restraint, disinhibition, and perceived hunger. Int.J.Eat.Dis.7: 635-647, 1988

Garner DM, Wooley SC. Confronting the failure of behawioral and dietary treatments for obesity. Clin. Psych.Rev.11: 729-780, 1991

Harris JK, French SA, Jeffery RW, McGowern PG, Wing RR. Dietary and physical activity correlates of long-term weight loss. Obes.Res.2: 307-313, 1994

Herman CP, Pollivy J. Restrained eating. In : Stunkard, A. ed.: Obesity, W.B.Saunders, Philadelphia, pg: 208-225, 1980

Karlsson J, Hallgren P, Kral J, Lindroos A-K, Sjöström L, Sulliwan M. Predictors and effects of long-term dieting on mental well-being and weight loss in obese women. Appetite 23:15-26, 1994

Keesey RE, Corbett SW. Metabolic defence of the body weight set-point. In: Eating and its disorders. Ed: Stunkard AJ, Stellar, E. Raven Press, New York pg: 87-96, 1984

Kempen K.PG. Metabolic effects of weight cycling in obesity. Thesis Maastricht University, 1996

Kramer FM, Jeffery RW, Forster JL, Snell MK. Long-term follow-up of behavioral treatment for obesity: patterns of weight regain among men and women. Int.J.Obes. 13: 123-136, 1989

Kuczmarski RJ, Flegal KM "Campbell SM, Johnson CL. Increasing prevalence of owerweight arnong US adults. The national health and nutrition examination surveys, 1960 to 1991. JAMA 272: 205-211, 1994

National Task Force on the Prevention and Treatment of Obesity. Weight cycling. JAMA 272: 1196-1202, 1994

Pasman WJ, Westerterp-Plantenga MS, Muis E, Vansant G, van Ree J, Saris WHM. The effectiveness of long-term fiber supplementation on weight maintenance in weight-reduced women. Int.J.Obes.21: 548 555,1997

Pasman WJ, Westerterp-Plantenga MS, Saris WHM. The effectiveness of long-term supplementation of carbohydrate, chromium, fiber and caffeine in weight maintenance. Int.J.Obes. (in press)

Pekkarinen $T$, Takaia 1 , Mustajoki $P$. Two year maintenance of weight loss after a VLCD and behavioral therapy for obesity", correlation to the scores of questionnaires measuring eating behaviour. Int.J.Obes. 20: $332-337,1996$

Ravussin E, Lillioja S, Knowler WC, Christin L, Freymond D, Abbott WGH, Boyce V, Howard BV, Bogardus C. Reduced rate of energy expenditure as a risk factor for body weight gain. N.Eng.J.Medi.318: $467-72,1988$

Ravussin E, Fontvieille AM, Swinburn BA, Bogardus C. Risk factors for the development of obesity. Ann.N.Y.Acad.Sc.683: 141-150, 1993

Rössner S. Defining success in obesity management. Int.J.Obes.21 (suppl.1): S2-S4, 1997 


\section{Chapter 9}

Sharis WHM. Physilotogical aspects of exercise in weight cycling. Am.J.Clin.Nutr.49: 1099-1104, 1989

Schutz $Y$. Abnormalities of fuel utilization as predisposing to the development of obesity in humans. Obes Res. 3: 173S-1785, 1995

Seidell JC, Muller DC, Sorkn JD, Andres R. Fasting respiratory exchange ratio and resting metabolic rate as predictors of weight gairr the Baltimore Longitudinal Studly on Aging. Int.J.Obes. 16: 227-674, 1992

Seidell JC. Obesity in Europe. Obes.Res.3(suppl.2): 89s-935, 1995

Sjôström L. Can the relapsing patient be identified? In: Björntorp, Cairella, Howard (eds.). Recent advances in obesity research: III. Proceedings of the third International Congress on Obesity. Libbey: London, pg: $85-93,1974$

Strien TV Frijters JER, Bergers GPA, Defares PB. The Dutch Eating Behavior Questionnaire (DEBQ) for assessment of restrained, emotional, and external eating behavior. Int. Jat.Dis.5: 295-315, 1986

stunkard AJ, Messick S. The three-factor eating questionnaire to measure dietary restraint, disinhibition, and huinger. J.Psychosom. Res. 29, 71183, 1985

Stunkard AJ, Sarensen TIA, Hanis C, Teasdale TW, Chakraborty R, Schull WJ, Schulsinger F. An adoption study of human obesity. N.Engl.J.Med.314; 193-198, 1986

Valtuena $S_{\text {, Sola }} \mathrm{R}$, Salass-Salvadó $\mathrm{J}$. A study of the prognostic respiratory markers of sustained weight loss in obese subjects after 28 days on a VLCD. Int.J.Obes. 21: 267-273, 1997

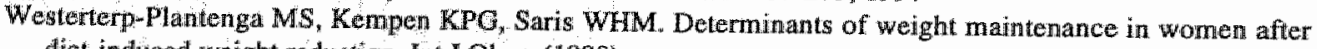
diet-induced weight reduction. Int.J.Obes. (1998)

Willams GC "Grow VM, Freedman $2 R_{\text {. }}$ Ryan RM, Deci EL. Motivational predictors of weight loss and weight-loss maintenance. J.Person Soc.Psych.70: 115-126, 1996

Wing RR. Insulin sensitivity as a predictor of weight regain. Obes.Res.5: 24-29, 1997

Zurlo F, Lillioja S, Esposito-Del Puente, Nyomba BL, Raz I, Saad MF, Swinburn BA, Knowler WC, Bogardus C, Raviussin E. Low ratio of fat to carbohydrate oxidation as predictor of weight gain: study of 24-h RQ. Am.J.Physiol.259(Endocrin. Metab. 22): E650-E657, 1990 


\section{Chapter 10}

\section{General discussion}

The research presented in the thesis was focussed on maintenance of body weight and prevention of regain after a diet intervention. The data shown in chapters 4,5 and 6 indicate that the interventions used in the follow-up phases were not effective for weight maintenance. Typical weight regain curves were found in all three studies, as is presented in fig. 10.1, in which average results of each study are shown.

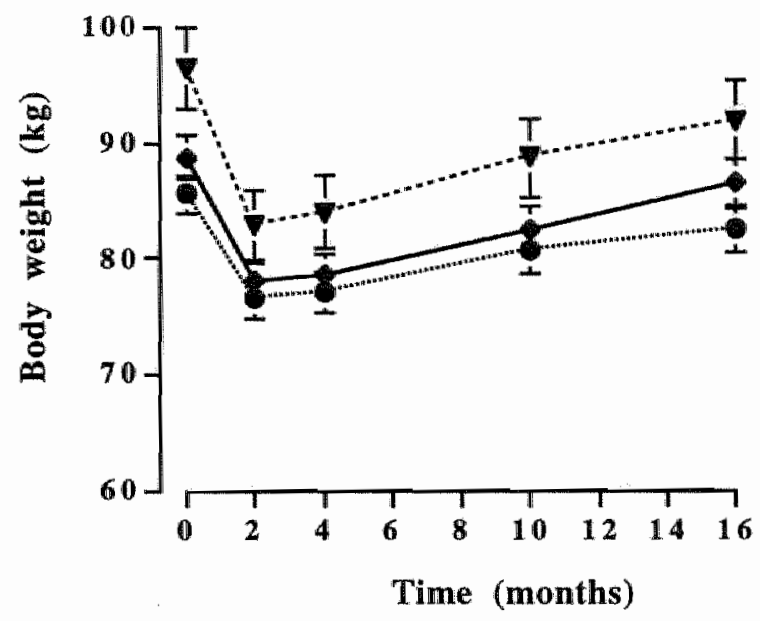

Fig. 10.1 The changes in (average) body weight of all participating subjects of each study is presented at the different time points. The fiber study (dimonds) (chapter 4), the $\mathrm{CHO}$ study (circles) (chapter 5) and the exercise study (triangles) (chapter 6) are shown (nean t sem).

Regain at 16 months has been expressed in the different chapters as a percentage of the weight lost during the diet intervention. On average the subjects in the fiber study (chapter 4 ) regained $83 \pm 12 \%$ (mean $\pm \mathrm{sem}$ ) of the weight lost (high-compliance group: $65 \pm 20 \%$; low-compliance group $123 \pm 20 \%$; control group $61 \pm 20 \%, p=0.07$ ). For the Carbohydrate, Chromium-picolinate, Fiber and Caffeine study the regain was on average 66 $\pm 14 \%$ (the complete supplement $\mathrm{CHO}+51 \pm 30 \%$; only $\mathrm{CHO}: 68 \pm 18 \%$; control group 86 $\pm 19 \%, \mathrm{p}=0.63$ ). Of the exercise training intervention on average a regain of $64 \pm 7 \%$ was found. The well-trained subjects showed the least regain: $52 \pm 11 \%$, and the male control group $74 \pm 7 \%(p=0.09)$. Whether the lower regain values with exercise were found because of the male participants or the exercise interwention is not clear from our data. The findings presented illustrate that a single intervention in the weight maintenance phase does not prevent regain in free living subjects.

Manipulation of energy intake with fiber supplements was shown to be effective in shortterm studies (chapter 3). However, long-term supplementation of fiber did not result in 
weight maintenance. Because subjects were grouped according to their compliance, only habituation and the environmental and social conditions when subjects are free-living, could explain the regain found (chapter 4). The food supplement with carbohydrates (CHO) used in chapter 5 was also not effective for weight maintenance, which could probably be explained by the energy content of the supplement that was added to the normal intake daily. The total daily CHO intake was however correlated with weight regain $(r=-0.40, p=0.05)$. Manipulation of energy expenditure as carried out in chapter 6, did not result in weight maintenance either. Especially, environmental and social conditions the free-living subjects live in, were given as possible explanations for failure of weight maintenance (chapters 4,5 and 6).

However, what are these environmental and social factors exactly, the subjects constantly live in? Which mechanisms are of importance for weight maintenance, but did not receive full attention in earlier chapters because they fell out of the scope of the discussion. Physiological and psychological factors related to weight maintenance and weight regain not dealt with in the studies presented in the thesis, will be discussed in more detail and linked to the outcome of the intervention studies on weight maintenance. Besides physiological and psychological factors, the study design and methods used could be a possible explanation for the weight regain found in the different studies. The study design will therefore be examined and compared with other weight-control interventions. At the end of the discussion recommendations for future research and conclusions are presented.

\section{Physiological mechanisms for weight maintenance}

\section{Set-point theory}

The physiological regulation of energy expenditure (EE) and energy intake (EI) resulting in a stable body weight (BW) is known as the 'set-point' of the body (Keesey and Corbett, 1984). Although there is not a day-to-day energy balance, maintenance of $B W$ requires energy balance over time (Harris, 1990; Westerterp et al., 1995). An increase of one kg of $\mathrm{BW}$ in one year (corresponding to $37 \mathrm{MJ}$ ), in which the subject consumed $10 \mathrm{MJ}$ per day for 365 days (a total of $3650 \mathrm{MJ}$ ), illustrates that energy balance deviated only $1 \%$. The ability to maintain energy balance despite differences in energy density of food implies the existence of a feedback signal that communicates changes in energy intake to mechanisms that control eating behaviour (Friedman, 1997).

Studies with brain-lesioned rats showed that damage of the hypothalamus caused dramatic changes in BW. Bilateral lesions in the ventromedial hypothalamus (VHM) resulted in development of obesity, whereas lesions in the lateral hypothalamus (LH) resulted in weight loss (Steffens et al., 1972; Steffens, 1975; Steffens and Strubbe, 1983; Keesey and Corbett, 1984; Harris, 1990; Steffens et al., 1990). It was found that hypothalamic lesions reset body weight set-point. Afferent signals to the brain affecting energy intake or energy expenditure may be: hormones (insulin, a satiety factor, NPY, CCK), nutrients (FFA and glucose), and dietary composition (Harris, 1990; Rosenbaum et al., 1997). Efferent signals have been suggested hormonal and neural, affecting energy intake and expenditure. An afferent satiety factor has recently been discovered as "leptin", a hormone secreted by adipose tissue (Zhang et al., 1994). New body weight regulation mechanisms have since then been suggested (Campfield et al., 1996). Leptin secreted from the fat cells and transported in the blood, signals the brain to regulate ingestive behaviour and energy balance, resulting in a stable 
body weight and fat mass (Campfield et al., 1996). The newly developed theory is a expansion of the "lpostatic theory" of Kennedy (1953) in which BW was suggested to be: regulated by body fat content, as a consequence of a satiety factor. It is also in agreement with the 'glucostatic theory' of Mayer (1955), in which insulin-sensitive cells in the brains were proposed to monitor arterio-venous differences in glucose concentration, as a measure for glucose utilization (Mayer, 1955). Others state that control of energy intake is based on the detection of a feedback signal generated in the processing of metabolic fuels for energy. Such a mechanism could serve as the energy sensor which controls energy intake (Friedman, 1997). The discovery of leptin has renewed the interest in the set-point theory of body weight and regulation of energy intake and energy expenditure. Detailed studies of leptin action, site of control., leptin receptors, and their physiological effects are now under investigation. In the next century the central regulation of BW control will be much better understood.

Long-term regulation of BW is according to the set-point theory a succession of short-term regulations, and the signals mentioned are all operating all the time, making distinctions between signals difficult (Harris, 1990; Strubbe, 1994; Rosenbaum et al., 1997). However, according to De Castro (1997) there seems to be no energy balance regulation. What may appear as regulation could be a total sum of multiple independent feedback loops (de Castro, 1997). However, the data of Edholm (1955) strongly support maintenance of energy balance over a week.

In the chapters 4,5 , and 6 only average regain figures were presented for the different interventions. However, absolute numbers of subjects maintaining a new set-point or returning to the old set-point are shown in table 10.1. The body weight achieved after the VLED intervention is defined as a new set-point when the weight achieved after the VLED + $25 \%$ of the weight lost during the diet is still maintained at 16 months. The BW before the VLED $-25 \%$ of the weight lost, is defined as the old set-point. The achievement of a new or the return of body weight to the old set-point at 16 months is presented in table 10.1 .

Table 10.1 Set-point in the weight maintenance interventions

\begin{tabular}{lllllll}
\hline & \multicolumn{2}{l}{ Fiber study } & CHO-study & Exercise-study \\
\hline Total number & 31 & $(100)$ & 33 & $(100)$ & 15 & $(100)$ \\
Newly achieved set-point & 9 & $(29)$ & 8 & $(24)$ & 2 & $(13)$ \\
Return to old set-point & 20 & $(65)$ & 20 & $(61)$ & 6 & $(40)$ \\
In between set-points & 2 & $(6)$ & 5 & $(15)$ & 7 & $(47)$ \\
\hline
\end{tabular}

Number of subjects at old or new set-point (the percentages of the group is presented in parentheses).

From these data presented in table 10.1 it is clear that a new set-point is not easily maintained. Whether it is the gender difference or the difference in intervention, in the exercise intervention less subjects had at the end of the study returned to their old set-point. Manipulation of energy expenditure in men seems to be more effective for prevention of weight regain than manipulation of energy intake in women, as performed in the supplementation studies. 


\section{Chapter 10}

\section{Fat cell characteristics and the relation with leptin}

Related to the set-point theory and leptin production, are the fat cells. It has frequently been suggested that a 'signal' from the adipose tissue regulates BW. As discussed above, the homone leptin plays an important role in energy balance. However, already two decades before the discowery of leptin, fat cell number and fat cell weight were mentioned as factors of importance for regain prognosis. In studies with rats (Faust, 1984) and humans (Sjöström, 1974; Björntorp, 1978; Andersson et all., 1987) it was found that hyperplastic and hypertrophic obesity were related with different weight loss and regain characteristics. Hyperplastic obesity ( $\approx$ gynoid obesity or lower body obesity) is characterized by an increased number of fat cells. Hypertrophic obesity ( $\approx$ android obesity or upper body obesity) has enlarged fat cells (Andersson et al., 1987). In rats it was found that at a high-fat diet fat cell weight increased, by increasing the amount of fat stored. At a certain point more fat cells were formed (Faust, 1984), and once formed adipocytes appear to become a permanent part of the body's fat cell population (van Itallie, 1984). Long lasting and severe obesity can therefore induce permanent biological changes in the animal (van Itallie, 1984), and perhaps act in the same way in humans too. Energy restriction affects the filling of the fat cells very rapid, resulting in lowered fat cell weights, however the fat cell number remains constant (Faust, 1984). Patients with hyperplastic obesity may resist fat loss more strongly than patients with the same amount of fat stored in enlarged adipocytes (van Itallie, 1984). Hyperplastic obesity has therefore not only been suggested with rapid weight loss by changes in fat cell filling, a fast regain of $\mathrm{BW}$ has been suggested too (Sjöström, 1974; Björntorp, 1978; Andersson et al., 1987). Weight loss was maintained longer in hypertrophic patients. This implies a gender difference in weight regain, when the typical fat distribution for men and women is taken into account. Female subjects (gynoid obesity, hyperplastic obesity) would regain BW faster than their male counterparts with hypertrophic fat cells, as could explain the gender difference of our results, mentioned above.

Based upon the finding that patients with hyperplastic forms of obesity relapsed much faster than hypertrophic patients, fat cell number was suggested to be a predictor for weight regain (Sjöström, 1974). Lowering of BW would in the long-term (7-9 years) be possible when EI was reduced for the total period of time. Fat cell number was suggested to decrease, although it is not clear how these fat cells disappear (Sjöström, 1974).

Finally, it has been found that exercise interventions are especially effective for hypertropic patients (enlarged fat cells). Hyperplastic fat cells lower fat cell weight till a normal weight, but the increased number results in a fat mass still higher than in hypertropic patients. In hypertropic paticnts the enlarged fat cell weight will decrease to normal, the number is normal, so fat mass is lower. Hypertrophic patients will benefit more from exercise (Björntorp, 1978). However, calculations with data of the exercise study (chapter 6 and 7) revealed no support for this suggestion. When hypertrophic obesity was examined by means of waist-hip ratio (WHR), sagittal diameter ( $\operatorname{sag} \phi)$ and body fat percentage (BF\%), the baseline values were not at all related to the difference in body weight during the exercise intervention (from month 0 to month 16) (WHR(0) and $\triangle B W(0-16) r=0.10, p=0.71$; sag. (0) and $\Delta B W(0-16) r=0.20, p=0.46$; and $B F \%(0)$ and $\Delta B W(0-16) r=0.34, p=0.21)$. These data indicate that subjects with android obesity did not benefit more from exercise than lower body obese subjects. However, the number of subjects in our exercise study might be too small to detect these relationships. 


\section{General discusision}

The history of weight gain, which influences whether increased fat mass is characterized by increased fat cell size or increased fat cell number, may play a role in the effectiveness of exercise for weight loss (Stefanick, 1993). As we discussed in chapter 7, the effect of exercise at leptin may well be related to this hyperthropic obesity, especially since recently is reported that leptin secretion is related to the amount of lipid stored in the fat cells (Loinnquist et $\mathrm{al}_{., 2}$ 1997). Whether our data in the exercise study showed relations of site specific obesity with leptin is shown with simple and partial correlations in table 10.2. As is seen in table 10.2, clear relations were found between body weight and body fat parameters with leptin levels at the same time point. The high simple correlations of sag with leptine indicates that site-specific obesity (android obesity) is of importance for leptin secretion. The partial correlation of sag. when corrected for body fat percentage, stills showed significant relations with leptin. However, relations of body fat mass and body fat percentage with leptin, when corrected for fat distribution by WHR, indicate that fat itself is of more importance than the site of fat storage. Based on these results it is clear that fat and fat distribution are of importance for leptin levels.

Table 10.2 Correlations of physical parameters with leptin

\begin{tabular}{|c|c|c|c|c|c|}
\hline Month & 0 & 2 & 4 & 10 & 16 \\
\hline$B W$ & $0.66 *$ & $0.53 *$ & 0.67 & $0.59 *$ & $0.63 *$ \\
\hline $\mathrm{BF} \%$ & $0.71 *$ & $0.64 *$ & $0.86 *$ & $0.89 *$ & $0.72 *$ \\
\hline WHR & $0.67 *$ & 0.43 & $0.56 *$ & $0.58 *$ & $0.70 *$ \\
\hline Sag & $0.95 *$ & $0.68 *$ & $0.75 *$ & $0.87 *$ & $0.80 *$ \\
\hline \multicolumn{6}{|c|}{ Partial correlations } \\
\hline $\mathrm{r}(\mathrm{FM} \mid \mathrm{WHR})$ & $0.82 *$ & $0.65^{*}$ & $0.84 *$ & 0.77 * & $0.79 *$ \\
\hline r (BF\% \|WHR) & $0.71 *$ & $0.53^{*}$ & $0.79^{*}$ & $0.84^{*}$ & $0.49 *$ \\
\hline $\mathrm{r}(\mathrm{Sag}, \mathrm{BF} \%)$ & $0.89 *$ & $0.47 *$ & 0.43 & $0.52 *$ & $0.62 *$ \\
\hline
\end{tabular}

Data presented from the exercise study. The partial correlations presented were between the first variable and leptin, when a constant (I) second variable was assumed. * $\mathrm{p}<0.05$

As discussed in chapter 7 , exercise resulted in significantly decreased leptin levels at month 16, decreased sag. $\%$, decreased BF\% and decreased WHR. The decrease of leptin by exercise as we found in chapter 7, was independent of BF\%. It is already suggested by different groups, that increased B-adrenergic stimulation as seen during exercise may stimulate adipocytes to lipolysis, resulting in less fat in the fat cells and lowered leptin production. The relation of leptin and fat distribution is based upon the following hypothesis.

The significant differences in regain of sagittal diameter and waist-hip ratio between the exercise and control group (chapter 6 and 7 ) indicate that the extra regain of fat mass in the control group is most probably located in the waist region. As already discussed in chapter 7 , the lowering of the abdominal fat depot by training probably results in increased insulin sensitivity. Findings from Mauriège and colleagues support the hypothesis that the abdominal fat depot is decreased by training (Mauriège et al., 1996). They found in female subjects a higher B-adrenergic sensitivity in trained women compared to untrained. It is also known that obese subjects have a blunted B-adrenergic mediated thermogenesis (Blaak et al., 1995; Nisoli et al., 1996), that might be activated by exercise (Balkan et al., 1992; Mauriège 
et al. 1996). Evidence for regional differences in catecholamine-induced lipolysis comes from Amer and coworkers (1990). The abdominal fat cells having more B1-adrenoceptor expression and more $B$-adrenoceptor binding sites than fat cells in the gluteal area in female and male subjects (Amer al., 1990). This difference in gene expression favours adipocyte lipolysis activity in abdominal fat depot. Besides the differences in B-adrenoceptor activity in obese animals and humans, site-specific differences exist in ob-gene expression. From rat studies it is known that abdominal fat depots have higher ob gene expression than subcutaneous adipose tissue (Zheng et al, 1996). These findings in Iterature support the hypothesis that leptin production might be site-specific. From $a b / o b$ mouse it is reported by Begin-Heick that they lack not only leptin but allso have depressed B3-receptor activity. The depression of B3-receptor in obesity might cause lipid accumulation (Bégin-Heick, 1996). From work of Collins and colleagues it becomes also clear that B3-adrenergic receptor activity is related to ob gene expression (1996). They suggested that ob gene expression serves as a sensor of fat cell hypertrophy (not fat cell number).

Based upon the results mentioned above it could be hypothesized that training might result in reduced leptin levels via increased $B$-adrenergic thermogenesis and/or increased leptin sensitiwity.

Fundamental studies to determine the relation between site specific fat cells and serum leptin are necessary, before the relation with exercise can be thoroughly understood. It is therefore suggested to examine again the number, size and filling of the fat cells at different sites of the body in future studies in relation to leptin regulation and weight maintenance.

\section{Insulin resistance}

Obesity is often complicated by insulin resistance, particularly in subjects with abdominal obesity. It has been speculated that insulin resistance is caused by a decreased number of insulin receptors. Because of the expanded fat cell size in the obese, the number of receptors per unit cell surface area is decreased (Lönnoth and Smith, 1993). The cluster of risk factors linked to insulin resistance are referred to as 'Syndrome $\mathbb{X}^{\text {w' }}$, or the 'metabolic syndrome' (Barnard and Wen, 1994; van Gaal et al, 1997). Coronary heart disease (CHD) risk factors are hypertension, hypertriglyceridaemia, depressed HDL-cholesterol, central body fat, glucose intolerance, hyperinsulinaemia, and obesity (Barnard and Wen, 1994; Godsland and Stevenson, 1995; van Gaal et al., 1997). The prevalence of insulin resistance is according to Godsland and Stevenson very high; they stated that people who exercise little or have an increased proportion of centrally located (android) body fat are insulin resistant (Godsland and Stevenson, 1995). The excess insulin necessary to normalize glucose levels, may affect atherogenesis (arterial lipid deposition), and further vascular dysfunction (Godsland and Stevenson, 1995). Although the effects of insulin resistance to CHD are detrimental, with respect to weight maintenance insulin resistance is thought to be beneficial (Eckel, 1992). The reduction in insulin action seen in insulin-resistant states affects metabolic fuel partitioning in a way that would prevent additional weight gain. The main sites of insulin action are skeletal muscle, adipose tissue and the liver. In skeletal muscle, insulin increases glucose transport, glucose oxidation, glycogen synthesis and protein synthesis. Proteolysis and lipoprotein lipase (LPL) are inhibited. In adipose tissue, insulin increases glucose transport, glucose oxygenation, and LPL, but inhibits lipolysis (Eckel, 1992). LPL, the rate limiting enzyme for hydrolysis and uptake of triglyceride fatty acids from circulating triglyceride-rich lipoproteins, chylomicrons and VLDL, plays a key role in weight 
maintenance. After an energy restricted diet, a metabolic setting exists that allows weight gain. With weight loss, insulin resistance is partly diminished. However, the maintenance of raised concentrations of fasting adipose tissue LPL and other enzym elevations, support an accelerated uptake and storage of lipids. According to Eckel these metabolic enzyme activities explain the high incidence of relapse after a diet intervention (Eckel, 1992). Instilin resistance would not result in enhanced fuel/lipid uptake and storage and is therefore in favour of weight maintenance. This is further supported by data suggesting that insulin sensitivity predict weight gain (Ravussin et al., 1993). A low insulin sensitivity (is insulin resistant) correlated with weight gain. However, the predictive value of insulin sensitivity is still under debate, because no rellation with weight regain has recently been reported too (Wing, 1997). The insulin resistance syndrome has especially been prevalent in abdominal obesity, particular when visceral adipose tissue is accumulated (Buemann and Tremblay, 1996). Different anthropometric indices of regional adiposity are available to measure abdominal obesity (waist circumference, hip circumference, waist-hip ratio, skinfolds, sagittal diameter). However, these measures are not interchangeable when related to insulin resistance. The minimal waist girth is the most valid for assessing risks inherent with the central deposition of body fat (Weidner et al., 1995).

As mentioned above (see fat cell characteristics), abdominal fat is especially affected by exercise training. Reduction of the abdominal fat depots with exercise will therefore also be of benefit for lowering of insulin resistance (Buemann and Tremblay, 1996; Eckel, 1997). The consequence could be that subjects gain weight because of the elevated LPL-activity in adipose tissue (Eckel, 1992). This is in agreement witly our findings in chapter 6, in which we found an increase of $5.0 \mathrm{~kg}$ in fat mass in the trained subjects, despite the strenuous exercise performed.

In conclusion, the reported insulin resistance often found in obese subjects, and even in healthy non-obese subjects (Godsland and Stevenson, 1995), is of importance for prevention of further weight gain. Insulin resistance seems to be an adaptation to obesity.

In the three long-term studies described in the thesis, insulin resistance was not a main factor for investigation. The fiber study (chapter 4) was performed with a soluble fiber, known of its glycemic lowering effect (Jenkins et al., 1977). As thoroughly discussed in chapter 2, less fluctuating glucose and insulin levels are thought to be beneficial with respect to energy intake and hunger and satiety feelings. In chapter 5 the study using the carbohydrate (CHO) and chromium-picolinate ( $\mathrm{Cr}-\mathrm{Pic})$ supplement was presented. $\mathrm{CHO}$ were supplemented to affect the macronutrient balance (as discussed below). $\mathrm{Cr}$-Pic was supplemented to improve the glucose tolerance factor (GTF) in our subjects. This would improve the insulin response (McCarthy, 1993). However, the oral glucose tolerance tests (OGTT) carried out in that study (data not shown), were not affected by Cr-Pic supplementation. Finally, it is wellknown that insulin sensitivity will improve with exercise (Barnard and Wen, 1994; Buemann and Tremblay, 1996; Clausen et al., 1996). In our exercise study (chapter 6) we found however no reduction of fasting insulin levels, caused by training.

\section{Energy balance and substrate oxidation}

Changes in energy expenditure (EE), and energy intake (EI), but also macronutrient intake can affect body weight (BW). Subjects predisposed to obesity have been found to have a decreased resting metabolic rate (RMR) (Shah et al., 1991; Ravussin et al., 1993; Astrup et 
al., 1996). This has also been reported in subjects after a diet intervention, a condition favoring weight gain (Raben and Astrup, 1996). A change in RMR was discussed in chapter 9 in our subjects; where the change in RMR caused by an energy restricted diet, was found to be a useful predictor for weight gain. Also depressed thermogenic responses to food have been reported in subjects prone to obesity (Golay, 1993), and blunted adrenergic responses (Kempen, 1996). Unless these subjects increase their EE with strenuous physical activity, the suppressed EE is easily overeaten resulting in a positive energy balance and weight gain (Ravussin et al., 1993; Golay, 1993). As we observed in chapter 6, subjects have to train at a very high level to prevent weight regain. Even with the relatively intense training program subjects regained body weight and fat mass.

Besides maintenance of energy balance it is now common knowledge that for weight maintenance the fuel mix oxidized must match the nutrient distribution in the diet (Flatt, 1995). The body is able to adapt CHO oxidation to CHO intake (Flatt, 1995; Schutz, 1995). However, matching fat oxidation to fat intake requires more time (Schrauwen et al., 1997). Adaptation is probably different for lean and obese subjects. In obese and pre- and postobese subjects low fat oxidation rates have been found (Ravussin et al., 1993; Blaak et al., 1994; Schutz, 1995). The impaired fat oxidation results in a positive fat balance when more fat is consumed, and storage of fat will take place. The increase in fat mass will stimulate fat oxidation, until a new balance between intake and oxidation is reached (Schutz, 1995; Flatt, 1995). High respiratory quotients (RQ) have therefore been found in 'carbohydrate oxidizers', people who store fat (Larson et al., 1995). A high RQ postprandially has been found to predict weight gain (Zurlo et al., 1990; Seidell et al., 1992; Froidevaux et al., 1993; Schutz, 1995; Valtuena et al., 1997). As discussed in chapter 9, our RQ data were not useful as predictors for weight regain. The substrate oxidation data presented in chapter 8 , also suggest that obese subjects have a low fat oxidation capacity. Exercise training, known to result in increased fat oxidation in normal weight subjects (Turcotte et al., 1992; CallesEscadón et al., 1996), was not effective in the obese subjects to increase 24h fat oxidation. Changing the intake of macronutrients could prevent weight gain by fat storage. Increased CHO intake as performed in Denmark with the high-CHO ad libitum diets has shown beneficial effects at BW (Raben et al., 1995; Siggaard et al., 1996; Toubro et al., 1997). According to Flatt's model of macronutrient balance, lowering of BW is possible because lowered fat intake requires a lowered percentage of body fat to match fat oxidation to fat balance. Therefore fat oxidation takes place till the body fat mass has decreased to a comparable level of fat intake (Flatt, 1995a). A high dietary CHO intake may prevent weight gain in individuals who are at risk for weight gain (pre - and post-obese subjects), in whom CHO may inhibit food intake and stimulate EE (CHO have a higher thermic effect of food than fat) (Astrup and Raben, 1995). A CHO-rich diet may help obesity-prone individuals achieve and maintain macronutrient balance and BW in the long term (Raben and Astrup, 1996). Our data of the CHO containing food supplements described in chapter 5 confirm the results of the ad libitum $\mathrm{CHO}$ studies. We found that the more $\mathrm{CHO}$ were consumed the less weight regain took place $(r=-0.40, p=0.05)$. Although the $\mathrm{CHO}$ containing supplements were not effectively discriminating weight maintenance between groups, the overall daily CHO intake correlated with weight maintenance. The supplement could be used to achieve a high $\mathrm{CHO}$ intake daily. 
With respect to both sides of the energy balance, low fat intake (high CHO intake) and increased fat oxidation (probably by exercise) should be advised to prevent and to treat obesity.

\section{Genetic aspects of human obesity}

The transient success of most weight loss programs support a genetic component to the development and maintenance of obesity (Campbell et al., 1994). However, family members not only share genes, also diet, cultural background, and a certain lifestyle are shared. A separation of this familial trait into its genetic and environmental components is therefore needed (Ravussin et al., 1993). Especially data of twin and adoption studies, have provided strong evidence for an important genetic basis for obesity (Bouchard et al., 1990; Stunkard et al., 1990). Subjects with a genetically determined predisposition to obesity become obese when they are exposed to a particular range of environmental conditions. It was therefore hypothesized that individuals predisposed to obesity have an inherited defective ability to adapt substrate oxidation following a change in diet. Consumption of a high-fat diet will therefore in subjects with an impaired capacity to increase their lipid-CHO oxidation ratio, result in fat storage and weight gain (Astrup and Raben, 1992). This was indeed found in women with (one or two) obese parents who consumed high-fat diets. A high dietary fat intake may have an obesity-promoting effect in women with a genetic predisposition (Heitmann et al, 1995). We also found that predisposed subjects (subjects with one or two obese parents) regained more weight in the weight maintenance phase than subjects with lean parents $(\mathrm{p}=0.06)$ (chapter 9).

Based upon differences between pairs - and similarities within pairs of twins, it was found that genotype accounts for a significant proportion $(>40 \%)$ of the individual differences in RMR, thermic effect of food, and energy cost of light exercise (Bouchard, 1992; Bouchard, 1996). The physiological action of the genetics of BW is discussed in the paragraph on "the set-point theory'.

Although a clear genetic component of obesity is found, it is still possible to prevent weight gain. Low-fat diet consumption and increase of $\mathrm{EE}$ are still potential methods to prevent weight gain, also in predisposed individuals (Astrup and Raben, 1992; Flatt, 1995b).

\section{Psychological mechanisms for weight maintenance}

\section{Behavioural aspects}

Dietary intake and physical activity are the main factors related to weight maintenance. Individual behavioural attitudes with respect to these factors, positive or negative, affects weight maintenance. Based upon analyses of true weight maintainers it seems now clear which type of behaviour is required for maintenance of body weight. Key strategies found were: regular exercise, consciousness of own behaviour, sociall support, problem-solving, and personal strategies (Kayman et al ${ }_{*}$ 1990; DePue et al., 1995). Especially problemsolving attitudes and skills were found to be important for successful weight maintenance (DePue et al., 1995). Comparison of weight regainers and weight maintainers revealed that regainers were less able to cope with stressful life-events (Gormally et al., 1980). Relapsers indicated that in response to a negative life-event they regained weight, because they were not able to prepare special foods and to continue exercise. However, maintainers were aware that they had to be careful about their food intake (quality and quantity) and about physical 
activity, all the time (Kayman et al., 1990). Being able to cope with stress and to make changes in sedentary lifestyles were associated with successful weight maintenance (Gormally et all., 1980).

To dissolve problems and to cope with stress, might be essential for weight maintenance. Subjects not able to handle stress were likely to use emotion-focused or escape-avoidance ways of coping, such as eating, sleeping more, or wishing the problem would go away (Kayman et al, 1990). All factors with a negative effect at weight maintenance.

Emotional eating, often measured with the Three Factor Eating Questionnaire (Stunkard and Messick, 1985), has found to be high in obese subjects. Not only emotional eating, also control over food intake, especially loss of control ('disinhibition') is measured with this factor (Stunkard and Messick, 1985; Ganley, 1988). Disinhibition has proven to be a better predictor of behaviour than dietary restraint (factor 1) under several conditions (Ganley, 1988; Karlsson et al., 1994; chapter 9 this thesis). Data of Lawson and coworkers support this (1995). The unrestraint overeaters (low restraint-high disinhibition group) in their study were very obese $(\mathrm{BMI}=37.4)$. It was found that high disinhibition was associated with adiposity and significant disturbances of eating (Lawson et al., 1995). With the disinhibition score, episodic overeating is indicated too. The data of the unrestraint overeaters were quite similar to scores of obese binge eaters (Lawson et al., 1995). This is not uncommon, because it is known that in the obese population Binge Eating Disorders (BED) are more prevalent $(23-30 \%)$ than in the total society $(2-4 \%)$ (Marcus, 1993). BED is mainly characterized by loss of control of food intake. A high amount of food is eaten: very fast, in a short period of time, and without control (Fairburn and Wilson, 1993). When no treatment is provided and obese subjects try to lose weight by themselves, the lack of control, and strategies to control food intake makes them vulnerable to BED and weight regain (Wardle, 1996). In the studies described in the chapters 4,5 and 6 changes in eating behaviour were investigated at all time points. For all three factors of the Stunkard and Messick eating behaviour questionnaire (1985) changes were found over time. At month 16 the score of each factor had however returned to baseline, indicating that no permanent changes took place (chapter 4 and 9). Comparison of scores at the Eating Disorder Examination questionnaire (EDE-Q) (Fairburn and Wilson, 1993) and the Dutch Eating Behaviour Questiuonnaire (DEBQ) (Van Strien et al., 1986) of the subjects participating in the supplementation studies $v s$ the 'population' scores as presented in textbooks, indicates that participants in research studies show even more disturbed behaviour than the control obese, female population (fig. 10.2). 


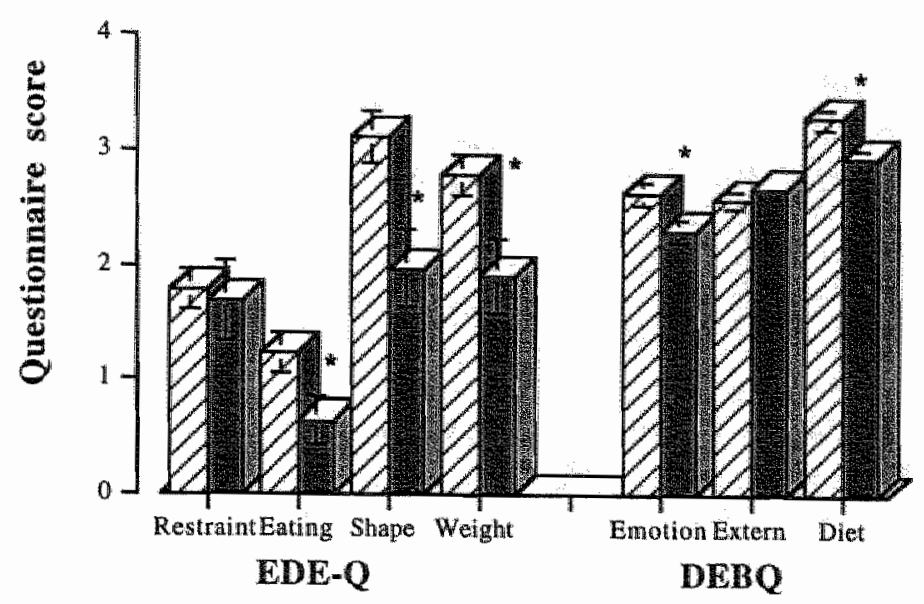

Fig. 10.2 Scores of the Eating Disorder Examination Questionnaire (EDE-Q) and the Durch Eating Behaviour Questionnaire (DEBQ) of the subjects participating in the fiber study and the CHO-study $(n=54)$ together (hatched bars) compared with text book values (Fairburn and Wilson, 1993) (filled bars).

$* p<0.05$

As already suggested in chapter 9 , it seems informative to use these eating behaviour questionnaires to characterise the subjects participating in the study. More adequate support to change eating behaviour might be possible.

Finally, the emotional difficulty of regaining lost weight reinforces the failure in the overweight subjects, and is often associated with lowered self-esteem (Wadden et al., 1988; Turner et al., 199; Foreyt et al., 1995). Weight stability was associated with greater psychological well-being than is fluctuation of weight, even in obese subjects (Foreyt et al,, 1995). Treatment of weight fluctuation has to deal with the negative psychological factors (negative self-efficacy and self-image), for an effective weight maintenance program (Foreyt et al., 1995; Wardle, 1996).

\section{Behavioural treatment strategies}

Different treatment interventions have been suggested. Because regular exercise and reduced dietary fat intake are the two maintenance behaviours that seem to be predictive of long-term success at keeping weight of, programs are concentrated on these two aspects (Haus et al., 1994; Stunkard, 1996). Behavioural therapy for obesity is to promote adherence to programs of healthy eating and exercise (Stunkard, 1996). Improvement of adherence to the program is a major goal. Awareness of behaviour of the obese subjects is important. Recording of food intake regularly during wejght maintenance has therefore been suggested to focus on eating, and awareness of their eating attitude $v s$ the modification learned during a program (Haus et al., 1994). Checking the food diaries carefully and giving feedback to the participants makes them aware of their eating habits. Recording food intake was found to be difficult when subjects regained weight (Haus et al., 1994). At this point subjects should be learned that a 'lapse' is not a 'relapse' (Turner et al., 1995; Stunkard, 1996). Training in relapse prevention involves coping with a slight weight gain (lapse), without a catastrophic reaction that all further efforts at weight control are hopeless (Stunkard, 1996). A lapse does 
not automatically mean that relapse takes place, and continuation of the program is still possible.

Programs for weight maintenance should be committed life-long, and focus on a healthy diet and physical activity. With respect to diet; frut, fat and fiber should be taken into account (Wing, 1995; Wardle, 1996). More fruit, less fat and more dietary fiber will result in a low energy dense diet, that often coincides with a low energy intake (Poppitt, 1995; WesterterpPlantenga et al, 1996). With respect to physical activity different activities, frequencies, durations and intensities have been suggested.

It has been found that subjects are very well able to educate themselves to positive changes in eating and exercise behawiour (Miller et al., 1993). Subjects who received a workbook about weight control, showed significantly lowered body weights and fat masses in comparison to controls after six months. They further ate more carbohydrates, less fat and more fiber, and trained significantly more than controls. It was concluded that obese adults can teach themselves to change eating and exercise habits positively (Miller et al., 1993). The internal locus of control, autonomous motivation, may be a factor in success or failure in weight control (Miller et al., 1993; Williams et al., 1996). Awareness again of own behaviour is effective with respect to weight maintenance (Miller, 1993; Williams, 1996).

Although motiwation has to be autonomous, social support and special environmental conditions are prerequisites for weight maintenance (Martin et al., 1984; Foreyt, 1987; Kayman et al., 1990; Perri et al., 1993; DePue et al., 1995). Just as social factors influence food intake positively; the more people present the larger the meal (de Castro, 1997), prevention of food intake or stimulation of exercise participation is also possible by others (Kayman et al, 1990; DePue et a1., 1995). Not only social support of peers and spouses are helpful, also supervision of trainers of the program (external locus of control) are helpful for a better compliance for especially training programs (Pavlou et al., 1989; Wing et al., 1996). An effective weight maintenance program should include:

dietary treatment, exercise sessions in groups and under supervision, education about food preparation and exercise training, and skills training to cope with stressful life-events (Foreyt , 1987; Kayman et al., 1990; Perri, 1993; Turner et al., 1995; DePue et al., 1995; Wing, 1995). So multidisciplinary, individually designed programs should be provided to subjects who are really motivated to control their body weight (Perri et al., 1993; Stunkard, 1996). Social support is essential, as well as involvement of a team of experts (physician, dietitian, psychologist and an exercise physiologist) (Tumer et al., 1995).

\section{Methodological considerations}

\section{Very low energy diets}

The three long-term interventions described in the thesis, had a similar study design. It is possible that the results found in the long-term are a consequence of the design used.

A very low energy diet (VLED) was used as an easy and standardized method to lose weight in a short period of time, to obtain a situation in which our subjects were vulnerable to weight regain and therefore the effect of our intervention could be tested. Without a prior weight-loss weight gain would take nuch more time, and the intervention period should be much longer. However, some studies have shown that a VLED is indeed effective for weight loss, but in the long-term maintenance of the weight lost was poor (Björvell and Rössner, 1986; Wadden et al., 1994). Wadden and coworkers compared a VLED of $420 \mathrm{kcal}$.day-1 


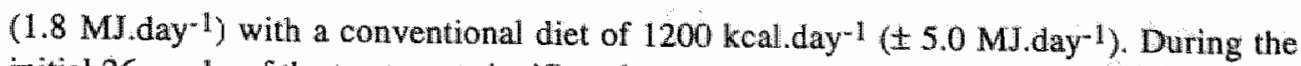
initial 26 weeks of the treatment significantly more weight was lost with a VLED (21.5 kg), than with a conventional diet $(11.9 \mathrm{~kg})$. Although the program was still continued with biweekly sessions, the energy restriction was withdrawn, and after one year regain was found. At the end of the total program at 78 weeks the group that started with a VLED had still a weight loss of $10.9 \mathrm{~kg}$ ( $51 \%$ regain) and the group that started with a conventional diet showed a weight loss of $12.2 \mathrm{~kg}$, so even more than after discontinuation of the diet (less than $0 \%$ regain!). Thus no long-term advantage of VLED was found (Wadden et al , 1994). The benefit of a VLED is the avoidance with normal food products, preventing subjects from eating them. However, the awoidance of conventional foods, the severe energy restriction, and the greater initial weight losses with a VLED, may have increased physiological and psychological pressures to weight regain (Wadden et al., 1994).

Recently the finding that less severe dieting had the same beneficial effects at body weight as a VLED was reported (Rössner and Flaten, 1997). A VLED (420 kcal or $530 \mathrm{kcal}_{\text {day }}{ }^{-1} ; 1.8$ or $2.2 \mathrm{MJ}$ day $^{-1}$ ) or a low energy diet (LED) of $880 \mathrm{kcal}_{\text {.day }}{ }^{-1}$ ( $3.7 \mathrm{MJ}_{\text {.day }}{ }^{-1}$ ) were equally effective in long-term treatment of obesity (Rössner and Flaten, 1997). The tendency to less side effects with a LED, and similar body weight outcomes in the long-term suggests that a LED deserves more attention for weight-maintenance studies. A less severe energy restriction might result in a less exaggerated response in regain and an intervention in the weight maintenance phase may become effective.

\section{Study period}

Long-term interventions are characterized by their long duration. The duration of the study period as an explanation for the poor weight maintenance results has already been discussed in the chapters 4 and 5. Habituation to the supplement supplied (the fiber supplement and/ or the mixed food supplement) might result in physical adaptations, as has been found for fiber supplementation (intestinal adaptation; Florent et al., 1985). In long-term interventions the compliance of the subjects to the treatment is crucial. Check-lists for supplement intake and counting the sachets used, are control mechanisms that are still open for bias, although frequent questioning also revealed confidence that the subjects complied very well. The training diaries used in the exercise studies in which the male subjects wrote down their training sessions, could easily be manipulated. However, the examination of the diaries of the investigator together with the participant revealed a much better inside in the real training output. However, more hard data for compliance is advised in future long term studies. Measurement of markers in blood and / or feces may be useful. Fiber analysis of the feces, or markers also added to the supplement, are suggested for control of compliance. It is also possible to measure markers in blood ( $\mathrm{Cr}-\mathrm{Pic}$ ) for consequent intake of the supplement. For the exercise intervention the future investigators are advised to give all training sessions by themselves, for maximal control of participation and manner of participation.

Although the study design used in the present thesis is clear and for comparison of the intervention and control group very useful, for clinically relevant outcomes other interventions are advised. For an optimal effect at weight maintenance a multidisciplinary program should be used. New treatment settings and opportunities for learning might result in better weight maintenance (Wadden et al., 1994). Booster sessions, incorporation of a two week VLED- or LED, after a period of weight maintenance was found to improve 
motivation of patients and adherence to the program, because weight loss was again achieved (Rosssnet and Flaten, 1997).

\section{Contact with participants}

The study design used focussed on the effect of an intervention in free living subjects. In the beginning of a study during the VLED subjects came to the lab every week. Before and after the VLED and again 2 months after finishing the VLED, participants were subject to measurements. So, in the first 4 months there was intense contact with the subjects. However, between 4 and 10 months and 10 and 16 months there was only a minimal amount of contact with the subjects, to study the supplement in free living conditions, without supervision. In this way we would study the sole effect of the supplement and not the effect of control. The lack of control could be seen as a major drawback, however, the effectiveness of an intervention without supervision, would indicate that the intervention is really useful under free living conditions. According to Wadden (1994; 1995) control sessions (visitations at the lab) were not effective in prevention of regain (Wadden et al., 1994; Wadden et all, 1995). Regain occurred in subjects who visited the lab biweekly. The first results of a large population study in the United States indicated too that the control group (no contact with the inwestigators) showed no different weight gain patterns than groups with contact with the investigators (Jeffery and French, 1997). We conclude therefore that minimal contact between measurements is an effective way to study the intervention of a single factor in more free living conditions.

\section{Number of subjects}

Power analysis revealed that a difference in regain could be studied with 34 subjects, assuming a regain in the treatment group of $50 \%$ (partly successful) and $80 \%$ in the control group (a standard deviation of $60 \%$ ). However, the intervention group showed higher regain levels, and it was found that our supplements were not effective at all, what could not be explained by the number of subjects studied. The assumptions for partly successful weight maintenance (the 50\% level) were based upon short-term interventions, in which promising results were found (chapter 3: short-term fiber study). Based upon literature we assumed that the mixed supplement contained functional ingredients with respect to weight maintenance (Dulloo et al., 1989; Evans, 1989; Mertz, 1993; McCarthy, 1993; Spiller, 1993; Toubro et al., 1997). Training has also been reported to be effective with respect to body weight control by many colleagues (van Dale et al ., 1990; Bouchard et al., 1993; Harris et al., 1994; Ewbank et al., 1995; Buemann and Tremblay, 1996). Because the training study was actually a pilot-intervention we started with $15 \mathrm{men}$. The difference in regain between the exercise and the control group almost reached the level of significance ( $\mathrm{p}=0.09$; chapter 6 ). This would have been significant with more subjects $(n=30)$. We would like to conclude however that the number of subjects in the supplementation studies were not the limiting factor for the lack of effect.

The number of subjects started and number of drop-out during VLED and during the weight maintenance phase were comparable with other long-term studies (table 10.3). 
Table 10.3 Drop-out information

\begin{tabular}{llllll}
\hline Sudy & Month 0 & Month 2 & Month 16 & $\%$ Month 0 & $\%$ Month 2 \\
\hline Fiber & 48 & 39 & 31 & $65 \%$ & $79 \%$ \\
CHO & 49 & 39 & 33 & $67 \%$ & $85 \%$ \\
Exercise & 16 & 15 & 15 & $94 \%$ & $100 \%$
\end{tabular}

Number of subjects participating in the three intervention studies are presented at the start of the study (month 0), after VLED ( 2 months) and at the end of the study (16 months). Participation at 16 months is further presented as percentages of the number of subjects at 0 and 2 months.

Comparison with other long-term interventions revealed that the drop-out rate is in the sane range as in other long-term dietary and / or activity studies (exercise $81 \%$, van Dale et al,, 1990; no intervention, just long-term 88\%, Hensrud et al., 1994; exercise 53\%, MacKeen et al., 1983; follow-up 65\%, Hartman et al., 1993).

\section{Placebo}

In the two supplementation studies no placebo was supplied to the control group. In the fiber supplementation study a placebo has the drawback that it almost always will contain more energy than the fiber supplement tested (Rössner, 1992). No placebo of the fiber supplied was therefore prepared. The enriched carbohydrate supplement study was controlled with a carbohydrate only supplement, and again with a group that did not receive a supplement. A control drink without energy (and carbohydrates) did not taste as well, and could not be supplied for 16 months. Therefore, and to compare the data of the control group with the first study, no placebo was supplied.

\section{Education}

Weight maintenance studies should contain education sessions to learn participants weight maintenance behaviour (Fairburn and Cooper, 1996). Although no clear effect of the intervention would have been found when education was included, for clinical purposes education is of importance. Subjects should be made aware of their lifestyle (eating and exercise attitude) with respect to weight maintenance, changing attitudes to maintain the weight lost during an energy restricted diet (Turner et al., 1995; Fairburn and Cooper, 1996).

It is further known that the prevalence of obesity is especially high in the low economic classes (Seidell and Flegal, 1997). More knowledge of food and exercise might therefore be beneficial for weight maintenance. This could further have positive implications with respect to social and economic consequences of obesity; discrimination against overweight individuals might decrease with decreasing body weight (Gortmaker et al., 1993). However, the large population study the Pound of Prevention in the United States, has shown so far that eduction did not result in a better body weight maintenance (Jeffery and French, 1997). Education of a healthy lifestyle has been suggested to be beneficial especially in children for prevention of obesity (Saris et al., 1982). In the Health Education project a 12 year longitudinal study was carried out at primary schools and kindergartens. Not only nutrition information was given, also topics about physical activity, personal health care, safety at home and in traffic, and environment (pollution) were educated. The program was used to produce changes in human behaviour, resulting in an improved health status of the 
community (Saris et al., 1982). A similar program with more specific attention for nutrition has started in Germany. In Kiel, the Kiel Obesity Prevention Study has started in primary schools. Increased activity levels and awareness of food consumption should lower the prevalence of obesity in the future (Körzinger et al., 1997). These health education programs deserve further attention in the prevention of obesity.

\section{Recommendations for future research}

Based upon the afore mentioned aspects of weight maintenance and weight regain, different physiological and psychological studies could be suggested for further study.

For fundamental studies relating to the cause of weight regain, the set-point theory, fat cells, insulin resistance, substrate oxidation, genetics and behaviour can be studied in more detail. With the discovery of leptin (Zhang et al., 1994) the interest in the genetics of obesity is renewed. The relation of leptin with fat mass and insulin (resistance), might give further inside in the pathology of obesity.

Studies examining weight maintenance could use the different aspects of each effective weight maintenance interwention. Especially multidisciplinary approaches, containing dietary and exercise activity sessions, training of coping skills and behavioural therapy might result in weight maintenance. Contact, supervision, and variation in sessions could be studied for their effectiveness.

A real relapse prevention program (Perri et al., 1993; Turner et al., 1995; Wadden at al., 1995; Fairburn and Cooper, 1996; Stunkard, 1996) might be clinically relevant but scientifically difficult to standardize and control for. Alternating different sessions (low-fat cooking; exercise activities; coping skills) with different diets (conventional and sometimes a booster session with a (V)LED) might result in weight maintenance for the participants in the long-term.

From the regain results presented in this thesis and available in literature it seems unethical to treat obesity, because so far no effective treatment is found (Wooley and Garner, 1994).

\section{Conclusions}

1. Monodisciplinary interventions alone (fiber supplementation; mixed food supplement; or exercise training) are not effective for weight maintenance in the long-term in free living subjects.

a. Supplementation of fiber is effective in short-term studies and may be useful in the treatment of obesity, by facilitating compliance to low energy intake. However, in free living conditions, eating ad libitum no effect was found of 14 months fiber supplementation at weight maintenance in weight-reduced women.

b. Supplementation of carbohydrates, chromium, dietary fiber and caffeine did not affect BW. The energy percentage intake of carbohydrates daily was increased significantly. However, it was found that a high En\% intake of carbohydrates and consequently a low En\% intake of fat daily was beneficial for prevention of weight regain.

c. Exercise training did not affect regain of body weight significantly. However, exercise training was found to be beneficiall: the trained group showed less regain of fat mass and higher levels of physical fitness, factors related with lower risk factors for CVD, compared to the control group. However, the regain of fat mass which occurred even in the exercising group suggests that maintenance of fat loss is extremely difficult. 
2. Endurance training decreased plasma leptin levels, independently of changes in plasma insulin levels and body fat percentage.

3. Endurance training increased the rellance on carbohydrate oxidation and did not increase fat oxidation, when studied for $24 \mathrm{~h}$ in a respiration chamber.

4. Frequency of dieting prior to the study was found to be a powerful predictor of weight maintenance. The additional predictive information obtained from factor 3 of the TFEQ and the change in RMR during dieting shows that weight regain has to be explained by behavioural and physiological factors.

\section{References}

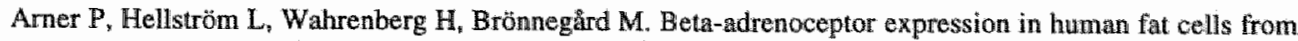
different regions. J.Clin.Invest.86: 1595-1600, 1990

Astrup A, Raben A. Obesity: an inherited metabolic deficiency in the control of macronutrient balance? Eur.J.Clin.Nutr.46: 611-620, 1992

Astrup A, Raben A. Carbohydrate and obesity. Int.I.Obes. 19: (suppl.5): S27-S37, 1995

Astrup A, Buemann B, Toubro S, Ranneries C, Raben A. Low resting metabolic rate in subjects predisposed to obesity: a role for thyroid status. Am.J.Clin.Nutr.63: 879-883, 1996

Balkan B, Dijk G wan, Strubbe JH, Bruggink JE, Steffens AB. Exercise-induced sympathetic FFA mobilization in VEM-lesioned rats is normalized by fasting. Am.J.Physiol.262: R981-985, 1992

Barnard RJ, Wen SJ. Exercise and diet in the prevention and control of the metabollic syndrome. Sports Med. 18: 218-228, 1994

Begin-Heick N. B-adrenergic receptors and G-proteins in the ob/ob mouse. Int.J.Obes.20: S32-\$35, 1996

Björntorp P. Physical training in the treatment of obesity. Int.J.Obes.2: 149-156, 1978

Björvell $\mathrm{H}$, Rössner $\mathrm{S}$. Long-term effects of commonly available weight reducing programmes in Sweden. Int.J.Obes.11: 67-71, 1986

Blaak EE, van Baak MA, Kemerik GJ, Pakbiers MTW, Heiendal GAK, Saris WHM. B-Adrenergic stimulation of energy expenditure and forearm skeletal muscle metabolism in lean and obese men. Arn.J.Physiol.267: E306-E315, 1994

Blaak EE, Baak MA van, Kester ADM, Saris WHM. B-Adrenergically mediated thermogenic and heart rate responses: Effect of obesity and weight loss. Metabolism 44:520-524, 1.995

Bouchard C, Tremblay A, Depres JP, Nadeau A, Lupien PJ, Thériault G, Dussault J, Moorjani S, Pinault S, Fournier $G$. The response to long-term overfeeding in identical twins. N.Engl.J.Med.322: 1477-1482, 1990

Bouchard C. Genetic aspects of human obesity. In: Björntorp, P. and Brodoff, B.N., ed.: Obesity, J.B. Lippincott Company, Philadelphia, pg: 343-35 , 1992

Bouchard C, Deprés J.P, Tremblay A. Exercise and obesity. Obes.Res. 1: 133-147, 1993.

Bouchard $C$. The causes of obesity: advances in molecular biology but stagnation on the genetic front. Diabetologia 39: 1532-1533, 1996

Buemann B. Tremblay A. Effects of exercise training on abdominall obesity and related metabolic complications. Sports Med.21: 191-212, 1996

Calles-Escadon J, Goran MI, O'Connell M, Sreekumaran Nair $\mathrm{K}$, Danforth E. Exercise increases fat oxidation at rest unrelated to changes in energy balance or lipolysis. Am.J.Physiol.270 (Endocrin.Metab. 33): E1009-E1014, 1996

Campbell PJ, Carlson MG, Nurjhan N. Fat metabolism in human obesity. Am.J.Physiol.266: E600-E605, 1994

Campfield LA, Smith FJ, Burn P. The OB protein (leptin) pathway - a link between adipose tissue mass and central neural networks. Horm.Metab.Res. 28: 619-632, 1996

Castro J de. How can energy balance be achieved by free-living human subjects? Proc. Nutr. Soc. 56:1-14, 1997

Clausen JO, Borch-Johnsen $K$, Ibsen $H$, Bergman RN, Hougaard $P$, Winther $K$, Pedersen $O$. Insullin sensitivity index, acute insulin response, and glucose effectiveness in a population-based sample of 380 young healthy caucasians. Analysis of the impact of the gender, body fat, physical fitness, and liferstylle factors. J.Clin.Inwest.98: 1195 1209; 1996

Collins S, Surwit RS. Pharmacologic manipulation of ob expression in a dietary model of obesity. I.Biol.Chem.271: $9437-9440,1996$ 
Dale $D$ van, Saris WWM, Hoor $F$ ten. Weight mintenance and resting metabolic rate 18 mo months atter a diet wercise trextrient. Int J, Obes. $14: 347-359,1990$

DePue JD, Clark WM, Ruggiero L, Medeiros ML, Pera V. Maintenance and weight loss: a needs assessment. Obes.Res. $3: 241-248,1995$

Dulloo AG, Geissler CA, Horton T, Collins A. Miller DS. Normal caffeine consumption: influence on thermogenesis and daily ewtergy expenditure in lean and post-obese human volunteers. Am.J.Clin. Nutr.49: 44-50, 1989

Eckel RH. Instilln resistance: an adaptation for weight maintenance. Lancet $340: 1452-1453,1992$

Eckel RH. Inisulin resistance in atherosclerosis (editorial). Am.J.Cln Nutr.65: 164 165, 1997

Evans $G$ W. The effect of chromium picolinate on insulin controlled parameters in humans lnt.J.Biosociall. Med.Research 11: 163-180, 1989

Ewbark PP, Darga LL, Lucas CP. Physical activity as a predictor of weight maintenance in previously obese subjeots. Obes.Res. 3: $257-263,1995$

Fairbum GC, Whison GT. Binge etaing: definition and classification. In: Binge eating. Nature, assessment, and treatment. GC Fairburm and GT Wilson (ed). The Guilford Press, New York, 1993

Fairburn $\mathrm{CG}$, Cooper $\mathrm{Z}$. New perspectives on dietary and behawioural treatments for obesity. Int.J.Obes. 20(suppl.1): \$9-\$13,1996

Faust IM, Role of the fat cell in energy balance physiology. In: Eating and its disorders. Ed: Stunkard AJ, Stellar, E Raven Press, New York, 1984, pg: $97-107$

Flat JP. Body composition, respiratory quotient, and weight maintenance. Am.J.Clin.Nutr.62 (suppl.): $1107 \mathrm{~s}-1117 \mathrm{~S}, 1995 \mathrm{a}$

Flatt JP. McCollum Award Lecture, 1995: Diet, lifestyle, and weight maintenance. Am.J.Clin. Nutr.62: 820$836,1995 b$

Florent C, Flourie B, Leblond A, Rautureau M, Bernier J-J, Rambaud J-C. Influence of chronic لactulose ingestion on the colonic metabolism of lactulose im man (an in vivo study). J.Clin.Invest,75: 608.613, 1985

Foreyt JP. Issues in the assessnent and treatment of obesity. J Consult.Clun.Psych.55: 677-684, 1987

Foreyt JP, Brunner RL, Goodrick GK, Cutter $G_{3}$ Brownell KD, St. Jeor TS. Psychological correlates of weight fluctuation. Int.J.Eat.Dis.17: 263-275, 1995

Friedman MI. Comtrol of energy intake by energy metabolism. Am.J.Clin. Nutr.62 (suppl.): 1096S-1100S, 1995

Friedman MI. An energy sensor for control of energy intake. Proc.Nutr.Soc.56: 41-50, 1997

Froidevaux F, Schutz Y, Christin L, Jéquier E. Energy expenditure in obese women before and during weight loss, after refeeding, and in the weightwelapse period. Am J.Clin.Nutr.57:35-42, 1993

Gaal LF van, Wauters MA, Leeuw IH de. The beneficial effects of modest weight Joss on cardiovascular risk (actors. Int. J.Obes.21 (suppl.1): S5-S9, 1997

Ganley RM. Emotional ating and how it relates to dietary restraint, disinhibition, and perceived hunger. Int.r. Eat.Dis. 7: $635 \cdot 647,1988$

Godsland IF and Stevenson JC. Insulin resistance: syndrome or tendency? Lancet 346: 100-103, 1995

Golay A. Blunted glucose-induced themogenesis: a factor contributing to relapse of obesity. Int.J.Obes. 17: $523 \times 527,1993$

Gormally 3 , Rardin $D_{*}$ Black $S$. Correlates of successful response to a behavioral weight control clinic. J.Counsel.Psych.27: 179-191, 1980

Gortmaker SL, Must A, Perrin JM, Sobol AM, Dietz WH. Social and econonic consequences of overweight in adolescence and young admlthood. N.Eng.J.Med.329:1008-1012, 1993

Harris RBS. Role of set-point theory in regulation of body weiglit. FASEB J.4: $3310-3318,1990$

Hatris JK, Fremch SA, Jeffery RW, McGovern PG, Wing RR. Dietary and physical activity correlates of long-term weight loss. Obes.Res.2, 307-313, 1994

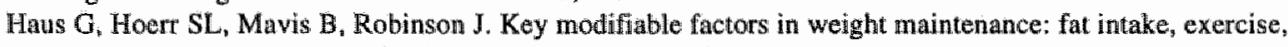
and weight cycling. J.Am. Diet.Assoc, 94:409-413, 1994

Heitmann BL, Lissner L, Sorensen TIA, Bengtsson C. Dietary fat intake and weight gain in women genetically predisposed for obesity. Am.J.Clin.Nutr.61: 1213-1217, 1995

Hensrud DD, Weinsier RL, Darnell BE, Hunter GR. A prospective study of weight maintenance in abese subjects reduced to nomall body weight without weight-loss training. Am.J.Clin.Nutr.60: 688-694, 1994

Itallie TB van. The enduring storage capacity for fat: implications for treatment of obesity. In: Eating and its disorders. Fd: Stunkard AJ, Steillar, E. Raven Press, New York, pg: 109.119, 1984

Jeffrery RW, French SA. Preventing weight gain in adults: design, methods and one year results from the Pound of Prevention study. Int.J. Obes.21: 457-464, 1997 


\section{General discussion}

Jenkins. DIA, Leeds AR, Gassull MA, Cochet B, Alberti KGMM. Decrease in postprandial insulin and glwcose concentrations by guar and pectin. Ann.Int.Med.86: 20-23, 1977

Karlsson J, Hallgren $P_{n}$ Kral J, Lindroos A-K, Sjöstronn $L_{n}$ Sullivan M. Predictors and effects of long-term dieting on mental well-being and weight loss in obese women. Appetite 23: 15-26, 1994

Kayman S, Bruwold W. Stern JS. Maintenance and relapse after weight loss in women: behavioral aspects. Am.J.Clin.Nutr.52: 800-807, 1990

Keesey RE, Corbett SW. Metabolic defence of the body weight set-point. In: Eating and its disorders. Ed: Stunkard AJ, Stellar, E. Raven Press, New York, pg: 87-96, 1984

Kempen KPG. Metabolic effects of weight cycling in obesity. Thesis at the Maastricht Uniwersity, 1996

Körtzinger I. Mast M, Bumbe A, Grund A, Maller MJ. School-oriented intervention for the prevention of obesity as part of KOPS (Kiel Obesity Prevention Study). Int.J.Obes.21 (Suppl.2): S30, 1997

Larson DE, Ferraro RT, Robertson DS, Ravussin E. Energy metabolism in weight-stable postobese individuals. Am.J.Clin.Nutr.62: 735-739, 1995

Lawson OJ, Williamson DA, Champagme CM, DeL_any JP, Brooks ER. Howat PM, Wozniak PJ, Bray CA, Ryan $\mathrm{DH}$. The association of body weight, dietary intake, and energy expenditure with dietary restraint and disinhibition. Obes.Res.2: 153-161, 1995

Lönnroth $P$, Smith $U$. Intermediary metabolism with an emphasis on lipid metabolism, adipose tissue, and fat cell metabolism: a review. In: Björntorp, P. and Brodoff, B.N., ed.: Obesity, J.B. Lippincott Company, Philadelphia, pg: 3-14, 1992

Mackeen PC, Franklin BA, Nicholas WC, Buskirk ER. Body composition, physical work capacity and physical activity habits at 18 -months follow-up of middle-aged women participating in an exercise intervention program. Int.J.Obes.7:61-71, 1983

Marcus MD. Binge eating in obesity. In: Binge eating. Nature, assessment, and treatment. GC Fahriburn and GT Wilson (ed). The Guilford Press, New York, pg: 77-96, 1993

Martin JE, Dubbert PM, Katell AD, Thompson JK, Raczynski JR, Lake M, Smith PO, Webster JS, Sikora $T$, Cohen RE. Behavioral control of exercise in sedentary adults: studies 1 through 6 . J.Consult.Clin.Psych. 52: 795-811, 1984

Mauriège P, Prud'homme D, Marcotte M, Yoshioka M, Tremblay A, Deprés. J-P. Chronic adaptation of adipose tissue metabolism to endurance training: existence of regional differences. Int.J.Obes.20(Suppl.4): 66,1996

McCarthy MF. Insulin resistance in mexican Americans - a precursor to obesity and diabetes? Med. Hypotheses 41: 308-315, 1993

Mertz W. Chromium in human nutrition: a review. J.Nutr. 123: 626-633, 1993

Miller WC, Eggert E, Wallace JP, Lindeman AK, Jastremski C. Successful weight loss in a self-taught, selfadministered program. Int.J.Sports Med.14: 401-405, 1993

Nisoli E, Tonello C, Briscini L, Flaim R, Carruba MO. Leptin and nerve growth factor regulate adipose tissue. Nature Med. 2: 130, 1996

Pavlou KN, Krey S, Steffee WP. Exercise as an adjunct to weight loss and maintenance in moderately obese subjects. Am.J.Clin.Nutr.49: 1115 i123, 1989

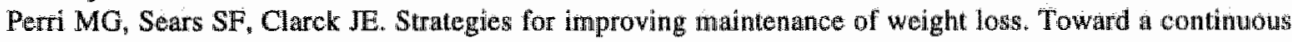
care model of obesity management. Diab.Care 16:200-209, 1993

Poppitt SD. Energy density of diets and obesity. Int.J.Obes.19 (suppl.5): S20-S26, 1995

Raben A, Due Jensen N, Marckmann P, Sandletrom B, Astrup A. Spontaneous weight loss during II weeks" ad libitum intake of a low fathigh fiber diet in young, normal weight subjects. Int.J.Obes.19: 916-923, 1995

Raben A, Astrup A. Manipulating carbohydrate content and sources in obesity prone subjects: effect on energy expenditure and macronutrient balance. Int J.Obes.20 S24-\$30, 1996

Ravussin $\mathbb{E}$, Fontvieille AM, Swinburn BA, Bogardus C. Risk factors for the development of obesity. Ann.N.Y.Acad.Sc.683: 141-150, 1993

Rosenbaum M, Leibel RL, Hirsch J. Obesity. New Eng.J.Med.337: 396-407, 1997

Rössner S. Dietary fiber in the prevention and treatment of obesity. In: Dietary fiber - A component of food. Chapter 15 (pg. 265-277). Ed. Schweizer TF, Edwards CA. London: Springer-Verlag, 1992

Rössner S, Flaten H. WLCD versus LCD in long-ternn treatment of obesity. Int.J.Obes.21: 22-26, 1997

Saris WHM, Binkhorst RA "Cramwinkel AB, Hegger WG, König KG. The development of a health education program for school children. T.Soc.Geneesk.60: 680-684, 1982

Schrauwen P, Marken Lichtenbelt WD vam, Saris WHM, Westerterp KR. Changes in fat oxidation in response to a high-fat diet. Am.J.Clin.Nutr.66: 276-282, 1997 


\section{Chapter 10}

Schulz $Y$. Abrormalities of fuel utilization as predisposing to the development of obesity in humans. Obes.Res. 3: 173s-178s, 1995

Seidell JC, Muller DC, Sorkin JD, Andres R. Fasting respiratory exchange ratio and resting metabolic rate as predictors of weight gain: the Baltimore Longitudinal Study on Aging. Int.J.Obes. 16: 227-674, 1992

Seidell JC, Flegal KM. Assessing obesity: classification and epidemiology. Brit.Med.Bull. 53: 238-252, 1997

Shah M, Jeffery RW. Is obesity due to overeating and inactiwity, or to a defective metabolic rate? A review. Aun.Behiav.Med.13: 73-81, 1991

Siggaard R, Raben A, Astrup A. Weight loss during 12 weeks' ad libitum carbohydrate-rich diet in overweight and normal-weight subjects at a Danish work site. Obes.Res.4: 347-356, 1996

sjôtröm L. Can the relapsing patient be identified? In: Björntorp. Cairella, Howard (eds.): Recent advances in obesity research: III. Proceedings of the third International Congress on Obesity. Libbey: London, pg: $85-93,1974$

spiller GA. Handbook of dietary fiber in human nutrition. CRC Press, Inc., second edition "Boca Ratom, USA, 1993

Stefanick ML. Exercise and weight control. Exerc.Sport Sci.Rev.21: 363-396, 1993

Steffeng AB, Mogenson GJ, Stevenson JAF. Blood glucose, insulin and free fatty acids after stimulation and lesions of the hypothalamus. Am.J.Physiol.222: 1446-1452, 1972

Steffens $A B$. Influence of reversible obesity on eating behavior, blood glucose and insulin in the rat. Am.J.Physiol.228: 1738-1744, 1975

Steffens AB, Strubbe JH. CNS regulation of glucose secretion. Advances in Metabolic Disorders, yol.10, CNS Regulation of Carbohydrate Metabolism. Ed. Szabo AJ, New York, Academic Press, 1983, 221-258

Steffens AB, Strubbe JH, Balkab B, Scheurink AJW. Neuroendocrine mechanisms involved in regulation of body weight, food intake and metabolism. Neurosci.Biobehav.Rev. 14:305-313, 1990

Strien T' van, Frijters JER ${ }_{*}$ Bergers GPA, Defares PB. The Dutch Eating Behavior Questionnaire (DEBQ) for assessment of restrained, emotional, and external eating behawior. Int.J.Eat.Disord. 5: 295-315, 1986

Strubbe JH. Regulation of food intake. In: Food intake and energy expenditure. Ed: Westerterp-Plantenga MS, Fredrix EWHM, Steffens AB. CRC Press, Boca Raton, Florida, pg: 141-154, 1994

Sturkard AJ, Messick S. The three-factor eating questionnaire to measure dietary restraint, disinhibition, and hunger. J.Psychosom.Res.29: 71-83, 1985

Stunkard AJ, Harris JR, Pederson NL, McClearn GE. The body-mass index of twins who have been reared apart. N.Engl.J.Med.322: 1483-1487, 1990

Stunkard A. "Diet, exercise and behavioral therapy": a cautionary tale. Obes.Res.4: 293-294, 1996

Toubro S, Astrup A. Randomised comparison of diets for maintaining obese subjects' weight after major weight loss: ad lib, low fat, high carbohydrate diet $v$ fixed energy intake. B.M.J. 314: 29-34, 1997

Turcotte LP, Richter EA, Kiens B. Increased plasma FFA uptake and oxidation during prolonged exercise in trained vs untrained humans. Am.J.Physiol,262 (Endocrinol.Metab. 25): E7911-799, 1992

Thiner LW, Wang MQ. Westerfield RC. Preventing relapse in weight control: a discussion of cognitive and behavioral strategies. Psych.Rep.77: 651-656, 1995

Valtuena S, Sola R, Salas-Salvado J. A study of the prognostic respiratory markers of sustained weight loss in obese subjects after 28 days on a VLCD. Int.J.Obes.21: 267-273, 1997

Wadden TA, Stunkard AJ, Liebschutz J. Three-year follow-up of the treatment of obesity by wery low callorie diet, behavior therapy, and their combination. J.Consult.Clin.Psych.56: 925-928, 1988

Wadden TA, Foster GD, Letizia KA. One-year behavioral treatment of obesity: comparison of moderate and severe caloric restriction and the effects of weight maintenance therapy. J.Consult.Clin.Psych.62: 165171,1994

Wadden TA, Bartlet SJ, Foster GD, Greenstein RA, Wingate BJ, Stunkard AJ, Letizia KA. Sertralime and relapse prevention training following treatment by very-low-calorie diet: a controlled clinical trial. Obes.Res. 3: 549-557, 1995

Wardle J. Obesity and behaviour change: matching problems to practice. Int.J.Obes.20 (suppl.1): \$1.S8, 1996

Weidner MD, Gavigan KE, Tyndall GL, Hickey MS, McCammon MR and Houmard JA. Which anthropometric indices of regional adiposity are related to the insulin resistance of aging? Int.J.Obes.19: $325-330,1995$

Westerterp KR, Donkers HHLM, Fredrix EWHM, Boekhoudt P. Energy intake, physical activity and body weight: a simulation model. Br.J.Nutr.73: 337-347, 1995 
Westerterp-Plantenga MS, Pasman W, Yedema MJW, Wijckmans-Duijsens NEG. Energy intake adaptation of food intake to extreme energy densities of food by obese and non-obese women. Eur. I.Clin Nutr. 50: $401-407,1996$

Williams GC, Grow VM, Freedman ZR, Ryan RM, Deci EL. Motivational predictors of weight loss and weight-loss maintenance. J.Person.Soc.Psych.70: $115-126,1996$

Wing RR. Changing diet and exercise behaviors in indiwduals at risk for weight gain. Obes.Res.3(suppl.2): 277S-282S, 1995

Wing RR, Jeffery RW, Pronk N, Hellersteds WL. Effects of a personal trainer and financial incentives om exercise adherence in overweight women in a behavioral weight loss program. Obes.Res.4: 457-462, 1996

Wing RR. Insulin sensitivity as a predictor of weight regain. Obes.Res. 5: 24-29, 1997

Wooley SC, Garner DS. Dietary treatments for obesity are ineffective. B.M.J. 309: 655-656, 1994

Zhang Y, Proenca R, Maffei M, Barone M, Leopold L, Friedman JM. Positional cloning of the mouse obese gene and its human homologue. Nature 372: 425-432, 1994

Zheng D, Jones JP, Usala SJ, Dohm GL. Differential expression of $o b$ mRNA in rat adipose lissue in response to insulin. Biochem.Biophys.Res.Commun.218: 434-437, 1996

Zurlo F, Lillioja S, Esposito-Del Puente, Nyomba BL, Raz I, Saad MF, Swinburn BA, Knowler WC, Bogardus $\mathrm{C}$, Ravussin $\mathrm{E}$. Low ratio of fat to carbohydrate oxidation as predictor of weight gain: study of 24-h RQ. Am.J.Physiol.259 (Endocrin. Metab.22): E650-E657, 1990 


\section{Summary}

The prevalence of obesity, defined as a body masss index (BMI) $>30 \mathrm{~kg} \cdot \mathrm{m}^{-2}$, has increased dramatically in western societies. Main factors of importance for the development of obesity are consumption of high-fat diets and an inactive lifestyle. Because obesity is known to be related with an increased risk in morbidity and mortality, weight loss is often prescribed to obese subjects. Although at first beneficial effects are found with weight loss, in the longterm weight regain takes place in almost all subjects. Because of the poor long-term results of weight loss, different interventions were carried out to investigate weight maintenance after a weight loss period, the results of which are described in this thesis.

Because weight maintenance requires energy balance at a certain level of body weight, manipulation of energy intake and energy expenditure could affect body weight. Dietary fiber has been suggested to be an effective food component to decrease energy intake. In the longterm this would result in weight loss. In a review about dietary fiber and weight control, we conclude that this effect of fiber in the long-term is not yet clear, because only a few longterm studies have been done. In short-term studies and in addition to a very low energy diet (VLED) a fiber supplement was found to be effective (chapter 2). We therefore started a fiber supplementation study with a newly available, enzymatically modified guar gum. In two short-term studies of one week we examined the effect of soluble fiber at energy intake and hunger and satiety feelings (chapter 3). Energy intake was decreased with fiber supplementation ( $6.7 \pm 0.4 \mathrm{MJ}_{\text {.day }}{ }^{-1}$ without fiber $v s 5.4 \pm 0.2 \mathrm{MJ}^{-d a y^{-1}}$ with fiber), whereas hunger and satiety scores were similar as without fiber supplementation. At two levels of energy intake, 4 and $6 \mathrm{MJ}$, it was found that fiber supplementation effectively reduced hunger scores at the low energy intake level (chapter 3). With these promising results in hand, at first a long-term fiber supplementation study was executed. After a weight loss intervention of 2 months, a group of women was supplemented with 20 grams of guar gum for 14 months. At the end of the study no significant differences were found in weight maintenance between the fiber supplemented groups (a group with a high compliance and a group with a low compliance) compared to the control group. Regain of body weight was 65 $\pm 65 \%$ for the high-compliance group; $123 \pm 63 \%$ for the low-compliance group and $61 \pm$ $66 \%$ for the control group. No effect of fiber consumption was found at cholesterol, blood pressure and energy intake in the long-term. Habituation to fiber consumption and social aspects of importance for free-living subjects, were mentioned as explanations for the ineffectiveness of fiber supplementation in the long-term (chapter 4).

Based on these results a second intervention study was carried out. A food supplement containing functional food components with respect to weight maintenance containing carbohydrates (CHO) (50 g), fiber (20 g), chromium-picolinate (Cr-Pic) (200 $\mu \mathrm{g})$ and caffeine $(100 \mathrm{mg})$ was examined. CHO were supplemented to increase total energy percentage CHO intake daily. CHO oxidation is known to be tightly regulated by $\mathrm{CHO}$ intake. The more CHO are consumed, the less fat is ingested, and weight loss might occur because of a negative fat balance. Again fiber was supplemented as a bulking ingredient. $\mathrm{Cr}$ Pic was administered to improve insulin sensitivity and finally caffeine was supplemented to increase thermogenic activity. All ingredients together were suggested to decrease body weight by decreasing energy intake and increasing energy expenditure. Long-term supplementation of a this enriched supplement was examined in obese women and compared 
with obese women consuming a food supplement with only plain CHO. Both supplemented groups were compared with a group of women who served as control. Weight maintenance was examined at 16 months after 2 months of VLED and 14 months supplementation. Again no effect of the supplements was found at body weight at 16 months. Blood pressure and cholesterol were not affected either. However, a clear positive relation was found between total daily $\mathrm{CHO}$ intake and weight maintenance $(\mathrm{r}=-0.40, \mathrm{p}=0.05)$. A high $\mathrm{CHO}$ intake daily prevented weight gain (chapter 5).

In the third intervention study, energy expenditure was the main subject of interwention. Male, inactive subjects participated in a 12 months exercise training study, after a training intervention of 4 months, also including a weight loss period. The subjects who trained according to the protocol, 3-4 times a week, showed less regain than the subjects training 12 times a week $(52 \pm 28 \%$ regain $v s 74 \pm 20 \%, \mathrm{p}=0.09)$. Regain of fat mass differed significantly $(4.8 \pm 1.9 \mathrm{~kg}$ for the trained $v s 9.0 \pm 3.3 \mathrm{~kg}$ for the controls). Regain of waist circumference, waist-hip ratio, and sagittal diameter were related with training hours; the more training hours performed weekly, the less regain did occur (chapter 6). The recently discovered hormone leptin, secreted from adipose tissue, has been suggested to be an important regulator of body weight and fat mass. Examination of leptin levels is therefore of interest in relation to weight maintenance. We found that training affected leptin levels. Although clear relations were found between leptin and body fat (percentage), and with insulin, hours of training was also found to affect leptin levels independently (chapter 7).

Investigation of substrate oxidation in the training study was carried out using respiration chambers. Obese subjects have been found to have an impaired fat oxidation, that could therefore easily result in a positive fat balance and weight gain. The well-known effect of endurance exercise to increase fat oxidation was studied at different moments of the exercise intervention study. It was found that training resulted in increased $\mathrm{CHO}$ oxidation over $24 \mathrm{~h}$ in the male, obese group, during a standardized protocol in the respiration chamber. Also very well-trained subjects showed under similar circumstances a higher reliance on $\mathrm{CHO}$ than fat. $24 \mathrm{H}$ fat oxidation was not increased by training in the obese group (chapter 8 ).

Interventions with obese subjects could be improved when predictors of weight maintenance would be available. Subjects at risk of weight regain, could get more support at moments that weight regain could occur. Therefore a meta-analysis of the two supplementation studies was carried out. The most powerful predictor of weight maintenance found was the frequency of dieting prior to the study $(r=0.46, p<0.05)$. The factor hunger of the eating behaviour questionnaire of Stunkard and Messick and the decrease in resting metabolic rate during a diet intervention were the two other important predictors of weight maintenance found. Physiological and behavioural factors might therefore be used as predictors, to prevent weight regain (chapter 9).

The results of the studies presented indicate that maintenance of a newly achieved body weight after a diet intervention, is very difficult. Physiological mechanisms to maintain a certain body weight (set-point), characteristics of fat cells, mechanisms related to insulin resistance, but also behavioural factors like eating and exercise habits, and sociall circumstances, all can affect body weight. Based upon this divergency of factors of importance for weight maintenance, and the poor results of single interventions at weight maintenance, combined therapies are advised for future study. 


\section{Samenvatting}

Overgewicht (body mass index $>30 \mathrm{~kg} \cdot \mathrm{m}^{-2}$ ) komt in de westerse samenleving steeds meer woor. De belangrijkste factoren die een rol spelen bij de ontwikkeling van overgewicht zijn het eten van vetrijke voeding en een inactieve levensstijl. Daar bekend is dat overgewicht geassocieerd is met een verhoogd risico op morbiditeit en mortaliteit, wordt aan mensen met overgewicht vaak een energiebeperkt dieet voorgeschreven. Hoewel door gewichtsreductie op korte termijn gunstige effecten met betrekking tot de gezondheid plaatsvinden, blijkt op de lange termijn handhaving van het lagere gewicht niet mogelijk. Het weer aankomen van het lichaamsgewicht dat met een lijnpoging was kwijtgeraakt, komt bij ongeveer $90 \%$ van de lijners voor. Vanwege deze slechte langetermijnresultaten zijn verschillende interventies uitgevoerd om handhaving van het lichaamsgewicht na een dieet te onderzoeken, waarvan de resultaten in het proefschrift zijn beschreven.

Handhaving van het gewicht vereist energiebalans bij een bepaald lichaamsgewicht. Manipulatie van energie-inname en/of energiegebruik kunnen effect hebben op het lichaamsgewicht. Van voedingsvezel is wel gesuggereerd dat het een voedingscomponent is dat de energie-inname kan onderdrukken. Dit zou op lange termijn resulteren in gewichtsverlies. In een overzichtsartikel over voedingsvezel en gewichtscontrole concluderen we echter dat dit effect van voedingsvezel nog niet geheel duidelijk is, omdat nog maar weinig lange termijn studies met vezel zijn uitgevoerd. In kortetermijnstudies en als supplement bij een laag calorisch, eiwit verrijkt dieet (Modifast ${ }^{(-)}$) blijkt vezel wel effectief (hoofdstuk 2). Daar wij beschikten over een nieuw, enzymatisch gemodificeerde, wateroplosbare voedingsvezel (guar gum), zijn hier eerst kortetermijnstudies mee verricht. In twee kortetermijnstudies van een week is bekeken of guar gum effect had op energie-inname en honger- en verzadigingsgevoelens (hoofdstuk 3). Energie inname was significant lager met vezelsuppletie $\left(6.7 \pm 0.4 \mathrm{MJ}_{\mathrm{dag}}{ }^{-1}\right.$ vs $\left.5.4 \pm 0.2 \mathrm{MJ}_{\mathrm{dag}}{ }^{-1}\right)$, terwijl honger- en verzadigingsscores gelijk waren. Bij bestudering van twee energie-innameniveaus, 4 en 6 MJ.dag ${ }^{-1}$, bleek suppletie van vezel vooral bij een laag energieniveau effecief te zijn: hongergevoelens waren significant lager met vezel in vergelijking met de scores zonder vezelsuppletie (hoofdstuk 3). Op basis van deze veelbelovende resultaten werd een langetermijnstudie met vezelsuppletie opgezet. Na een gewichtsreductie periode van 2 maanden, consumeerde een groep vrouwen dagelijks 20 gram vezel extra met behulp van het supplement voor 14 maanden. Aan het eind van de in totaal 16 maanden durende studie werd geen significant verschil gevonden in handhaving van het lichaamsgewicht tussen de vezelgroepen vergeleken met de controlegroep. Het percentage gewicht dat men weer was aangekomen ten opzichte van het gewicht dat met het dieet was kwijtgeraakt was $65 \pm 65 \%$ voor de vezelgroep die de gevraagde hoeveelheid vezel gebruikte; $123 \pm 63 \%$ voor de vezelgroep die maar de helft van de gevraagde hoeveelheid vezels gebruikte; en $61 \pm 66 \%$ voor de controlegroep. Er werd geen effect van vezelsuppletie waargenomen op cholesterol, bloeddruk en energie-inname op de lange termijn. Gewenning aan de vezelconsumptie en sociale factoren die een rol spelen bij vrij levende deelnemers, zijn mogelijke verklaringen voor de ineffectiviteit van het vezelsupplement op de lange termijn (hoofdstuk 4).

Op basis van de resultaten van de vezelsuppletiestudie werd een tweede interventic uitgevoerd. Een voedingssupplement dat mogelijk effectieve componenten bevatte met betrekking tot gewichtshandhaving, koolhydraten $(\mathrm{KH})$, voedingsvezel, cafeïne en chroom- 
picolinaat (Cr-Pic), werd onderzocht. KH werden toegediend om de totale, dagelijkse inname atan $\mathrm{KH}$ te verhogen. De mate wan $\mathrm{KH}$-oxidatie is naw gerelateerd aan de mate van KH-inname. De toename in KH-inname leidt mogelijk tot een afname van energiepercentage inname vet per dag, wat kan resulteren in een negatieve vetbalans en gewichtsverlies. Opnieuw werd vezel toegediend als een bukstof. Cr-Pic werd gegeven om de insulinegevoeligheid te verbeteren en tenslotte diende cafeine voor een stimulatie van het sympatisch zenuwstelsel. Tezamen zouden de afname in energie-iniame en de toename in energiegebruik moeten leiden tot het handhaven van het lichaamsgewicht. Het langdurig toedienen van een supplement dat 50 gram $\mathrm{KH}, 20$ gram voedingsvezel, $200 \mu \mathrm{g}$ Cr-Pic en $100 \mathrm{mg}$ cafeine bevat, werd onderzocht in een groep obese vrouwen en vergeleken met obese vrouwen die een voedingssupplement consumeerden dat alleen $\mathrm{KH}$ bevatte. Beide groepen werden tevens vergeleken met een groep vrouwen die als controle diende. Handhaving van het gewicht werd onderzocht op 16 maanden, na twee maanden een laag calorisch eiwitverrijkt dieet te hebben gewolgd en 14 maanden het supplement te hebben gebruikt. Opnieuw werd geen effect gevonden van de supplementen op handhaving van het lichaamsgewicht op 16 maanden. Bloeddruk en cholesterol waren eveneens niet beinvloed door de voedingssupplementen. Echter, een duidelijk positieve relatie werd waargenomen tussen de totale dagelijkse KH inname en gewichtshandhaving $(r=-0.40, p=0.05)$. Het gebruiken van cen koolhydraatrijke voeding voorkomt gewichtstoename (hoofdstuk 5).

In de derde studie was het effect van inspanning op gewichtshandhaving het voornaamste doel van onderzoek. Vijftien inactieve mannen met overgewicht namen deel aan een trainingstudie van in total 16 maanden. Naast een dieet van 2 maanden namen alle mannen deel aan een trainingsprogramma van 4 maanden. Na 4 maanden bleven 7 mannen trainen in de frequentie zoals was voorgeschreven (3-4keer per week) (getrainden) en 8 mannen trainden slechts 1-2 keer per week (controle). De getrainden vertoonden minder gewichtstoename op maand 16 dan de controles (regain $52 \pm 28 \%$ vs $74 \pm 20 \%, p=0.09$ ). Het weer aankomen van vetmassa verschilde significant op maand 16 tussen beide groepen; de getrainden $\mathrm{kwamen} 4.8 \pm 1.9 \mathrm{~kg}$ vet bij, terwijl de controle groep $9.0 \pm 3.3 \mathrm{~kg}$ vet aankwam. Toename van de taille-omvang, taille-heup-ratio en sagitale dwarsdoorsnede waren genelateerd aan trainingsuren; hoe groter het aantal trainingsuren per week, hoe minder terugvall er plaatsvond (hoofdstuk 6). Het recent ontdekte hormoon leptine, afgescheiden door vetweefsel, zou een belangrijke regulator zijn van lichaamsgewicht en vetmassa. Het onderzoeken van leptinespiegels in het bloed is daarom mogelijk van belang in relatie tot gewichtshandhaving. Training bleek effect the heben op leptinespiegels in het bloed. Hoewel duidelijk relaties werden waargenomen tussen leptine en lichaamsvet(percentage) en met insuline, bleek het aantal uren training per week een onafhankelijk effect te hebben op leptinespiegels (hoofdstuk 7).

In de trainingsstudie werd substratoxidatie onderzocht door gebruik te maken van respiratickamers. Bij obesen is reeds een beperkte vetoxidatie waargenomen, waardoor makkelijk een positieve vetbalans zou kunnen ontstaan en toename van het gewicht zou kunnen plaatsvinden. Het algemeen bekende fenomeen dat duurtraining de vetoxidatie stimuleert, werd op werschillende tijdstippen van de studie onderzocht. Training bleek, gemeten over 24 uur, een toename in koolhydraatoxidatie te geven in de groep obese mannen. Echter ook in een groep erg goed getrainde, normaalgewichtige duuratleten bleek bij een gelijk protocol en gelijke omstandigheden in de respiratiekamer de oxidatie van 
koolhydraten een grotere voorkeur te hebben boven vetten. De 24-uurs vetoxidatie nam niet toe door training in de obese groep (hoofdstuk 8).

Uitkomsten van onderzoeken met obese deelnemers zou mogelijk verbeterd kunnen worden, wanneer voorspellers voor handhaving van het lichaamsgewicht beschikbaar zouden zijn. Door meer steun en advies te geven aan personen die een verhoogd risico lopen na een dieetperiode weer terug te komen op het oude gewicht, zou mogelijk een terugval van het gewicht voorkomen kunnen worden. Een meta-analyse van de twee suppletiestudies is uitgevoerd om voorspellers voor gewichtshandhaving te achterhalen. De belangrijkste voorspeller voor gewichtstoename bleek het aantal lijnpogingen te zijn dat iemand al had ondernomen, voorafgaand aan het onderzoek $(r=0.46, p<0.05)$. De factor 'honger' van de Stunkard en Messick eetgedragvragenlijst en de afname van het rustenergiegebruik tijdens het dieet waren verder belangrijke voorspellers. Zowel fysiologische als gedragsvariabelen kunnen mogelijk gebruikt worden als voorspellers van gewichtshandhaving om gewichtstoename te voorkomen (hoofdstuk 9).

De resultaten van de verschillende studies, gepresenteerd in dit proefschrift tonen aan dat handhaving van het lichaamsgewicht, bereikt na een dieetinterventie, erg moeilijk is. Fysiologische mechanismen voor handhaving van een bepaald gewicht (set-point), vetcelkarakteristieken, mechanismen gerelateerd aan insuline-resistentie, maar ook gedragskenmerken, zoals eetgedrag en sportgewoonten en sociale omstandigheden, beïnvloeden mogelijk het lichaamsgewicht. Gebaseerd op de verscheidenheid aan factoren die een rol spelen bij overgewicht en de slechte resultaten van een enkele interventie op handhaving van het lichaamsgewicht worden gecombineerde therapieën aangeraden voor toekomstig onderzoek naar gewichtshandhaving. 


\section{Abbreviations}

\begin{tabular}{|c|c|}
\hline ANOVA & analysis of variance \\
\hline BMI & body mass index \\
\hline BMR & basal metabolic rate \\
\hline BPdia & diastolic blood pressure \\
\hline BPsys & systolic blood pressure \\
\hline BW & body weight \\
\hline $\mathrm{C}$ & controll \\
\hline $\mathrm{CHO}$ & carbohydrate \\
\hline $\mathrm{CO}_{2}$ & carbon dioxïde \\
\hline CVD & cardiovascular diseases \\
\hline DEBQ & Dutch Eating Behaviour questionnaire \\
\hline EDTA & ethyleen-diamine-tetra-acetate \\
\hline $\mathrm{EDE}-\mathrm{Q}$ & Eating Disorder Examination questionnaire \\
\hline $\mathrm{EE}$ & energy expenditure \\
\hline 24h EE & 24 hour energy expenditure \\
\hline $\mathrm{EI}$ & energy intake \\
\hline $\mathrm{En} \%$ & energy percent \\
\hline FFM & fat free mass \\
\hline FM & fat mass \\
\hline$\% \mathrm{FM}$ & body fat percentage \\
\hline $\mathrm{FQ}$ & food quotient \\
\hline $\mathrm{h}$ & hour \\
\hline HDL & high densilty lipoprotein \\
\hline $\mathrm{Hi} . \mathrm{F}$ & high fat \\
\hline $2 \mathrm{H}_{2} \mathrm{O}$ & deuterium \\
\hline $\mathrm{J}$ & joule \\
\hline $\mathrm{kg}$ & kilogram \\
\hline $\mathrm{KJ}$ & kilojoule \\
\hline $\mathrm{L}$ & liter \\
\hline $\mathrm{LDL}$ & low density lipoprotein \\
\hline $\mathrm{m}$ & meter \\
\hline $\min$ & minute \\
\hline $\mathrm{MJ}$ & megajoule \\
\hline $\mathrm{n}$ & number \\
\hline NS & not significant \\
\hline $\mathrm{O}_{2}$ & oxygen \\
\hline $\mathrm{P}$ & protein \\
\hline $\mathrm{p}$ & probability \\
\hline PAI & physical activity index \\
\hline pcc & partial correlation coefficient \\
\hline$r$ & correlation \\
\hline Red.F & reduced fat \\
\hline RER & respiratory exchange ratio \\
\hline
\end{tabular}




\section{Abbreviations}

$\begin{array}{ll}\text { RIA } & \text { radio-imuno assay } \\ \text { RMR } & \text { resting metabolic rate } \\ \text { RQ } & \text { respiratory quotient } \\ \text { Sag } \emptyset & \text { sagittal diameter } \\ \text { Sd } & \text { standard deviation } \\ \text { Sem } & \text { standard error of the mean } \\ \text { SMR } & \text { sleeping metabolic rate } \\ \text { T } & \text { trained } \\ \text { TBW } & \text { total body water } \\ \text { TFEQ } & \text { Three Factor Eating questionnaire } \\ \text { V } & \text { volume } \\ \text { VO2 } & \text { oxygen consumption } \\ \text { VCO2 } & \text { carbon dioxide production } \\ \text { VLED } & \text { very low energy diet } \\ \text { VO2max } & \text { maximal oxygen uptake } \\ \text { ws } & \text { versus } \\ \text { W } & \text { watt } \\ \text { Wcompleted } & \text { completed work load } \\ \text { Wmax } & \text { maximal power output } \\ \text { WHR } & \text { waist-hip ratio }\end{array}$




\section{Mijn dank is groot!!!}

Hoe vaak heb ik dit gezegd tegen:

- alle deelnemers aan de verschillende proeven; niet alleen in en rond Maastricht, indien nodig werden ook collega"s van de vakgroep en naburige vakgroepen voor de diverse pilotstudies benaderd. Vooral voor de deelne(e)m(st)ers an de drie langdurige studies heb ik

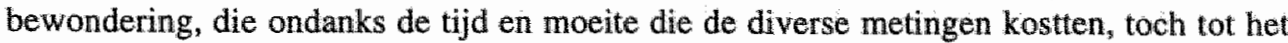
einde toe bleven komen;

- Wim en Margriet, in vast andere bewoordingen, voor het mogelijk maken van het uitvoeren van drie grote projecten met ieder een duidelijk eigen inbreng: Wim voor het opperen van experimenten, die in meer of mindere mate uitwoerbaar waren (zie proefschrift) en het onvermoeibaar blijven wijzigen en verbeteren van de manuscripten; Margriet voor het snelle corrigeren, maar vooral voor de interesse voor eetgedrag en sociaal gerelateerde aspecten van overgewicht die je op mij hebt overgedragen;

- Jos en Joan voor hun mee- en tegenwerking op het lab; de ontelbare hoeveelheden Cobasbepalingen (Jos) en evenzovele insuline bepalingen (Joan);

- Loek en Paul voor technische- en computerondersteuning; als 's achtends in de vroegte de ventilated hood weer eens kuren had (Loek) of in het weekend bij kamermetingen de warmteregulatie of fiets manco's vertoonde (Paul);

- de beoordelingscommissie, die in vier weken tijd vier jaar werk 'moet beoordelen; prof. Harm Kuipers, dr. Marleen van Baak, dr. Jaap Seidell en prof. Tjerk de Bruin. Prof. Stephan Rössner is also gratefully acknowledged for his time for reading the thesis and attending the defense;

- het water-trio, Loek, Wouter en Klaas, voor het bepalen van meer dan 300 deuteriummonsters, zodat vetmassa, vetvrijemassa $a_{*}$ en vetpercentages berekend konden worden van de deelne(e)m(st)ers tijdens het gehele project en het water-duo: Wouter en Adje voor de broombepalingen, zodat naast lichaamssamenstelling ook nog een verdeling tussen intra- en extracellulair water gemaakt kon worden;

- de twee Belgische studentes, Machteld Wauters en Isolde Aerden, die in het kader van een Erasmus-uitwisselingsprogramma hun stage liepen bij de lange termijn studies en tevens hun eigen proeven uitvoerden;

- Fred Hartgens, Wim (in een andere funktie) en Margret Foreman voor de eindeloze aantallen medische keuringen van proefpersonen, zodat we zeker wisten dat ze medisch gezien tot een streng dieet in staal waren;

- Frank, Ton en Annemie voor het mogelijk maken wan het bepalen van de ademmonsters op het stabiele isotopenlab, zodat (il)legaal al mijn monsters toch zijn bepaald;

- het secretariaat, Truus, Desiree en Marco, die altijd bereid waren te helpen, hoe onbenullig mijn vraag ook was. Grote enveloppen, printpapier, sheets en natuurlijk de fax scoorden bij mij het hoogst;

- collega's. Natuurlijk zijn er altijd collega's die er meer of minder uitspringen, omdat je daar meer mee samenwerkt of goed mee overweg kan. Maar toch wil ik de hele vakgroep Humane Biologie bedanken voor de fijne sfeer waarin gewerkt is en de gedrevenheid van alle medewerkers. Ik heb als niet-Zuiderling goed kunnen aarden in het Maastrichtse en zal deze 4 jaar niet vergeten. Niet alleen divisie 1, ook aan de 'vetzuren'-groep ben ik dank 
verschuldigd: Frank Cox (voor de hulp bij het 'cholesterollen'); en natuurlijk Liesbeth, als vriendin en medestrijder naar het doctorschap;

- kamergenoten: heel kort Asker en Ed; iets langer Carlijn en Daphne, en tenslotte Patrick en Freddy en (af en toe) Stefan Coolen. Patrick en Freddy wil ik beiden bedanken voor het uitprinten van de via de post gestuurde files en het beheren van mijn (e-)mail. Zo bleef ik het laatste jaar ondanks mijn lijfelijke afwezigheid toch volledig op de hoogte. Daphne, vanaf het begin heeft het tussen ons goed geklikt. Zowel tijdens als na het werk werd vooral gepraat over zaken die niet en wel over het werk gingen. Ik hoop en geloof dat de geografische afstand tussen ons geen belemmering zal zijn om onze vriendschap in stand te houden;

- matnma, pa en ma De Ruiter, Adri en Rolien, Everdien en Jan Marten, Conny en Daniël, Lean en Edwin en natuurlijk mijn neefjes Tim en Rik Jan; voor jullie begrip als ik weer eens stralde van afwezigheid bij verjaardagen en partijen, omdat de afstand te groot was of er weer proeven gedaan moesten worden. Hoewel ook deze gebeurtenis zonder pappa plaatsvindt, koester ik mij met de gedachte dat hij vast heel trots zou zijn;

- Jo! Wat je al moet doen en laten om te promoveren... Je geweldige relativerings- en incasseringsvermogen hebben er zeker toe bijgedragen dat we zelfs de afgelopen vier jaar zonder problemen zijn doorgekomen. Ik geloof niet dat ik dit nog eens kan (en wil) opbrengen. 


\section{Curriculum vitae}

Wilrike Pasman werd geboren op 21 oktober 1968 te Zutphen (Gld), waarna zij opgroeide in Eefde. In 1987 behaalde zij het VWO-B diploma aan hell Baudartius College te Zutphen. Aansluitend studeerde zij Bewegingswetenschappen aan de Vrije Universiteit te Amsterdam, met als afstudeerrichting Inspanningsfysiologie en bijvakken Biochemie en Sportpsychologie. Van augustus 1991 tot juli 1992 was zij als student-assistent werkzaam bij de vakgroep Inspanningsfysiologie. In april 1993 behaalde zij haar doctoraal examen (cum laude). In dezelfde maand startte ze als assistent in opleiding bij de vakgroep Humane Biologie aan de Universiteit Maastricht, te Maastricht, onder leiding van prof.dr. W.H.M. Saris en dr. M.S. Westerterp-Plantenga. In 1997 kreeg zij van de European Association on the Study of Obesity een reisbeurs toegekend. Het onderzoek dat zij gedurende vier jaar verrichtte bij de vakgroep Humane Biologie is beschreven in dit proefschrift. 



\section{Publications}

\section{Articles}

- Westra HG, Berden JA, Pasman WJ. A model for the regulation of actin-activated $\mathrm{Mg}^{2+}$. myosin ATPase activity : inhibition of the formation of actin-myosin complex by IMP. Neuromuscular Fatigue. Eds. A. Sargeant and D. Kernell. North Holland, Amsterdam, pg.24-26, 1993

- Pasman WJ, van Baak MA, Jeukendrup AE, de Haan A. The effect of different dosages of caffeine on endurance performance time. Int.J.Sports Med.4: 225-230, 1995

- Pasman WJ, Saris WHM, Wauters MAJ, Westerterp-Plantenga MS. Effect van vezelsuppletie op honger - en verzadiging, energie-inname en gewichthandhaving. Voeding 56: 32-33, 1995

- Westerterp-Plantenga MS, Pasman WJ, Yedema MYW, Wijkmans-Duijsens NEG. Energy intake adaptation of food intake to extreme energy densities of food by obese and non-obese women. Eur.J.Clin.Nutr.50: 401-407, 1996

- Pasman WJ, Wauters M, Westerterp-Plantenga MS, Saris WHM. Effect of one week of fibre supplementation on hunger and satiety or energy intake. Appetite 29:77-87, 1997

- Pasman WJ, Westerterp-Plantenga MS, Muls E, Vansant G, van Ree J, Saris WHM. The effectiveness of long-term fiber supplementation on weight maintenance in weightreduced women. Int. J.Obes. 21: 548-555, 1997

- Pasman WJ, Westerterp-Plantenga MS, Saris WHM. The effectiveness of long-term supplementation of carbohydrate, chromium, fiber and caffeine in weight maintenance. Int.J.Obes. Int. J.Obes. 21:1143-1151, 1997

- Pasman WJ, Westerterp-Plantenga MS, Saris WHM. The effect of exercise training on leptin levels in obese males. Am.J.Phys.(Endocrin.Metab.) (In press)

- Pasman WJ, Saris WHM, Muls E, Vansant G, Westerterp-Plantenga MS. The effect of exercise training on long-term weight maintenance in weight-reduced men. Metabolism (Accepted)

- Pasman WJ, Westerterp-Plantenga MS, Saris WHM. Dietary fiber and body weight control. A review. Br.J.Nutr. (Submitted)

- Pasman WJ, Westerterp-Plantenga MS, Saris WHM. The effect of exercise training on 24h substrate utilization. Am.J.Phys.(Endocrin.Metab.) (Submitted)

- Pasman WJ, Saris WHM, Westerterp-Plantenga MS. Predictors of weight maintenance. B.M.J. (Submitted)

\section{Abstracts}

- Westra HG, Berden JA, Pasman WI. A model for regulation of actin activated myosin ATPase: inhibition of the formation of actin-myosin complex. Pflügers Arch. 420 (Suppl.1): R93, 1992

- Pasman WJ, Jeukendrup AE, v. Baak MA, Saris WHM, de Haan A. The effect of varied dosages of caffeine on endurance performance time. Basic and applied exercise physiology, congress Nijmegen june 10-11, 1993

- Pasman WJ, Westerterp MS, Saris WHM. Adaptation of hunger and satiety feelings and/or energy intake to fiber supplementation. Int.J.Obes.18 (suppl.2): 123, 1994 
- Pasman WJ, Westerterp-Plantenga MS, Saris WHM. Aanpassing wan honger - e1 verzadigingsgevoelens en/of energie-inname aan vezelsuppletie. Voeding 55: 29, 1994

- Pasman WJ, Saris WHM, Westerterp-Pllantenga MS. The effect of a weight loss ant exercise program on $24 \mathrm{~h}$ substrate balance feeding a high or low fat diet. Int.J.Obes. 19 (suppl.2): 91, 1995

- Pasman WJ, Saris WHM, Westerterp-Plantenga MS. The effect of fiber supplementation on long-term weight maintenance. Int.J.Obes. 19 (suppl.2): 155, 1995

- Ijedema MYW, Westerterp-Plantenga MS, Wijckmans-Duijsens NEG, Pasman WJ Macronutrient and energy intake in relation to energy density in obese and non-obes: women. Int.J.Obes. 19 (suppl.2): 27, 1995

- Pasman WJ, Saris WHM, Westerterp-Plantenga MS. Are long-term weight maintenance intervention outcomes predictable? Int.J.Obes.20 (Suppl.4): 103, 1996

- Pasman WJ, Saris WHM. The relation of insulin and OB-protein in trained and contro, weight-reduced males. Obes.Res.4 (Suppl.1):14S, 1996

- Pasman WJ, Saris WHM. Estimation of energy expenditure in lean, trained and obese, untrained subjects. Med.Sci.Sports Exerc. 29 (suppl.): S155, 1997

- Pasman WJ, Westerterp-Plantenga MS, Saris WHM. The effect of exercise training on long-term weight maintenance in weight-reduced males. Int.J.Obes. 21 (suppl.2): S30, 1997

- Pasman WJ, Saris WHM. Relatie tussen insuline en leptine. Effecten van training en dieet. Voeding 58: 29, 1997 